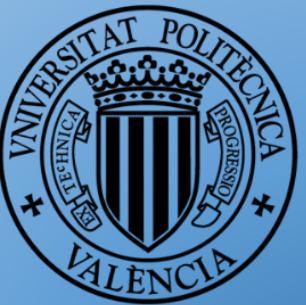

UNIVERSITAT POLITÈCNICA DE VALĖNCIA

$\underline{\text { PhD Thesis }}$

Numerical Analysis for Efficiency Enhancement of Thin Film Solar Cells

Author

Faisal Baig

Supervisor

Prof. Dr. Bernabé Marí Soucase 



\title{
Numerical Analysis for Efficiency Enhancement of Thin Film Solar Cells
}

\author{
Dissertation submitted \\ in partial fulfillment of the requirements \\ for the degree of \\ Doctor of Philosophy
}

Author:

Faisal Baig

Supervisor:

Prof. Dr. Bernabé Marí Soucase

Instituto de Diseño para la Fabricación y Producción Automatizada

Escuela Técnica Superior de Ingeniería del Diseño

Universitat Politècnica de València

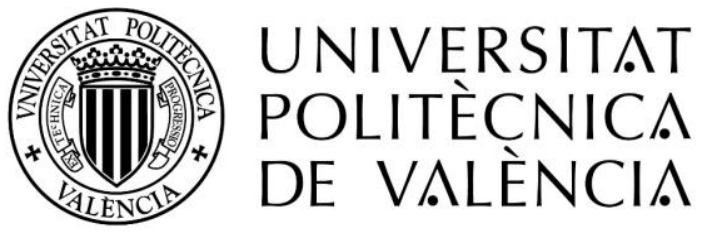

Universitat Politècnica de València

February, 2019 
This page intentionally left blank 


\begin{abstract}
A decade of extensive research has been conducted to enhance the power conversion efficiency (PCE) of silicon (Si) solar cells and to cut their prices short. But still, the fabrication of Si solar cells are costly. So, to reduce the fabrication cost of the solar cell search for alternate earth abundant and non-toxic absorber materials is thriving. Among different absorber materials tin sulfide ( $\mathrm{SnS}$ ) is found to be a suitable candidate for the non-organic solar cell with a band gap of $1.3 \mathrm{eV}$. But the PCE achieved for SnS is $4.6 \%$ that is far less from the PCE of (Si), whereas among other organic non-organic solar cells like methylammonium lead halide perovskite $\left(\mathrm{MAPbI}_{3}\right)$ is proven to be a suitable candidate with PCE reaching to a value of $23 \%$. The problem with the commercialization of $\mathrm{MAPbI}_{3}$ is due to the toxic nature of lead $(\mathrm{Pb})$. So, in dealing with these issues of solar cell numerical analysis can play a key role as numerical analysis allows flexibility in the design of realistic problem and experimentation with different hypotheses can easily be performed. Complete set of device characteristic can often be easily generated by consuming less amount of time and effort. Because of this reason numerical analysis was used to revisit solar cells design parameters and the effect of solar cell physical parameters on solar cell performance. There are various simulation software's available that are used for solar cell numerical analysis. Here in this work, we used Solar cell capacitance simulator (SCAPS) software, it is freely available and is most popular among the research community. To achieve effective design for efficient solar cell a numerical guide was proposed based on which PCE of an experimental designed solar cell can be enhanced. This was done by reproducing results for the experimentally designed solar cell in SCAPS environment with structure $\mathrm{p}-\mathrm{SnS} / \mathrm{n}-\mathrm{CdS}$ having a conversion efficiency of $1.5 \%$. After reproduction of experimental results device performance was optimized by varying thickness of (absorber layer, buffer layer), minority carrier lifetime, doping concentration (absorber, buffer), and adding window layer. By stepwise optimization of device parameters, PCE of an experimental designed solar cell in SCAPS with architecture p $\mathrm{SnS} / \mathrm{n}-\mathrm{CdS} / \mathrm{n}-\mathrm{ZnO}$ was reached to a value of $14.01 \%$. From the analysis, it was found that PCE of a solar cell is highly depended upon doping concentration of the absorber layer, the thickness of the absorber layer and interface defects. Based on the results evaluated an analysis was performed for tin based organic non-organic methylammonium tin halide perovskite solar cell $\left(\mathrm{MASnI}_{3}\right)$ to find the effect of interface recombination on
\end{abstract}


solar cell performance and how it can be governed. The reason for this transition from SnS to $\mathrm{MASnI}_{3}$ was because $\mathrm{MASnI}_{3}$ can be fabricated simply by spin-coating methylammonium iodide (MAI) over SnS layer. To perform this task analysis was performed for the selection of suitable buffer layer for $\mathrm{Pb}$ free methylammonium tin halide perovskite solar cell $\left(\mathrm{MASnI}_{3}\right)$ and it was found that PCE of the solar cell is also depended upon band alignment between absorber and buffer layer. Based on the results a new structure was proposed for $\mathrm{Pb}$ free perovskite solar cell (Back contact/MASnBr $3 /$ $\mathrm{MASnI}_{3} / \mathrm{CdZnS}$ /FTO) with PCE of $18.71 \%$ for absorber thickness of $500 \mathrm{~nm}$ and acceptor doping concentration of $1 \times 10^{16} \mathrm{~cm}^{3}$. The results achieved in this thesis will provide an imperative guideline for researchers to design efficient solar cells. 


\section{Resumen}

Desde hace una década se esta investigando intensamente la forma de mejorar la eficiencia de conversión de energía (PCE) de las células solares de silicio ( $\mathrm{Si}$ ) y reducir sus precios. Sin embargo, a pesar de las mejoras obtenidas, la fabricación de células solares de Si sigue siendo costosa y puede rebajarse usando materiales en forma de capa fina. Por ello la búsqueda de materiales absorbentes alternativos, no tóxicos, abundantes en la naturaleza y con buenos rendimientos de conversión se ha intensificado en los últimos años. Entre los diferentes materiales absorbentes el sulfuro de estaño ( $\mathrm{SnS})$, con una banda prohibida de 1.3 eV cercana a la óptima, es un candidato adecuado para la conversión fotovoltaica. Pero para células experimentales de $\mathrm{SnS}$ el rendimiento alcanzado hasta ahora es de $4.6 \%$, que es mucho menos que el PCE para dispositivos de silicio, mientras que entre otras células híbridas (orgánicas-no orgánicas) como la perovskita de metilamonio de plomo y yodo (MAPbI3) se demuestra que es un candidato adecuado con PCE que alcanza un valor del 23\%. Aparte de la estabilidad, uno de los problemas para la comercialización de células de MAPbI3 es la naturaleza tóxica del plomo $(\mathrm{Pb})$. Por este motivo, se ha utilizado el análisis numérico para revisar los parámetros de diseño de las células solares de perovskita híbrida sustituyendo el absorbente MAPbI3 por MASnI3 y estudiar el efecto del resto de parámetros de diseño en el rendimiento de estas células solares. Hay varios softwares de simulación disponibles que se utilizan para el análisis numérico de células solares. En este trabajo hemos usamos un software llamado "A Solar Cell Capacitance Simulator" (SCAPS), está disponible de forma gratuita y es muy popular entre la comunidad científica y tecnológica. Para lograr un diseño efectivo para una célula solar eficiente, se propuso una aproximación numérica basada en la mejora de la PCE de una célula solar experimental. Esto se hizo reproduciendo los resultados para la célula solar diseñada experimentalmente en un entorno SCAPS con estructura p-SnS / n-CdS con una eficiencia de conversión del 1,5\%. Después de la reproducción de los resultados experimentales, el rendimiento del dispositivo se optimizó ajustando el grosor de la capa absorbente y la capa tampón, la el tiempo de vida de los portadores minoritarios, la concentración del dopado en las capas absorbente, tampón y en la capa de la ventana. Mediante la optimización gradual de los parámetros del dispositivo, se alcanzó un valor de 14.01\% en PCE de células solares diseñadas con SCAPS con arquitectura p-SnS / n-CdS / n-ZnO. A partir del análisis, se encontró que la PCE de una célula solar depende en gran medida de la concentración de dopaje de la capa absorbente, el espesor de la capa absorbente y los 
defectos de la interfaz. Sobre la base de los resultados obtenidos, se realizó un análisis para determinar el efecto de la recombinación de la interfaz en el rendimiento de las células solares y cómo se puede controlar. Para realizar esta tarea, se realizó un análisis para la selección de la capa tampón adecuada para la célula solar de perovskita metilamonio de estaño y yodo (MASnI3) y se encontró que el PCE de la célula solar también depende de la alineación de la banda entre el absorbedor y la capa de tampón. Por otra parte, se ha propuesto una nueva estructura para la célula solar de perovskita libre de $\mathrm{Pb}$ (contacto posterior / MASnBr3 / MASnI3 / CdZnS / FTO) con un PCE de 18.71\% para un espesor del absorbedor de $500 \mathrm{~nm}$ y una concentración de dopado en el aceptor de 1x1016 cm-3. Los resultados obtenidos en esta tesis proporcionarán una guía para que los investigadores experimentales puedan construir células solares más eficientes. 


\section{Resum}

Des de fa una dècada s'està investigant intensament la forma de millorar l'eficiència de conversió d'energia (PCE) de les cèl-lules solars de silici ( $\mathrm{Si}$ ) i reduir els seus preus. No obstant això, tot i les millores obtingudes, la fabricació de cèl-lules solars de Si segueix sent costosa i pot rebaixar-se usant materials en forma de capa fina. Per això la recerca de materials absorbents alternatius, no tòxics, abundants en la naturalesa i amb bons rendiments de conversió s'ha intensificat en els últims anys. Entre els diferents materials absorbents, el sulfur d'estany ( $\mathrm{SnS}$ ), amb una banda prohibida de $1.3 \mathrm{eV}$ propera a l'òptima, és un candidat adequat per a la conversió fotovoltaica. Però per a cèl-lules experimentals de $\mathrm{SnS}$ el rendiment assolit fins ara és de 4.6\%, que és molt menor que el PCE per a dispositius de silici, mentre que entre altres cèl·lules híbrides (orgàniques-no orgàniques) com la perovskita de metilamonio de plom i iode (MAPbI3) es demostra que és un candidat adequat amb PCE que arriba a un valor del 23\%. A part de l'estabilitat, un dels problemes per a la comercialització de cèl·lules de MAPbI3 és la naturalesa tòxica del plom $(\mathrm{Pb})$. Per aquest motiu, s'ha utilitzat l'anàlisi numèrica per revisar els paràmetres de disseny de les cèl-lules solars de perovskita híbrida substituint l'absorbent MAPbI3 per MASnI3 i estudiar l'efecte de la resta de paràmetres de disseny en el rendiment d'estes cèl·lules solars. Hi ha diversos programaris de simulació disponibles que s'utilitzen per a l'anàlisi numèric de cèl·lules solars. En aquest treball hem fem servir un programari anomenat " $A$ Solar Cell Capacitance Simulator" (SCAPS), està disponible de forma gratuïta i és molt popular entre la comunitat científica i tecnològica. Per aconseguir un disseny efectiu per a una cèl·lula solar eficient, es va proposar una aproximació numèrica basada en la millora de la PCE d'una cèl·lula solar experimental. Això es va fer reproduint els resultats per a la cèl-lula solar dissenyada experimentalment en un entorn SCAPS amb estructura p-SnS / n-CdS amb una eficiència de conversió de 1'1,5\%. Després de reproduir els resultats experimentals, el rendiment del dispositiu es va optimitzar ajustant el gruix de la capa absorbent y de la capa tampó, el temps de vida dels portadors minoritaris, la concentració del dopatge en les capes absorbent, tampó i en la capa finestra. Mitjançant l'optimització gradual dels paràmetres del dispositiu, es va assolir un valor de $14.01 \%$ en PCE de cèl·lules solars dissenyades experimentalment en SCAPS amb arquitectura p-SnS / n-CdS / n-ZnO. A partir de l'anàlisi, es va trobar que la PCE d'una cèl-lula solar depèn en gran mesura de la concentració de dopatge de la capa absorbent, el gruix de la capa absorbent i els defectes de la interfície. D'altra banda, es va realitzar una anàlisi per determinar l'efecte de la 
recombinació de la interfície en el rendiment de les cèl·lules solars i com es pot controlar. Per realitzar aquesta tasca, es va realitzar una anàlisi per a la selecció de la capa tampó adequada per a la cèl·lula solar de perovskita de metilamoni d'estany i iode (MASnI3) i es va trobar que el PCE de la cèl-lula solar també depèn de l'alineació de la banda entre l'absorbidor i la capa de tampó. 


\section{Acknowledgements}

First, In the name of ALLAH, the Entirely Merciful, all praises are to ALLAH, lords of the worlds, who gave me enough strength to complete this research work.

I would like to thank my supervisor Dr. Bernab Mari Saucase for his guidance and providing the inspiration for the research work. The research could not complete without his genuine support and assistance.

I am grateful to my beloved parents, sister, brother, wife, son Abdul Rehman and Afsar Khattak family for supporting me during this period of research. I would not have achieved the goals without their sincere cooperation and love.

Thanks to my Masirs for being the shoulder that I always depend upon, especially Sajid, Bashir, Zahoor and Jalil who were always there for me when I needed their support in my life.

Special thanks to Dr. Shafi Ullah, Dr. Hanif Ullah, and Mr. Inayat Ullah, with my friends Hassan, Abrar, Ziafat, Faheem, Ch Toseef, Touseef and Jabir as I always felt so loved and appreciated by them.

FUUAST Islamabad thank you for being so perfect. For being exactly what I needed. For teaching me so much both about the world and about myself. I will forever hold you near and dear to my heart.

Mr. Yousaf Hameed Khattak thank you and I appreciate your love, kindness, support, and generosity.

I shall always remember you in my prayers.

Faisal Baig 
This page intentionally left blank 


\section{Dedication}

This thesis is dedicated to

My grandmother: for being my first teacher

My mother: for her advice, her patience, and her faith, because she understood

My father: for being the person that I become depends on what my father taught me at odd moments when he was not trying to teach me

My uncle: For being my guardian during my educational career

My siblings: you mean everything to me 
This page intentionally left blank 


\section{Motivation}

The demand of electric power is rising, this rise in electric energy demand has urged the utility companies to install more electric power generation plants. As most of the world, electric power demand is met by thermal power plants, and these plants produce electric power by process fossil fuels combustion, and combustion of fossil fuels produces toxic gases in the environment and these gases causing serious environmental changes around the globe. The rapid change in an ecosystem has stems the researcher to find some alternate energy sources that are eco-friendly, and among these energy sources, one of the major sources of energy that is the base of terrestrial life is solar irradiation that is irradiated by the sun. The amount of energy transmitted by sun irradiation is around 420 trillion KWh and this amount of energy irradiated is greater than the amount of electrical energy consumed by human beings on earth. This energy can be harnessed by capturing sunlight and convert this light to electrical energy. The idea of conversion of light energy into electrical power drives the researchers to find some source/ material that can convert sunlight into electrical current. Soon after the invention of a solar cell, solar photovoltaic gained importance among the researchers and with a passage of time the demand of PVpower system has increased drastically. Now many types of solar cells and solar cell modules are available in the market for small scale as well as for large scale production. But up till now, low cost and high efficiency solar cell device fabrication were not made possible. So, to achieve a low cost and high efficiency solar cell design, understanding of device mechanism is important. To deeply understand device operating mechanism computer based numerical simulation programme was developed by the research community. This work is also intended to use the available software for some of the wellknown and newly emerged type of solar cell. That is to fill the gaps between the device physics and state of the art design of solar cell. Numerical simulation can aid the researchers to evaluate their solar cell design and to implement their knowledge at an early basis before experimentally fabricating the device structure. This will save time and expense of research community. So, efficient design of solar cell requires keen knowledge and understanding of basic solar cell physical parameters. And by numerical analysis of solar cell in simulation software, we hope to achieve better device performance for an experimental solar cell by underlying the key factors that can aid in efficiency enhancement of solar cell. 
This page intentionally left blank 


\section{Summary}

The invention of semiconductor revolutionized the industry and semiconductor is playing a key role in today's commercial applications. Among different commercial application, one of the major applications of semiconductor devices is its role in harvesting sunlight and converting into electric current. There are different types of photovoltaic cells available for commercial application and they majorly belong to the crystalline group. But the cost of production of these materials is very high as compared to other compounds like polycrystalline and monocrystalline. Today, silicon dominates the manufacturing of PV technology but due to the poor absorption coefficient of silicon $200 \mu \mathrm{m}-500 \mu \mathrm{m}$ thick absorber layer is utilized to absorb a significant amount of sunlight. Due to poor absorption and thicker absorber layer for silicon solar cell an optimal thickness absorber layer is required, and this gives rise to thin film technology in which optimal absorber thickness is $5 \mu \mathrm{m}$. In thin film technology, less material is required as compared to silicon and processing cost of thin film technologies are less than silicon processing. Thin film technology is proven to be one of the most cost-effective and efficient technology for the manufacturing of photovoltaic cells and it is an excellent subject of intense research in photovoltaic industry. Among thin film technologies cadmium telluride (CdTe) and copper-indium-gallium-selenide (CIGS) cells that have achieved record efficiencies close to $20 \%$. Unfortunately, cadmium is toxic in nature and gallium, indium and tellurium are non-abundant and expensive materials. Alternate for those materials must be sought for PV technology to scale up to the level of modern-day non-renewable energy production. In search of more alternate absorber material, quaternary blends can circumvent the issue for availability and cost; and their PV properties can be tailored by varying the stoichiometry of individual components. $\mathrm{Cu}_{2} \mathrm{ZnSnS}_{4}$ (CZTS), has achieved a greater efficiency of $10.1 \%$. The availability of those materials is not a concern in the environment but to tailor their PV characteristic is quite difficult to handle.

So, an alternative to those materials must be sought and among them the most attractive candidate for thin film PV applications is SnS. SnS possess an orthorhombic structure and a direct band gap of 1.30-1.43 eV. Effective optical absorption of $\mathrm{SnS}$ coincides with the optimum band gap for maximum efficiency according to the Shockley-Queisser limit within the AM 1.5 solar spectrum. The absorption coefficient of SnS is higher than CdTe, CIGS and other available PV technologies. Despite being suitable for PV technology still, 
SnS devices have not yet surpassed $4.6 \%$ efficiency. The limitation in the efficiency of SnS may be due to the defects and impurities in SnS layers related to deposition technique and self-oxidation of $\mathrm{Sn}^{2+}$ to $\mathrm{Sn}^{4+}$.

Apart from a non-organic solar cell, Lead halide perovskite solar cell (LHPSC) in recent years has drawn a great amount of attention because of their good absorption properties, optimal band gap, good carrier diffusion length, and low-cost processing technique. Power conversion efficiency (PCE) of perovskite solar cell in the past few years has enhanced from $3.8 \%$ to $22 \%$. Despite the rapid development in PCE and simplification in the fabrication process of LHPSC still, the stability of LHPSC and toxic nature of lead hindered the way of commercialization of perovskite solar cell. Theoretical and experimental studies show that tin halide perovskite $\left(\mathrm{CH}_{3} \mathrm{NH}_{3} \mathrm{SnI}_{3}\left(\mathrm{MASnI}_{3}\right)\right)$ has an optimal band gap of $1.3 \mathrm{eV}$ and considered as a possible replacement for LHPSC. Due to its smaller band gap, it can cover a wide range of the visible light spectrum, than the LHPSC. Tin (Sn) perovskite-based planner structure solar cell has been developed with heterostructure architecture. The major limitation of Sn based perovskite is oxidation of $\mathrm{Sn}$ from $\mathrm{Sn}^{2+}$ to $\mathrm{Sn}^{4+}$ in the air which limits the performance of the device. With extensive research, development of encapsulation process increases the stability of the Sn based perovskite materials. By the addition of tin fluoride $\left(\mathrm{SnF}_{2}\right)$ in the fabrication process reduces the chance of oxidation of $\mathrm{Sn}^{2+}$ to $\mathrm{Sn}^{4+}$. Despite the rapid improvement in $\mathrm{Sn}$ based perovskite material still, PCE achieved from $S n$-based perovskite solar cell is very low. This is mainly due to the lack of understanding of device properties and the effect of band structure on device performance.

Therefore, the effort to improve the efficiency of a solar cell and the reduction in their prices has been the main subject of interest for a long time. In this research work, numerical modeling is carried out of different solar cell structures to understand the basic insight physics of solar cell working and to estimate the effect of physical parameters on solar cell performance. Device modeling can be performed on the dedicated SCAPS simulation software. To analyze the performance of a photovoltaic device, an analysis was performed on different physical parameters such as thickness and doping concentration of absorber, buffer and window layers, temperature effect and effect of illumination power of the sun on a solar cell. First simple cell structure SnS/CdS/ZnO was simulated with PCE of $26.18 \%$. However, up to date, practical solar cell devices do not surpass $4.36 \%$. So, numerical analysis was carried out to understand the physic for the limitation of SnS 
based solar cell device performance. From the analysis, it was found out that the major limitation in efficiency enhancement of SnS solar cell is optimal absorber thickness, band tailing, interface density defect, and absorber defects. We found that interface defects behave like a serial resistance and reduce the open circuit voltage $\left(\mathrm{V}_{\mathrm{oc}}\right)$, while absorber defects mainly act as recombination centers and limits the short circuit current $\left(\mathrm{J}_{\mathrm{sc}}\right)$. The analysis for efficiency limits of SnS solar cell was very helpful in further investigating the efficiency enhancement of SnS solar cell.

Therefore, we proposed a model guide about how numerical analysis can aid in the improvement of the power conversion efficiency of solar cell based on our previous studies. In this step numerical analysis was performed in SCAPS to optimize the parameters of a solar cell like absorber layer thickness, buffer layer thickness, window layer effect, doping density and minority carrier lifetime. From observation, it was found that experimentally designed solar cell efficiency can be enhanced with the aid of numerical analysis. After optimization of physical parameters for experimental solar cell simulated in SCAPS-1D, PCE jumps from $4.36 \%$ to $14.01 \%$. The result presented in this work can provide a valuable guideline to a researcher for the efficient design of solar cell with optimized parameters.

From numerical analysis guide about how to improve the efficiency of the solar cell, we proposed a method for the selection criteria of the ETL layer for lead-free perovskite solar cell. As from analysis, it was found that interface recombination is a major limitation in designing of a high efficiency solar cell. So, in this work impact of different ETL and effect of their band alignment on solar cell performance was analyzed. From the numerical analysis it was found that conduction band offset can play a significant role in solar cell performance by creating a hole barrier at the interface and suppressing the interface recombination. Based on the results it was found that interface recombination of $\mathrm{MASnI}_{3}$ solar cell can be controlled with ETL CBO, ETL thickness, ETL donor doping concentration and absorber doping concertation. With a small - CBO "Spike" at an interface is beneficial for efficiency enhancement of solar cell, but too high spike will degrade solar cell performance by impeding the flow of charge carriers. Similarly, ETL with moderate - CBO is less prone to interface recombination with the comparison to ETL having a +CBO with absorber material. In terms of selection of ETL materials for $\mathrm{MASnI}_{3}$ absorber based solar cell, interface with moderate - CBO should be advantageous for ETL choice. 
After detail studies of the effect of defects and effect of an interface layer band offset on solar cell performance an optimized structure was proposed for lead-free perovskite solar cell in SCAPS software. For the first time, a numerical model was presented for lead-free HTL layer $\mathrm{MASnBr}_{3}$ with $\mathrm{Cd}_{1-\mathrm{x}} \mathrm{Zn}_{\mathrm{x}} \mathrm{S}$ as ETL for $\mathrm{MASnI}_{3}$ absorber layer. Effect of HTL layer band offset was analyzed and based on results it was concluded that HTL band offset can greatly affect solar cell performance. Optimal thickness $(0.5 \mu \mathrm{m})$ and optimal doping concentration of absorber layer $\left(1 \times 10^{16} \mathrm{~cm}^{-3}\right)$ was found in this work. Effect of two different ETL's on solar cell performance was analyzed and it was found that by adjusting the band offset of $\mathrm{Cd}_{1-\mathrm{x}} \mathrm{Zn}_{\mathrm{x}} \mathrm{S}$ layer can lead to a PCE of $18.71 \%$. Effect of defect density of the absorber layer was analyzed, and it was found that with an increase in defect density will limit the thickness of the absorber layer. The results proposed in this work should provide a baseline for alternate ETL and HTM layer selection and for the design of an efficient solar cell. 


\section{Acronyms}

\begin{tabular}{|c|c|}
\hline Symbol & Explanation \\
\hline PCE & Power conversion efficiency \\
\hline $\mathbf{F F}$ & Fill factor \\
\hline $\mathbf{V}_{\text {oc }}$ & Open circuit voltage \\
\hline $\mathbf{J}_{\text {sc }}$ & Short circuit current density \\
\hline $\mathbf{J}_{\mathbf{0}}$ & Diode saturation current density \\
\hline I & Diode current \\
\hline $\mathbf{I}_{\mathbf{0}}$ & Diode saturation current \\
\hline $\mathbf{V}_{\mathbf{D}}$ & Diode voltage \\
\hline $\mathbf{V}_{\mathbf{T}}$ & Thermal voltage \\
\hline $\mathbf{E}$ & Photon energy \\
\hline $\mathbf{v}$ & Frequency of light \\
\hline c & Speed of light \\
\hline$\lambda$ & wavelength \\
\hline $\mathbf{v}$ & Applied potential \\
\hline $\mathbf{I}_{\mathbf{L}}$ & Light generated photon current \\
\hline $\mathbf{f}_{\mathrm{t}}$ & Probability of occupation of trap state \\
\hline D & Diffusion constant \\
\hline$\alpha$ & Absorption coefficient \\
\hline G & Generation rate \\
\hline $\mathbf{k}$ & Boltzmann constant \\
\hline $\mathbf{T}$ & Temperature \\
\hline $\mathbf{Q}$ & Charge \\
\hline $\mathbf{v}_{\text {th }}$ & Thermal velocity of charge carriers \\
\hline$\delta_{\mathbf{p}}$ & Capture cross section area of hole \\
\hline$\delta_{\mathbf{n}}$ & Capture cross section area of electron \\
\hline $\mathbf{E}_{\mathbf{C}}$ & Conduction band minimum \\
\hline $\mathbf{E}_{\mathrm{V}}$ & Valence band minimum \\
\hline$E_{f n}$ & Electron quasi-Fermi level \\
\hline $\mathbf{E}_{\mathrm{fp}}$ & Hole quasi-Fermi level \\
\hline$\Delta \mathbf{E}_{\mathrm{C}}$ & Conduction band offset \\
\hline$\Delta \mathbf{E}_{\mathbf{V}}$ & Valence band offset \\
\hline $\mathbf{N}_{\mathrm{A}}$ & Uniform acceptor density \\
\hline $\mathbf{N}_{\mathrm{D}}$ & Shallow uniform donor density \\
\hline
\end{tabular}




\begin{tabular}{|c|c|}
\hline$\tau_{\mathrm{e}}$ & Electron lifetime \\
\hline$\tau_{h}$ & Hole lifetime \\
\hline$L_{n}$ & Electron diffusion length \\
\hline$L_{p}$ & Hole diffusion length \\
\hline СвO & Conduction band offset \\
\hline VBO & Valance band offset \\
\hline $\boldsymbol{R}_{i F}$ & Interface recombination \\
\hline$S_{i F}$ & Interface recombination velocity \\
\hline Si & Silicon \\
\hline Sns & Tin sulfide \\
\hline $\mathrm{CH}_{3} \mathrm{NH}_{3} \mathrm{SnI}_{3}$ & Methylammonium tin iodide \\
\hline $\mathrm{CH}_{3} \mathrm{NH}_{3} \mathrm{SnBr}_{3}$ & Methylammonium tin bromide \\
\hline $\mathrm{CH}_{3} \mathrm{NH}_{3} \mathrm{PbI}_{3}$ & Methylammonium lead iodide \\
\hline CIGS & Copper indium gallium sulfide \\
\hline CdTe & Cadmium telluride \\
\hline$C d S$ & Cadmium sulfide \\
\hline Zno & Zinc Oxide \\
\hline $\mathrm{TiO}_{2}$ & Titanium dioxide \\
\hline$Z n S$ & Zinc sulfide \\
\hline $\operatorname{In}_{2} S_{3}$ & Indium sulfide \\
\hline $\mathrm{SnS}_{2}$ & Tin disulfide \\
\hline ZnSe & Zinc selenide \\
\hline CMO & Calcium manganese oxide \\
\hline FTO & Fluorine doped tin oxide \\
\hline ETL & Electron transport layer \\
\hline HTL & Hole transport layer \\
\hline
\end{tabular}




\section{Symbols}

\begin{tabular}{|c|c|c|}
\hline Symbol & Explanation & Unit \\
\hline$P C E$ & Power conversion efficiency & $\%$ \\
\hline$F F$ & Fill factor & $\%$ \\
\hline$V_{o c}$ & Open circuit voltage & $\boldsymbol{V}$ \\
\hline$J_{s c}$ & Short circuit current density & $\mathrm{mA} / \mathrm{cm}^{2}$ \\
\hline$J_{0}$ & Diode saturation current density & $\mathrm{mA} / \mathrm{cm}^{2}$ \\
\hline$I$ & Diode current & $\boldsymbol{A}$ \\
\hline$I_{0}$ & Diode saturation current & $\boldsymbol{A}$ \\
\hline$V_{D}$ & Diode voltage & $\boldsymbol{V}$ \\
\hline$V_{T}$ & Thermal voltage & $\boldsymbol{V}$ \\
\hline$E$ & Photon energy & $e V$ \\
\hline$v$ & Frequency of light & $h z$ \\
\hline$c$ & Speed of light & $\mathrm{m} / \mathrm{s}$ \\
\hline$\lambda$ & wavelength & $n m$ \\
\hline $\boldsymbol{V}$ & Applied potential & $\boldsymbol{V}$ \\
\hline$I_{L}$ & Light generated photon current & $\boldsymbol{A}$ \\
\hline$D$ & Diffusion constant & $m^{2} / s$ \\
\hline$\alpha$ & Absorption coefficient & $\mathrm{cm}^{-1}$ \\
\hline$k$ & Boltzmann constant & $m^{2} \operatorname{kgs}^{-2} K^{-1}$ \\
\hline$T$ & Temperature & $\boldsymbol{K}$ \\
\hline$Q$ & Charge & C \\
\hline$v_{t h}$ & Thermal velocity of charge carriers & $\mathrm{m} / \mathrm{s}$ \\
\hline$\delta_{p}$ & Capture cross section area of hole & $\mathrm{cm}^{2}$ \\
\hline$\delta_{n}$ & Capture cross section area of electron & $\mathrm{cm}^{2}$ \\
\hline $\mathbf{E}_{\mathbf{C}}$ & Conduction band minimum & $e V$ \\
\hline $\mathbf{E}_{\mathbf{V}}$ & Valence band minimum & $e V$ \\
\hline$E_{f n}$ & Electron quasi-Fermi level & $e V$ \\
\hline $\mathbf{E}_{\mathrm{fp}}$ & Hole quasi-Fermi level & $e V$ \\
\hline$\Delta \mathbf{E}_{\mathrm{C}}$ & Conduction band offset & $e V$ \\
\hline$\Delta \mathbf{E}_{\mathrm{V}}$ & Valence band offset & $e V$ \\
\hline $\mathbf{N}_{\mathrm{A}}$ & Uniform acceptor density & $\mathrm{cm}^{-3}$ \\
\hline $\mathbf{N}_{\mathbf{D}}$ & Shallow uniform donor density & $\mathrm{cm}^{-3}$ \\
\hline$\tau_{\mathrm{e}}$ & Electron lifetime & s \\
\hline$\tau_{h}$ & Hole lifetime & $\mathrm{s}$ \\
\hline
\end{tabular}




\begin{tabular}{clc}
\hline $\boldsymbol{L}_{\boldsymbol{n}}$ & Electron diffusion length & $\mathrm{m}$ \\
$\boldsymbol{L}_{\boldsymbol{p}}$ & Hole diffusion length & $\mathrm{m}$ \\
$\boldsymbol{C B O}$ & Conduction band offset & $\mathrm{eV}$ \\
$\boldsymbol{V B \boldsymbol { O }}$ & Valance band offset & $\mathrm{eV}$ \\
$\boldsymbol{S}_{\boldsymbol{i F}}$ & Interface recombination velocity & $\mathrm{cm} / \mathrm{s}$ \\
\hline
\end{tabular}




\section{Table of Contents}

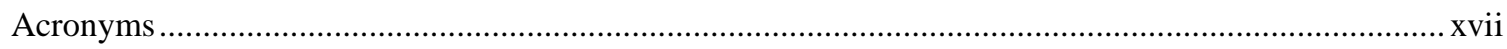

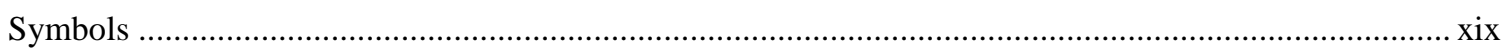

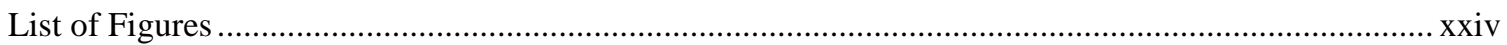

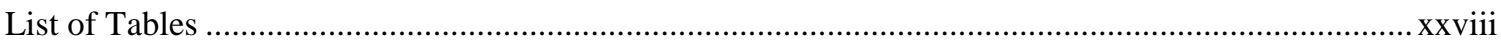

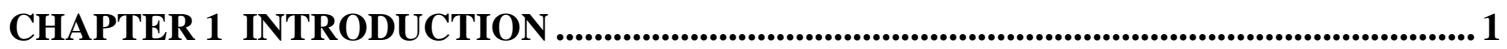

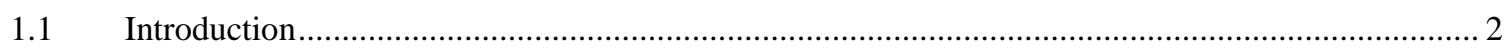

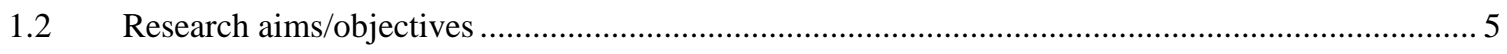

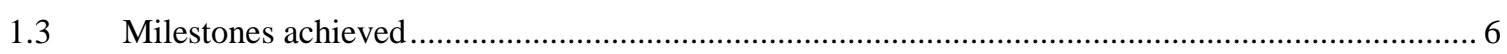

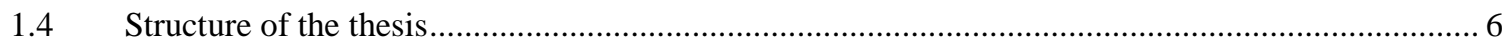

CHAPTER 2 THEORY OF SEMICONDUCTOR .............................................................. 7

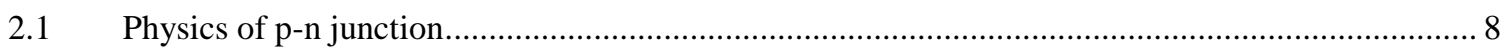

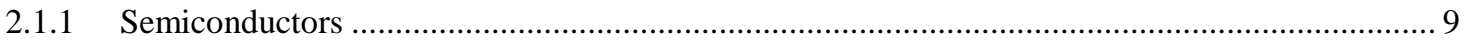

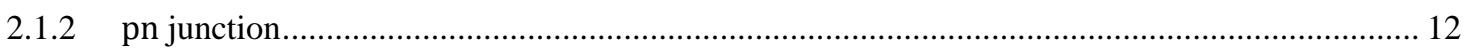

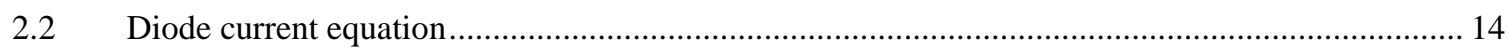

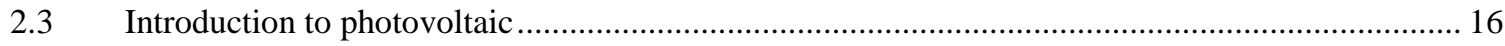

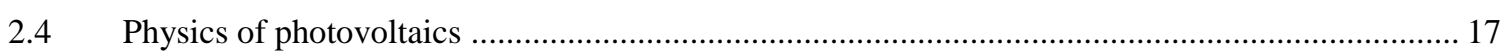

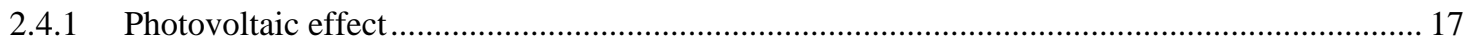

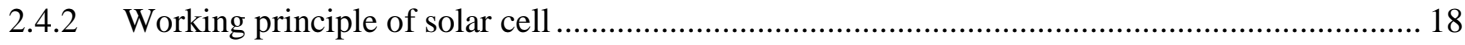

2.5 Basic parameters and electrical characterization methods ......................................................... 21

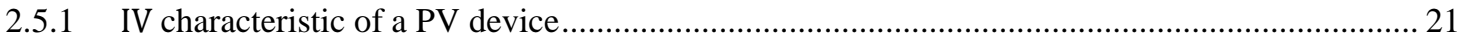

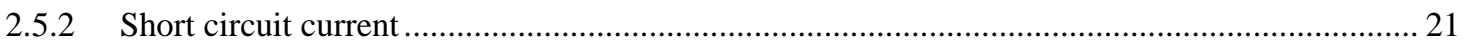

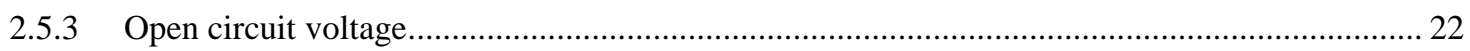

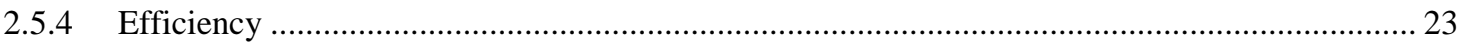

CHAPTER 3 RECOMBINATION LOSES IN SOLAR CELL IN PRESEPECTIVES OF SCAPS

.

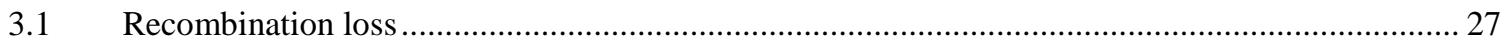

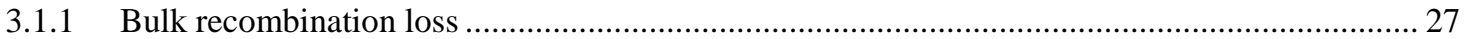

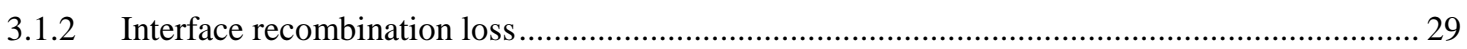

3.1.3 Recombination at metal semiconductor contacts .......................................................... 31

Effect of minority charge carrier mobility on recombination ............................................... 32

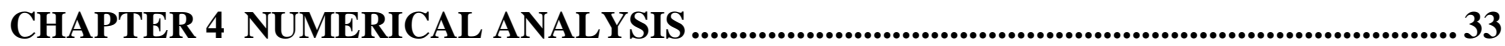

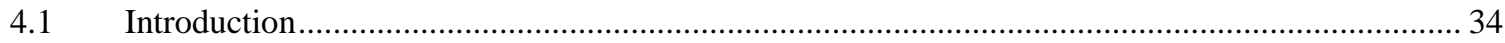

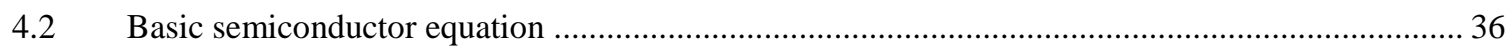

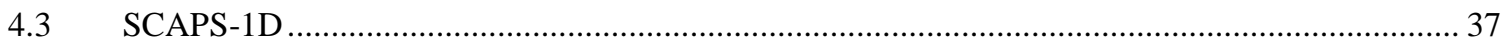

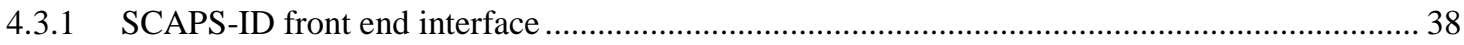




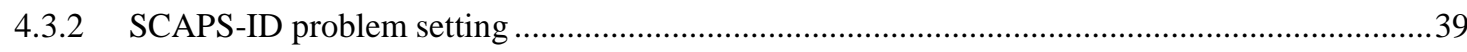

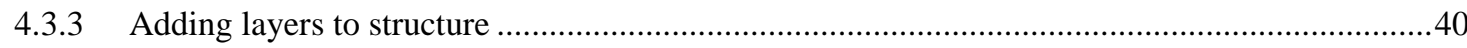

4.4 Baseline simulation for numerical analysis of $\mathbf{S n S}$ solar cell ................................................41

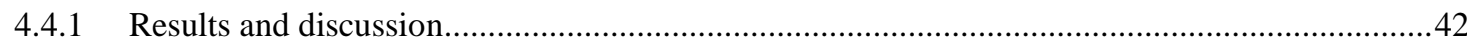

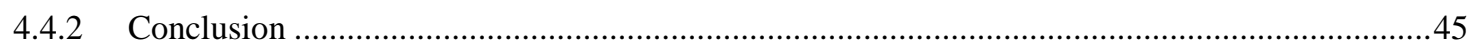

4.5 Adding back surface field layer to $\mathrm{ZnO} / \mathrm{n}-\mathrm{CdS} / \mathrm{p}-\mathrm{SnS}$ structure .......................................45

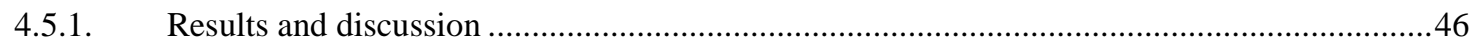

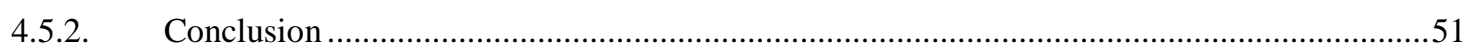

CHAPTER 5 EFFICIENCY ENHANCEMENT OF EXPERIMENTALLY DESIGNED SOLAR CELL .... 53

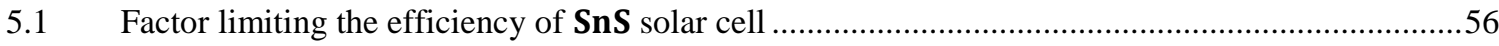

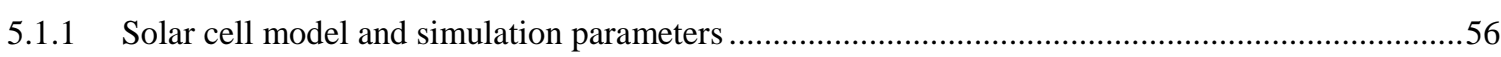

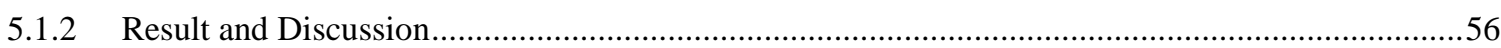

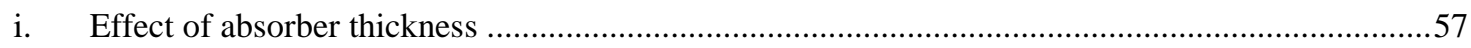

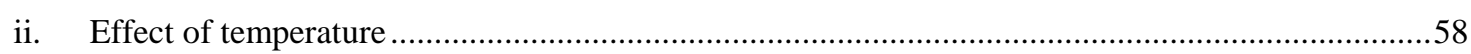

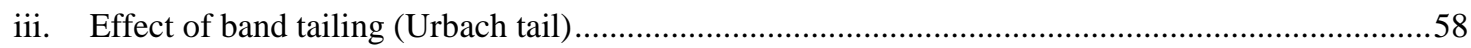

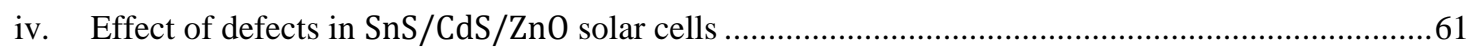

v. Comparison with experimental design solar cell result ........................................................62

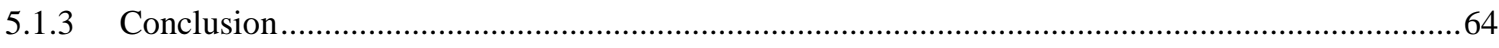

5.2 Numerical analysis a guide to improve the efficiency of experimental solar cell .......................64

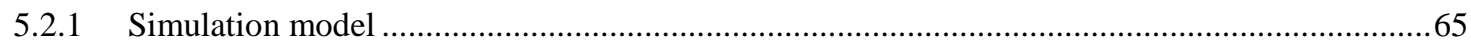

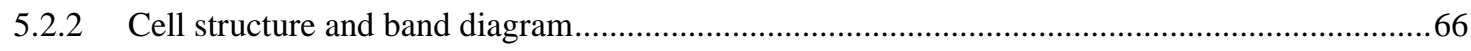

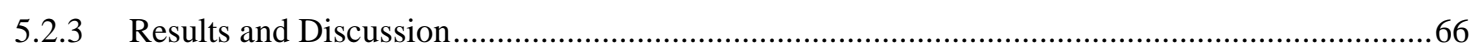

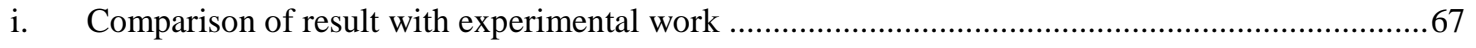

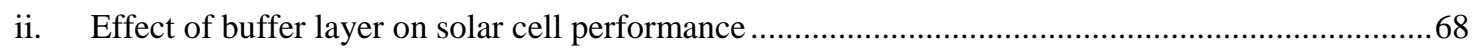

iii. Effect of absorber layer on solar cell performance ................................................................6. 68

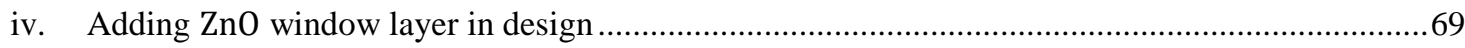

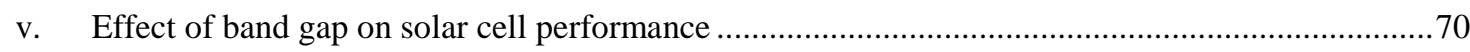

vi. Effect of mobility and diffusion length on solar cell performance ........................................... 71

vii. Effect of absorber acceptor and buffer donor doping concentration ....................................73

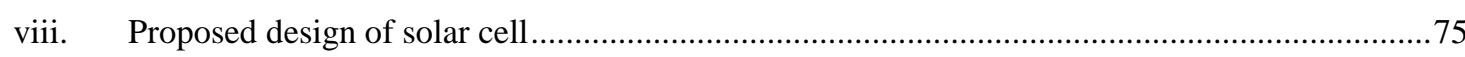

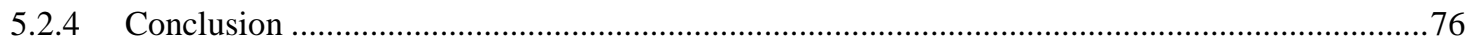

CHAPTER 6 EFFICIENCY ENHANCEMENT OF CH3NH3SnI3 SOLAR CELL ......... 77

6.1 Mitigation of interface recombination by careful selection of ETL for efficiency enhancement of

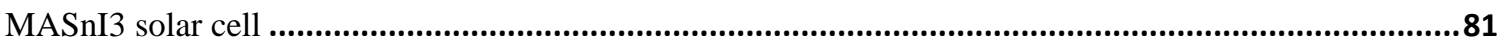

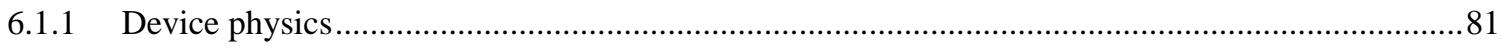

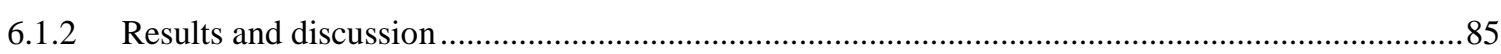

i. Effect of ETL CBO on J - V characteristics and interface recombination .....................................85

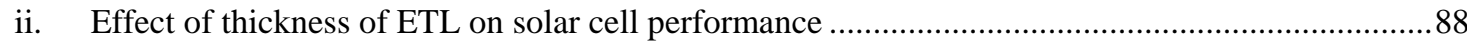


iii. Effect of donor doping of ETL on solar cell performance ........................................................ 90

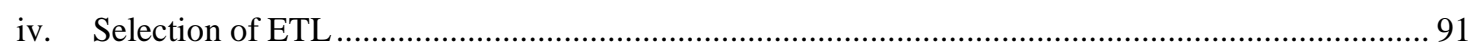

v. Effect of absorber thickness on solar cell performance ............................................................. 92

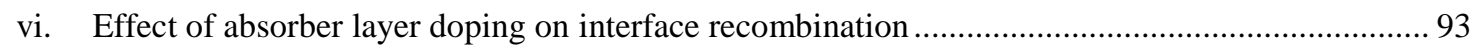

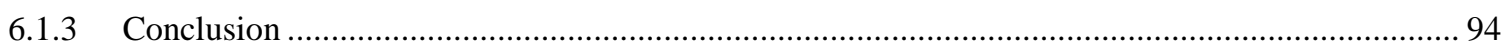

6.2 Efficiency enhancement of CH3NH3SnI3 solar cell by device modeling ................................ 95

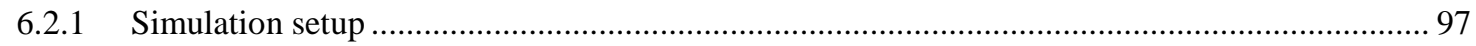

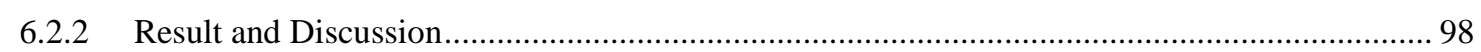

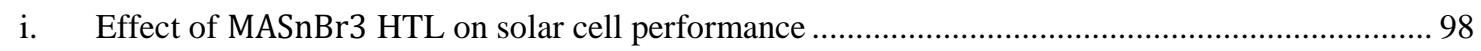

ii. Effect of Absorber thickness and doping concentration of solar cell performance..................... 100

iii. ETL band gap and electron affinity effect on solar cell performance ......................................... 102

iv. Effect of absorber layer defect on solar cell performance ...................................................... 103

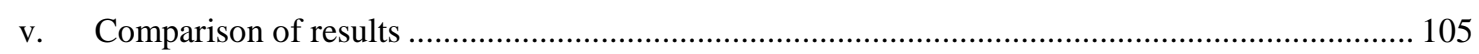

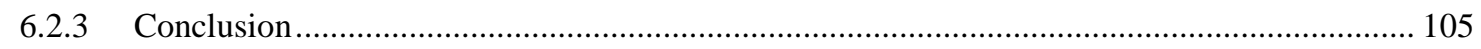

CHAPTER 7 CONCLUSION AND FUTURE WORK ...................................................... 107

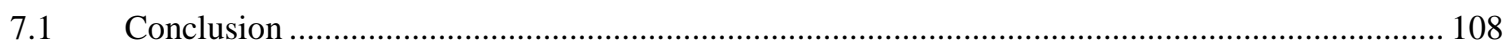

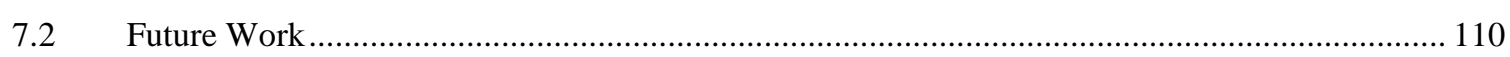

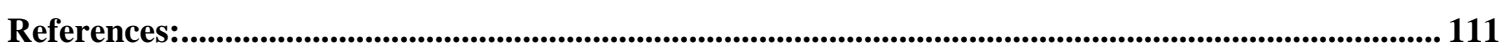

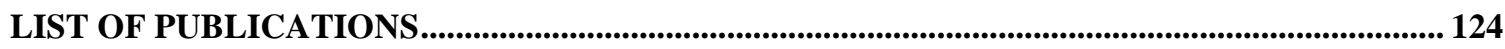


This page intentionally left blank 


\section{List of Figures}

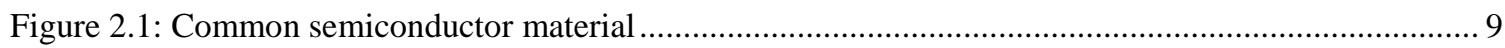

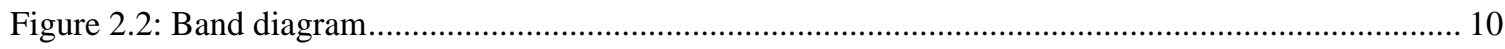

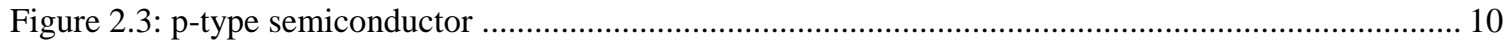

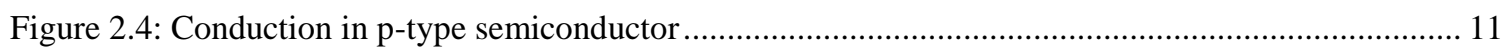

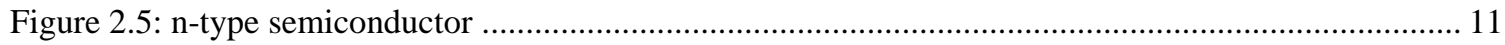

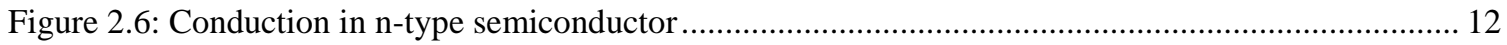

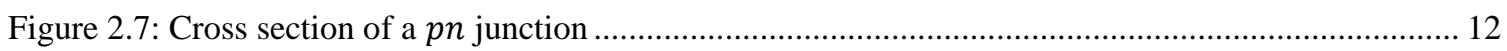

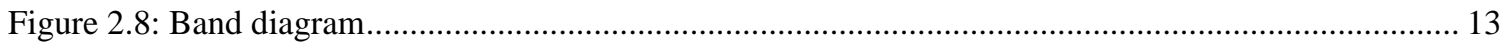

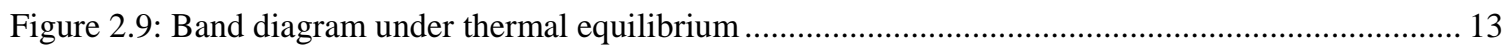

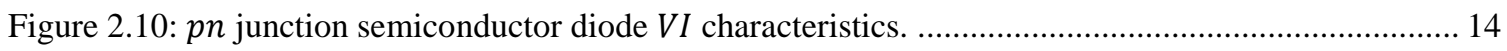

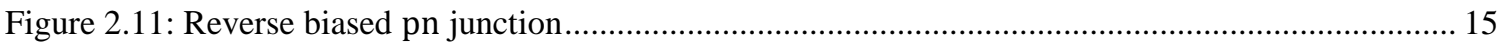

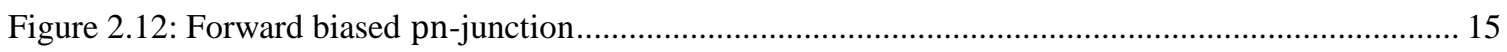

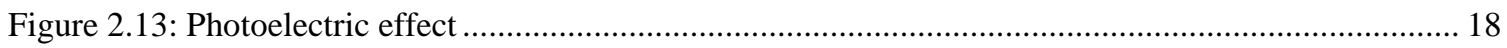

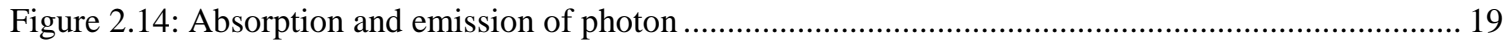

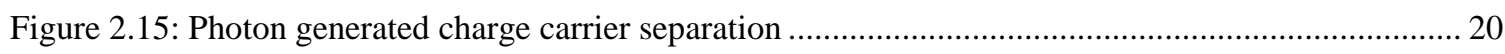

Figure 2.16: Short circuit current and open circuit voltage representation in VI cure ............................ 22

Figure 2.17: Graphical representation of open circuit voltage …..................................................... 22

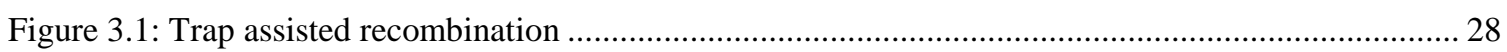

Figure 3.2: Interface between absorber/buffer layer ................................................................... 30

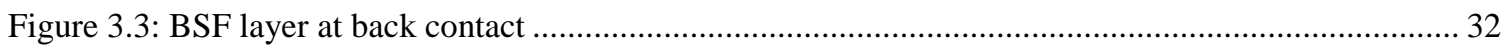

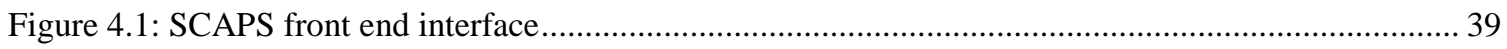

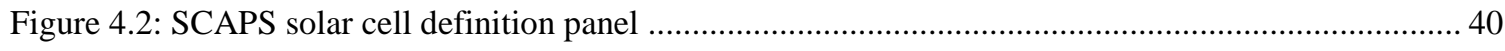

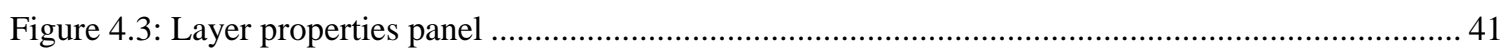

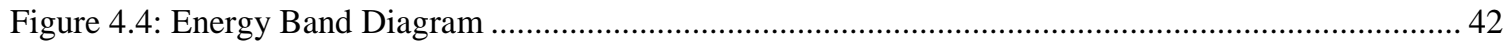

Figure 4.5: Dark and Illuminated Curve of Photovoltaic Cell .......................................................... 43

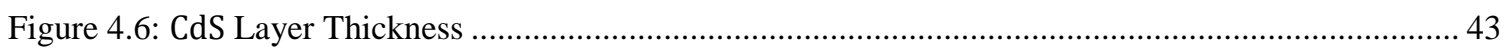

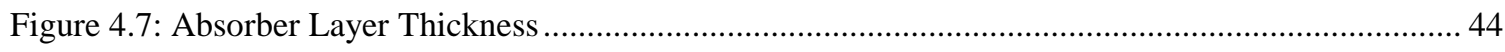

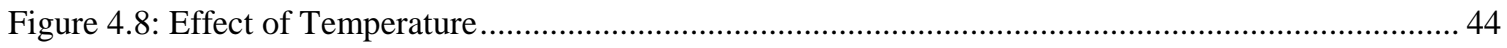

Figure 4.9: Cell structure and energy band diagram of proposed solar cell ............................................ 46

Figure 4.10: Dark and Illuminated J - V Curve of solar cell ........................................................... 47

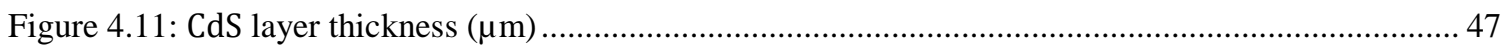

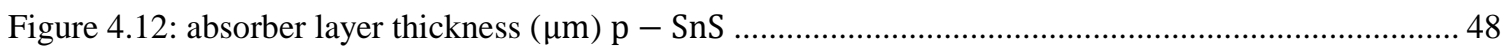

Figure 4.13: Quantum efficiency (QE \%) of SnS solar cell as a function of absorber layer thickness........ 49

Figure 4.14: BSF layer $(\mathrm{p}+-\mathrm{SnS})$ thickness effect on solar cell performance $(\mu \mathrm{m})$............................ 49

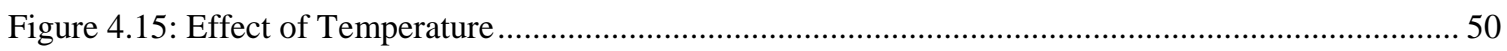

Figure 4.16: J - V Comparison between $\mathrm{p}+-\mathrm{SnS} / \mathrm{SnS} / \mathrm{CdS} / \mathrm{ZnO}$ with SnS/CdS/ZnO ........................ 51

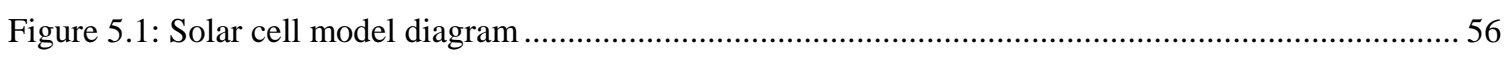

Figure 5.2: Effect of the absorber thickness on performance parameters of SnS solar cells......................57 
Figure 5.3: Effect of temperature on SnS/CdS/ZnO solar cell.........................................................58

Figure 5.4: Effect on absorption coefficient for different energy level of Urbach tail. ............................59

Figure 5.5: Urbach tail effect of SnS thin film solar cells....................................................................59

Figure 5.6: Effect of defect density of state at the interface of SnS/CdS layer.....................................61

Figure 5.7: Effect of capture cross section area for electron and hole of SnS absorber layer on the performance of solar cell. .....62

Figure 5.8: Comparison between experimental data and the simulation output using SCAPS. .................63

Figure 5.9: Cell structure and energy band diagram of proposed solar cell..........................................66

Figure 5.10: Comparison between experimental data (Ref. 8) and the simulation output using SCAPS. ....67

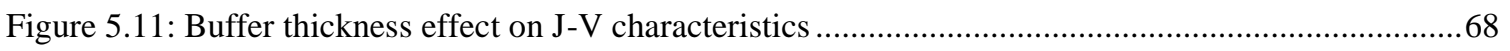

Figure 5.12: Buffer thickness effect on solar cell performance .......................................................69

Figure 5.13: Absorber thickness effect on solar cell performance.............................................................69

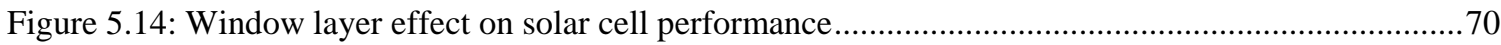

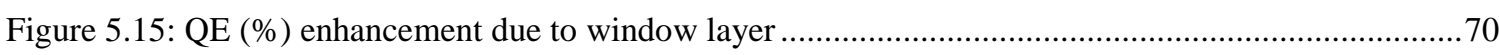

Figure 5.16: Bandgap variation effect on PCE .................................................................................. 71

Figure 5.17: Minority carrier lifetime of SnS absorber layer effect on J - V characteristics of solar cell ....72

Figure 5.18: Minority carrier lifetime of SnS absorber layer effect of solar cell performance ...................72

Figure 5.19: Mobility vs. PCE for SnS/CdS/ZnO solar cell .................................................................73

Figure 5.20: Acceptor doping concentration effect on solar cell performance ......................................74

Figure 5.21: Band structure with different acceptor doping concentration...............................................74

Figure 5.22: Effect of donor doping concentration of CdS layer on solar cell performance.......................75

Figure 5.23: Comparison of structure between experimental and numerical optimized structure...............75

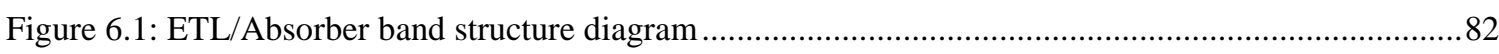

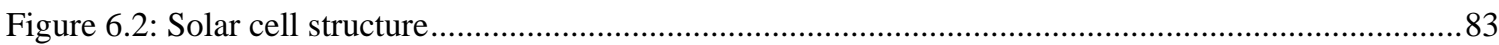

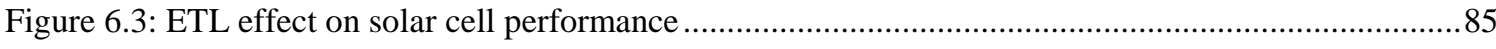

Figure 6.4: Different band diagram with different values of $\mathrm{CBO}$........................................................87

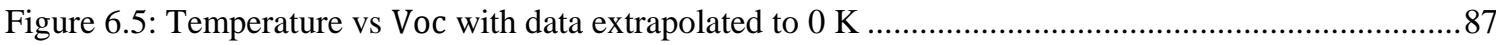

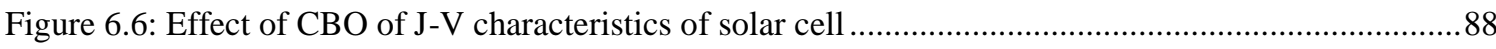

Figure 6.7: Effect of CBO on performance of solar cell vs different interface recombination velocities .....88

Figure 6.8: Effect of ETL thickness on hole concentration for recombination with different CBO ............89

Figure 6.9: Effect of ETL thickness on Voc of solar cell with different CBO.......................................89

Figure 6.10: ETL donor doping vs band bending for different CBO values .........................................90

Figure 6.11: Effect of ETL doping on solar cell performance with different CBO values .......................91

Figure 6.12: Solar cell performance parameters of different ETL as function of SiF..............................92

Figure 6.13: Effect of absorber thickness on hole concentration at interface .........................................93

Figure 6.14: Effect of absorber thickness on Voc of solar cell with different CBO ...............................93

Figure 6.15: Effect of Absorber doping concentration on solar cell performance.....................................94

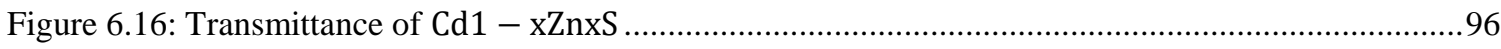

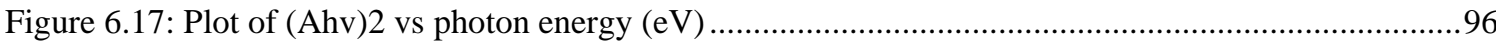

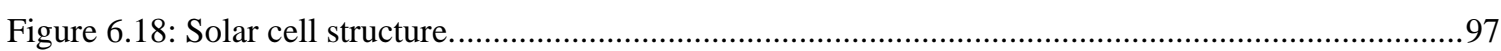

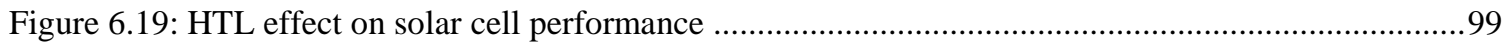


Figure 6.20: Band interface for HTL with absorber layer.

Figure 6.21: Effect of Electron affinity on solar cell performance .................................................. 100

Figure 6.22: Absorber layer thickness effect on solar cell performance .................................................. 100

Figure 6.23: Acceptor carrier concentration effect on solar cell performance ..................................... 101

Figure 6.24: QE as a function of acceptor concentration vs wavelength .............................................. 102

Figure 6.25: (a) Effect of ETL's on solar cell J-V characteristics curve (b) Effect of CBO of Cd1 - xZnxS on solar cell performance (c) Band structure for $\chi$ ETL $>\chi$ Absorber (d) Band structure for $\chi$ ETL $<\chi$ Absorber $\ldots \ldots \ldots \ldots \ldots \ldots . . . . . .103$

Figure 6.26: PCE vs Absorber thickness for different diffusion lengths................................................. 104

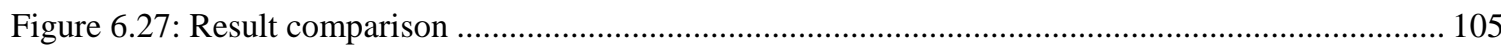


This page intentionally left blank 


\section{List of Tables}

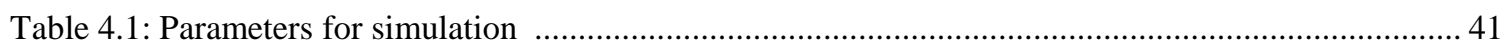

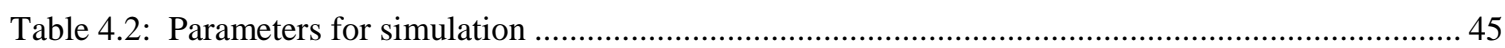

Table 5.1: Simulation parameters for the different layers in $S n S / C d S / Z n O$ thin film solar cells. ............ 56

Table 5.2: Reported PV parameters for simulated SnS solar cells in literature with different cell structures. ...........60

Table 5.3: Reported PV parameters for experimental SnS solar cells in literature with different cell structures........ 60

Table 5.4: Defects in SnS absorber layer according to references . .................................................6 63

Table 5.5: Calculated PV parameters for SnS/CdS solar cells with and without defects...........................63

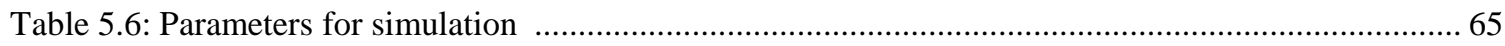

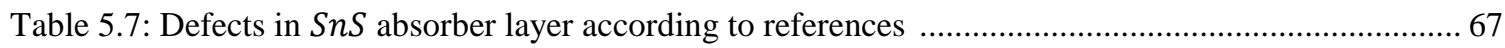

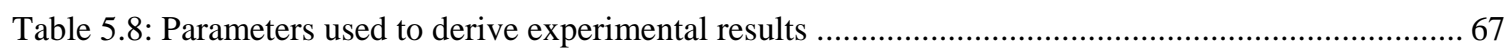

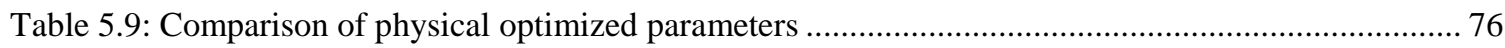

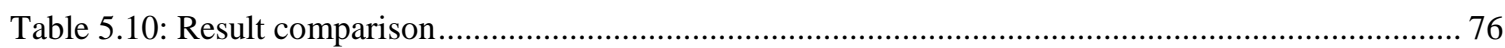

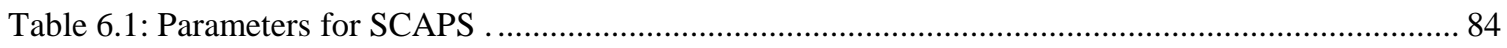

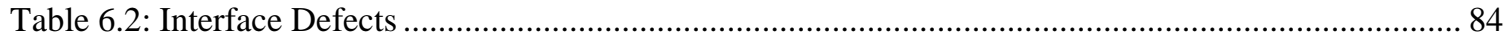

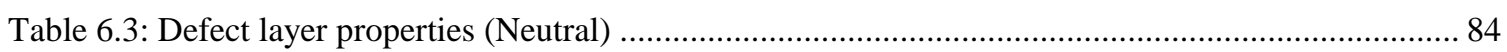

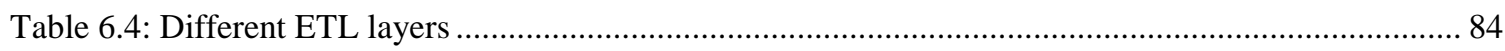

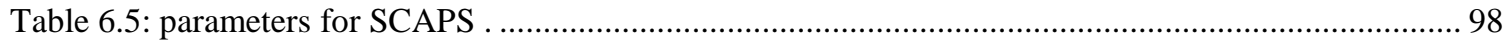

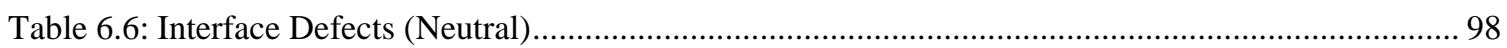

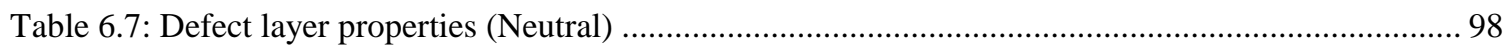

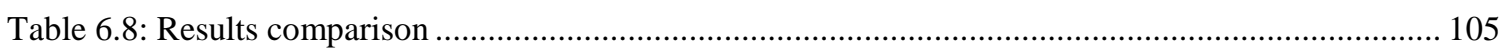


This page intentionally left blank 
CHAPTER 1 INTRODUCTION 
This page intentionally left blank 


\subsection{Introduction}

The invention of semiconductor revolutionized the industry and semiconductor is playing a key role in today's commercial applications. Among different commercial application, one of the major applications of semiconductor devices is its role in harvesting sunlight and converting into electric current. There are different types of photovoltaic cells available for commercial application and they majorly belong to the crystalline group. But the cost of production of these materials is very high as compared to other compounds like polycrystalline and monocrystalline. Today, silicon dominates the manufacturing of PV technology but due to the poor absorption coefficient of silicon $200-500 \mu \mathrm{m}$ thick absorber layer is utilized to absorb a significant amount of sun light. Due to poor absorption and a large area of absorber layer for silicon optimal absorber layers are required and this gives rise to thin film technology in which optimal absorber thickness is $5 \mu m[1,2]$. In thin film technology, less material is required as compared to silicon and processing cost of thin film technologies are less than silicon processing [3,4]. Thin film technology is one of the most cost-effective and efficient technology for the manufacturing of photovoltaic cells and it is an excellent subject of intense research in photovoltaic industry. Thin films are very suitable for low and large-scale photovoltaic cell applications. With the passage of time, the demand of renewable energy sources increases. One of the natures free gifts as an alternative energy source is solar energy. Due to the energy crisis and energy demands photovoltaic (PV) devices are used extensively to meet the increasing electrical energy demands. Importance of PV devices due to the reason of limitation in natural fossil fuels resources and the associated greenhouse effect caused by carbon. Increasing demand for PV devices at low cost with higher energy conversion efficiency drives in the world to explore for thinner, low-cost processing, cheaper materials with more efficient device structures. To fulfill the consumer demand and for the generation of electricity, the high-power conversion efficiency solar cell without degradation of materials and economical photovoltaic cells are fabricated.

Among thin film technologies successful are cadmium telluride (CdTe) and copperindium-gallium-selenide (CIGS) cells that have achieved record efficiencies close to $20 \%$ $[5,6]$. Unfortunately, cadmium is toxic in nature and gallium, indium and tellurium are non-abundant and expensive materials. Alternate for those materials must be sought for PV technology to scale up to the level of modern-day non-renewable energy production [7]. In search of more alternate absorber material, quaternary blends can circumvent the 
issue for availability and cost; and their PV properties can be tailored by varying the stoichiometry of individual components. $\mathrm{Cu}_{2} \mathrm{ZnSnS}_{4}$ (CZTS), has achieved a greater efficiency of $10.1 \%$ [8]. The availability of those materials is not a concern in the environment but to tailor their PV characteristic is quite difficult to handle.

So, an alternative to those materials must be sought and among them the most attractive candidate for thin film PV applications is SnS. SnS possess an orthorhombic structure and a direct band gap of 1.20-1.40 eV [9]. Effective optical absorption of SnS coincides with the optimum band gap for maximum efficiency according to the Shockley-Queisser limit with in the AM 1.5 solar spectrum. The absorption coefficient of SnS is higher than CdTe, CIGS and other available PV technologies. For producing tin based thin films solar cell large scale production units are already available for converting different metals into their corresponding sulphide using a range of sulfurization processes. Different techniques are utilized for the preparation of SnS thin films such as cathodic electrodeposition, electrochemical deposition, spray pyrolysis, vacuum evaporation, rf-sputtering, plasma enhanced chemical vapor deposition, and chemical vapor deposition [10-13].

Experimental investigation on performances of $\operatorname{SnS}$ has been carried out on how temperature affects the physical and chemical properties of deposited SnS layers vary with source and substrate temperature [14]. Similarly, numerical analysis of SnS material shows a maximum efficiency of $10.6 \%$ [15]. From the numerical analysis, $\mathrm{SnS}$ is proven to be a fruitful candidate for future PV technology but despite being suitable for PV technology still, SnS devices have not yet surpassed $4.6 \%$ efficiency. The limitation in the efficiency of SnS may be due to the defects and impurities in SnS layers related to deposition technique and self-oxidation of $\mathrm{Sn}^{2+}$ to $\mathrm{Sn}^{4+}$.

Apart from a non-organic solar cell, Lead halide perovskite solar cell (LHPSC) in recent years has drawn a great amount of attention because of their good absorption properties, optimal band gap, good carrier diffusion length and low-cost processing technique [1619]. Power conversion efficiency (PCE) of perovskite solar cell in the past few years has enhanced from $3.8 \%$ to $22 \%$ [20-25]. Despite the rapid development in PCE and simplification in the fabrication process of LHPSC still, the stability of LHPSC and toxic nature of lead hindered the way of commercialization of perovskite solar cell. Theoretical and experimental studies show that $\mathrm{CH}_{3} \mathrm{NH}_{3} \mathrm{SnI}_{3}\left(\mathrm{MASnI}_{3}\right)$ has an optimal band gap of $1.3 \mathrm{eV}$ and considered as a possible replacement for LHPSC. Due to its smaller band gap, it can cover a wide range of the visible light spectrum, than the LHPSC. Tin (Sn) 
perovskite-based planner structure solar cell has been developed with heterostructure architecture [26-28]. The major limitation of $S n$ based perovskite is oxidation of $S n$ from $S n^{2+}$ to $S n^{4+}$ in the air which limits the performance of the device. With extensive research, development of encapsulation process increases the stability of the $S n$ based perovskite materials. By the addition of tin fluoride $\left(S n F_{2}\right)$ in the fabrication process reduces the chance of oxidation of $\mathrm{Sn}^{2+}$ to $\mathrm{Sn}^{4+}$ [29]. Moreover, like LHPSC its band gap can also be tuned by changing iodine $(I)$ with bromide $(B r)$ and with an addition of $\mathrm{Br}$ its bandgap increases. The tunability of bandgap provides an opportunity to use $S n$ based perovskite for solar cell application as a possible replacement for LHPSC [30]. Despite the rapid improvement in $S n$-based perovskite material still, PCE achieved from $S n$ based perovskite solar cell is very low. This is mainly due to the lack of understanding of device properties and the effect of band structure on device performance $[31,32]$.

In this research work, numerical modeling is carried out to estimate or analyze the parameters of different photovoltaic thin film solar cells. Device modeling can be performed on the dedicated SCAPS simulation software. To analyze the performance of a photovoltaic device, numerical analysis was performed on different physical parameters such as thickness and doping concentration of absorber, buffer and window layers, temperature effect and effect of illumination power of the sun on a solar cell. This analysis can help to achieve the high conversion efficiency from thin film solar cell.

\subsection{Research aims/objectives}

The main aims and objectives of the research work presented in this thesis are:

i. One dimensional numerical analysis of an experimental solar cell in SCAPS-1D

ii. Find the factors that limit the efficiency of experimental solar cell

iii. Find effect of a buffer layer on solar cell performance

iv. Propose guidelines for efficiency enhancement of experimental designed solar cell

v. To propose new buffer and window layers to improve the efficiency of solar cells.

vi. To propose new absorber materials for getting high output voltage and high efficiency from thin film photovoltaic devices.

vii. To discover alternate solutions for the cost reduction of thin film solar cells.

viii. To propose a new photovoltaic device structure. 
Device performances are described based on numerical modeling by using SCAPS software. The analysis was performed on the following parameters such as the thickness and doping concentration of absorber, buffer and window layers and working temperature to analyze their effects on the cell performance. SCAPS simulation software was used for the analysis of photovoltaic solar cells.

\subsection{Milestones achieved}

The main result accomplished in this work were:

i. Numerical analysis guide is proposed to enhance the efficiency of experimental designed solar cell.

ii. Interface recombination mitigation was proposed.

iii. A new structure was proposed to enhance the efficiency of a solar cell.

\subsection{Structure of the thesis}

The thesis is organized in seven chapters whose contents are described below

i. Chapter 1 includes the problem statement and contributions in this thesis. Thesis organization is also described in it.

ii. Chapter 2 describes the semiconductor theory.

iii. Chapter 3 Recombination losses in solar cell.

iv. Chapter 4 Numerical analysis in SCAPS

v. Chapter 5 Efficiency enhancement of experimental designed solar cell in SCAPS.

vi. Chapter 6 proposed a model to select a suitable ETL for efficiency enhancement of $\mathrm{CH}_{3} \mathrm{NH}_{3} \mathrm{SnI}_{3}$ solar cell

vii. Chapter 7 presents the concluding remarks 
CHAPTER 2 THEORY OF SEMICONDUCTOR 
This page intentionally left blank 


\subsection{Physics of p-n junction}

\subsubsection{Semiconductors}

Semiconductor material belongs to group IVA of the periodic table with some alloys belongs to other groups of periodic table highlighted in blue shown in Figure 2.1 below [33].

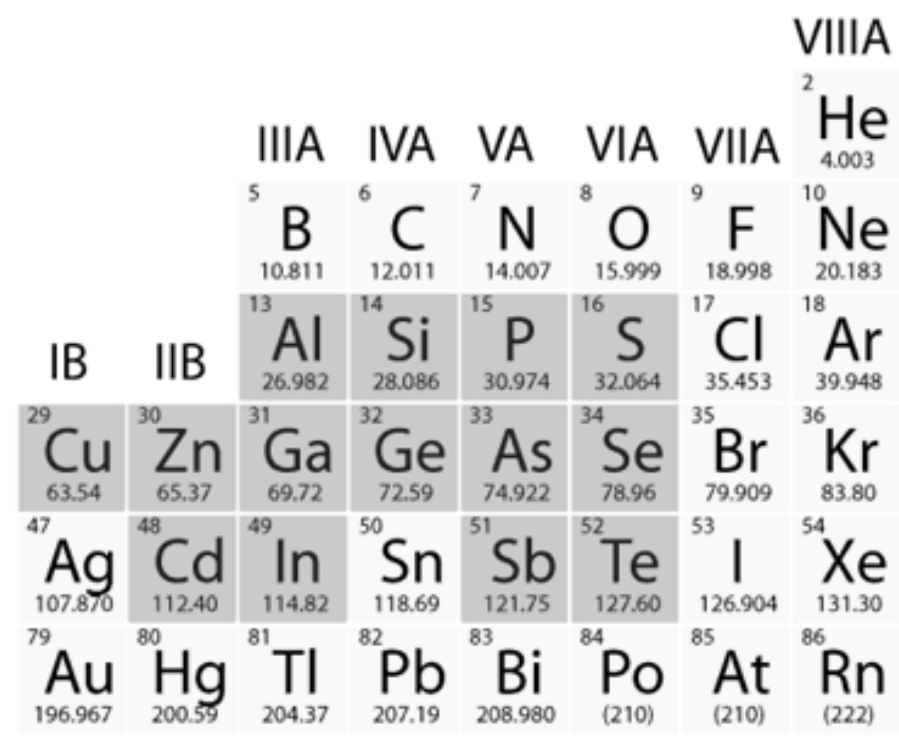

Figure 2.1: Common semiconductor materials

Semiconductors are materials whose electrical properties lie in between of conductor and insulator. This happens because of the band gap of semiconductor material lies in between of conductor and insulator. So, in semiconductors electron need external energy to jump from valance band to conduction band to participate in electrical current. Electrical properties of semiconductors are heavily depended upon temperature. As with increase in temperature, the conductivity of semiconductor materials increases unlike in metals. This is well explained with the aid of band diagram for conductor, semiconductor and insulator. From Figure 2.2 for insulator the band gap energy value is too high to conduct current whereas for conductor band gap energy is zero so for electrons there is no external energy required for conduction of electric current but for semiconductor band gap energy is neither too large neither zero. So, for electrons in valance band for semiconductor requires a small amount of energy to jump from valance band to conduction band to participate in electric current. And when an electron (-) jumps from valance band to conduction band in case of semiconductor it leaves a vacant space in valance band that is filled by a hole $(+)$ and with an increase in temperature concentration of electron in conduction band increases with proportional to holes in valance band. At given temperature $\mathrm{T}$ under thermal equilibrium current in pure semiconductors flows because of electrons in the conduction 
band and holes in valance band. Because of this nature semiconductors gained much importance in the scientific community that flow of current can be altered at any given time just by controlling the ratio of charge carriers. To do so pure semiconductors were doped with impurities.

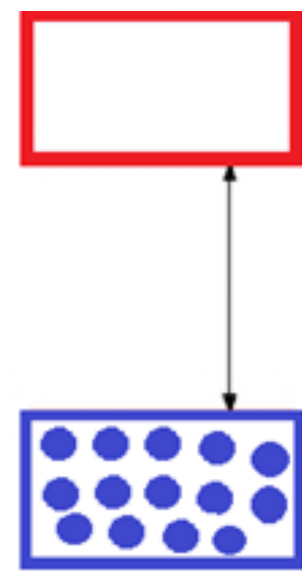

Insulator Semiconductor
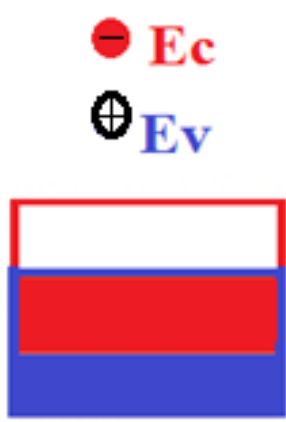

Conductor

Figure 2.2: Band diagram

\section{i. $\quad$ Trivalent doped semiconductor (p-type):}

The p-type semiconductor material is formed by adding trivalent boron (B) atom in the crystal lattice of pure silicon ( $\mathrm{Si}$ ) semiconductor material. Because of this trivalent atom, the concentration of holes increases as it acts as an acceptor concentration. This happens because added impurity is bonded with four atoms of Si but it only has three electrons to share with Si, a hole is created. This hole created by impurity behaves like a positive charge. This is shown in Figure 2.3 below [34].

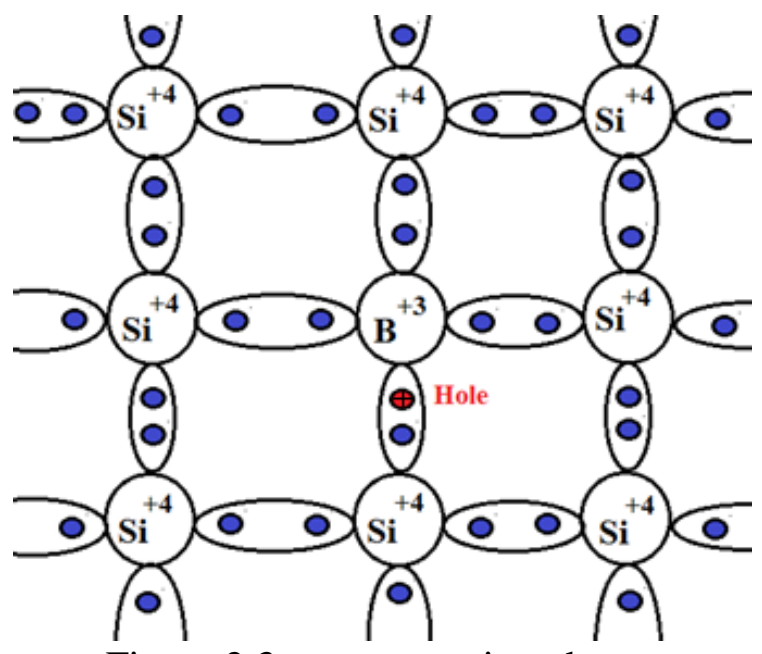

Figure 2.3: p-type semiconductor

When a p-type semiconductor is sourced by voltage supply; holes in valence band moves towards the negative terminal and thermally generated free electrons towards the positive terminal of the voltage supply source. This phenomenon is well understood from Figure 
2.4. In p-type semiconductor, holes population in the valence band is more than thermally generated free electrons of conduction band under thermal equilibrium. Hence, in the ptype semiconductor, minority carriers are free electrons and majority carriers are holes.

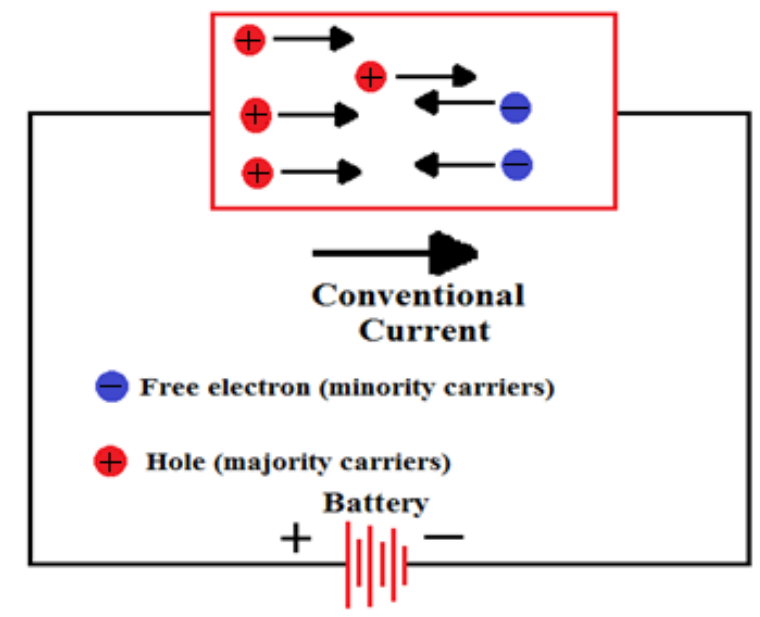

Figure 2.4: Conduction in p-type semiconductor

\section{ii. Pentavalent doped semiconductor (n-type):}

The n-type semiconductor is fabricated by insertion of a pentavalent atom into the pure silicon (Si) semiconductor lattice. By insertion of pentavalent phosphorous $(\mathrm{P})$ into the $\mathrm{Si}$ crystal lattice a free electron is created with every $\mathrm{P}$ atom in the crystal lattice and these impurities are called donor impurity. The free electron is created because $\mathrm{P}$ has 5 electrons to share with neighboring four $\mathrm{Si}$ atoms so one extra electron is given to conduction band. This is shown in Figure 2.5 for n-type semiconductor.

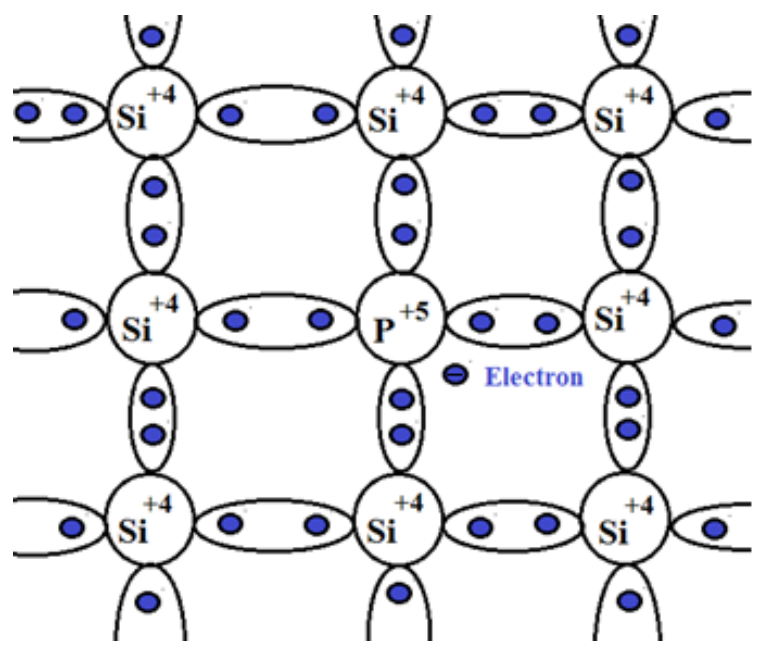

Figure 2.5: n-type semiconductor

When an n-type semiconductor is sourced by voltage supply; holes in valence band moves towards the negative terminal and free electrons towards the positive terminal of the voltage supply source. This phenomenon is well understood from Figure 2.6. In an n-type semiconductor, free electrons population in the conduction band is more than holes of a 
valence band. Hence, in n-type semiconductor, minority carriers are holes and majority carriers are free electrons.

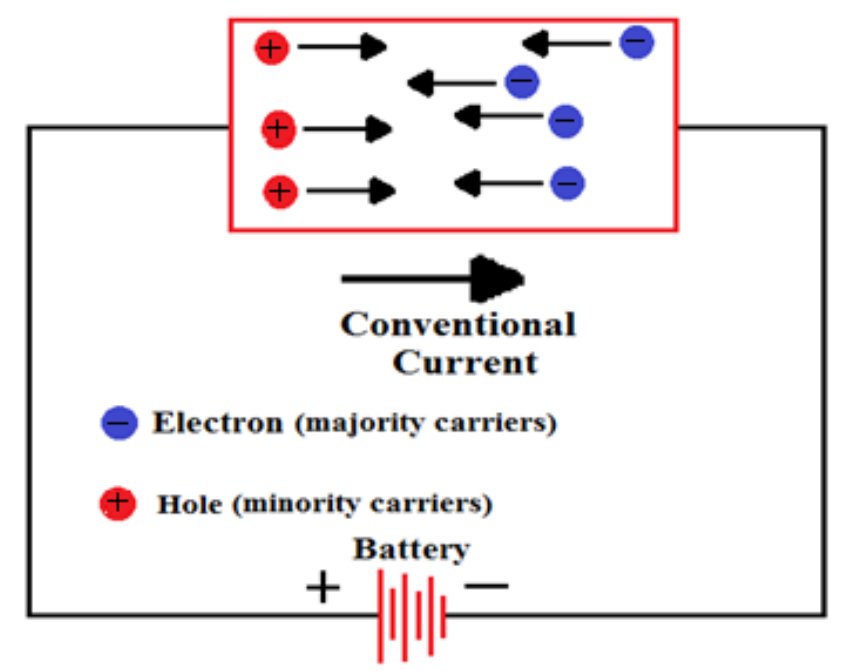

Figure 2.6: Conduction in n-type semiconductor

\subsection{2 pn junction}

A junction is formed by combining two different doped regions of a semiconductor that is p-type and n-type [35]. As shown in Figure 2.7, the left-hand side is a p-type region with the hole as majority carriers whereas the right-hand side is an n-type region with electrons as majority carriers.

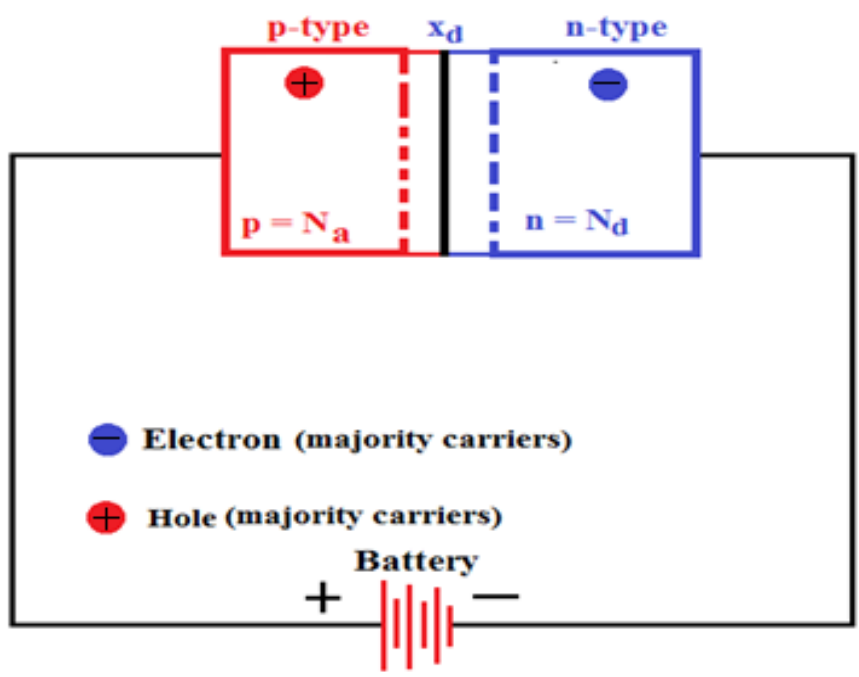

Figure 2.7: Cross section of a $p n$ junction

The principle of operation of formation of junction barrier at the interface is shown in Figure 2.8 with the aid of band diagram with vacuum energy level. From the band diagram in Figure 2.8 it is visible that Fermi energy level for $\mathrm{p}$ and $\mathrm{n}$ region are not aligned and to achieve thermal equilibrium diffusion of electron in $\mathrm{p}-$ side and hole in $\mathrm{n}-$ side is expected. This diffusion of the electrons and holes across the boundary interface leaves the ionized donor near to the junction region. This moment of electrons and holes across 
the region create a depletion region which further stops the flow of electrons and holes across the junction. The band diagram for pn junction under thermal equilibrium is shown in Figure 2.9.

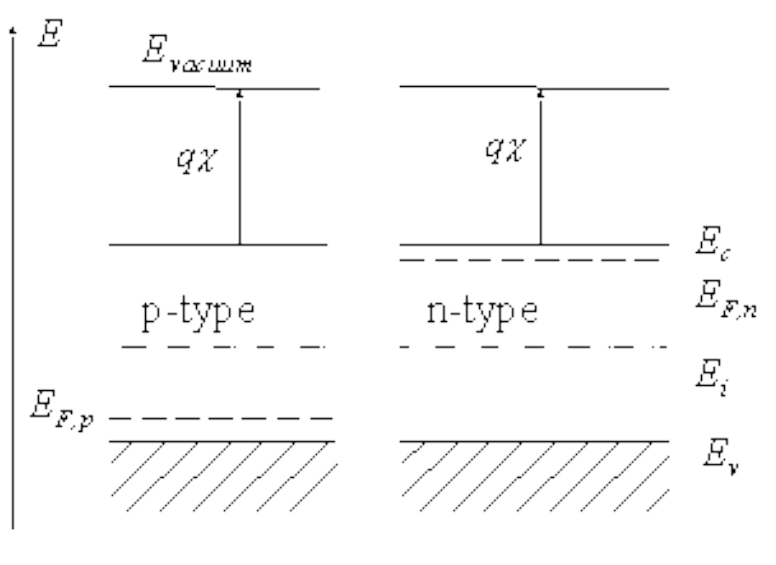

(a)

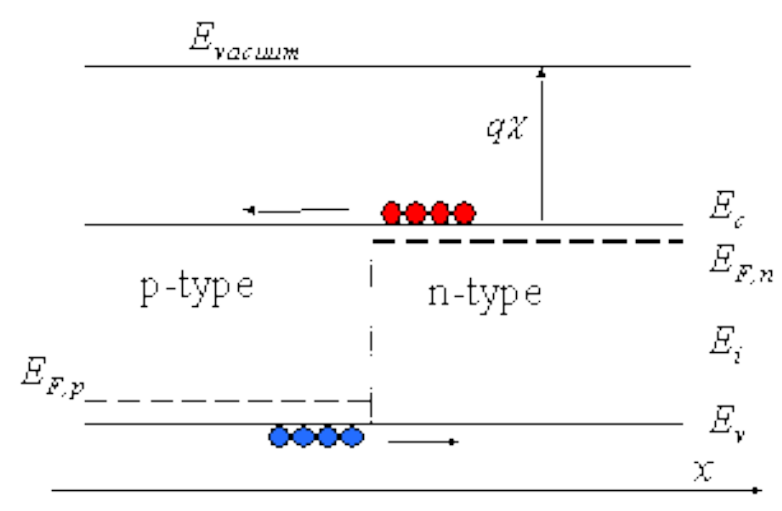

(b)

Figure 2.8: Band diagram

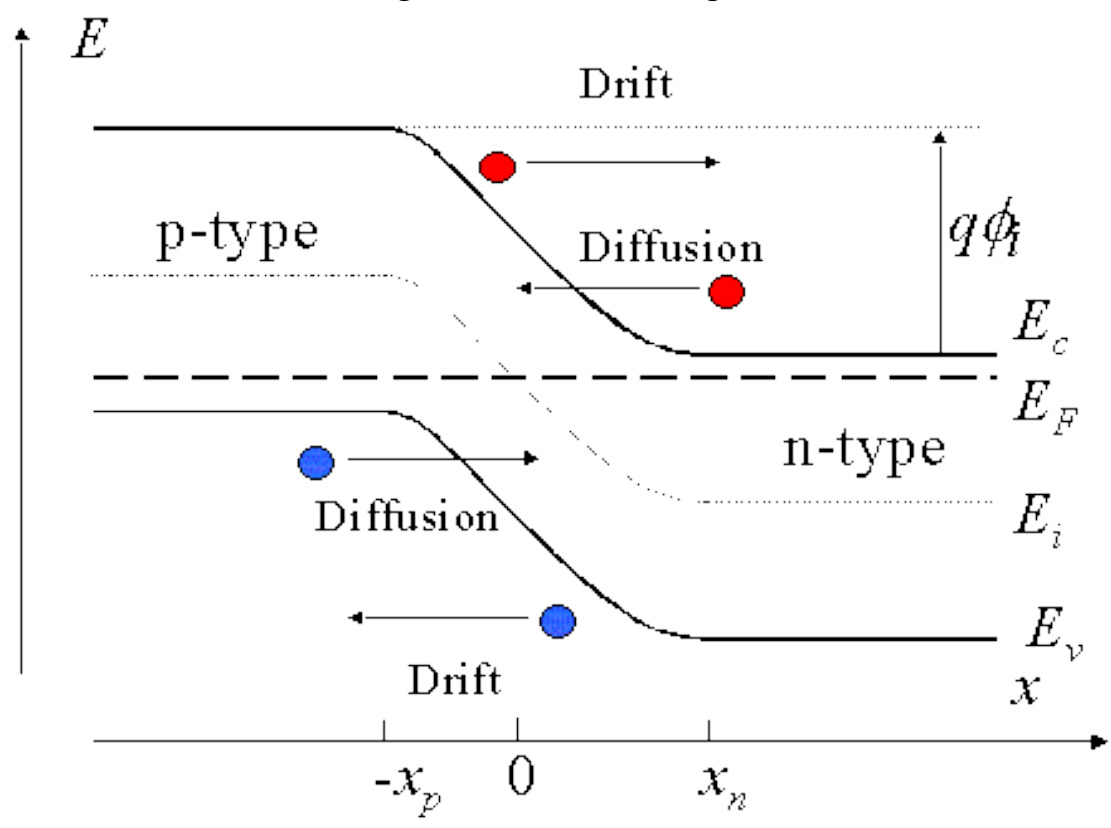

Figure 2.9: Band diagram under thermal equilibrium

pn junction semiconductor diode has two electrodes, the anode, and cathode. Diode offered very low resistance to flow the electric current in one direction whereas very high resistance in other direction. Thus, a diode is a unidirectional device. Which only allow the flow of current in on direction while stops the current in other direction. To attain extreme current in the forward direction or in low resistance, diode must be connected in forward bias (anode with positive and cathode with negative source potential) as shown in Figure 2.7. IV characteristics cure of pn junction diode is shown in Figure 2.10. The barrier potential for silicon diode is $0.7 \mathrm{~V}$ and for germanium diode is $0.3 \mathrm{~V}$. This barrier potential 
is termed as cut-in voltage or knee voltage. Reverse characteristics can be obtained by reverse biasing the diode. Notice that a reversed biased diode only allows a flow of very small current because of minority charge carrier up to the point of breakdown and after that reverse current increases rapidly.

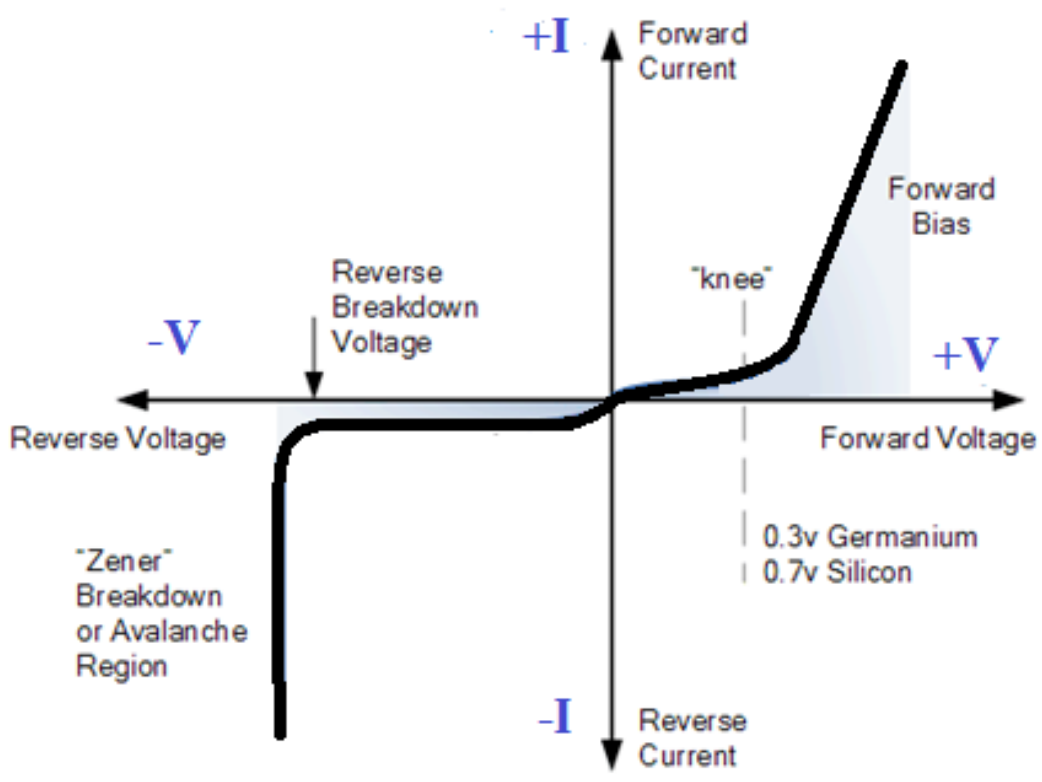

Figure 2.10: $p n$ junction semiconductor diode VI characteristics.

\subsection{Diode current equation}

Shockley's equation explains the general characteristics for the reverse and forward bias regions of $\mathrm{p}-\mathrm{n}$ junction diode[36]. The diode current equation is given below in equation 2.1 .

$$
I=I_{0}\left[e^{\frac{V_{D}}{\eta V_{T}}}-1\right]
$$

Where

$\mathrm{I}=$ Diode current

$\mathrm{I}_{0}=$ Reverse saturation current

$\mathrm{V}_{\mathrm{D}}=$ Diode voltage

$\eta=$ semiconductor constant, depends on the construction and operating conditions ( 1 to 2 , usually taken as 1)

$\mathrm{V}_{\mathrm{T}}=$ Thermal voltage $\left(\right.$ where $\left.\mathrm{V}_{\mathrm{T}}=\frac{\mathrm{k}_{\mathrm{B}} \mathrm{T}}{\mathrm{q}}\right)$

Where

$\mathrm{k}_{\mathrm{B}}=$ Boltzmann's constant $=1.38 \times 10^{-23} \mathrm{~J} / \mathrm{K}$

$\mathrm{T}=$ Absolute temperature in Kelvin 
$\mathrm{q}=$ magnitude of electronic charge $=1.6 \times 10^{-19} \mathrm{C}$

Therefore, with aid of equation 2.1 Figure 2.10 can be explained as with $V_{D}>0$ there will be an exponential increase in the diode current and with $V_{D}<0$ the current through the diode will be negligible. For voltage across the diode $V_{D}<0$ the diode is in reverse biased region and this is shown in Figure 2.11.

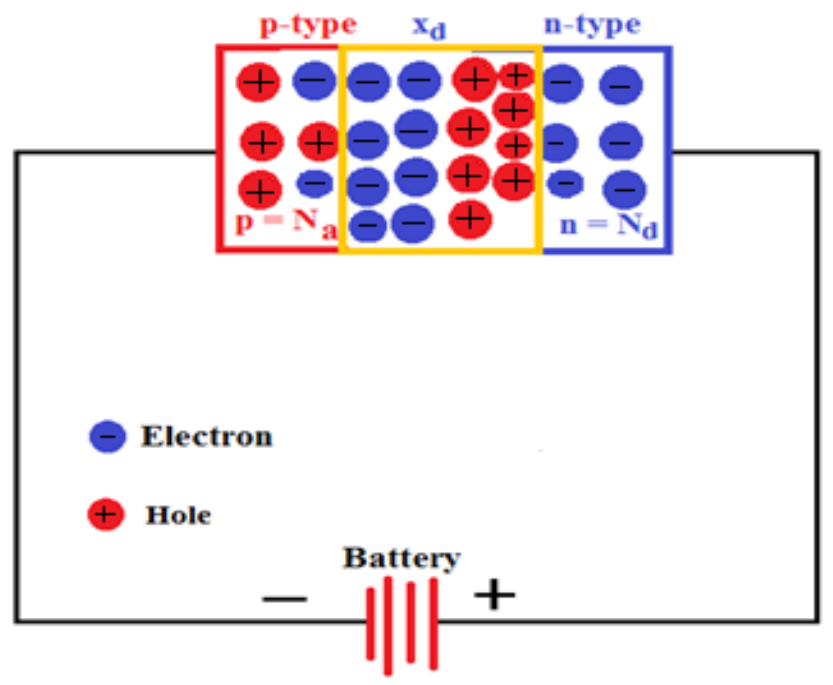

Figure 2.11: Reverse biased pn junction

With the negative end of the battery is connected to $\mathrm{p}$-side of a diode and positive end of a battery is connected to n-type of a diode as shown in Figure 2.11. The width of the depletion region will increase and stopping the flow of current through the diode. Whereas when we change the polarity and positive end of the battery is connected to p-side of diode and n-side is connected to a negative end of the battery as shown in Figure 2.12 the width of depletion layer will be reduced and will force a large current to flow through the diode.

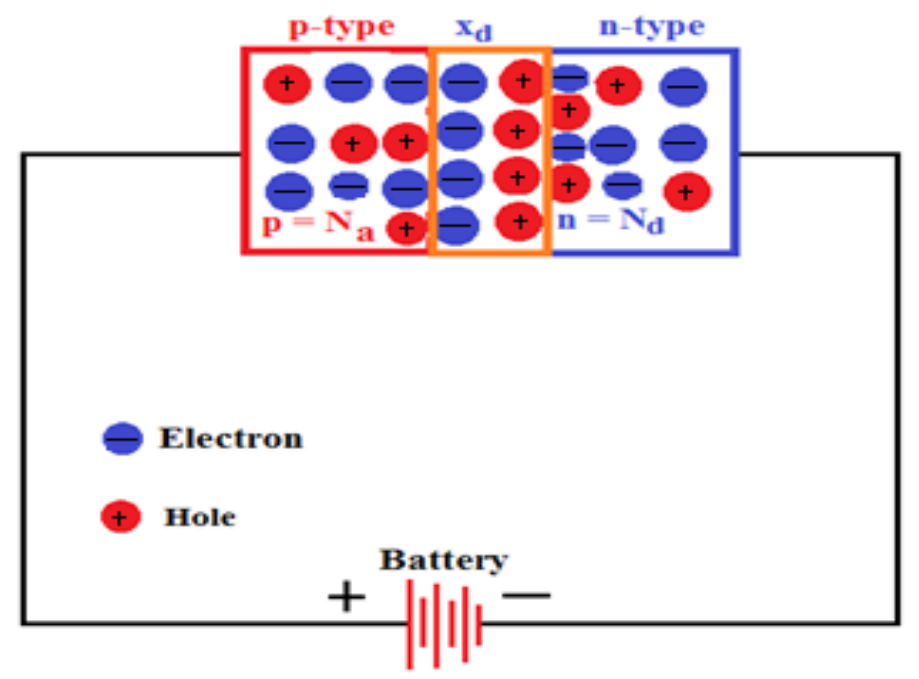

Figure 2.12: Forward biased pn-junction 
The current through diode will rise exponentially when the voltage across the diode increases the diode potential because diode offer low resistance in this region and with further increase in potential more charge carriers will be pushed.

Application of pn-junction diode:

pn-junction diodes are heavily used in daily life for commercial applications around the globe in power converter
i. $\quad \mathrm{AC}$ to $\mathrm{DC}$ converter
ii. $\quad \mathrm{DC}$ to $\mathrm{AC}$ converter
iii. Oscillator

Photonic applications
i. LED's (Light emitting diodes)
ii. LASER diodes (Light amplification stimulated emission radiation)
iii. Photodetectors (Infra-red and photocoupler)

Photovoltaic application

i. $\quad$ Solar cells (e.g. Si solar cell)

From here we will discuss the application of semiconductor in photovoltaic.

\subsection{Introduction to photovoltaic}

The word "photovoltaic" was made up from the Greek word "pros" means light and "voltaic" means electricity associated with the name of Italian physicist Alessandro Volta. Electricity can be produced from the "photovoltaic effect". An appropriate definition of the photovoltaic effect is the direct conversion of electromagnetic radiation (light) into electrical energy. The term "solar cell" is employed to describe a device, that can convert the energy of the sunlight into electrical energy. Sunlight is an important and abundant source that can be utilized to produce electrical energy by using solar cells. The first practical solar cell that was made available for industrial application was in 1950 after a long effort of intensive investigation by the research community. But the photovoltaic process was first discovered in 1839 by a French scientist Edmond Becquerel. Silver chloride $\left(\mathrm{AgCl}_{2}\right)$ electrode was placed in acidic solution while connected with plutonium (Pt) electrodes [35]. When electrodes were illuminated it generates electric current and this was called photovoltaic effect which at that time was also known as "Becquerel effect". The next significant development in photovoltaic came when Adams and Day (1877) invented the first metal solar cell by exposing metal selenium (Se) to solar radiation. Light-induced crystallization of the outer layers of the selenium bar to the 
photogenerated current was attributed by Adams and Day. The next breakthrough came in solar cell was after seven years from the invention of Se metal solar cell by Fritts (1883). This was the first thin film solar cell by placing Se metal between two different metals electrodes. The area of the first thin film solar cell invented in 1883 was of $30 \mathrm{~cm}^{2}$. But after the extensive studies, the first commercially available solar cell that was used in a satellite orbiting around the globe was demonstrated by Chapin, Pearson, and Fuller in 1954 [37].

Today, mono-crystalline and poly-crystalline silicon solar cells with 1-sun conversion efficiencies ranging from $14.7 \%$ to around $25 \%$ have been demonstrated using different fabrication techniques with different device structures. There are several competing PV technologies available to produce commercial PV modules for terrestrial power generation and consumer electronics applications. They are (i) silicon solar cell modules made from single-crystal and polycrystalline silicon, (ii) low-cost thin-film solar cell modules fabricated from a-Si: $\mathrm{H}, \mathrm{Cu}(\mathrm{In}, \mathrm{Ga}) \mathrm{Se}_{2}$ (CIGS), and CdTe materials, and (iii) highefficiency multijunction tandem solar cells and concentrator solar cells using III-V compound semiconductors such as InGaP/GaAs and InGaP/GaAs/Ge material systems for solar cell fabrication. These solar cells and solar cell modules can be used in a wide variety of applications for consumer electronics, office, residential buildings, remote irrigation systems, microgrids and off-grid industrial systems [38]. To calculate the conversion efficiency of a solar cell, one needs to know the exact incident solar irradiance power under different illumination conditions.

\subsection{Physics of photovoltaics}

\subsubsection{Photovoltaic effect}

Photovoltaic is a process that converts light energy into electrical energy when exposed to sun and the device that performs this task is called a photovoltaic cell or a solar cell. These cells made up of different semiconductor materials (p-type, n-type) that are merged together to form a pn-junction. By joining these two materials create a barrier which allows the flow of electron only in one direction and holes in the opposite direction to electrons. When light falls on semiconductor materials it generates electron-hole pairs in material that are extracted to provide power to an external load. 


\subsubsection{Working principle of solar cell}

The solar cell working principle is based on the photovoltaic effect that is the generation of charge carrier by absorbing light photons. This effect is closely related to the photoelectric effect, where the emission of electrons from a material is due to light absorption with a frequency above a material-dependent threshold frequency. This effect was explained by the scientist Albert Einstein in 1905 by assuming that the light comprises of well-defined energy quanta, called photons. The energy of such photon $E_{p h}$ is given in equation 2.2.

$$
E_{p h}=h v
$$

Where

$$
v=\frac{c}{\lambda}
$$

Here $\mathrm{c}$ is the speed of light in a vacuum (c $\left.=3 \times 10^{8} \mathrm{~m} / \mathrm{s}\right), \mathrm{h}$ is the Planck's constant $\left(\mathrm{h}=6.626 \times 10^{-34} \mathrm{Js}\right)$ and $v$ is the frequency of the light. For the explanation of this effect Einstein received the Nobel Prize in Physics in 1921

Based on the theory if a photon has enough energy it will transfer its energy to the electron and eject it from the material surface and the kinetic energy of ejected electron was given as in equation 2.4.

$$
K_{\max }=h v-\emptyset
$$

$\emptyset=h f_{0}$ is the work function, that is the energy required to knock out electron from the surface of a material with frequency $v>f_{0}$. The experimental study of the proposed theory is depicted in figure 2.13 .

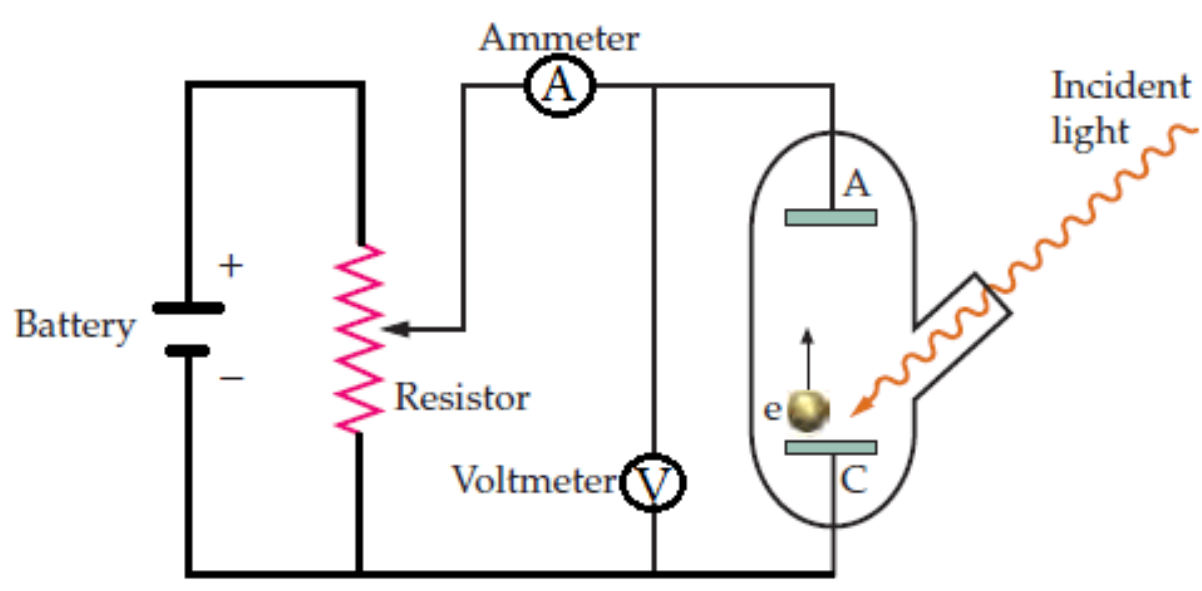

Figure 2.13: Photoelectric effect 
When the light hit the metal electrode (C) situated inside the bulb with frequency $v>f_{0}$ connected to a negative end of the battery with other ends of electrode (A) connected to a positive end of the battery via potentiometer to break the photoelectron. A galvanometer is connected in series to electrode A to measure the photocurrent.

Whereas in solar cell photoelectric works the same way for the generation of the electrons by incident of photons but for solar cell electron do not leave the material surface. In a solar cell these generated electrons were pulled off and fed to an external circuit called load. The photovoltaic effect can be divided into the following three basic processes [39]:

\section{i. Generation of charge carrier due to absorption of photons}

Photon absorption in PV material excites the electrons and they move from initial energy state $\left(E_{\mathrm{i}}\right)$ to higher energy state $\left(E_{h}\right)$ as given in Figure 2.14 and it is illustrated that electron present in the valance band ( $E_{i}$, initial energy state) shifted to conduction band $\left(\mathrm{E}_{\mathrm{h}}\right.$, final energy state) after absorption of photon energy.

absorption

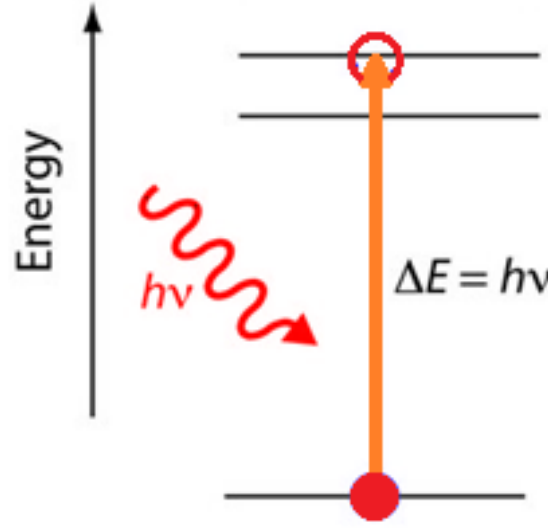

$\mathbf{E}_{\mathbf{h}}$

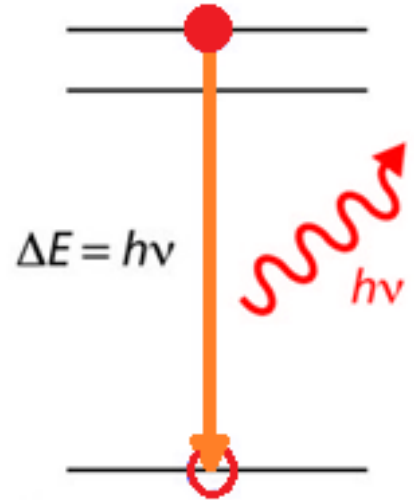

Figure 2.14: Absorption and emission of photon

Photon energy can be absorbed only if $\mathrm{E}_{\mathrm{h}}$ and $\mathrm{E}_{\mathrm{i}}$ electron energy levels are present and are equal to their difference $\left(h v=E_{h}-E_{i}\right)$.

In an ideal case, electron populates below the valance band edge $\left(E_{v}\right)$ and above the edge of the conduction band $\left(E_{c}\right)$ in a semiconductor. There is no other energy level for the population of electron in-between these two states. Hence the energy difference between $E_{c}$ and $E_{v}$ is called the band gap energy $\left(E_{g}\right)$ and is given in equation 2.5.

$$
\mathrm{E}_{\mathrm{g}}=\mathrm{E}_{\mathrm{c}}-\mathrm{E}_{\mathrm{v}}
$$

So, the photon energy smaller than this band gap energy will not be absorbed. And for $E_{p h} \geq E_{g}$ electron will be excited from $E_{i}$ state to $E_{f}$ state creating a void in valance band. This void created by absorption of photon will also be represented by a particle called hole. 
So, absorption of a photon will lead to a generation of electron hole pair as shown in figure 2.15 below and this shows the conversion of radiation energy of sunlight in to chemical energy of electron hole pairs.

\section{ii. Separation of photo-generated charge carrier in a junction}

Recombination takes place in electron-hole pairs and the electron will fall back to its initial energy state $E_{i}$ by releasing absorber energy in the form of radiative recombination (photon emission) or non- radiative recombination (transfer of energy to other electron-holes pairs). So, to utilize the energy absorbed by electron-hole pairs and provide power to external load semipermeable membrane must be present on both sides of the absorber layer that allow the use of energy stored in these electron-hole pairs. Electrons flow out from one membrane whereas holes from other as depicted in Figure 2.15 [40]. From Figure 2.15 it is illustrated that electrons and holes are separated due to semipermeable membranes. These membranes are formed by p-type and n-type materials. The solar cell is designed in such a manner that before recombination of electron-hole pairs they must be reached to the membrane. It means that time required to reach these charge carriers to their respected membrane must be shorter than their lifetime. Because of this reason, optimal thickness of the absorber material was chosen in efficient solar cell design.

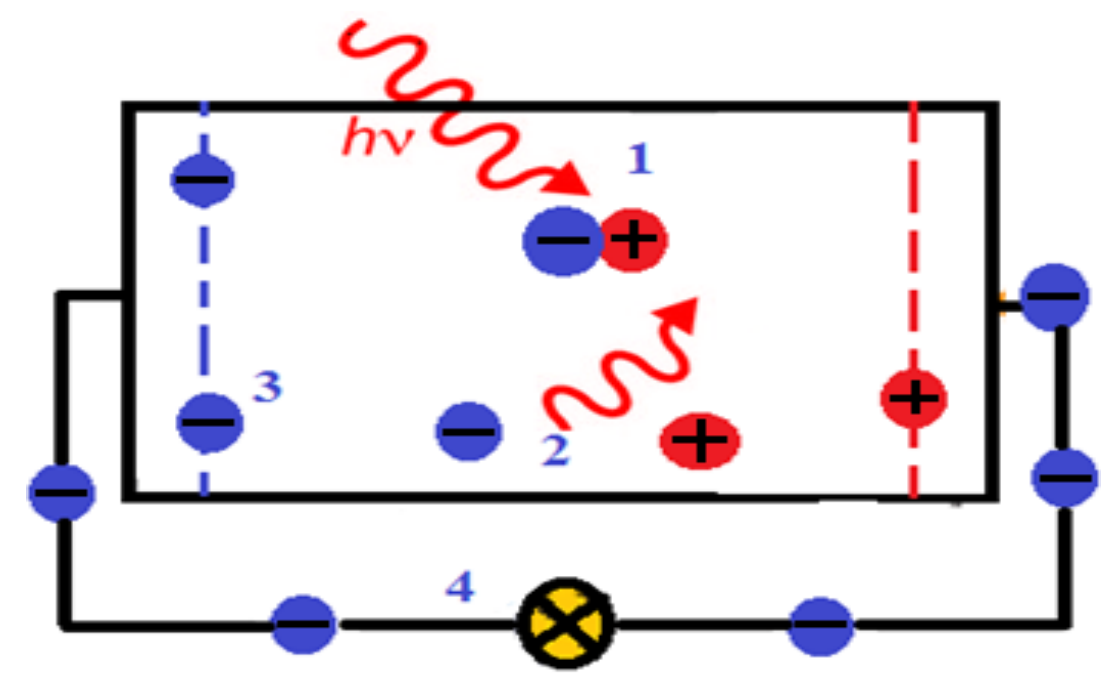

Figure 2.15: Photon generated charge carrier separation

\section{iii. Extraction of photo-generated charge carrier due to absorption of light}

Photogenerated charge carriers are extracted with the help of externally connected electrical contacts or terminals and able to use this energy in an external circuit. This phenomenon is well illustrated in Figure 2.15. Finally, in this stage, light energy is 
converted into electrical energy. After passing from external circuit these electrons are recombined with holes at back contact and at the absorber layer interface.

\subsection{Basic parameters and electrical characterization methods}

\subsubsection{IV characteristic of a PV device}

IV characteristics curve of a photovoltaic device is the graphical representation of the operation of the solar cell. The photovoltaic cell IV characteristics curve is the superposition of the IV curve of the solar cell diode in dark (absence of light) and illuminating (under light) conditions[41]. In dark conditions solar cell has same electrical characteristics as a large diode. When light falls on the solar cell, electrical power can be extracted and IV curve down into the fourth quadrant. Amount of shift is directly proportional to the incident light intensity. Illuminating a cell adds to the normal "dark" currents in the diode so that the diode law becomes as given in equation 2.6.

$$
I=I_{0}\left[\exp \left(\frac{q V}{n k T}\right)-1\right]-I_{L}
$$

where

$\mathrm{I}_{0}=$ diode leakage current in absence of light or dark saturation current

$\mathrm{I}_{\mathrm{L}}=$ light generated current

$\mathrm{q}=$ electronic charge

$\mathrm{V}=$ applied terminal voltage across diode

$\mathrm{n}=$ ideality factor

$\mathrm{k}=$ Boltzmann's constant

$\mathrm{T}=$ temperature

\subsubsection{Short circuit current}

Short circuit current $\left(\mathrm{I}_{\mathrm{sc}}\right)$ is the maximum current flows through the solar cell at zero load condition (i.e. solar cell at short-circuited). At the largest value of $\mathrm{I}_{\mathrm{sc}}$ voltage across the solar cell will be zero. The short-circuit current flows due to generation and collection of light generated carriers. It mainly depends on the number of incident photons as well as its spectrum, optical properties, collection probability and the area of a solar cell. The graphical representation of short circuit current is given in Figure 2.16. 


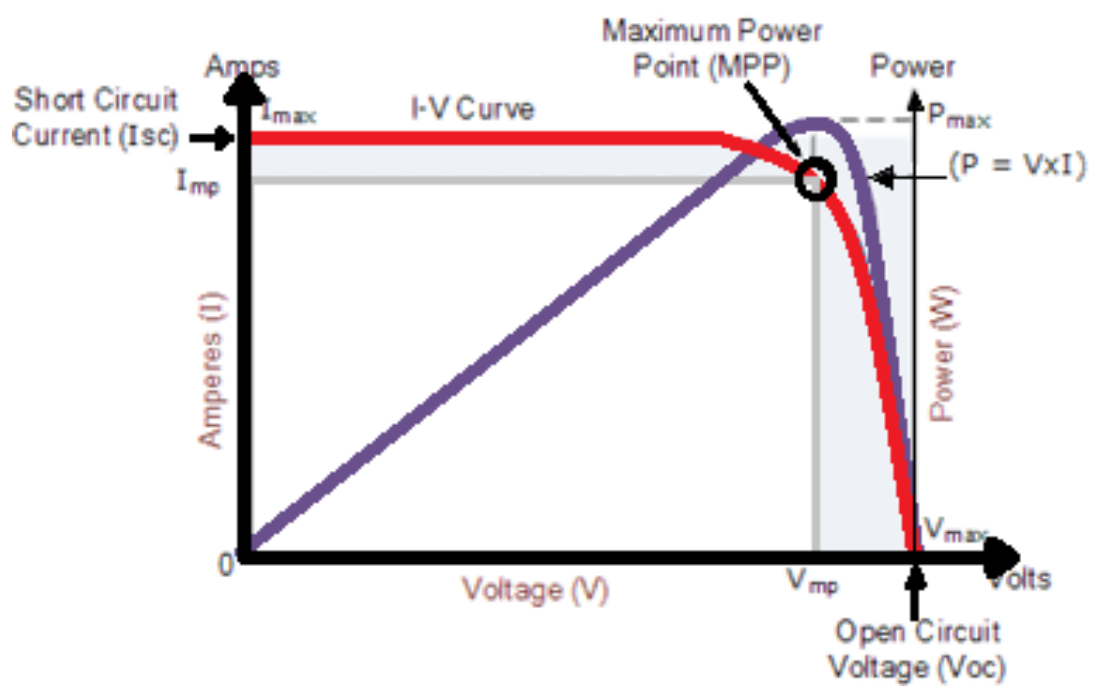

Figure 2.16: Short circuit current and open circuit voltage representation in VI cure

\subsubsection{Open circuit voltage}

The open circuit voltage $\left(\mathrm{V}_{\mathrm{oc}}\right)$ is the maximum voltage taken from a solar cell. When a solar cell is open circuited, there is no connected load across the solar cell then current will be at its minimum (zero) value whereas the voltage will be at maximum value. $V_{\text {oc }}$ can be derived by setting net current to zero in solar cell equation 2.7 .

$$
V_{o c}=\frac{n k T}{q} \ln \left(\frac{I_{L}}{I_{0}}+1\right) a t I=0
$$

From the above equation, open circuit voltage $\left(\mathrm{V}_{\mathrm{oc}}\right)$ depends on the light generated $\left(\mathrm{I}_{\mathrm{L}}\right)$ and saturation current $\left(I_{0}\right)$. $I_{0}$ depends on recombination in the solar cell. so, $V_{\text {oc }}$ is a measure of the amount of recombination in a solar cell. The graphical representation of open circuit voltage is given in Figure 2.17.

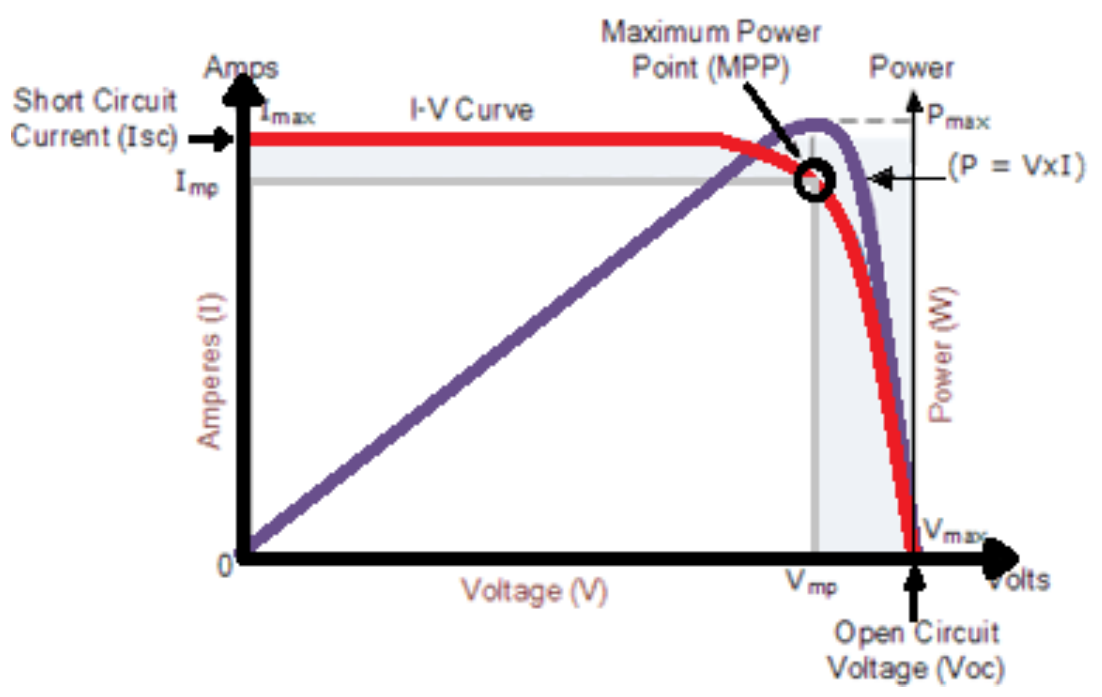

Figure 2.17: Graphical representation of open circuit voltage 


\subsubsection{Efficiency}

Efficiency is the ratio of output power to input power and solar cell efficiency is defined in regime 0 to $\mathrm{V}_{\mathrm{oc}}$ in which solar cell will deliver power. So, the output power density of solar cell is given by equation 2.8 .

$$
P_{\max }=J_{\max } V_{\max }
$$

Power $\left(P_{\max }\right)$ reached to its maximum at cell maximum power point shown in Figure 2.17. So, efficiency of solar cell is defined by equation 2.9 .

$$
\eta=\frac{J_{\max } V_{\max }}{P_{S}}
$$

$P_{S}$ is the incident power of sunlight.

Equation 2.9 can be rearranged in terms of fill factor (FF) and FF is the quality measure for solar cell performance by taking the ratio of maximum power delivered by a solar cell to the theoretical power of a solar cell. FF can also be interpreted as the ratio of rectangular areas depicted in figure 2.17 for maximum power point and (MPP) and theoretical maximum power $\mathrm{P}_{\max }$.

FF is defined in equation 2.10 .

$$
F F=\frac{J_{\max } V_{\max }}{J_{o c} V_{o c}}
$$

So, by rearranging equation 2.10 we will get $\left(U_{\max } V_{\max }=F F \times J_{o c} V_{o c}\right)$ and by replacing the value of $\left(J_{\max } V_{\max }\right)$ in equation 2.9 we will get equation 2.11 as given below.

$$
\eta=\frac{J_{S c} V_{o c} F F}{P_{S}}
$$


This page intentionally left blank 
CHAPTER 3

RECOMBINATION LOSES IN SOLAR CELL IN PRESEPECTIVES OF SCAPS 
This page intentionally left blank 
The core of this study is to provide an overview of how a solar cell performance is affected by recombination loss in perspective of SCAPS-1D for the realization of an experimental solar cell in a simulation environment. A brief overview about semiconductor and the solar cell was covered in chapter 2. Whereas in this section, we will relate basic physical properties of charge transfer of recombination loss in a solar cell.

\subsection{Recombination loss}

Incident photon generates an electron-hole pair in solar cell and these generated electronhole pairs are called carriers. Generated carriers need to separate before they combined again and emit energy. This recombination in a solar cell causes the loss of photon generated carriers which in terms affect the conversion efficiency of solar cell. Recombination in the solar cell occurs at different places as carriers are generated in the different the region of a solar cell. Carriers generated near depletion region are separated by the electric field of depletion region but carries generated at the front, bulk and far end of solar cell has a small probability to get separated. So, carriers generated in these regions will recombine again with the emission of absorbed energy and will not contribute to the photovoltaic process. So, to improve the efficiency of solar cell recombination of those carriers must be governed.

There are three major kinds of recombination losses in a solar cell that affect solar cell performance, and these are listed as.

i. Bulk recombination loss

ii. Interface recombination loss

iii. Recombination at metal semiconductor contacts

\subsubsection{Bulk recombination loss}

If impurities are present in the semiconductor material, then these impurities create energy state which acts as a trap for photon generated carriers. A model for trap assisted bulk recombination loss is given by Shockley-Read hall recombination and this is illustrated with the aid of Figure 3.1 [42].

Figure 3.1 shows the possible ways with which holes and electron may recombine and these processes are denoted by, R1 a possible way with which electron will be capture at energy state $E_{t}, R 2$ emission of electrons from trap state, R3 capture of holes, R4 emission of holes. So, to find out the dependency of these process on trap state we will analyze these four processes individually. For R1 as from diagram, trapping of the electron is depended 
upon the concentration of electrons, defect density of state and probability of the empty state of these traps. Mathematically this is expressed as in equation 3.1.

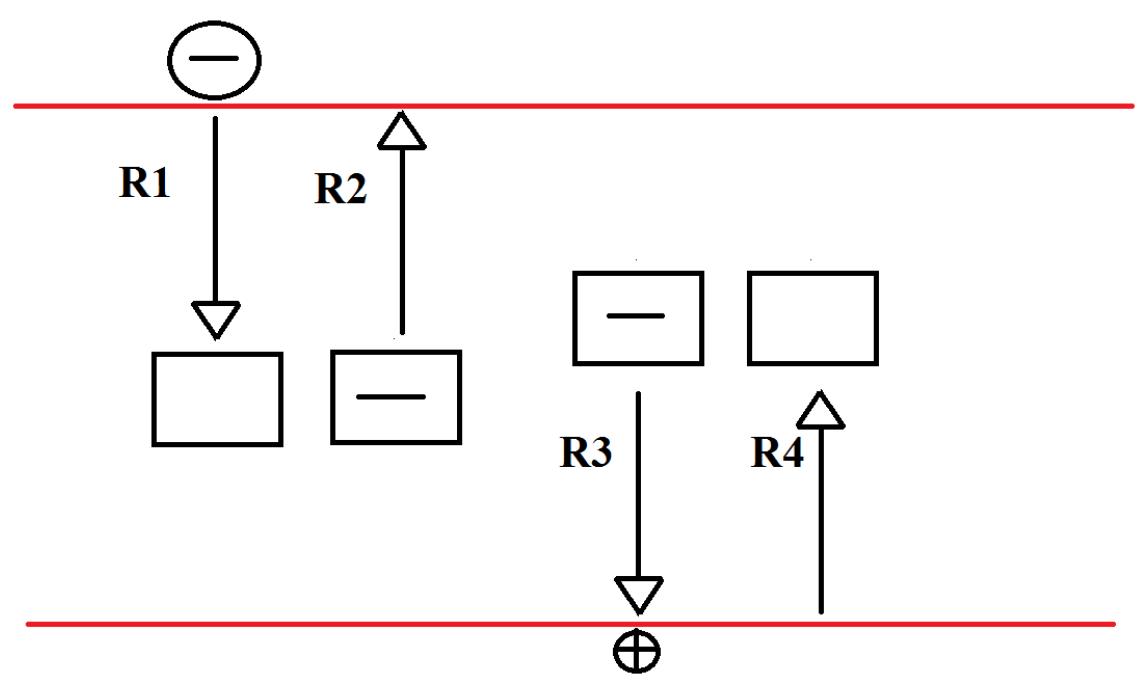

Figure 3.1: Trap assisted recombination

$$
R_{1}=v_{t h} \sigma_{n} n N_{t}\left(1-f_{t}\right)
$$

$v_{t h} \sigma_{n}$ are proportionality constants, $\mathrm{n}$ is concentration of electrons, $N_{t}$ is density in trap states, and $f_{t}$ is the probability of occupation of trap state for electron. And expression for $f_{t}$ is given in equation 3.2 .

$$
f_{t}=\frac{1}{1+\exp ^{\left(\frac{E_{t}-E_{f}}{k T}\right)}}
$$

$E_{t}$ is energy of trap state and $E_{f}$ is fermi energy level.

For process $\mathrm{R} 2$ in which electron is emitted in to conduction band is expressed as emission of electron with probability of occupation of trap state. This relation is given in equation 3.3 .

$$
R_{2}=e_{n} N_{t} f_{t}
$$

$e_{n}$ is emission of electron. For hole capture and hole emission expression is given in equation 3.4 and 3.5 .

$$
\begin{aligned}
& R_{3}=v_{t h} \sigma_{n} p N_{t} f_{t} \\
& R_{4}=e_{p} N_{t}\left(1-f_{t}\right)
\end{aligned}
$$

To find the emission rate for electron we assume that capture of electron and emission of electron from trap state are equal. So related R1 and R2 with each other we can find emission rate for electron.

$$
R_{1}=R_{2}
$$


putting value of R1 and R2 in equation 3.6 it will become as

$$
v_{t h} \sigma_{n} n N_{t}\left(1-f_{t}\right)=e_{n} N_{t} f_{t}
$$

further solving, rearranging for $e_{n}$ and putting value for $f_{t}$ in equation 3.7 it will become as equation 3.8.

$$
\begin{gathered}
v_{t h} \sigma_{n} n\left(1-f_{t}\right)=e_{n} f_{t} \\
e_{n}=\frac{v_{t h} \sigma_{n} n\left(1-f_{t}\right)}{f_{t}} \\
e_{n}=v_{t h} \sigma_{n} n\left(\frac{1}{f_{t}}-1\right) \\
e_{n}=v_{t h} \sigma_{n} n \exp ^{\left(\frac{E^{-} E_{f}}{k T}\right)}
\end{gathered}
$$

where $n=n_{i} \exp ^{\left(\frac{E f-E i}{k T}\right)}$ so replacing $\mathrm{n}$ with the value we will get

$$
e_{n}=v_{t h} \sigma_{n} n_{i} \exp ^{\left(\frac{E_{t}-E_{i}}{k T}\right)}
$$

for $e_{p}$ the expression will be as given in equation 3.9.

$$
e_{p}=v_{t h} \sigma_{n} n_{i} \exp ^{\left(\frac{E_{i}-E_{t}}{k T}\right)}
$$

now to derive Shockley recombination model we know that under equilibrium generation rate is equal to recombination rate.

$$
G=U=R_{1}-R_{2}=R_{3}-R_{4}
$$

so, solving it for equation 3.10 we will get equation 3.11 for total recombination.

$$
U=v_{t h} \sigma_{(n, p)} N_{t} \frac{n p-n_{i}^{2}}{n+p+2 \cosh \left(\frac{E_{t}-E_{i}}{k T}\right)}
$$

from equation 3.11 it is evident that recombination is highly depended upon density of defect states $N_{t}$, capture cross section for (electron, holes) $\sigma_{(n, p)}$ and concentration of (electron, holes).

\subsubsection{Interface recombination loss}

The incomplete bonds at the interface of solar cell work as a trap for photon generated carriers. So, loss due to irregular crystal shape at the interface is called interface recombination loss. defects at the interface arise because of lattice mismatch, different size 
in grain boundaries and injection of impurity during junction formation between absorber buffer interface. These trap state at the interface cause interface recombination and result in loss of open circuit voltage $\left(V_{o c}\right)$ of a solar cell. This is illustrated with the aid of Figure 3.2 and from Figure 3.2, there are two possible interfaces that can be formed between the absorber/buffer interface [43]. With electron affinity of absorber smaller than the buffer, a cliff like an interface will be formed with positive conduction band offset $(+\mathrm{CBO})$ as shown in Figure 3.2(a). And with the electron affinity of absorber larger than the buffer a spike like interface will be formed with a negative conduction band offset (-CBO) as shown in Figure 3.2(b).

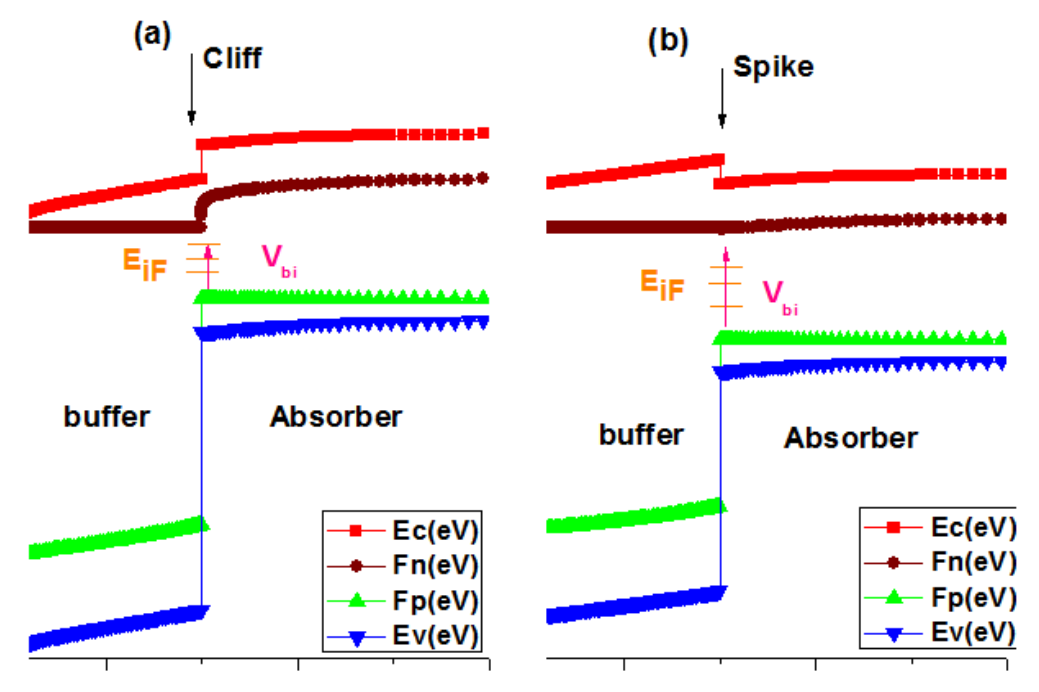

Figure 3.2: Interface between absorber/buffer layer

The difference between these two interfaces is the built-in potential at the junction interface. For cliff like interface the built-in potential is smaller than that of spike interface thus creating a weak charge separation in the depletion layer and leading to high interface recombination.

Interface recombination of a solar cell is depended upon defect density and the relation for interface recombination can be derived from equation 3.10 and solving it for interface recombination. Now putting the value of $R_{1}$ and $R_{2}$ in the equation 3.10 we will get equation 3.12 .

$$
R_{i F}=S_{n} n\left(1-f_{t}\right)-S_{n} f_{t} n_{1}
$$

whereas $f_{t}=\frac{S_{n} n+S_{p} p_{1}}{S_{p}\left(p+p_{1}\right)+S_{n}\left(n+n_{1}\right)}$ that can be found from equation 3.10 by solving it for $f_{t}, S_{p}=v_{t h} \sigma_{p} N_{t}, S_{n}=v_{t h} \sigma_{n} N_{t}$ and $n_{1}=n_{i} \exp \left(\frac{E_{t}-E_{i}}{k T}\right)$. Now putting the value 
of $f_{t}$ in equation 3.12 we will get the result for interface recombination that is expressed in equation 3.13 .

$$
\begin{gathered}
R_{i F}=S_{n}\left(1-\frac{S_{n} n+S_{p} p_{1}}{S_{p}\left(p+p_{1}\right)+S_{n}\left(n+n_{1}\right)}\right)-S_{n} \frac{S_{n} n+S_{p} p_{1}}{S_{p}\left(p+p_{1}\right)+S_{n}\left(n+n_{1}\right)} n_{1} \\
R_{i F}=\frac{S_{n} S_{p}\left(\mathrm{np}-n_{i}^{2}\right)}{S_{n}\left(n+n_{1}\right)+S_{p}\left(\mathrm{p}+p_{1}\right)} \\
R_{i F}=\frac{\mathrm{np}-n_{i}^{2}}{S_{p}^{-1}\left(n+n_{1}\right)+S_{n}^{-1}\left(\mathrm{p}+p_{1}\right)}
\end{gathered}
$$

$p_{i F}$ concentration of hole at interface,,$n_{i F}$ concentration of electron at interface, $(p=$ $\left.N_{v} e^{-\left(E_{i F}-E_{(V, i F)}\right)} k T\right)$ is the emission rate of holes from defect states, $(n=$ $\left.N_{c} e^{-\left(E_{(c, i F)}-E_{i F}\right)} / k T\right)$ emission rate of electrons from defect states, $S_{p}$ is hole interface recombination velocity, $S_{n}$ is electron interface recombination velocity and $R_{i F}$ is total interface recombination. Whereas $\left(S_{p}, S_{n}\right)$ are depended upon defect density at the interface $N_{t(i F)}$, capture cross section area for electron and hole at interface $\left(\partial_{n}, \partial_{p}\right)$ and thermal velocity of carries $v_{t h}$.

From equation 3.13 it is evident that surface/interface recombination loss is depended upon defect density and concentration of charges (electron, holes) at the interface. So, this loss can be reduced by introducing a passivation layer to avoid any lattice mismatch between absorber/buffer interface or by controlling band offset between the absorber/buffer interface.

\subsubsection{Recombination at metal semiconductor contacts}

When a metal brings in contact to a semiconductor a junction is formed between the metal contact and the semiconductor material of a solar cell both at the front and at the back. Back contact contributes more in the recombination process as it has a wider contact area with the semiconductor of solar cell, this is shown in Figure 3.3.

Carriers that are generated and separated by depletion region electric field need to be collected at metal contacts to provide power to load. Because if they get recombine by defects in metal semiconductor contact then this in term affect solar cell efficiency [44]. Passivation of rear contact or creating a strong electric field at rear contact can reduce surface recombination velocity and recombination process. Strong Electric field at rear contact can sweep those generated carriers very quickly. The electric field at the back contact can be created by heavily doping the semiconductor near the contact region. This 
high doping at rear contact will create a back-surface field (BSF) and this field helps in to improve the efficiency of a solar cell $[45,46]$.

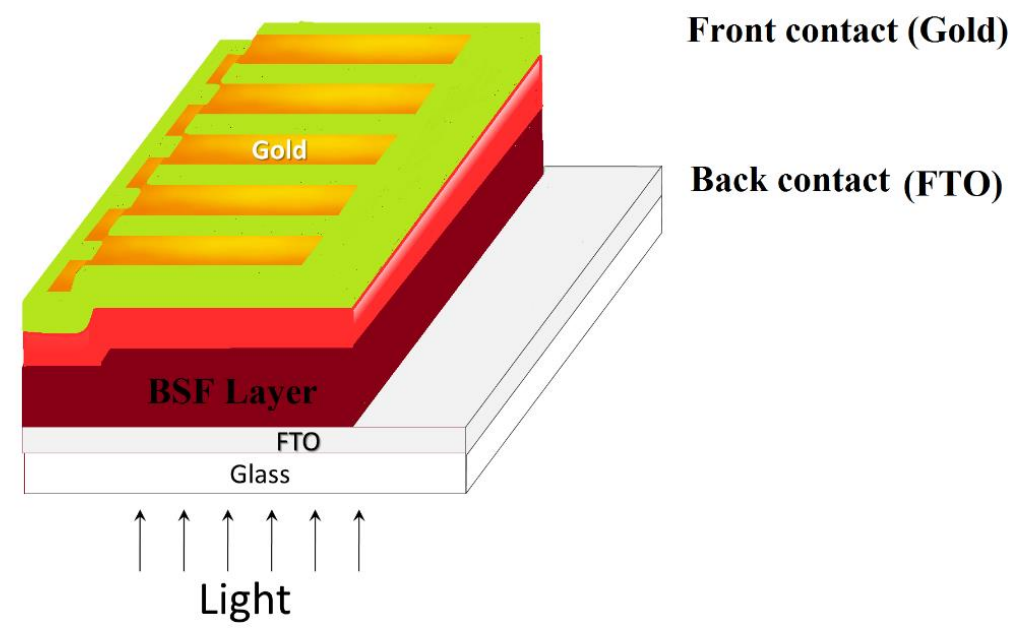

Figure 3.3: BSF layer at back contact

\subsection{Effect of minority charge carrier mobility on recombination}

The mobility of the charge carrier of bulk semiconductor material can greatly affect the performance of solar cell [47]. As it also plays a key role in defining the diffusion length of minority carriers $\left(L_{\text {diff }}\right)$. Diffusion length is average length scale over which it can travel in semiconductor material before recombining. Minority carrier diffusion length is defined in equation 3.14 [48].

$$
L_{\text {diff }}=\sqrt{D \tau}
$$

$D$ is diffusion coefficient and $\tau$ is minority carrier lifetime. $D$ is depended upon elementary charge of carrier $(q)$, environment temperature $(T)$, Boltzmann's constant $k$ and mobility of carrier $\mu$. Relation ship of $D$ is given in equation 3.15 .

$$
D=\mu \frac{k T}{q}
$$

So, putting the value of equation 3.15 in equation 3.14 it will become as given in equation 3.16 .

$$
L_{\text {diff }}=\sqrt{\mu \frac{k T}{q} \tau}
$$

From equation 3.16 , the mobility of minority carriers will greatly affect the diffusion length. With an increase in mobility the probability of collection of photogenerated charge carrier at the terminals will increase and thus contributing in enhanced photocurrent for a solar cell. Whereas a reduction in mobility will cause degradation in solar cell performance. 
CHAPTER 4 NUMERICAL ANALYSIS 
This page intentionally left blank 


\subsection{Introduction}

Performing numerical analysis methods by integrating real-life problem into a virtual machine environment like a computer are considered a high priority job. By the integration of computers in numerical problem solving has led the researcher to find an optimum way of performing complex problem-solving in an efficient way. With the aid of computers, precious time was saved, and it was easy to optimize any real time design problem without physically implementing it in real test environments. Because of this reason computerbased learning is emphasized over worldwide universities. Computer-based learning systems have helped the researchers in the field of semiconductor devices. As today most of the world market is dominated by semiconductor devices like mobile phones, laptops, computers, street lights, and solar panels. In the field of semiconductor devices, the most prominent field is a solar cell. A semiconductor device can be used to convert sunlight into electrical energy and due to excessive demand of electric energy by consumers solar cell is a good alternative to meet user demands [49-52]. But currently, most of the world energy demand is meet by hydel power plants, coal-fired thermal power plants, natural gas-fired thermal power plants, and nuclear power plants [53]. The burning of fossil fuel has a drastic effect on climate change, so extensive research is being done in the field of solar photovoltaics (solar cell) [54-56]. New and improved design for a solar cell is developed at a very rapid pace with efficiency reaching to limit of $22 \%$ [38]. But the cost, availability, and stability of these devices for further commercial development is still an issue [57-59]. So, in dealing with these issues of solar cell numerical analysis of solar cell on a computer can play a vital role. As Computer allows flexibility in the design of realistic problem, experimentation with different hypotheses can easily be performed. And a complete set of device characteristic can often be easily generated by consuming less amount of time and effort than a small set of hand-calculated single point values.

Based on the discussion above it is evident that for rapid improvement in design and efficiency numerical analysis of photovoltaic solar cells is an imperative approach to assess the practicability of the proposed physical structure and its performance. In this chapter effect of physical parameters like the thickness of solar cell layers, doping concentration of layers and temperature on solar cell performance will be explained with the aid essential input parameters for a solar cell. It is very valuable to take a common baseline or starting point for numerical analysis of solar cell [60]. This numerical 
investigation will yield fallouts for, predicting the outcome of changes in material properties and testing the practicability of proposed physical explanation.

\subsection{Basic semiconductor equation}

To analyze solar cell with the aid of numerical analysis software must be capable of solving basic semiconductor equations. These equations play a key role in analyzing solar cell performance and its possible output. Among these equations, the governing equation is Poison equation for electrostatic potential. Equation 4.1 represent Poison's equation for electrostatic potential [61].

$$
\frac{\mathrm{d}^{2} \mathrm{~V}}{\mathrm{dx}^{2}}=\frac{\rho}{\varepsilon}
$$

$\rho$ is density of charge $\left(\mathrm{C} / \mathrm{cm}^{3}\right)$ and $\varepsilon$ is product of semiconductor dielectric constant and permittivity of free space. From charge neutrality equation $\rho$ can be expressed as given in equation 4.2 with assumption that dopant is totally ionized.

$$
\rho=q\left(p-n+N_{D}^{+}+N_{A}^{-}\right)
$$

where $q$ is electronic charge, $p$ is concentration of holes, $n$ concentration of electrons, $N_{A}^{-}$ ionized acceptor dopant carrier concentration and $N_{D}^{-}$is ionized donor dopant carrier concentration. by putting the value of equation 4.2 in equation 4.11 it will become as equation 4.3.

$$
\frac{\mathrm{d}^{2} \mathrm{~V}}{\mathrm{dx}^{2}}=\frac{q\left(p-n+N_{D}^{+}+N_{A}^{-}\right)}{\varepsilon}
$$

And to solve equation 4.3 for $\mathrm{V}$ as a function position value of $\mathrm{x}$ one must have to rearrange the expression for concentration of carriers $(p, n)$.

Second equation called continuity equation, the reason that continuity equation is called governing equation is because drift, diffusion, generation and recombination are analyzed simultaneously. equation 4.4 and equation 4.5 represent continuity equation for concentration change in electron and hole.

$$
\begin{aligned}
& \frac{\partial n}{\partial t}=\frac{1}{q} \frac{\partial J_{n}}{\partial x}+\left(G_{n}-R_{n}\right) \\
& \frac{\partial p}{\partial t}=\frac{1}{q} \frac{\partial J_{p}}{\partial x}+\left(G_{p}-R_{p}\right)
\end{aligned}
$$

The output from equation 4.1,4.4 and 4.5 have non-linear dependencies on charge carrier concentration $(p, n)$. So, these equations will be solved with numerical techniques with standard approaches like discretization of equation, discretization of device and set of boundary conditions. To measure current characteristics of solar cell simulator must be 
able to solve drift-diffusion equation for current in solar cell. The equation for driftdiffusion of charge carriers is given in equation 4.6 and equation 4.7 [62].

$$
\begin{aligned}
& J_{n}=q \mu_{n} n \epsilon+q D_{n} \partial n \\
& J_{p}=q \mu_{p} p \epsilon-q D_{p} \partial p
\end{aligned}
$$

$\left(J_{n}, J_{p}\right)$ are the current density for electron and holes, $\left(\mu_{n}, \mu_{p}\right)$ mobility of carriers, $\left(D_{n}, D_{p}\right)$ diffusion coefficient of electron and holes and from Einstein relationship diffusion coefficient is depended upon mobility of carrier with product of carrier lifetime. Relation of $D_{n}$ with mobility of carrier is given in equation 4.8 .

$$
D_{(n, p)}=\mu_{(n, p)} \frac{k T}{q}
$$

other quantities need to solve to find the solution for equation 4.3, 4.4 and 4.5 are generation and recombination $(G, R)$ and this can also be expressed as net recombination in device (U). That is represented in equation 4.9 for $n$-type semiconductor.

$$
U=\frac{p-p_{0}}{\tau_{p}}
$$

There are different commercially available software and educational software for numerical analysis of solar cell that solves these basic semiconductor equations. The list of software that are available free for an educational purpose is listed below.

i. SCAPS-1D (Solar cell capacitance simulator)

ii. AMPS-1D (Analysis of Microelectronics and Photonics Structures)

iii. AFORS-HET (Automat FOR Simulation of Heterostructures)

iv. PC1D

v. ASA (Amorphous Semiconductor Analysis)

Among these different software's listed above we use SCAPS-1D for our work and the reason for selection of SCAPS is because extensive literature is available for SCAPS and its possible applications for the analysis of a solar cell.

\subsection{SCAPS-1D}

SCAPS-1D (Solar Cell Capacitance Simulator) is a one-dimensional solar cell simulation program developed at the Department of Electronics and Information Systems (ELIS) of the University of Gent, Belgium. Several researchers have contributed to its development: Alex Niemegeers, Marc Burgelman, Koen Decock, Stefaan Degrave, Johan Verschraegen. 
SCAPS program was originally developed for $\mathrm{CuInSe} 2$ and the CdTe family. Recent developments make the program now also applicable to crystalline solar cells (Si and GaAs family) and amorphous cells (a-Si).

The most recent version, SCAPS 3.7, April 2012, includes:

i. Seven semiconductor layers.

ii. All physical parameters required for solar cell / semiconductor can be modeled in SCAPS. $\left(E_{g}, \chi, \varepsilon, N_{C}, N_{V}, v_{t h n}, v_{t h p}, \mu_{n}, \mu_{p}, N_{A}, N_{D}\right.$, (defects) $\left.N_{t}\right)$.

iii. Recombination profiles in solar cell. (SRH, Auger).

iv. Defects density in bulk of semiconductor and at interface.

v. Defects with charge type. (Neutral, Single (donor, acceptor), double (donor, acceptor), defined by a user).

vi. Defect with different energy distribution: uniform distribution, single level distribution, Gaussian distribution, and band tails.

vii. Work function of working electrodes/contacts for a solar cell with an optical filter.

viii. Illumination of a working structure with different spectra available in the literature (AM0, AM1.5D, AM1.5G, monochromatic, white).

ix. Illuminate device from either side. (Front contact, back contact with cutoff filters).

x. Calculate: (Energy band diagram, I - V curve, $\mathrm{C}-\mathrm{V}$ curve, quantum efficiency, recombination profile with temperature).

xi. Run simulation under batch setting with controlled iteration.

xii. Simulation can be run by writing scripts for SCAPS.

xiii. A user can save its personalized setting for startup of SCAPS.

xiv. Friendly user interface.

xv. A built-in curve fitting facility.

\subsubsection{SCAPS-ID front end interface}

Figure 4.1 shows the front-end interface of SCAPS-1D software. it majorly consists of 4 panels and the overview of these panels is listed below.

i. Problem definition panel is used to define a solar cell structure that we want to define in SCAPS software, analyze simulated output, save data of simulated output and clear simulated history from SCAPS. To define a solar cell structure, we need to click on a set problem button. 
ii. Action panel is for reading scale setting and this panel consists of $\mathrm{I}-\mathrm{V}$ characteristics scale calibration and setting, $\mathrm{C}-\mathrm{V}$ capacitance voltage setting, $\mathrm{C}-$ F capacitance frequency setting and QE quantum efficiency setting.

iii. Illumination panel is for spectrum setting and direction from where solar cell structure will be illuminated

iv. Working point is for a setting of operating temperature

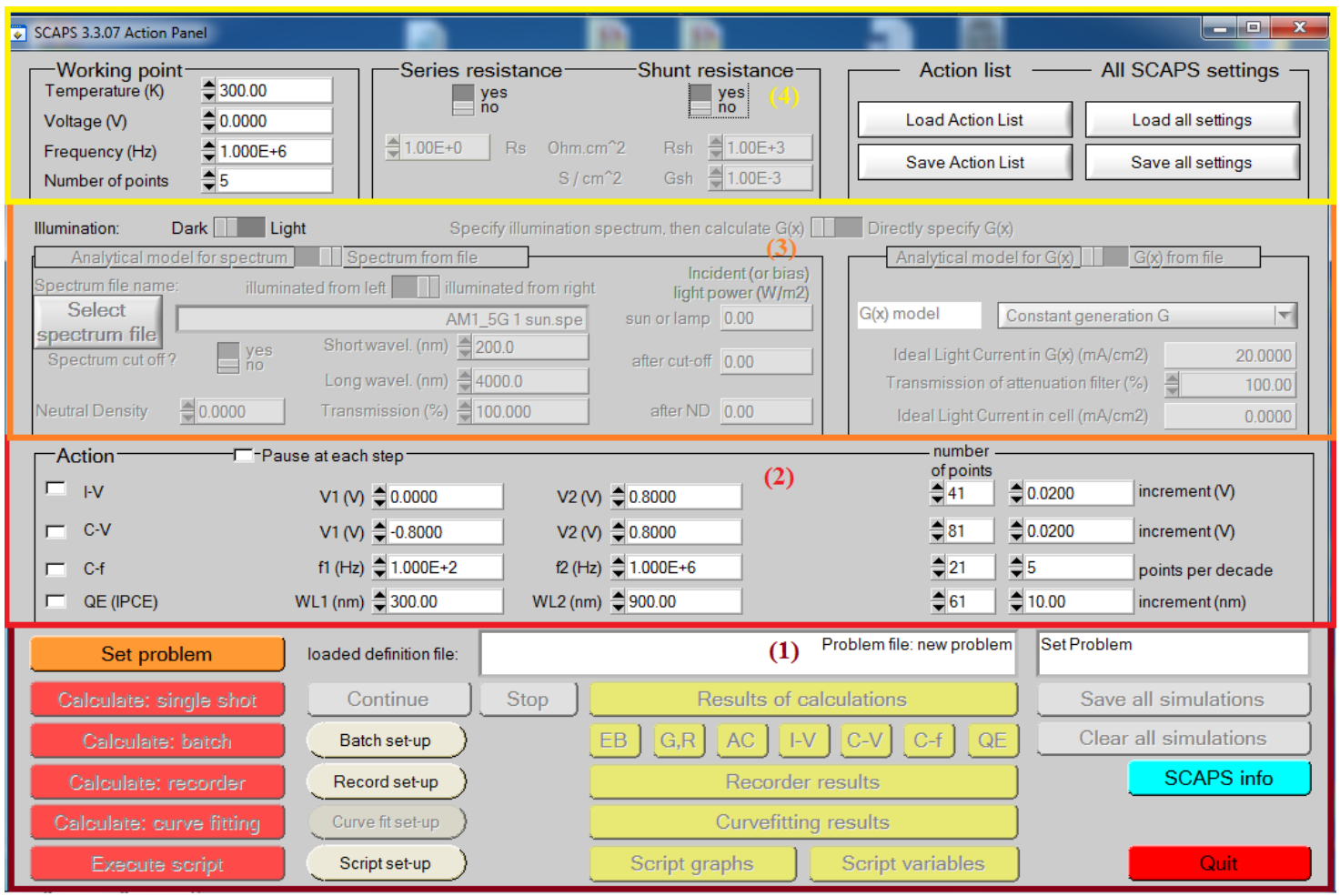

Figure 4.1: SCAPS front end interface

\subsubsection{SCAPS-ID problem setting}

To set or define a problem in SCAPS we click on "Set problem" button and after clicking on set problem button another interface will open. This interface is called "Solar cell definition panel" and in this panel, we define the structure of our solar cell. This panel plays a key role in defining solar cell because structure definition and visualization is shown in this panel. To explain this panel, it is divided into three categories as shown in Figure 4.2.

Explanation of these categories is listed below.

i. Consists of 5 buttons and the function of these buttons is to load a structure file from SCAPS structure definition library or to save already modeled structure in SCAPS definition library. After loading the file or creating the new structure we click "OK" to return to the main front-end interface for further analysis. 
ii. This consists of front and back contact and layers that we are going to define for our solar cell structure. From Figure 4.2, it is visible that SCAPS can only support 7 layers structure for numerical analysis of solar cell.

iii. This section is for visualization of defined solar cell structure with illumination from the front or back contact. In this section there are some buttons which are used to define illumination from front or back contact, applied potential and current reference.

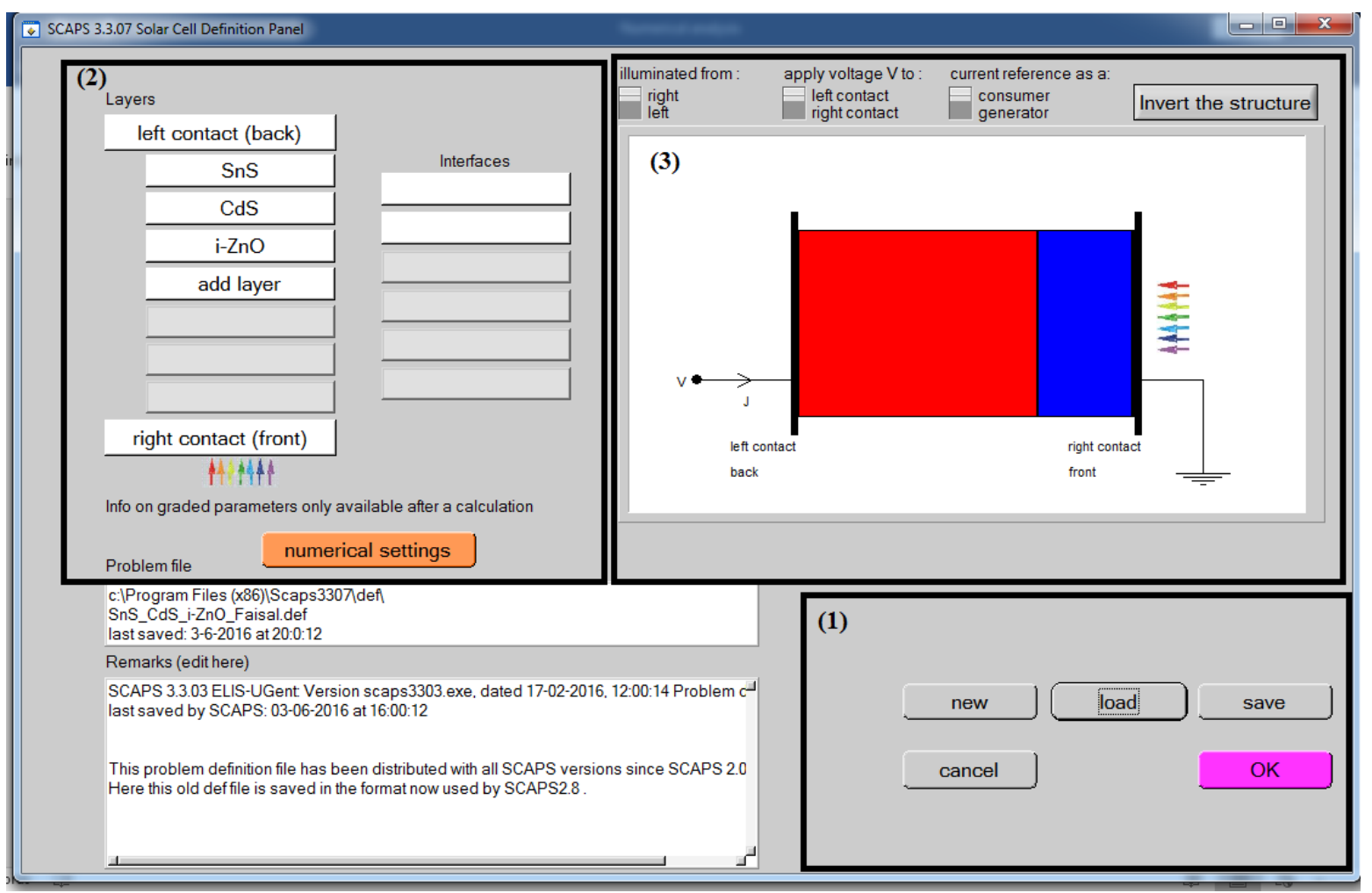

Figure 4.2: SCAPS solar cell definition panel

\subsubsection{Adding layers to structure}

To define layers in SCAPS for construction of solar cell structure we click on add layer as shown in Figure 4.2 section 2. So, by clicking on add layer another panel will open, and this is called "Layer properties panel". In this panel, we will set the basic physical parameters for our layer and this shown in Figure 4.3.

After setting the problem in SCAPS environment next step was to perform numerical analysis for defined structure and to analyze the effect of different physical parameters on solar cell performance like the thickness of absorber layer, buffer layer, doping concentration of absorber layer, a buffer layer, and operating temperature. 


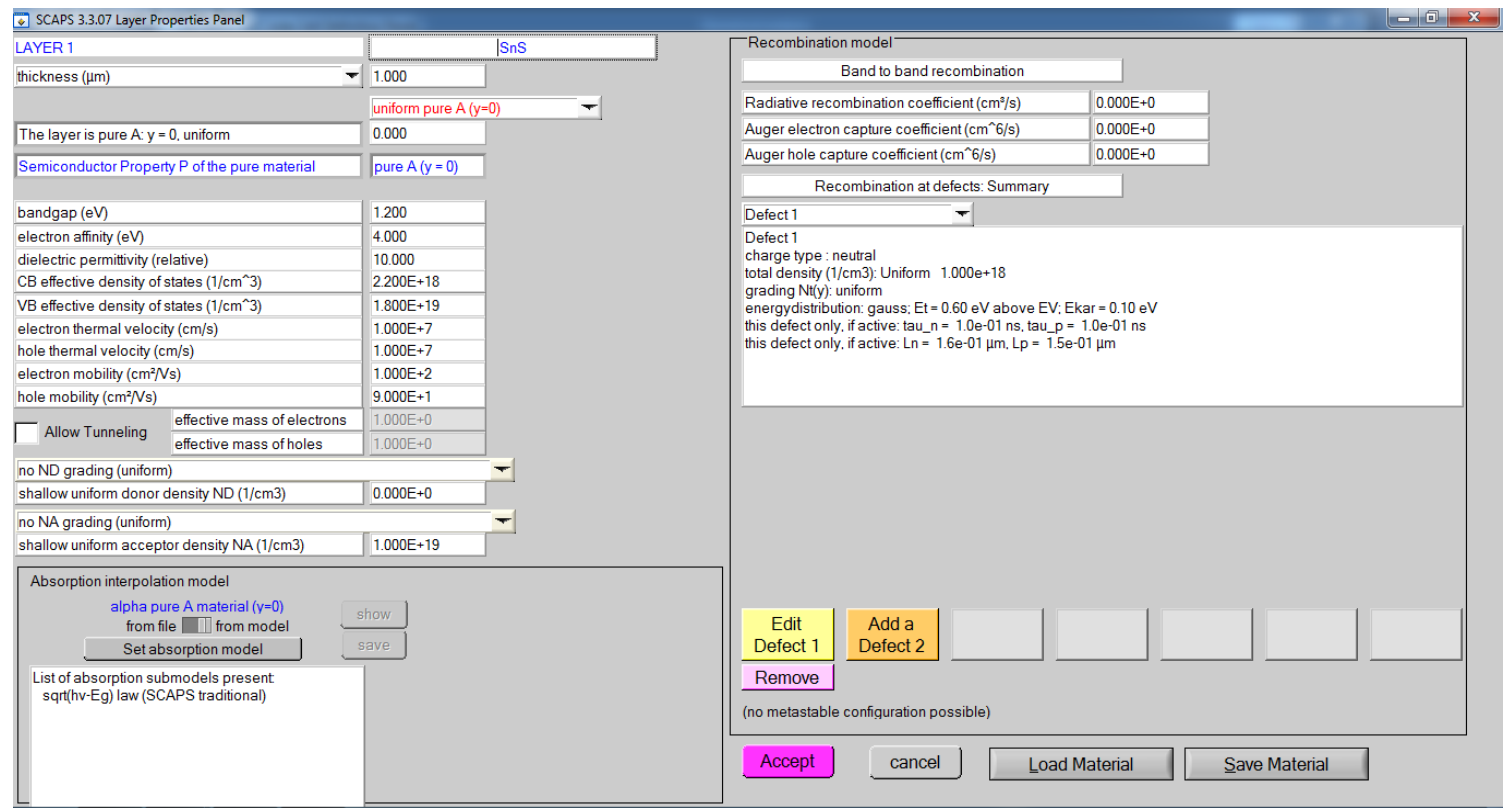

Figure 4.3: Layer properties panel

\subsection{Baseline simulation for numerical analysis of SnS solar cell [63]}

The simulation model that was set up in SCAPS software used to found out the electrical characteristics (AC and DC) of heterojunction solar cell. In this environment, the solution which was generated for the case of our simulation has the result of dark and illumination current along with some other characteristics. Based on Poison equation, electron, and hole current equation SCAPS had the distinction to appropriately evaluate the steady-state band diagram, recombination profile; transport carrier in 1D. Model proposed in this section consists of three layers and these were $\mathrm{ZnO} / \mathrm{n}-\mathrm{CdS} / \mathrm{p}-\mathrm{SnS}$. The output of a photovoltaic device is highly depended on the parameters such as the concentration of charge carriers, temperature thickness of photovoltaic cell also optical and electrical properties. The necessary parameters in the SCAPS-1D simulation environment for PV device including SnS absorbers are presented in Table 4.1.

Table 4.1: Parameters for simulation [9-10]

\begin{tabular}{lccc}
\hline \multicolumn{1}{c}{ Parameters } & ZnO & n-CdS & SnS \\
\hline Thickness, $\mathrm{W}(\mu \mathrm{m})$ & $0.01-0.1$ & $0.01-0.5$ & $0.1-4$ \\
Bandgap, $\mathrm{Eg}(\mathrm{eV})$ & 3.35 & 2.42 & $1.2-1.4$ \\
Electron affinity, $\chi(\mathrm{eV})$ & 4.5 & 4.4 & $4-4.2$ \\
Dielectric permittivity, $\varepsilon / \varepsilon_{0}$ & 9 & 10 & 13 \\
Conduction band Density of states, $\mathrm{NC}\left(\mathrm{cm}^{-3}\right)$ & $2.2 \times 10^{18}$ & $2.2 \times 10^{18}$ & $1.18 \times 10^{18}$ \\
Valance band Density of states, $\mathrm{NV}\left(\mathrm{cm}^{-3}\right)$ & $1.8 \times 10^{19}$ & $1.7 \times 10^{19}$ & $4.76 \times 10^{18}$ \\
Electron mobility, $\mu_{\mathrm{e}}\left(\mathrm{cm}^{2} / \mathrm{Vs}\right)$ & 100 & 340 & 15 \\
Hole mobility, $\mu_{\mathrm{p}}\left(\mathrm{cm}^{2} / \mathrm{Vs}\right)$ & 25 & 50 & 100 \\
concentration of Electron and hole, $\mathrm{n}, \mathrm{p}\left(\mathrm{cm}^{-3}\right)$ & $10^{18}$ & $1 \times 10^{17}$ & $1 \times 10^{15}$ \\
\hline
\end{tabular}




\subsubsection{Results and discussion}

In this section, we will analyze the energy band diagram and the effect of various physical parameters on solar cell performance like the thickness of each layer (absorber, buffer) and operating temperature. The purpose of this work was to get an idea that how these parameters affects solar cell performance.

\section{i. Energy band diagram}

$\mathrm{p}-\mathrm{SnS} / \mathrm{n}-\mathrm{CdS} / \mathrm{ZnO}$ photovoltaic cell Energy band diagram is given in Figure 4.4 with illumination in a biased condition. This was obtained for analysis from the output of SCAPS. The band diagram helps in explaining the property of a photovoltaic cell and it is visible that $\mathrm{SnS}$ has a band gap in the range of $1.2 \mathrm{eV}$ to $1.4 \mathrm{eV}$. For incident light photons the value that is best for most of light to be absorbed for effective conversion efficiency is equal to or greater than maximum value of $1.2 \mathrm{eV}$.

\section{ii. Current density and voltage characteristics of $\boldsymbol{S n S}$ based photovoltaic device}

In this step, we tested photovoltaic cell characteristics under dark and illuminated conditions. The working of a photovoltaic cell is to alter light energy into electrical energy. To analyze a diode, and to find out diode operating characteristics dark current analysis was needed. A photovoltaic cell is a big flat diode in the dark. Figure 4.5 shows the $\mathrm{J}-\mathrm{V}$ curve of SnS/CdS/ZnO photovoltaic cell. Photovoltaic cell gives an extreme minimum value of current due to its minority carriers in dark. Under illumination, the photovoltaic process starts because of incident photons, and these photons will generate charge carriers which are produced after exposing the solar cell to sunlight condition of 1 Sun (Air Mass $1.5)$.

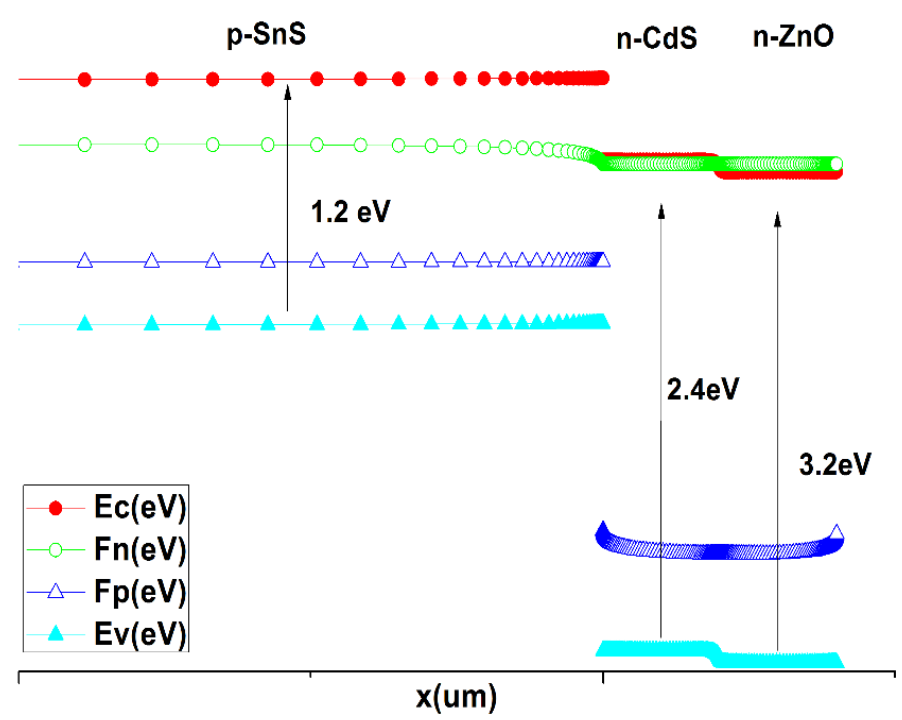

Figure 4.4: Energy band diagram 


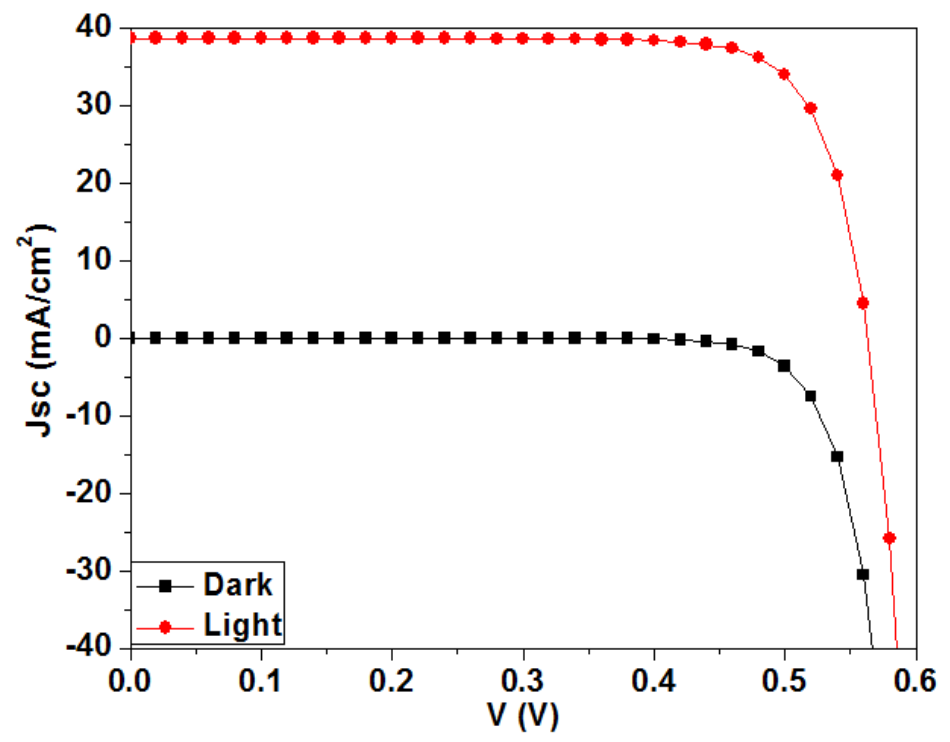

Figure 4.5: Dark and illuminated curve of photovoltaic cell

\section{iii. Effect of $\boldsymbol{C d S}$ layer on photovoltaic cell performance}

In this stage, the outcome of thickness of CdS layer was analyzed by varying the thickness and keeping another layer thickness constant. Layer thickness was varied from $0.1 \mu \mathrm{m}$ to $0.5 \mu \mathrm{m}$. Figure 4.6 shows the effect of main photovoltaic cell parameters by varying thickness of the CdS buffer layer. From figure 4.6 CdS layer thickness has no effect on photovoltaic cell performance, so this result was comprehended that change in thickness of CdS layer has no effect on solar cell performance.

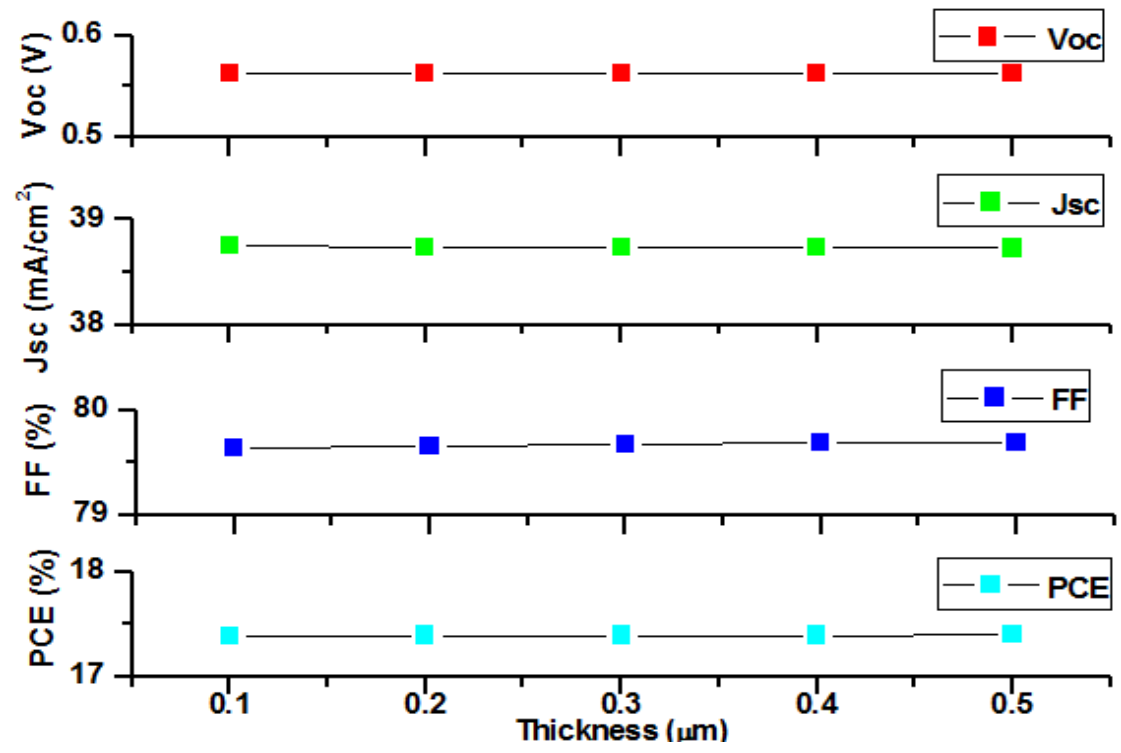

Figure 4.6: CdSlLayer thickness

\section{iv. Optimization of absorber layer thickness}

In this step, absorber layer thickness was varied from $1 \mu \mathrm{m}$ to $3 \mu \mathrm{m}$ to find out the optimum point for maximum conversion efficiency of SnS based photovoltaic cell. The outcome of 
the main factors of a soalr cell as a function of a thickness of the absorber layer for $\mathrm{SnS}$ is shown in Figure 4.7. It was observed that by increasing the thickness of $\mathrm{SnS}$ absorber layer the efficiency of light conversion for a solar cell was improved, but with a much slower rate reaching $3 \mu \mathrm{m}$. Optimal thickness for absorber layer was $3 \mu \mathrm{m}$, as shown in the spectral representation.

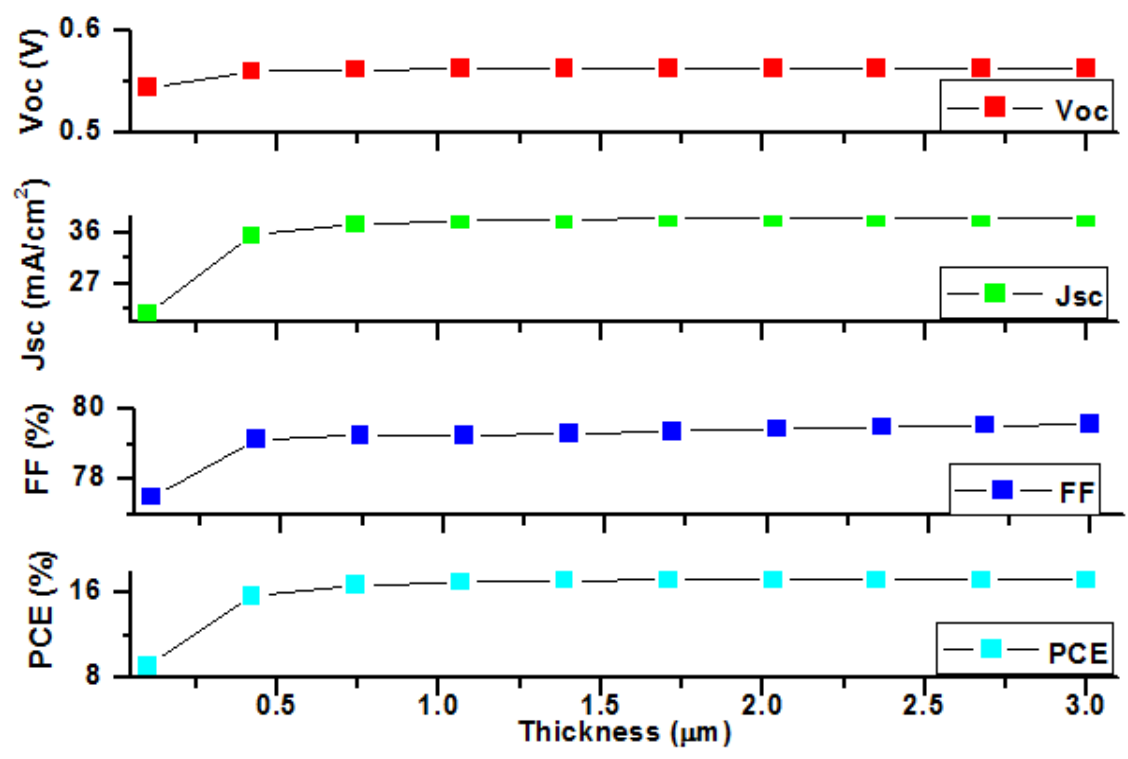

Figure 4.7: Absorber layer thickness

\section{v. Effect of temperature on the performance of photovoltaic cell}

From diode characteristic equation it is evident that environmental temperature has a key part in evaluating the performance of a solar cell. The solar cell performance was affected by varying temperature. To carry out simulation the temperature was varied from $260 \mathrm{~K}$ to $400 \mathrm{~K}$. Figure 4.8 shows the effect of temperature on photovoltaic cell performance.
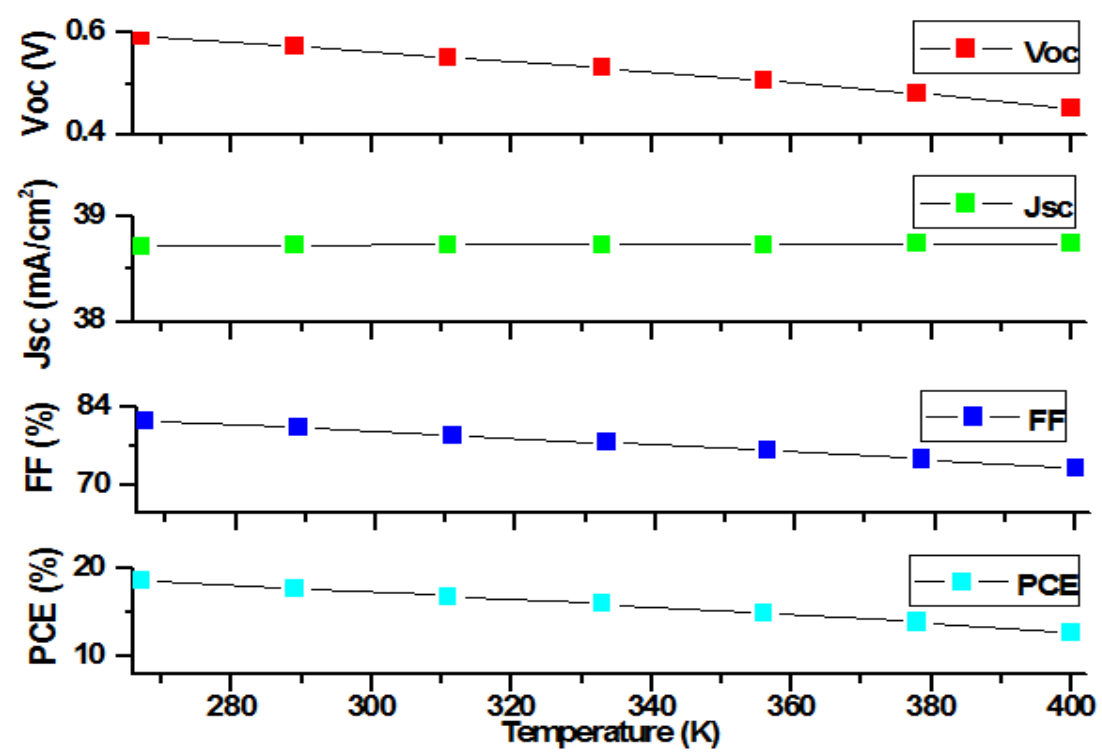

Figure 4.8: Effect of Temperature 
At room temperature photovoltaic cell operates at its near maximum. But with a slight change in temperature, there is a drastic change in photovoltaic cell parameters. As temperature directly affect the mobility electron hole-pair, carrier concentration and band gap of material.

\subsubsection{Conclusion}

The numerical model of a solar cell helps a researcher to get the inside details of a solar cell. This works reports the outcome for changing the thickness of absorber layer, temperature, and doping concentration of acceptor on the performance of SnS based thin film soalr cell. The dark characteristic of solar cell is just like a normal Schottky diode but in illumination, the current density increased up to $38.52 \mathrm{~mA} / \mathrm{cm}^{2}$. The thickness of the absorber layer also affects the current density, efficiency, fill factor and open circuit voltage. The optimum value of absorber thickness was chosen to be $3 \mu \mathrm{m}$. Temperature also influences photovoltaic cell performance; the optimal temperature which was used for numerical analysis is $300 \mathrm{~K}$. Overall efficiency decreased with increase in temperature.

\subsection{Adding back surface field layer to $\mathrm{ZnO} / \mathrm{n}-\mathrm{CdS} / \mathrm{p}-\mathrm{SnS}$ structure [63]}

The model that is proposed in section consists of four layers and these are $\mathrm{ZnO} / \mathrm{n}-$ $\mathrm{CdS} / \mathrm{p}-\mathrm{SnS} / \mathrm{p}+-\mathrm{SnS}$ layer. The output of a photovoltaic device is highly depended on the parameters such as a concentration of charge carriers, temperature, and thickness of solar cell also optical and electrical properties. $\mathrm{ZnO}$ used as an optical window and $\mathrm{CdS}$ as a buffer layer for better charge transportation to contact, both materials properties were available in the literature. The required parameters for SCAPS simulations in PV devices involving SnS absorbers are displayed in Table 4.2.

Table 4.2: Parameters for simulation

\begin{tabular}{lcccc}
\hline \multicolumn{1}{c}{ Parameters } & ZnO & n - CdS & SnS & $\mathbf{p}^{+}-\mathbf{S n S}$ \\
\hline Thickness, W $(\mu \mathrm{m})$ & $0.01-0.1$ & $0.01-0.5$ & $0.1-4$ & $0.1-1$ \\
Bandgap, $\mathrm{Eg}(\mathrm{eV})$ & 3.35 & 2.42 & $1.2-1.4$ & $1.2-1.4$ \\
Electron affinity, $\chi(\mathrm{eV})$ & 4.5 & 4.4 & $4-4.2$ & $4-4.2$ \\
Dielectric permittivity, $\varepsilon / \varepsilon 0$ & 9 & 10 & 13 & 13 \\
Conduction band Density of states, $\left(\mathbf{c m}^{\mathbf{3}}\right)$ & $2.2 \times 10^{18}$ & $2.2 \times 10^{18}$ & $2.2 \times 10^{18}$ & $2.2 \times 10^{18}$ \\
Valance band Density of states, $\left(\mathbf{c m}^{3}\right)$ & $1.8 \times 10^{19}$ & $1.8 \times 10^{19}$ & $4.76 \times 10^{18}$ & $4.76 \times 10^{18}$ \\
Electron mobility, $\mu \mathrm{e}\left(\mathbf{c m}^{2} / \mathrm{Vs}\right)$ & 100 & 340 & 15 & 15 \\
Hole mobility, $\mu \mathrm{p}\left(\mathbf{c m}^{2} / \mathrm{Vs}\right)$ & 25 & 50 & 100 & 100 \\
concentration of Electron and hole, $\left(\mathbf{c m}^{3}\right)$ & $10^{18}$ & $10^{17}$ & $10^{15}$ & $10^{17}$ \\
\hline
\end{tabular}




\subsubsection{Results and discussion}

The simulation was done to achieve the optimal performance of SnS based solar cell. This was done by analyzing the energy band diagram then then effect of SnS layer thickness on the performance of solar cell to choose the optimal thickness of the layer.

\section{i. Cell structure and band diagram}

$\mathrm{p}+-\mathrm{SnS} / \mathrm{p}-\mathrm{SnS} / \mathrm{n}-\mathrm{CdS} / \mathrm{ZnO}$ solar cell energy band diagram is given in Figure 4.9.

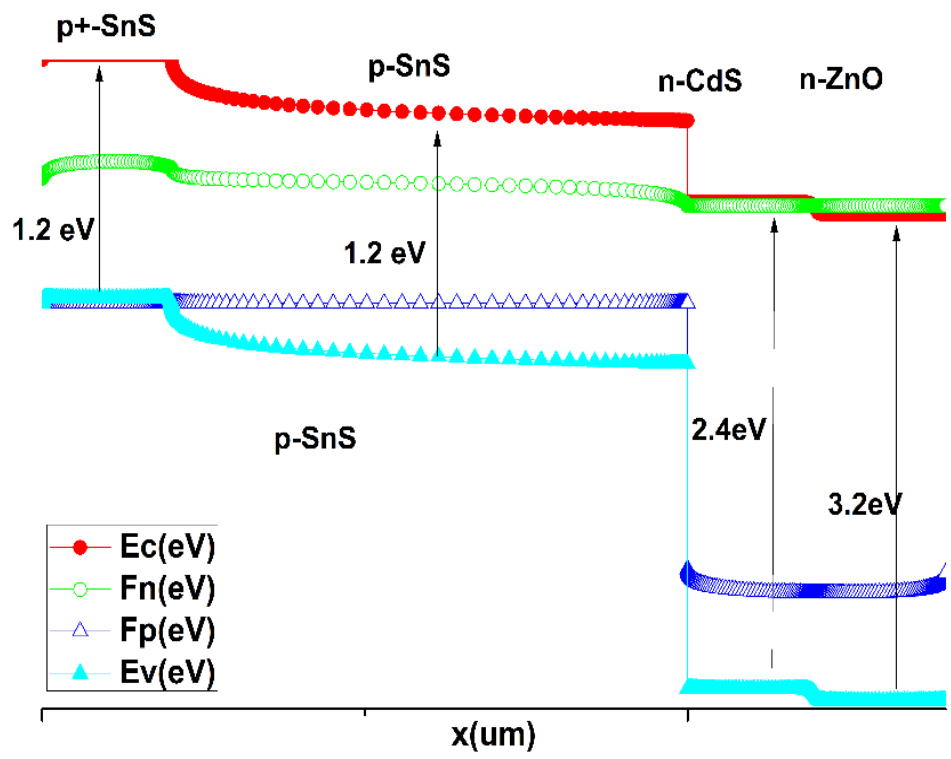

Figure 4.9: Cell structure and energy band diagram of proposed solar cell

The band diagram helps in explaining the property of a solar cell and from the band diagram it is visible the hole can easily be extracted from $\mathrm{p}-\mathrm{SnS}$ layer due to its valance band offset (VBO) with layer $\mathrm{p}^{+}-\mathrm{SnS}$, whereas electron moving to the back contact will be stopped by the $\mathrm{p}^{+}-\mathrm{SnS}$ due to conduction band offset (CBO). Similarly, the hole entering at the CdS layer will be stopped by VBO between $\mathrm{p}-\mathrm{SnS} / \mathrm{CdS}$ layer and this will help in improving the efficiency of SnS based solar cell.

\section{ii. $\quad J-V$ dark and light characteristics of solar cell}

In this step, solar cell characteristics were tested under dark and illuminated conditions. To analyze a diode, the dark current analysis is necessary to find out diode operating characteristics. The current and voltage $(J-V)$ curve of a solar cell with structure $\mathrm{p}^{+}-$ $\mathrm{SnS} / \mathrm{p}-\mathrm{SnS} / \mathrm{n}-\mathrm{CdS} / \mathrm{ZnO}$ is shown in Figure 4.10. In dark solar cell gives an extreme minimum value of current that is due to the thermal activation of minority carriers. The PV process starts due to incident photons by illuminating the solar cell by 1 Sun (Air Mass 1.5) and these photons will generate charge carriers. 


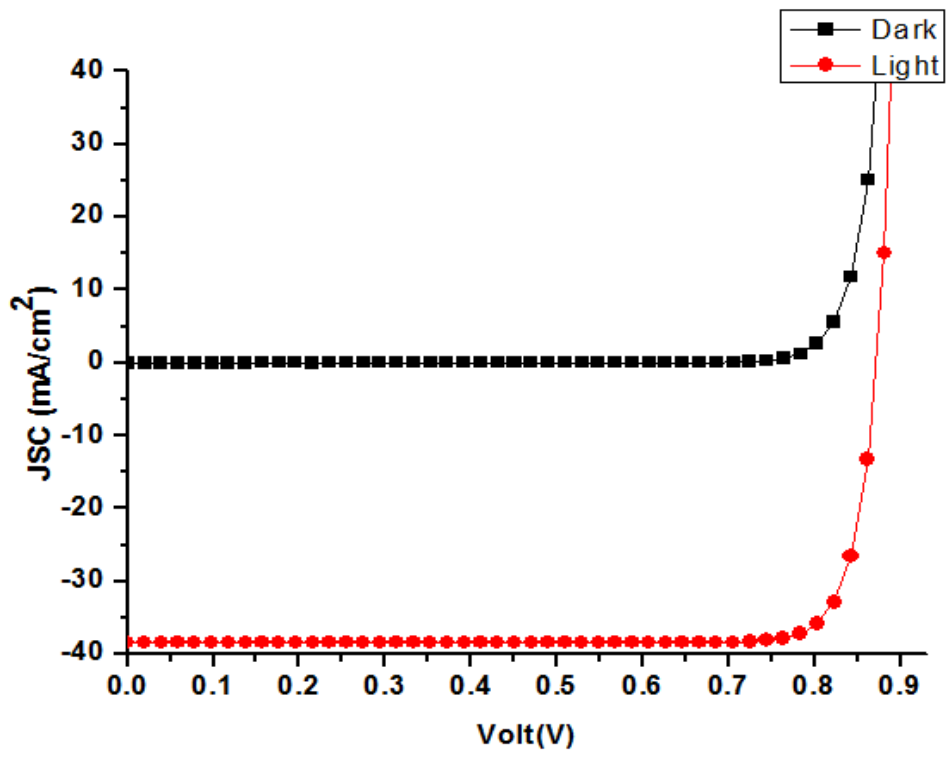

Figure 4.10: Dark and Illuminated J - V Curve of solar cell

\section{iii. Effect of $C d S$ layer on solar cell performance}

In this step, effect of CdS layer thickness was analyzed by varying its thickness and keeping another layer's thickness constant. The thickness of the CdS layer is varied from 0.1 um to 1 um. Figure 4.11 shows the effect of main solar cell parameters by varying thickness of the CdS buffer layer. From Figure 4.11 variation in CdS thickness has a negligible effect on solar cell performance. So, with increasing CdS thickness $V_{o c}$, eta and $J_{S C}$ changes but with a minor variation due to which $\mathrm{FF}$ almost remains constant. In this step, we have chosen thickness of $0.3 \mu \mathrm{m}$ for CdS layer.

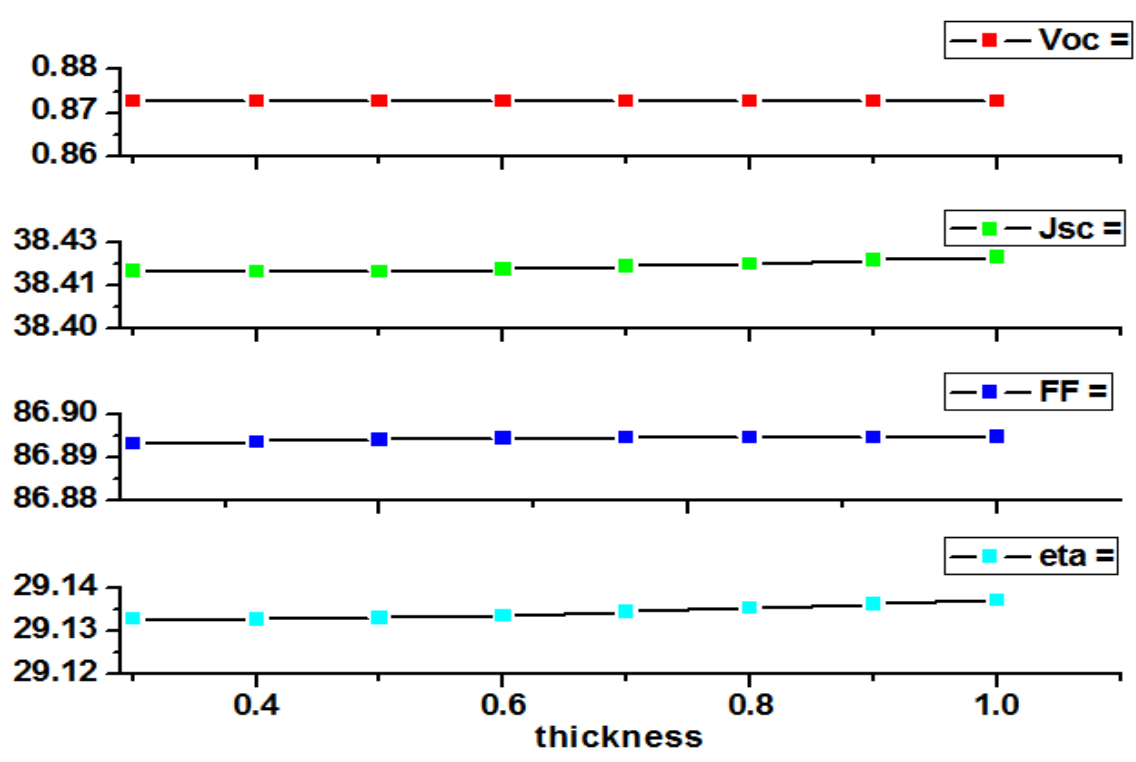

Figure 4.11: CdS layer thickness $(\mu \mathrm{m})$ 


\section{iv. Effect of absorber layer $p-S n S$ thickness on solar cell performance}

To analyze the effect of the absorber layer on solar cell performance thickness of the absorber layer was varied from $0.1 \mu \mathrm{m}$ to $2 \mu \mathrm{m}$. The results for the effect of changing absorber thickness on the main parameters of PV solar cell are shown in Figure 4.12.

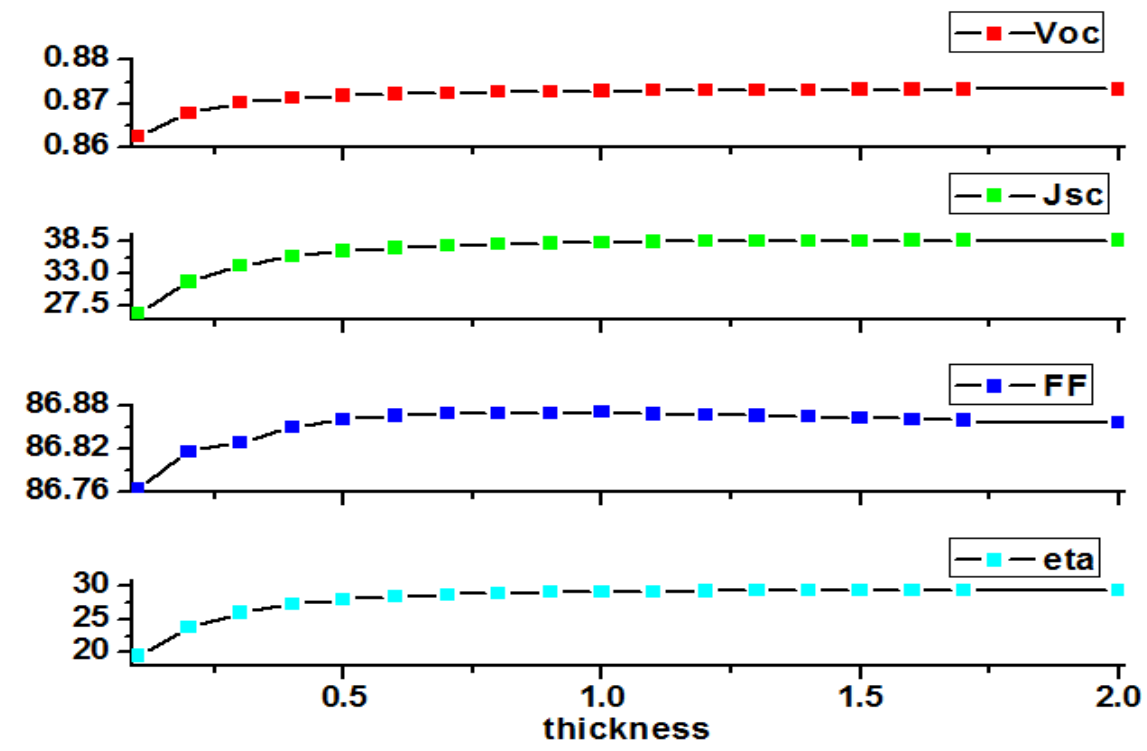

Figure 4.12: absorber layer thickness $(\mu \mathrm{m}) \mathrm{p}-\mathrm{SnS}$

It was analyzed that with an increase in absorber layer thickness the conversion efficiency of the solar cell is increased. It was also observed that FF (fill factor) starts decreasing after increasing thickness from 0.9-1.1 $\mu \mathrm{m}$. From spectral representation in Figure 4.13 with inset graph, optimum thickness is around $1 \mu \mathrm{m}$ because quantum efficiency (QE \%) almost reaches to its maximum for $\mathrm{SnS}$ absorber layer. But for analysis thickness was varied to 2 $\mu \mathrm{m}$ and the variation in calculated efficiency is between $20 \%$ and $29 \%$, respectively. Comparing the results with the $29 \%$ conversion efficiency electrons will be captured easily by the back contact. The increasing trend in eta $(\%), \mathrm{V}_{\mathrm{oc}}$ and $\mathrm{J}_{\mathrm{sc}}$ can be seen when the absorber layers thickness is increased but there was a decrease in FF. The chosen optimum thickness for $\mathrm{SnS}$ absorber layer was $1 \mu \mathrm{m}$.

\section{i. Optimization of BSF layer $\left(p^{+}-S n S\right)$ thickness}

In this step, the thickness of the back-surface layer with highly doped SnS was varied from $0.1 \mathrm{um}$ to $1 \mathrm{um}$. Figure 4.14 shows the result for $\mathrm{p}^{+}-\mathrm{SnS}$ layer. From Figure 4.14 an increase in thickness will help in increase in $V_{o c}, J_{s c}$, eta but FF start to decrease after a thickness of $0.6 \mu \mathrm{m}$. As the change in $V_{o c}, J_{s c}$ after the thickness of $0.4 \mu \mathrm{m}$ was very small so FF starts to decrease. Therefore, optimum value of thickness was chosen $0.6 \mu \mathrm{m}$. 


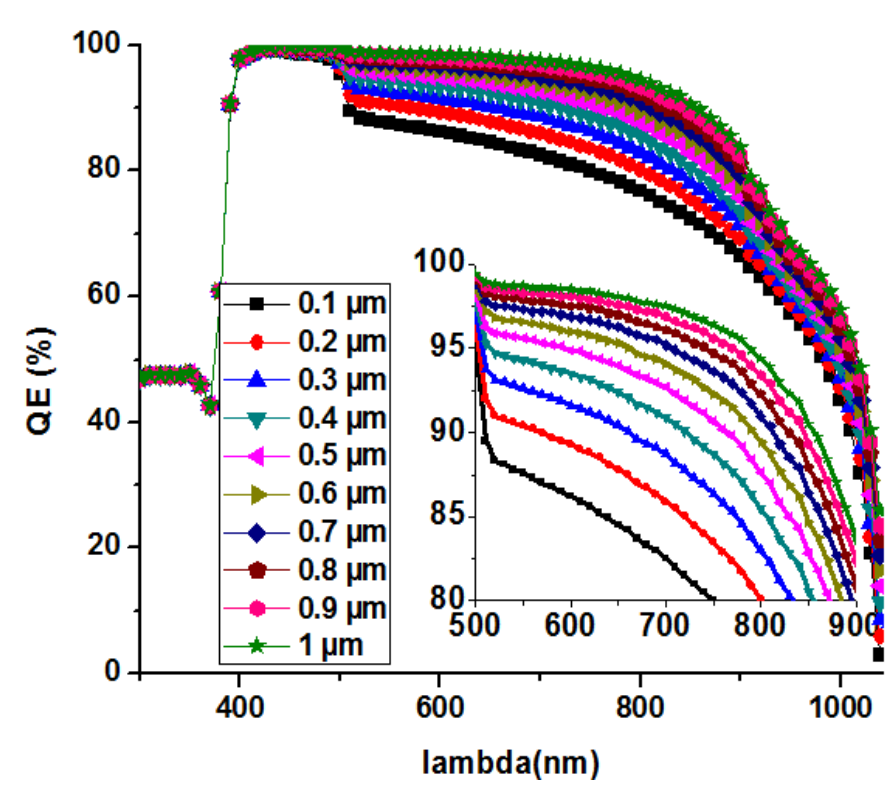

Figure 4.13: QE \% of SnS solar cell as a function of absorber layer thickness

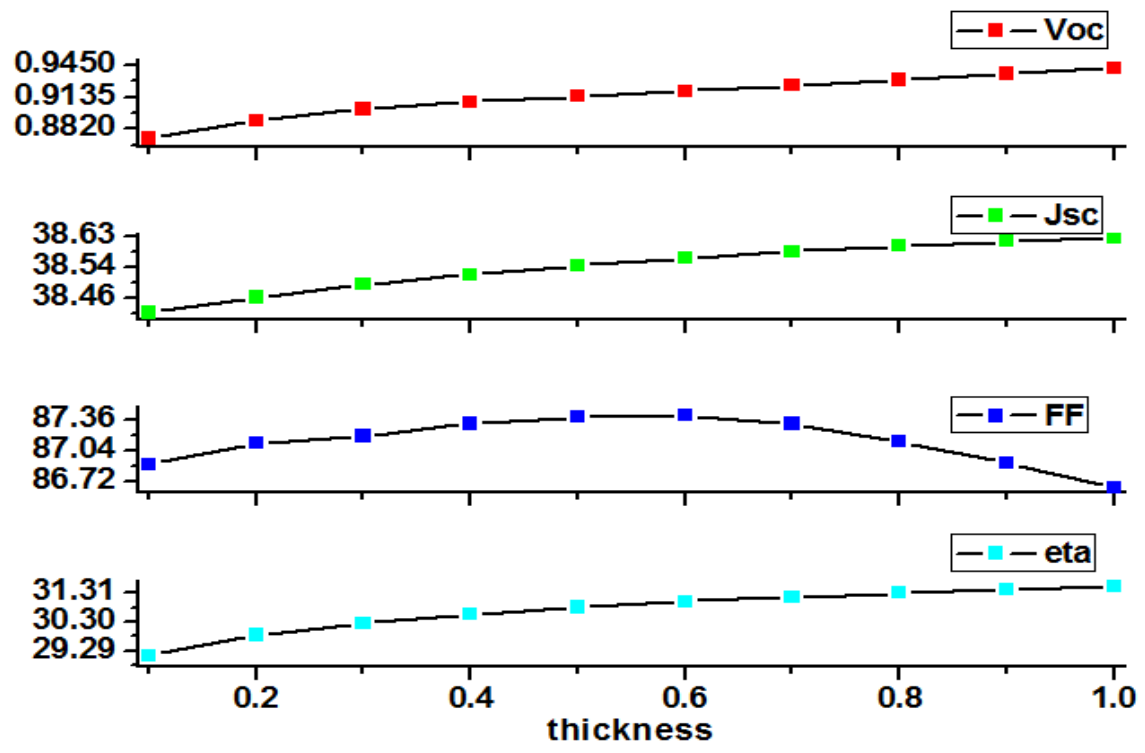

Figure 4.14: BSF layer $\left(\mathrm{p}^{+}-\mathrm{SnS}\right)$ thickness effect on solar cell performance $(\mu \mathrm{m})$

\section{ii. Effect of temperature on solar cell performance}

Diode characteristic heavily depended upon temperature, from Figure 4.15 it is evident that temperature plays a vital role in the performance of a solar cell. To carry out simulation the temperature was varied from $230 \mathrm{~K}$ to $400 \mathrm{~K}$. Figure 4.15 shows the effect of temperature on solar cell performance. At room temperature solar cell operates at its near maximum. But with a slight change in temperature, there was a drastic change in solar cell parameters. As in SCAPS temperature directly affect the thermal velocity $\left(v_{t h}\right)$, thermal 
voltage $(\mathrm{kT})$ and density of state for conduction band $\left(N_{C}\right)$ and valance band $\left(N_{v}\right)$. This is given in equation 4.1 to 4.3 .
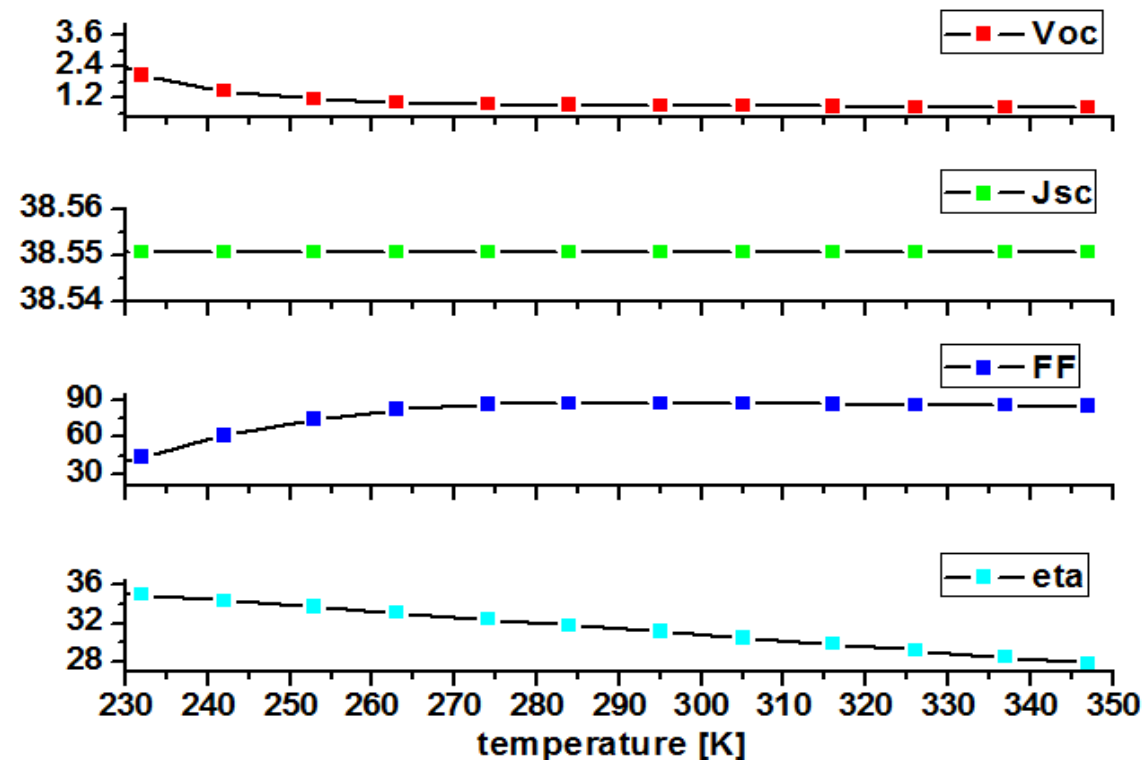

Figure 4.15: Effect of Temperature

$$
\begin{aligned}
& \mathrm{N}_{\mathrm{C}}=\mathrm{N}_{\mathrm{c}}\left(\frac{\mathrm{T}}{\mathrm{T}_{0}}\right)^{1.5} \\
& \mathrm{~N}_{\mathrm{V}}=\mathrm{N}_{\mathrm{V}}\left(\frac{\mathrm{T}}{\mathrm{T}_{0}}\right)^{1.5} \\
& \mathrm{v}_{\text {th }}=\mathrm{v}_{\text {th }}\left(\frac{\mathrm{T}}{\mathrm{T}_{0}}\right)^{0.5}
\end{aligned}
$$

So, with increase in ambient temperature intrinsic carrier concentration of solar cell increases and this given in equation 4.4 .

$$
n_{i}=\sqrt{N_{C} N_{V}} e^{\frac{-\left(E_{C}-E_{V}\right)}{k T}}
$$

Based on the result from equation 4.4, the reverse saturation current of device will increase, and this will result in decrease in open circuit voltage. The relationship for reverse saturation current and open circuit voltage is given in equation 4.5 and equation 4.6.

$$
\begin{aligned}
& \mathrm{J}_{0}=\mathrm{BT}^{3} \mathrm{e}^{\frac{-\mathrm{Eg}}{\mathrm{kT}}} \\
& \mathrm{V}_{\mathrm{oc}}=\frac{\mathrm{kT}}{\mathrm{q}} \ln \left(\frac{\mathrm{J}_{\mathrm{SC}}}{\mathrm{J}_{\mathrm{o}}}\right)
\end{aligned}
$$




\section{iii. Comparison with simple $S n S / C d S / Z n O$ cell}

Figure 4.16 shows the comparison between $\mathrm{p}^{+}-\mathrm{SnS} / \mathrm{SnS} / \mathrm{CdS} / \mathrm{ZnO}$ and SnS/CdS/ZnO solar cell. From Figure 4.16 for solar cell of type $\mathrm{p}^{+}-\mathrm{SnS} / \mathrm{SnS} / \mathrm{CdS} / \mathrm{ZnO}$ has a higher $\mathrm{V}_{\mathrm{oc}}$ and $\mathrm{J}_{\mathrm{sc}}$ with comparison to $\mathrm{SnS} / \mathrm{CdS} / \mathrm{ZnO}$ solar cell.

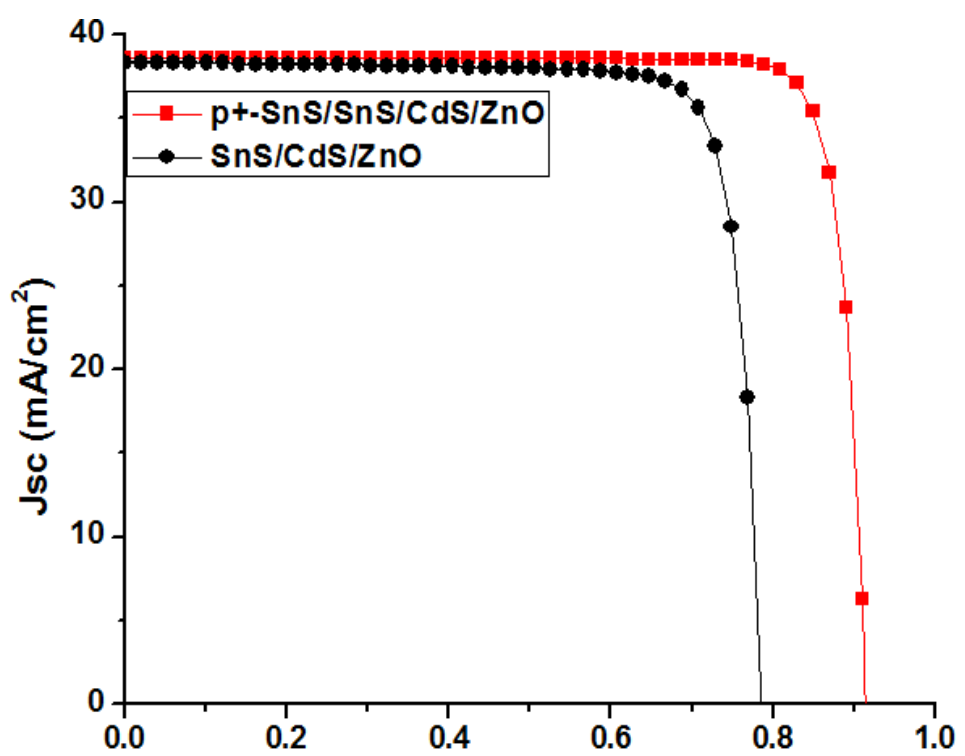

Figure 4.16: J - V Comparison between $\mathrm{p}^{+}-\mathrm{SnS} / \mathrm{SnS} / \mathrm{CdS} / \mathrm{ZnO}$ with SnS/CdS/ZnO

\subsubsection{Conclusion}

The numerical simulation of solar cell helps the researcher to get the inside details of a solar cell. This work reports the effect of absorber layer thickness, acceptor doping concentration in absorber layer and temperature on the performance of SnS based thin film solar cell. The dark characteristic of the solar cell is just like a normal Schottky diode but in illumination, the current density increased up to $38.55 \mathrm{~mA} / \mathrm{cm}^{2}$. The thickness of the absorber layer also affects the current density, efficiency, fill factor and open circuit voltage. The optimum value of absorber thickness is chosen to be $1 \mu \mathrm{m}$ with a back-surface layer thickness of $0.6 \mu \mathrm{m}$. Temperature also had a direct effect on solar cell performance as with an increase in temperature overall efficiency decreased. This happens because with the increase in temperature diode reverse saturation current increases that in terms affect the open circuit voltage of the solar cell. So, with a decrease in open circuit voltage other function parameters of solar cell also reduced. It is also found that BSF layer thickness can affect the performance of the solar cell. With BSF layer we achieve a solar cell with a conversion efficiency of $30.18 \%$. the study presented in this work can be helpful in designing efficient and low-cost SnS absorber based solar cell. 
This page intentionally left blank 
CHAPTER 5

EFFICIENCY ENHANCEMENT OF EXPERIMENTALLY DESIGNED SOLAR CELL 
This page intentionally left blank 
Over a decade of extensive work in thin film (TF) solar cells technology, TF had made impressive improvements in conversion efficiency of device, with cadmium telluride (CdTe) and Copper indium gallium sulfide selenide (CIG(S, Se)) solar cell reaching to conversion efficiency of $21 \%$ [64]. Due to the toxic nature of Cd, the scarcity of (In, Te) and a high price of Ga make it impossible for terawatt scale applications and production. There for alternate earth abundant, non-toxic, low cost and easy to process material must be explored for large scale production of the high conversion efficiency of solar cell. Kesterite / Copper zinc tin sulphide selenide (CZT(S, Se)) is another promising candidate for thin film technology with a conversion efficiency of $11.5 \%$ is reported [65]. But the major issue with kesterite solar cell is to control the composition of this compound during fabrication to achieve maximum conversion efficiency. apart from (CZT(S, Se)) other nonorganic absorber materials for thin film technologies that had been extensively explored and studied are $\mathrm{SnS}, \mathrm{FeS}_{2}, \mathrm{Cu}_{2} \mathrm{O}$ and $\mathrm{Cu}_{2} \mathrm{~S}$ [66-69], but still their conversion efficiencies are far less than from expectation.

$\mathrm{SnS}$ tin sulphide is the future of energy source due to its abundance and non-toxicity with energy band gap ranging from 1.1 1.4 eV. SnS is group IV-VI compound semiconductor with orthorhombic structure with absorption coefficient of $\left(\alpha \propto 10^{4}\right)$ with higher carrier concentration of $\left(p-10^{15}, p-10^{18}\right)$ with theoretical efficiency of $30 \%$ [70][71]. But still, tin sulphide suffers low power conversion efficiency is due to the lack of knowledge to successfully process and produce a pure SnS device. Up till now maximum power conversion efficiency reported for SnS was $4.4 \%$ by the atomic layer deposition with crystal structure (040) [72]. Due to its anisotropic behaviour electrical characteristics of $S n S$ are highly depended upon crystal structure [73][74]. Although improving in efficiency and simplification in process of SnS fabrication, still some drawback which hinders the way in the commercialization of SnS materials. So, to achieve the optimized design and good conversion efficiency the detailed understanding of the device operation needs to be done. To accomplish this task, various parameters like absorber thickness, acceptor doping density, buffer layer thickness, donor density of buffer layer and minority carrier lifetime were analysed for a solar cell with structure SnS/CdS/ZnO. To the best of our knowledge, there has been no numerical model proposed to explain the factor that limits the conversion efficiency of SnS solar cell and to propose a numerical guide to enhance the efficiency of experimentally designed solar cell. 
Here the device simulation is carried out in solar cell capacitance simulator (SCAPS) developed by the University of Gent. SCAPS is a one-dimensional software used to calculate, band diagram, IV characteristic, quantum efficiency/spectral response (QE) and AC quantities. This program was mainly developed for the analysis of CIGS and CdTe solar cell and was widely used for the optimal design of these solar cells [75,76].

\subsection{Factor limiting the efficiency of SnS solar cell}

As discusses in detail in chapter 3 that the performance of a solar cell is highly affected by recombination at the interface, at bulk semiconductor, and at contacts. So, in this work, we will evaluate the performance of SnS solar cell under these defects and will propose a study about how we can improve the efficiency of experimental designed solar cell.

\subsubsection{Solar cell model and simulation parameters}

Model for a solar cell that is evaluated in SCAPS is shown in Figure 5.1 below.

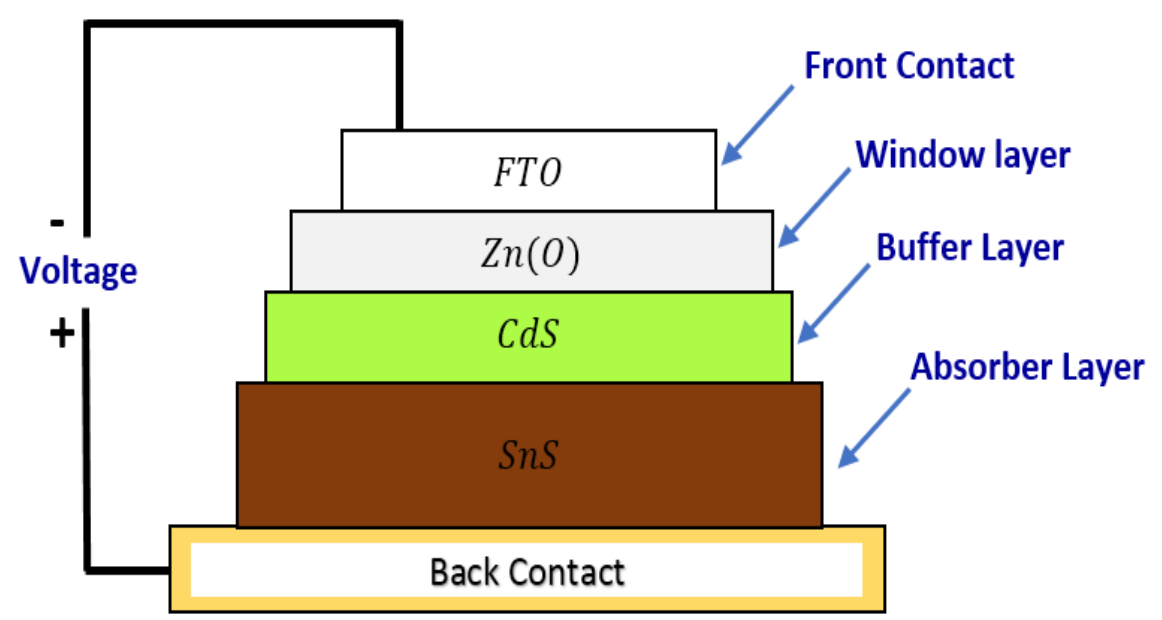

Figure 5.1: Solar cell model diagram

Table 5.1: Simulation parameters for the different layers in $S n S / C d S / Z n O$ thin film solar cells.

\begin{tabular}{lccc}
\hline \multicolumn{1}{c}{ Parameters } & ZnO & n $-\mathbf{C d S}$ & $\mathbf{p}-\mathbf{S n S}$ \\
\hline Thickness, $\mathrm{W}(\mu \mathrm{m})$ & 0.1 & 0.05 & $1-25$ \\
Bandgap, Eg $(\mathrm{eV})$ & 3.35 & 2.42 & $1.1-1.4$ \\
Electron affinity, $\chi(\mathrm{eV})$ & 4.5 & 4.4 & 4 \\
Dielectric permittivity, $\varepsilon / \varepsilon_{0}$ & 9 & 10 & 13 \\
Effective density of states, $\mathrm{N}_{\mathrm{C}}\left(\mathbf{c m}^{-3}\right)$ & $2.2 \times 10^{18}$ & $2.2 \times 10^{18}$ & $1.18 \times 10^{18}$ \\
Effective density of states, $\mathrm{N}_{\mathrm{V}}\left(\mathbf{c m}^{-3}\right)$ & $1.8 \times 10^{19}$ & $1.7 \times 10^{19}$ & $4.76 \times 10^{18}$ \\
Electron mobility, $\mu_{\mathrm{e}}\left(\mathbf{c m}^{2} / \mathrm{Vs}\right)$ & 100 & 340 & 15 \\
Hole mobility, $\mu_{\mathrm{p}}\left(\mathbf{c m}^{2} / \mathrm{Vs}\right)$ & 25 & 50 & 100 \\
Electron and hole concentration, $\mathrm{n}, \mathrm{p}\left(\mathbf{c m}^{-3}\right)$ & $10^{18}$ & $10^{17}$ & $10^{15}$ \\
\hline
\end{tabular}

To run numerical simulations for the designed solar cell in SCAPS several parameters for SnS absorber layers need to be defined, like absorber layer thickness, doping density, 
electron-hole mobility, band gap, electron affinity, and intrinsic carrier concentration. Similar parameters are required for both, window and buffer layers. These parameters were extracted from available literature [15,63,77], and are listed in Table 5.1.

\subsubsection{Result and Discussion}

In this part, the effect of the absorber thickness, operating temperature and the band tailing of the absorber material affecting the performance of solar cell were analysed.

\section{i. Effect of absorber thickness}

Absorber thickness has a direct effect on the PCE of solar cell because the number of absorbed photons depends on both the absorption coefficient and the thickness of the absorber, this is shown in equation 5.1.

$$
a(\lambda, W)=1-e^{(-2 \alpha(\lambda) W)}
$$

$\mathrm{W}$ is the thickness of a solar cell, $\alpha(\lambda)$ is the absorption of a solar cell with wavelength $\lambda$. The absorption coefficient for $\mathrm{SnS}$ thin film solar cell is given in equation 5.2.

$$
\alpha(\lambda)=\frac{4 \pi k}{\lambda}
$$

$k$ is the extinction coefficient of SnS. Based on equation 5.2 the absorption coefficient $\alpha(\lambda)$ depends upon $\lambda$ and $k$. Figure 5.2 displays the effect of absorber thickness on the performance of an SnS based solar cell, as the thickness increases $V_{o c}$ increases linearly and $J_{s c}$ and PCE increases drastically up to about $5 \mu \mathrm{m}$ and then remain nearly constant. The FF reaches a maximum at about $5 \mu \mathrm{m}$ and then starts to decrease. So, the optimal thickness for the absorber layer to gain maximum efficiency from SnS solar cell was $5 \mu \mathrm{m}$.

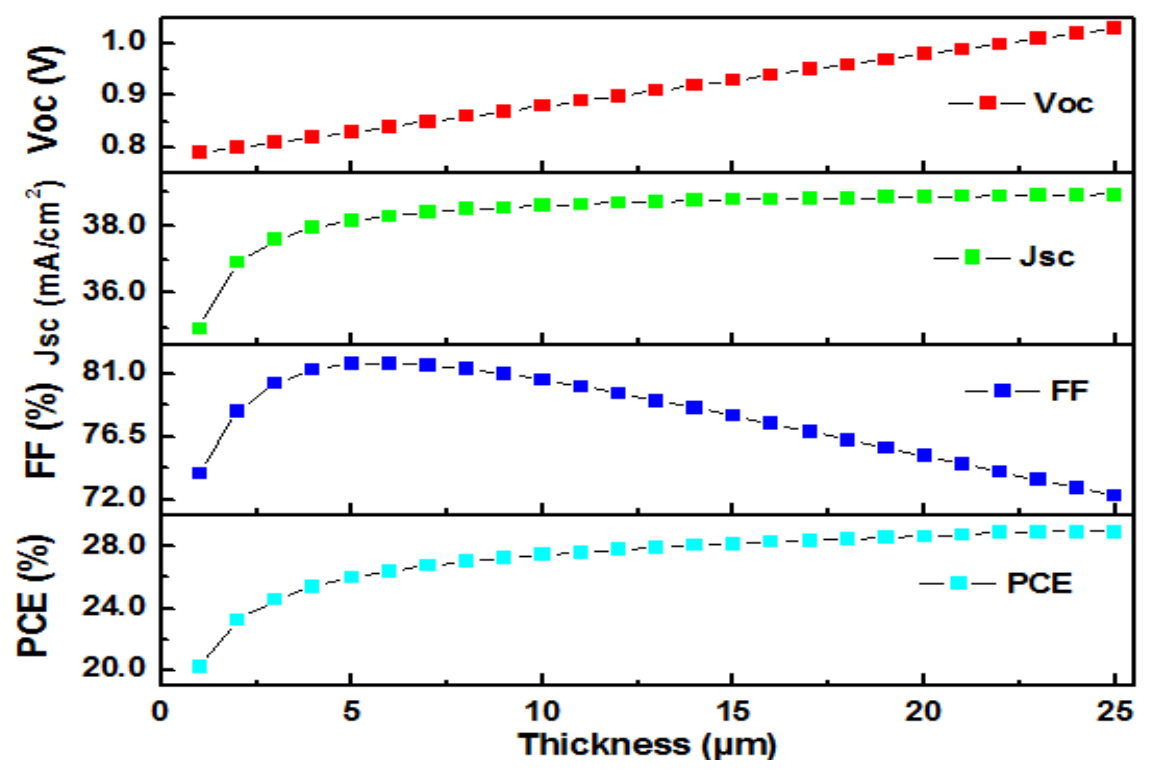

Figure 5.2: Effect of the absorber thickness on performance parameters of SnS solar cells 


\section{ii. $\quad$ Effect of temperature}

Effect of temperature on solar cell parameters can be inferred from equation 5.3 and 5.4.

$$
\begin{aligned}
V_{o c} & =\frac{k T}{q} \ln \left(\frac{J_{L}}{J_{0}}+1\right) \\
\mathrm{J}_{0} & =\mathrm{BT}^{3} \mathrm{e}^{\frac{-\mathrm{Eg}}{\mathrm{kT}}}
\end{aligned}
$$

From equation 5.3 and 5.4, temperature directly affect the performance parameters of solar cell. With increase in temperature the reverse saturation current increases and this results in decrease in open circuit voltage of solar cell. With decrease in open circuit voltage of solar cell PCE was also affected.

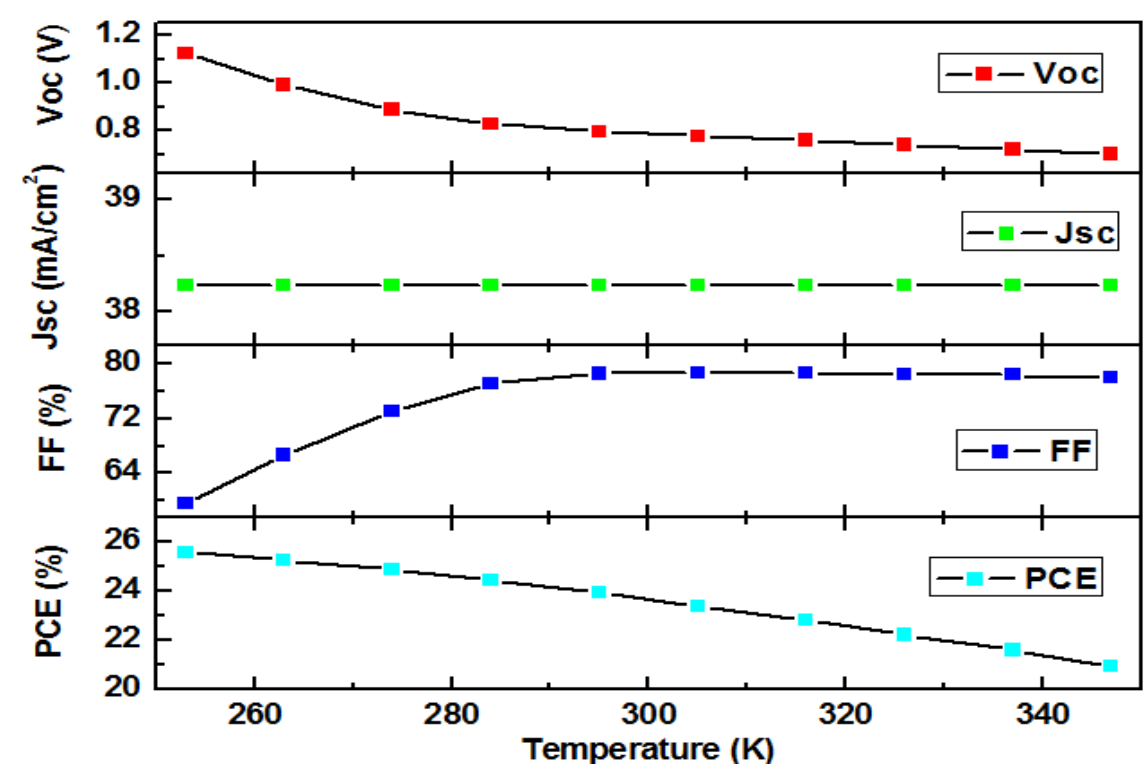

Figure 5.3: Effect of temperature on SnS/CdS/ZnO solar cell.

Figure 5.3 shows the behaviour of the main photovoltaic parameters as a function of the operating temperature. As the operating temperature increases the open circuit voltage tends to decrease.

\section{iii. $\quad$ Effect of band tailing (Urbach tail)}

Many impurities are inserted into the host lattice for heavily doping a semiconductor. Insertion of those impurities introduces a band level in the band gap, so these band level can interact to form a band tail at higher densities. This effect may be view as a shift of conduction band towards valance band and this can also be called a band gap narrowing. In disordered materials, the prominent observation is the exponential Urbach tail. Band tailing has a direct effect on the performance of a solar cell, it creates a trap density of state in solar cell devices. The equation for the effect of band tail/Urbach tail is given in [7880] and for SnS thin film it is represented in equation 5.5.

$$
\alpha=\left\{\begin{array}{c}
\alpha_{0} \exp \left(E-E_{g} / E_{0}\right) E<E_{g} \\
\alpha_{0}\left(1+E-E_{g} / E_{\text {prime }}\right) E \geq E_{g}
\end{array}\right.
$$


$\alpha$ is absorption profile, $\alpha_{0}>10^{4} \mathrm{~cm}^{-1}$ is absorption coefficient, $\mathrm{E}$ is photon energy, the Urbach tail $E_{0}$ for $\mathrm{SnS}$ is given in [78] and $E_{\text {prime }}$ is constant. The result for Urbach tail effect is shown in Figure 5.4 and Figure 5.5. Figure 5.4 shows the result for Urbach tail effect on absorption profile that was evaluated from equation 5.5 by putting different values of Urbach tail. Figure 5.5 with inset graph shows the effect of the Urbach tail of the performance parameters of a solar cell.

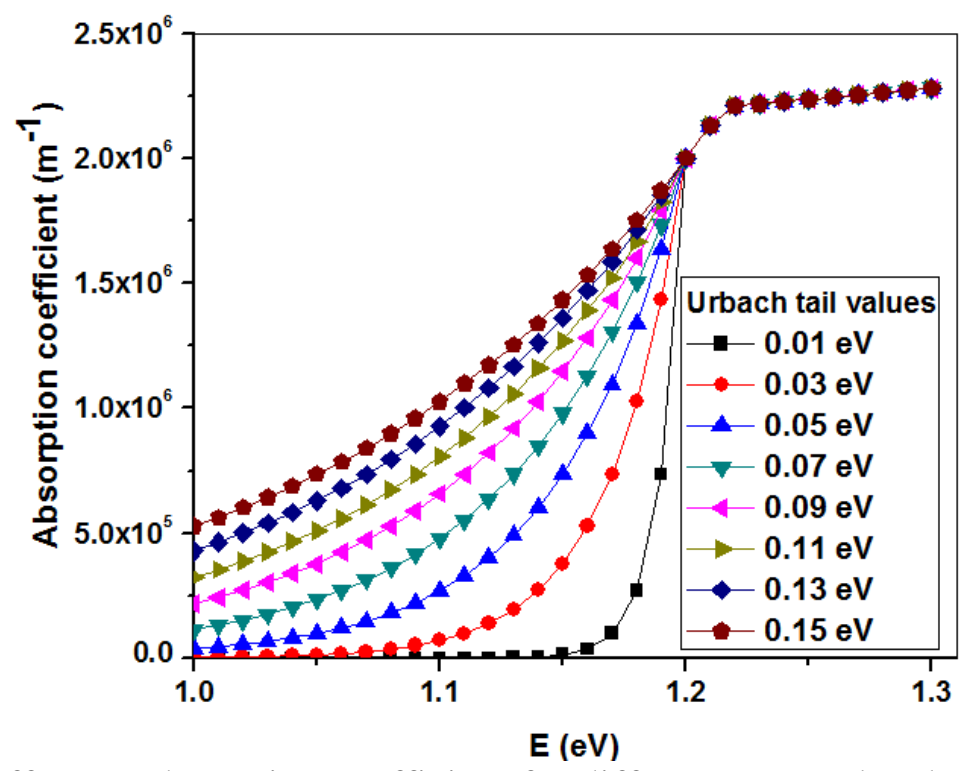

Figure 5.4: Effect on absorption coefficient for different energy level of Urbach tail.

Figure 5.5 shows the result of solar cell parameters for the Urbach tail. For analysis, we vary the value of $E_{0}$ from 0 to $0.14 \mathrm{eV}$. Figure 5.5 shows that as Urbach tail value is increased efficiency of the $\mathrm{SnS}$ thin film solar cell starts to decrease, this happens because the creation of band tail leads to strong recombination in the band gap region.

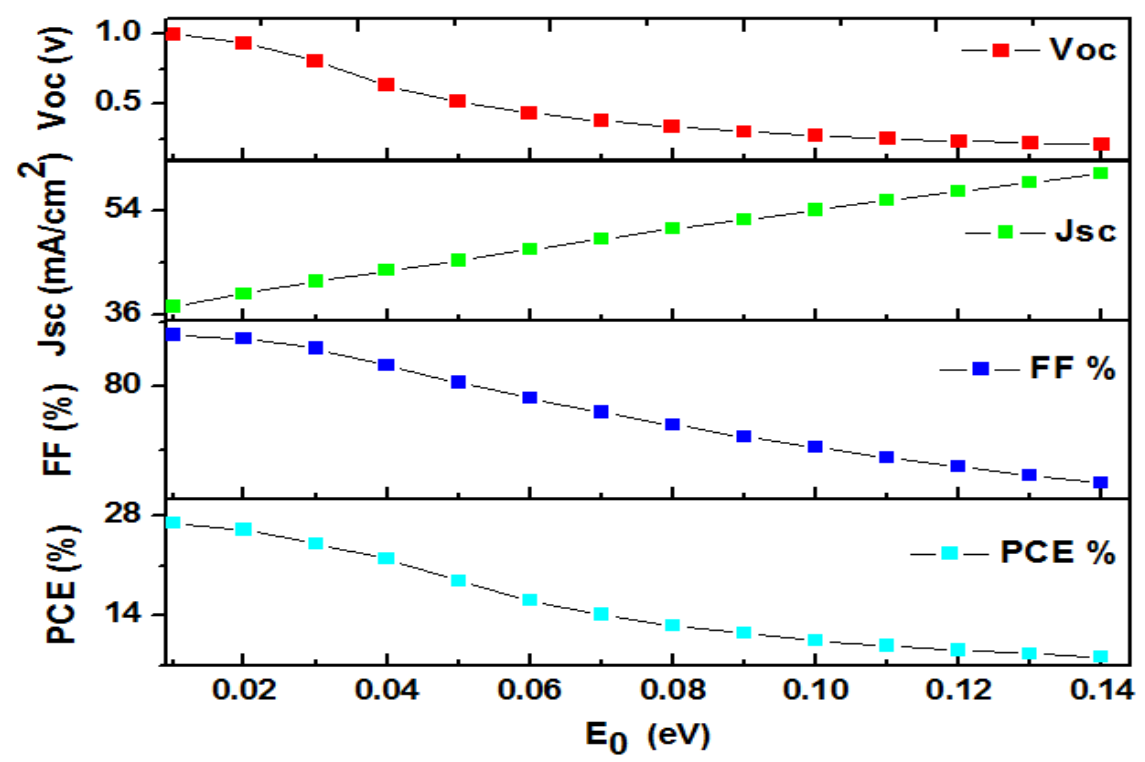

Figure 5.5: Urbach tail effect of SnS thin film solar cells. 
Based on the discussion above the SnS solar cell can reach an efficiency of $28 \%$ with no band tail, defects, and optimum absorber thickness. This can also be validated from the results presented in Table 5.2 that have been extracted from the literature.

Table 5.2: Reported PV parameters for simulated SnS solar cells in literature with different cell structures.

\begin{tabular}{cccccc}
\hline Cell Structure & Voc $(\mathbf{V})$ & Jsc $\left(\mathbf{m A} / \mathbf{c m}^{2}\right)$ & PCE $(\%)$ & FF $(\%)$ & Reference \\
\hline SnS/CdS & 0.920 & 13.40 & 10.6 & 86.00 & {$[15]$} \\
SnS/ZnS & 0.894 & 31.88 & 16.3 & 57.0 & {$[81]$} \\
SnS/a - Si & 0.893 & 30.67 & 14.3 & 52.2 & {$[81]$} \\
SnS/SnS & 0.985 & 29.31 & 25.3 & 87.6 & {$[82]$} \\
SnS/CdS & 0.800 & 38.60 & 26.0 & 85.0 & {$[63]$} \\
SnS/ZnO & 0.749 & 26.86 & 17.03 & 85.0 & {$[83]$} \\
\hline
\end{tabular}

The numerical analysis results presented in Table 5.2 are far ahead of experimental known conversion efficiency because experimentally reported $\mathrm{SnS}$ solar cell has a maximum conversion efficiency of $4.6 \%$. The results for the experimental work of SnS solar cell is presented in Table 5.3.

Table 5.3: Reported PV parameters for experimental SnS solar cells in literature with different cell structures.

\begin{tabular}{cccccc}
\hline Cell Structure & Voc $(\mathbf{V})$ & Jsc $\left(\mathbf{m A} / \mathbf{c m}^{2}\right)$ & PCE $(\%)$ & FF $(\%)$ & Reference \\
\hline SnS/CdS & 0.26 & 9.6 & 1.30 & 53 & {$[84]$} \\
SnS/CdS & 0.12 & 7 & 0.29 & 35 & {$[85]$} \\
SnS/CdS & 0.14 & 8.4 & 0.5 & 38 & {$[86]$} \\
SnS/CdS & 0.274 & 0.301 & 0.08 & 40 & {$[87]$} \\
SnS/CdS & 0.217 & 19 & 1.6 & 39.2 & {$[88]$} \\
SnS/CdS & 0.223 & 26.1 & 2.53 & 43.5 & {$[89]$} \\
SnS/CdZnS & 0.288 & 9.16 & 0.71 & 27 & {$[90]$} \\
SnS/ZnMgO & 0.28 & 12.5 & 2.1 & - & {$[91]$} \\
SnS/ZnMgO & 0.575 & 9.96 & 2.02 & 36.4 & {$[92]$} \\
SnS/Zn $(\mathbf{O}, \mathbf{S})$ & 0.244 & 19.4 & 2.04 & 42.97 & {$[93]$} \\
SnS/Zn $(\mathbf{0}, \mathbf{S})$ & 0.261 & 24.9 & 2.9 & 44.4 & {$[94]$} \\
SnS/Zn(0,S) & 0.334 & 20.645 & 3.88 & 56.28 & {$[95]$} \\
SnS/Zn $(\mathbf{0}, \mathbf{S})$ & 0.37 & 20.2 & 4.36 & 58 & {$[96]$} \\
SnS/TiO2 & 0.471 & 0.3 & 0.1 & 71 & {$[97]$} \\
SnS/SnS2 & 0.12 & 10.87 & 0.51 & 39 & {$[98]$} \\
SnS/SnS & 0.65 & 7.64 & 1.95 & 39 & {$[99]$} \\
\hline
\end{tabular}


So, from Table 5.3 experimentally reported solar cell has an efficiency less than reported in numerical studies and this was mainly due to the defects that are present in a solar cell. Defects are the major cause for the loss in a solar cell, these are interface defects and absorber layer defects. In step below, we analyse the effect of defects on solar cell performance.

\section{iv. Effect of defects in $\mathrm{SnS} / \mathrm{CdS} / \mathrm{ZnO}$ solar cells}

Indeed, the presence of defects in the different layers of the solar cell, as well as defects in the interlayers, will disturb the performance of the devices. In this part, the effects of two kinds of defects such as defects in the interface absorber/buffer (SnS/CdS) and defects in the absorber SnS layer were analysed [100].

Figure 5.6 shows the $\mathrm{J}-\mathrm{V}$ curves for different densities of interlayer defects with neutral charge, energy distribution $0.6 \mathrm{eV}$ and density ranging from $10^{10}$ to $10^{14} \mathrm{~cm}^{-2}$. As the trap density of state increases performance of solar cell starts to decrease. Figure 5.6 illustrates that $V_{o c}$ and $J_{S c}$ are higher for a solar cell with no defects at the interface but as the amount of trap defect density increases in SnS solar cell the open circuit voltage starts to decrease, and this happens due to band traps at the interface which captures the electron and hole. Thus, causing recombination at the interface. From the analysis it is shown that interface recombination due to the density of defects majorly affect the open circuit voltage of the SnS/CdS/ZnO solar cell.

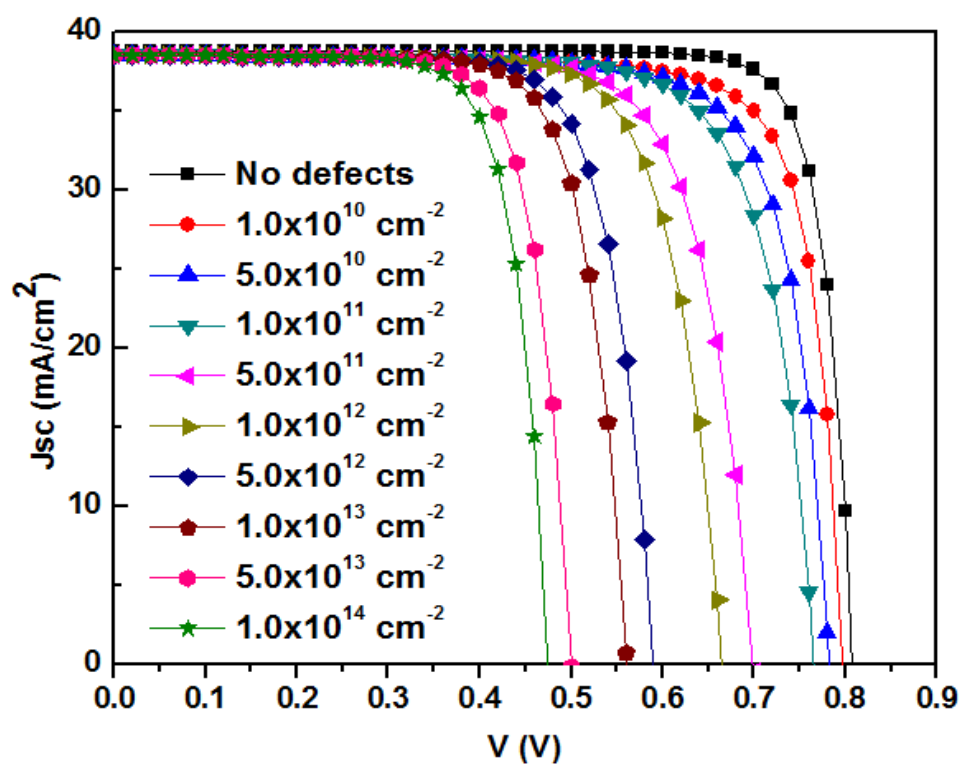

Figure 5.6: Effect of defect density of state at the interface of SnS/CdS layer

Figure 5.7 shows the result for the effect of SnS layer defect, in this defect density was kept constant with a value of $1 \times 10^{14} \mathrm{~cm}^{-3}$ and capture cross section electrons and capture cross section holes was varied from $10^{-15}$ to $10^{-10} \mathrm{~cm}^{-2}$. 
From Figure 5.7 it is shown that $\mathrm{SnS}$ absorber layer defects will also affect the performance of the solar cell, by reducing the value of capture cross-section of electron and hole in absorber layer we are reducing the diffusion length of photogenerated electron Ln and hole Lp. This is shown in equation 5.6 below.

$$
L_{\text {diffusion }}=\sqrt{\frac{k T \mu \tau}{q}}
$$

whereas $L_{\text {diffusion }}$ is the diffusion length of electron and hole, $\mu$ is mobility and $\tau$ is the lifetime of these carriers. Similarly, the lifetime of the carrier is depended upon on the parameters described in equation 5.7 below.

$$
\tau=\frac{1}{N_{t} \delta v_{t h}}
$$

$N_{t}$ is the density of state, $\delta$ is capture cross-section area and $v_{t h}$ is thermal velocity. As capture-cross section area increases the lifetime of carrier will decrease and with respect to that diffusion length will also decrease. The reduction in length means holes and elections will easily be captured within the material thus affecting the efficiency of a solar cell and this will also limit the thickness of the absorber layer.

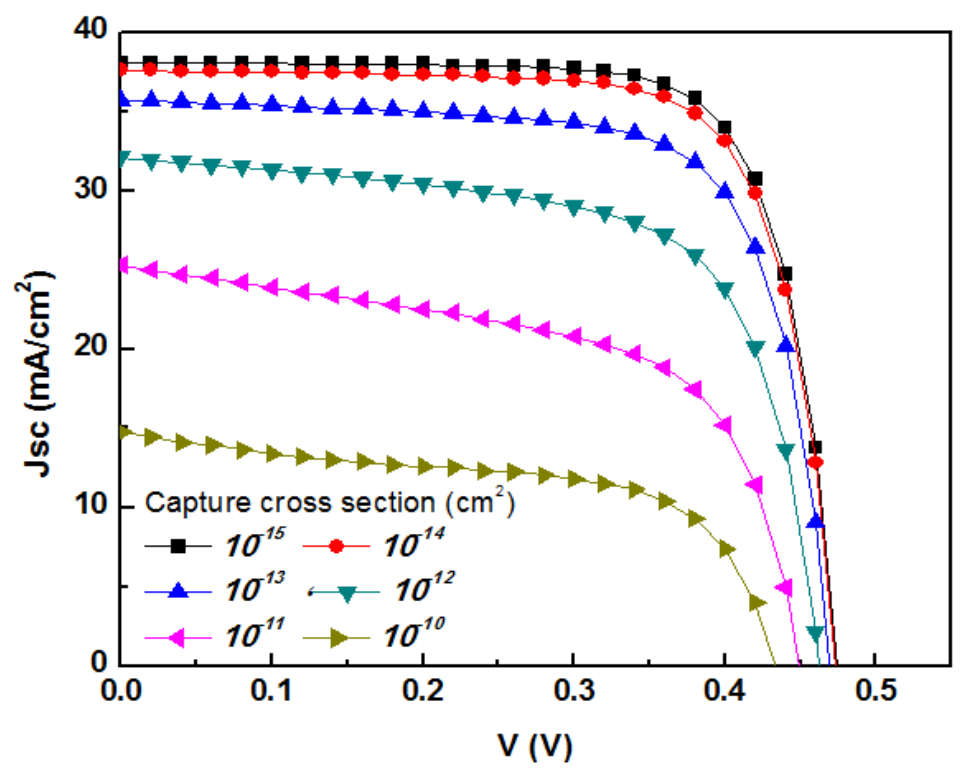

Figure 5.7: Effect of capture cross section area for electron and hole.

\section{v. Comparison with experimental design solar cell result}

To validate the design and effect of the defect on solar cell performance we compare the simulated result with experimental results. The value of defect density that was added between the interface of SnS/CdS is $\mathrm{N}_{\mathrm{t}}=5 \times 10^{11}\left(\mathrm{~cm}^{-2}\right)$ and for SnS absorber layer defect Table 5.4 is drawn below. 
Table 5.4: Defects in SnS absorber layer according to references [100,101].

\begin{tabular}{lc}
\hline \multicolumn{1}{c}{ Defect properties } & Values \\
\hline Energy level with respect to Reference $(\mathrm{eV})$ & 0.200 \\
Total Density $\left(\mathbf{1} / \mathbf{c m}^{\mathbf{3}}\right) \mathbf{N}_{\boldsymbol{t}}$ & $5 \times 10^{14}$ \\
Capture Cross section area of electrons $\left(\mathbf{c m}^{\mathbf{2}}\right) \boldsymbol{\delta}_{\boldsymbol{e}}$ & $1.8 \times 10^{-12}$ \\
Capture Cross section area of holes $\left(\mathbf{c m}^{2}\right) \boldsymbol{\delta}_{\mathbf{h}}$ & $1.8 \times 10^{-12}$
\end{tabular}

Figure 5.8 shows the results of SnS/CdS solar cell simulated in SCAPS with defects and result from experimental work presented in [84] are compared. From Figure 5.8 it is shown that the added defects in SCAPS for the analysis SnS/CdS solar cell can lead us to match the experimental result of SnS/CdS solar cell. With further investigation of those defects, it is possible that we can improve the efficiency of SnS/CdS solar cell with careful optimization of physical parameters.

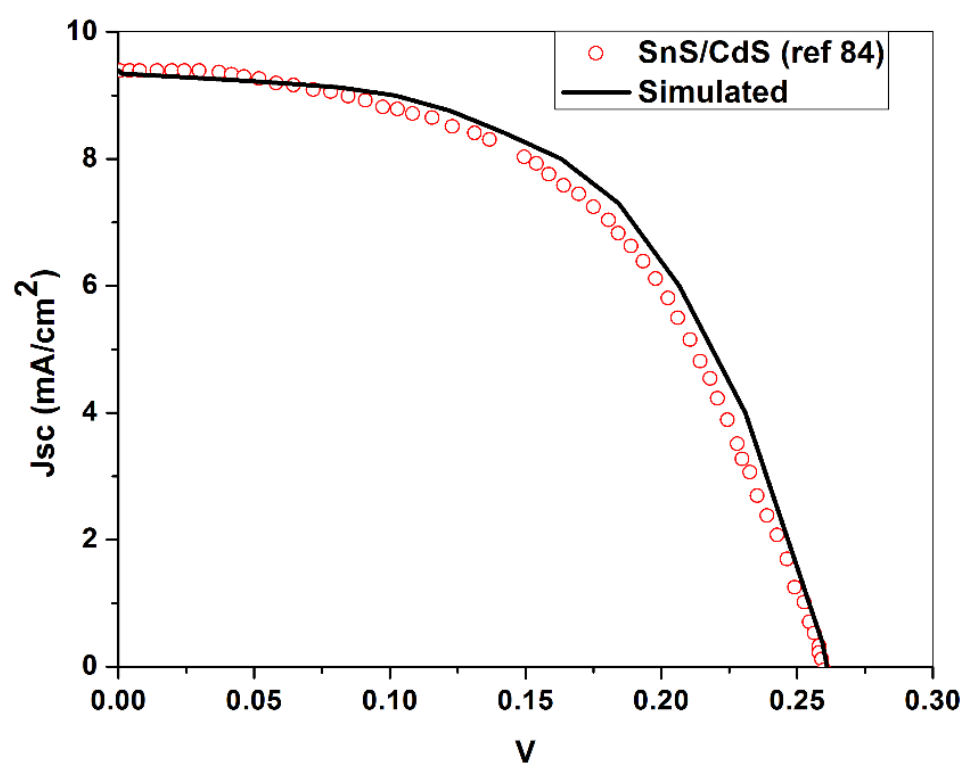

Figure 5.8: Comparison between experimental data and the simulation output using SCAPS.

The obtained results of SnS/CdS solar cell with defects and without any defects are presented in Table 5.5.

Table 5.5: Calculated PV parameters for SnS/CdS solar cells with and without defects.

\begin{tabular}{lccccc}
\hline & Cell Structure & $\operatorname{Voc}(\mathbf{V})$ & Jsc $\left(\mathbf{m A} / \mathbf{c m}^{2}\right)$ & PCE (\%) & FF (\%) \\
\hline Without defects & SnS/CdS & 0.848 & 39.4 & 28.33 & 84.7 \\
With defects & SnS/CdS & 0.260 & 9.6 & 1.33 & 54.5 \\
Experimental [25] & SnS/CdS & 0.260 & 9.6 & 1.30 & 53.0 \\
\hline
\end{tabular}




\subsubsection{Conclusion}

Numerical simulation using the solar cell software SCAPS has been used for analysing the main factors limiting the efficiency of SnS based solar cells. Owing to the optical and electrical characteristics of SnS semiconductor a photon conversion efficiency of $28 \%$ is expected for solar cells based in $\mathrm{SnS}$ absorbers. However, up to date, practical solar cell devices do not surpass $4.36 \%$. The proposed method evaluates the efficiency of SnS thin film device under the influence of absorber thickness, temperature, band tailing energy and defects in a solar cell. From the analysis, it was found out that the major limitation in efficiency enhancement of SnS solar cell was band tailing, interface density defect, and absorber defects. As all these factors lead to recombination of photogenerated charge carriers. We found that interface defects behave like a serial resistance and then reduce the $\mathrm{V}_{\mathrm{oc}}$, while absorber defects mainly act as recombination centres and then limit the $\mathrm{J}_{\mathrm{sc}}$. The IV curve and PV parameters of experimental SnS based solar curve are well fitted by introducing both types of defects in the SnS layer absorber and in the interlayer bufferabsorber. The simulation carried out in this work will be very helpful in further investigating the efficiency limits of SnS solar cell.

\subsection{Numerical analysis a guide to improve the efficiency of experimental solar cell [32]}

In this section, a numerical analysis guideline was proposed about how to improve the efficiency of experimentally designed solar cells with the aid of numerical analysis. To validate the study presented in this section, we first reproduce the results for an experimentally designed solar cell in SCAPS with solar cell structure $\mathrm{p}-\mathrm{SnS} / \mathrm{n}-\mathrm{CdS}$ having a conversion efficiency of $1.5 \%$. After this device performance was optimized in solar cell capacitance simulator (SCAPS) by changing absorber layer thickness, buffer layer thickness, minority carrier lifetime, absorber acceptor doping concentration, buffer donor doping concentration and adding window layer. After optimization of physical device parameters and structure the new solar cell structure $\mathrm{p}-\mathrm{SnS} / \mathrm{n}-\mathrm{CdS} / \mathrm{n}-\mathrm{ZnO}$ achieves power conversion efficiency (PCE) of $14.01 \%$ in SCAPS.

Our approach for the improvement of SnS solar cell performance was by means of addressing the following facts:

i. Validation of simulated results for SnS/CdS solar cell in SCAPS.

ii. Optimization of buffer and absorber thickness.

iii. Adding ZnO window layer in SCAPS.

iv. Effect of minority carrier lifetime on solar cell performance. 
v. Effect of mobility of carrier on solar cell performance.

vi. Optimization of absorber layer doping concentration.

vii. Optimization of buffer layer doping concentration.

viii. Comparison of Results.

The proposed results in this study will give a beneficial guideline for the designing of high performance SnS based solar cells. Here the device simulation was carried out in SCAPS, developed by the University of Gent Belgium. SCAPS is one-dimensional software used to calculate, band diagram, IV characteristic, quantum efficiency/spectral response (QE) and AC quantities. This program was mainly developed for the analysis of CIGS and CdTe solar cell and was widely used for the optimal design of different solar cells [102,103].

\subsubsection{Simulation model}

Table 5.6: Parameters for simulation $[63,82,83]$

\begin{tabular}{lc}
\hline \multicolumn{1}{c}{ Parameters } & SnS \\
\hline Thickness, $\mathrm{W}(\mu \mathrm{m})$ & $0.1-4$ \\
Bandgap, Eg $(\mathrm{eV})$ & $1.2-1.4$ \\
Electron affinity, $\chi(\mathrm{eV})$ & $4-4.2$ \\
Dielectric permittivity, $\varepsilon / \varepsilon_{0}$ & 13 \\
Conduction band Density of states, $\mathrm{NC}\left(\mathbf{c m}^{-3}\right)$ & $1.18 \times 10^{18}$ \\
Valance band Density of states, $\mathrm{NV}\left(\mathbf{c m}^{-3}\right)$ & $4.76 \times 10^{18}$ \\
Electron mobility, $\mu_{\mathrm{e}}\left(\mathbf{c m}^{2} / \mathrm{Vs}\right)$ & 30 \\
Hole mobility, $\mu_{\mathrm{p}}\left(\mathbf{c m}^{2} / \mathrm{Vs}\right)$ & 90 \\
concentration of Electron and hole, $\mathrm{n}, \mathrm{p}\left(\mathbf{c m}^{-3}\right)$ & $1 \times 10^{15}$ \\
\hline
\end{tabular}

To find out the electrical characteristic's AC and DC of the heterojunction solar cell simulation model was set up in SCAPS software. SCAPS was developed for CIGS and CdTe thin film solar cells, but the simulation environment of SCAPS can be extended to analyse solar cells other then CdTe and CIGS. In SCAPS environment the results generated for your simulation contains the result of dark and illumination current along with some other characteristics. These results are extracted based on Poison equation, electron, and hole current equation. SCAPS can calculate properly the steady-state band diagram, recombination profile; transport carrier in 1D. Recombination current is calculated using the Shockley-Read-Hall (SRH) model for bulk and interface defects. The SRH approach in SCAPS allows carriers from both bands conduction and valence to participate in the 
interface recombination process. SCAPS software gives graphical user interface to provide a visual interface for the spectral response of $\mathrm{J}-\mathrm{V}, \mathrm{C}-\mathrm{V}, \mathrm{C}-\mathrm{f}$, and $\mathrm{Q}-\mathrm{V}$ characteristics. The model proposed in this paper consists of three layers and these layers are $\mathrm{ZnO} / \mathrm{n}-$ $\mathrm{CdS} / \mathrm{p}-\mathrm{SnS}$ layer. The output of a photovoltaic device is highly depended on the parameters such as the concentration of charge carriers, temperature, and thickness of solar cell also optical and electrical properties. $\mathrm{ZnO}$ was used as an optical window and $\mathrm{CdS}$ was used as a buffer layer for better charge transportation to contact, both materials properties can be easily found in the literature. The required parameters for SnS absorber layer in SCAPS simulation are given in Table 5.6.

\subsubsection{Cell structure and band diagram}

$\mathrm{p}-\mathrm{SnS} / \mathrm{n}-\mathrm{CdS}$ solar cell energy band diagram is given in Figure 5.9. The band diagram helps in explaining the property of a solar cell. From band diagram, it is visible that the SnS absorber material has an optimal band gap based on the theory presented by Shockley Queisser limit, whereas CdS is working as a buffer layer and its valance band offset with absorber stops the hole from getting into buffer layer.

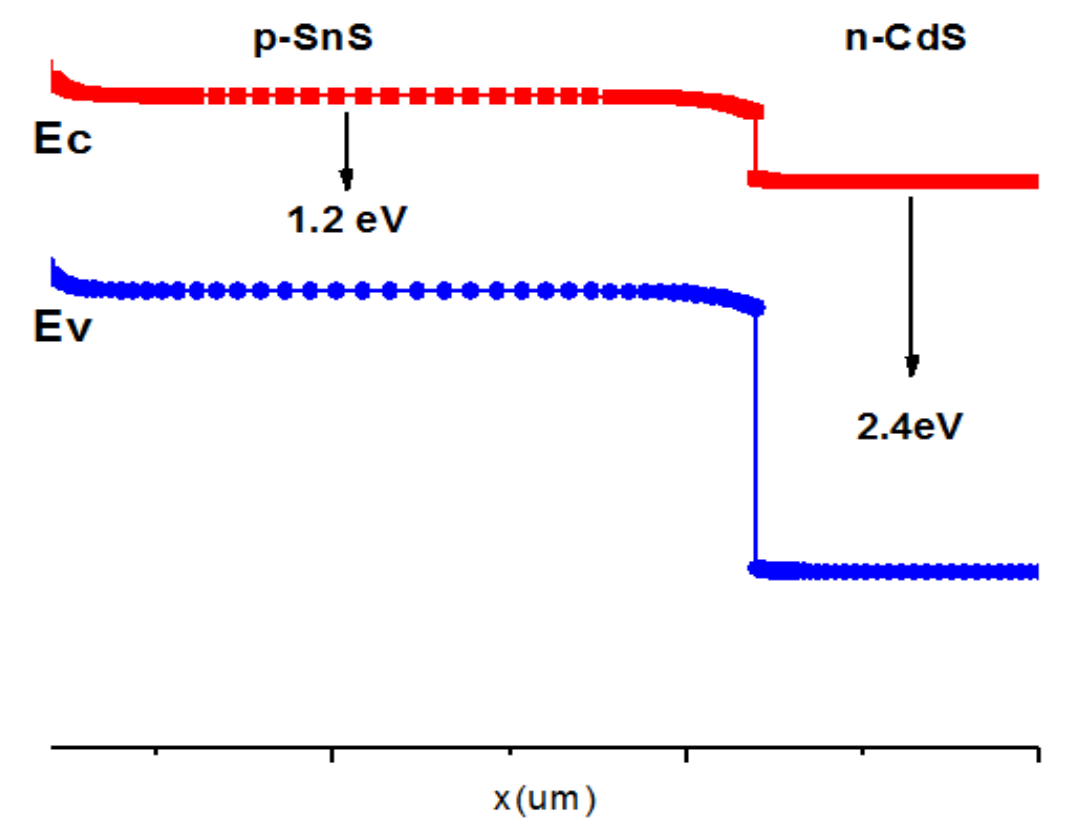

Figure 5.9: Cell structure and energy band diagram of proposed solar cell

\subsubsection{Results and Discussion}

To compare the simulated result with experimental work defect density was added between the interface of $\mathrm{SnS} / \mathrm{CdS}$ is $\mathrm{N}_{\mathrm{t}}=5 \times 10^{11}\left(\mathrm{~cm}^{-2}\right)$ with neutral charge distribution and the capture cross-section area of electrons and holes $\left(\mathbf{c m}^{2}\right)$ is $1.0 \times 10^{-15}$. For defect density in absorber layer table 5.7 is drawn below. 
Table 5.7: Defects in $S n S$ absorber layer according to references [101,104,105]

\begin{tabular}{lc}
\hline \multicolumn{1}{c}{ Defect properties } & Values \\
\hline Energy level with respect to Reference $(\mathrm{eV})$ & 0.200 \\
Total Density $\left(1 / \mathbf{c m}^{3}\right) \boldsymbol{N}_{\boldsymbol{t}}$ & $1.0 \times 10^{14}$ \\
Capture Cross section area of electrons $\left(\mathbf{c m}^{2}\right) \boldsymbol{\delta}_{\boldsymbol{e}}$ & $1.8 \times 10^{-12}$ \\
Capture Cross section area of holes $\left(\mathbf{c m}^{2}\right) \boldsymbol{\delta}_{\boldsymbol{h}}$ & $1.8 \times 10^{-12}$ \\
\hline
\end{tabular}

\section{i. Comparison of result with experimental work}

Figure 5.10 shows the results comparison of $S n S / C d S$ solar cell simulated in SCAPS and result taken from experimental work that was fabricated in [84]. From Figure 5.10 it is shown that the added defects in SCAPS for the analysis SnS/CdS solar cell can lead us to match the experimental results for a solar cell. Solar cell parameters used to derive the results in SCAPS are given in Table 5.8 with defects density given in Table 5.7.

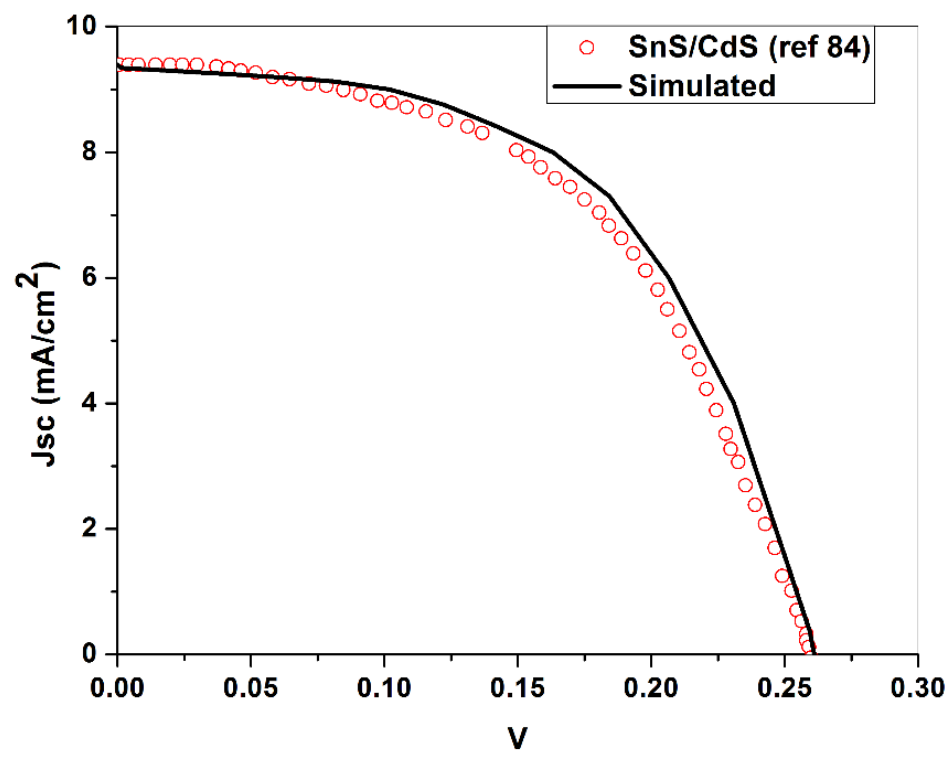

Figure 5.10: Comparison between experimental data (Ref. 84) and the simulation output using SCAPS.

Table 5.8: Parameters used to derive experimental results

\begin{tabular}{lcc}
\hline \multicolumn{1}{c}{ Parameters } & $\mathbf{n}-\mathbf{C d S}$ & SnS \\
\hline Thickness, $\mathrm{W}(\mu \mathrm{m})$ & 0.6 & 0.6 \\
Bandgap, Eg $(\mathrm{eV})$ & 2.42 & $1.2-1.4$ \\
Electron affinity, $\chi(\mathrm{eV})$ & 4.4 & $4-4.2$ \\
Dielectric permittivity, $\varepsilon / \varepsilon_{0}$ & 10 & 13 \\
Conduction band Density of states, $\mathrm{NC}\left(\mathbf{c m}^{-3}\right)$ & $2.28 \times 10^{18}$ & $1.18 \times 10^{18}$ \\
Valance band Density of states, $\mathrm{NV}\left(\mathbf{c m}^{-3}\right)$ & $1.7 \times 10^{19}$ & $4.76 \times 10^{18}$ \\
Electron mobility, $\mu_{\mathrm{e}}\left(\mathbf{c m}^{2} / \mathrm{Vs}\right)$ & 25 & 30 \\
\hline
\end{tabular}




\begin{tabular}{lcc}
\hline Hole mobility, $\mu_{\mathrm{p}}\left(\mathbf{c m}^{2} / \mathrm{Vs}\right)$ & 100 & 90 \\
concentration of Electron and hole, $\mathrm{n}, \mathrm{p}\left(\mathbf{c m}^{-3}\right)$ & $1 \times 10^{17}$ & $1 \times 10^{15}$ \\
\hline & Front Contact & Back contact \\
\hline Surface recombination velocity for electron $(\mathrm{cm} / \mathrm{s})$ & $1 \times 10^{7}$ & $1 \times 10^{7}$ \\
Surface recombination velocity for hole $(\mathrm{cm} / \mathrm{s})$ & $1 \times 10^{7}$ & $1 \times 10^{7}$ \\
\hline
\end{tabular}

\section{ii. Effect of buffer layer on solar cell performance}

In experimental work [84], the thickness of buffer layer was $0.6 \mu \mathrm{m}$ and with thicker buffer layer less photon will reach to absorber layer to participate in solar cell conversion efficiency. So, to improve the efficiency we optimize the thickness of buffer layer for $\mathrm{SnS} / \mathrm{CdS}$ solar cell. For this thickness of the buffer layer was varied from $0.1 \mu \mathrm{m}$ to $1 \mu \mathrm{m}$ in SCAPS while other parameters were kept constant. Figure 5.11 shows the results for the effect of buffer layer thickness on solar cell $\mathrm{J}-\mathrm{V}$ characteristics and performance.

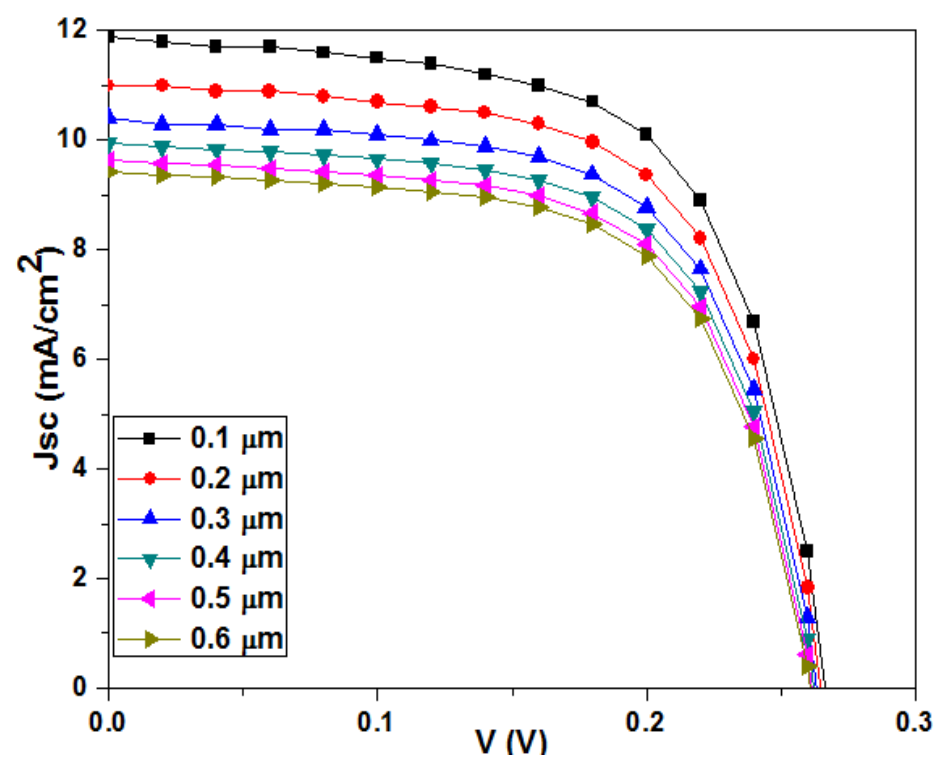

Figure 5.11: Buffer thickness effect on J-V characteristics

From Figure 5.12 the thinner buffer layer leads to efficient solar cell design because with thinner buffer layer more photon will reach the absorber layer and will take part in the enhancement of power conversion efficiency (PCE) of a solar cell. The optimal thickness chosen for the buffer layer is $0.1 \mu \mathrm{m}$.

\section{i. Effect of absorber layer on solar cell performance}

The thickness of the absorber layer was optimized by varying thickness of the absorber layer from $1 \mu \mathrm{m}$ to $6 \mu \mathrm{m}$ in SCAPS. Figure 5.13 shows the results for absorber layer thickness and from Figure 5.13 change in absorber thickness has a minor effect on the 
performance of a solar cell due to bulk recombination of defects in the absorber layer. Therefore, for our simulation from this point, the thickness for the absorber layer chosen for analyses was $2 \mu \mathrm{m}$. Based on thickness optimization of buffer and absorber layer the PCE can jump from $1.57 \%$ of to $2.1 \%$ with same defect values given in Table 5.7.
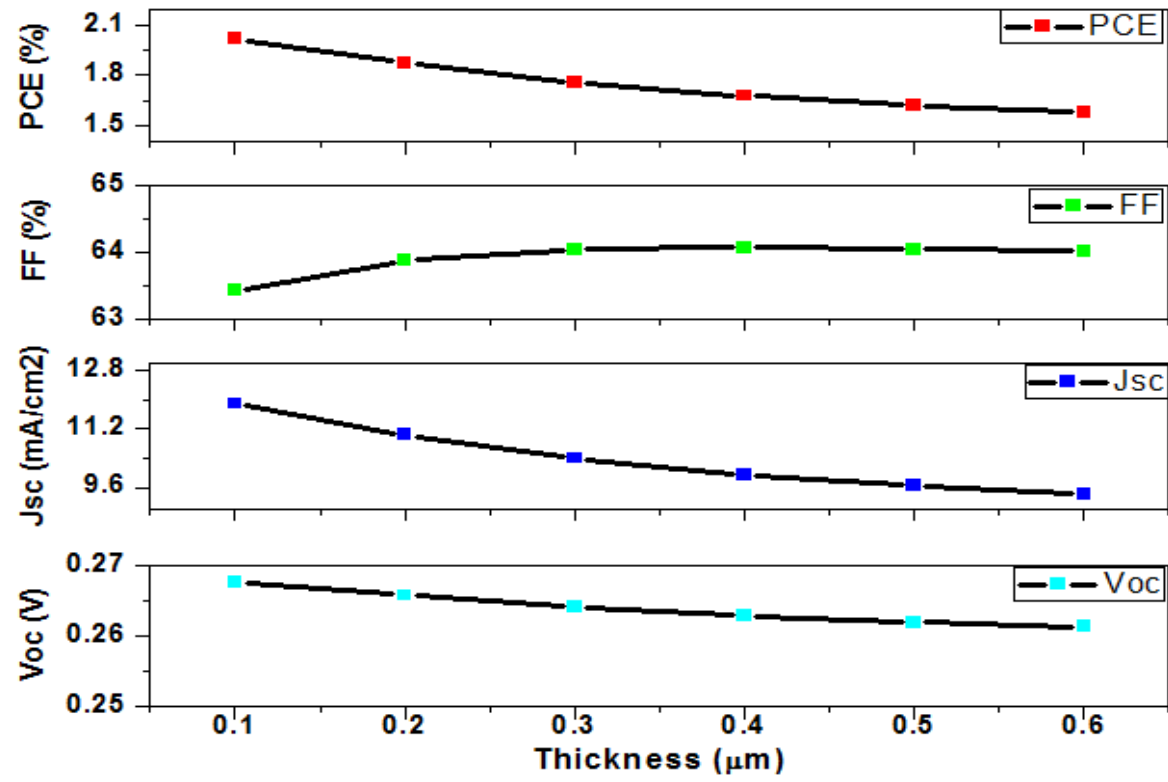

Figure 5.12: Buffer thickness effect on solar cell performance

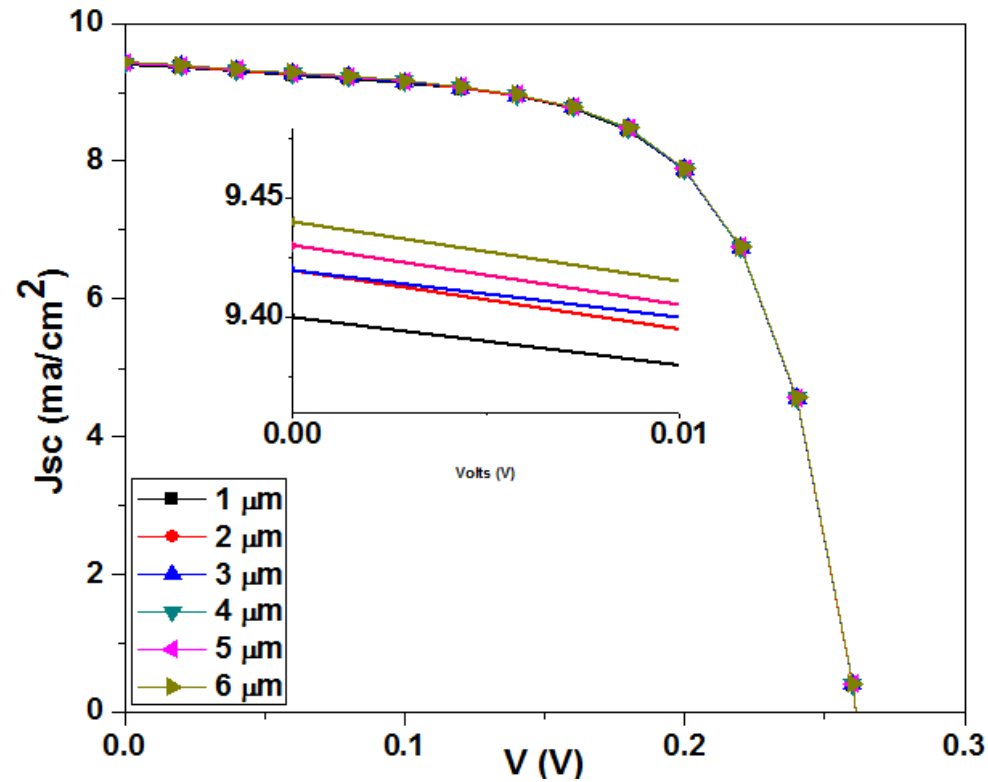

Figure 5.13: Absorber thickness effect on solar cell performance

\section{ii. Adding $\mathrm{ZnO}$ window layer in design}

To further improve the PCE of solar cell $\mathrm{ZnO}$ as window layer, was added to the simulation structure and Figure 5.14 shows the result for effect of $\mathrm{ZnO}$ window layer on solar cell performance. Because of the wide band gap of $\mathrm{ZnO}$ window layer more photons will be 
absorbed, and this can help to further improve the efficiency of experimental designed solar cell. This generalization is well explained with aid of results given in Figure 5.14 and Figure 5.15.

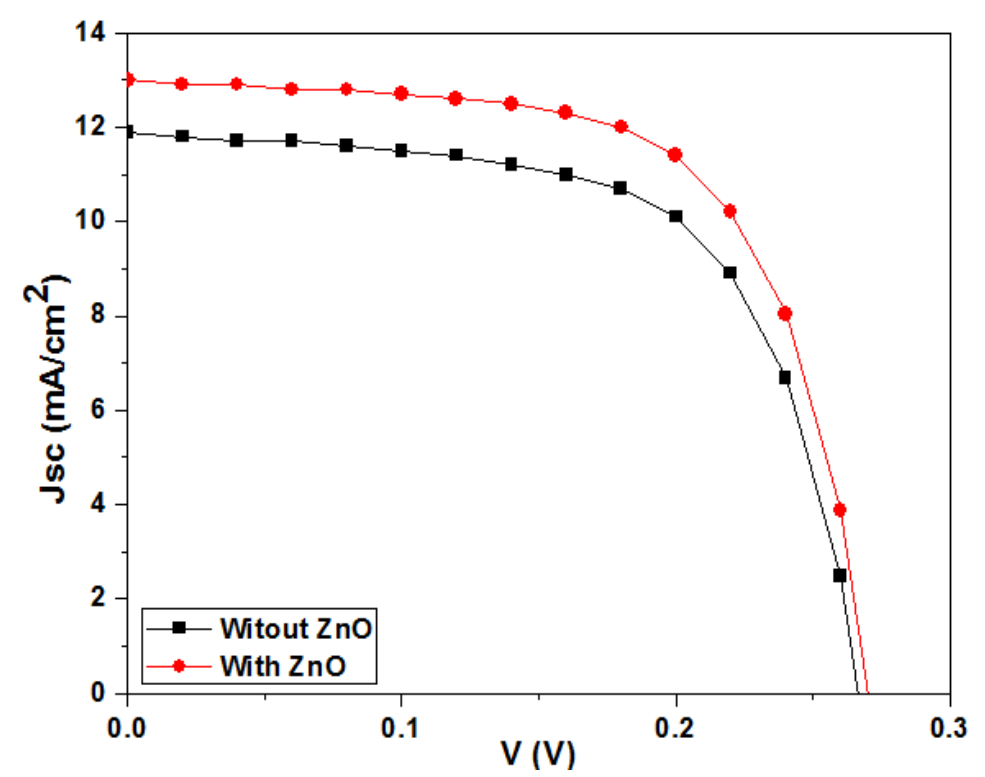

Figure 5.14: Window layer effect on solar cell performance

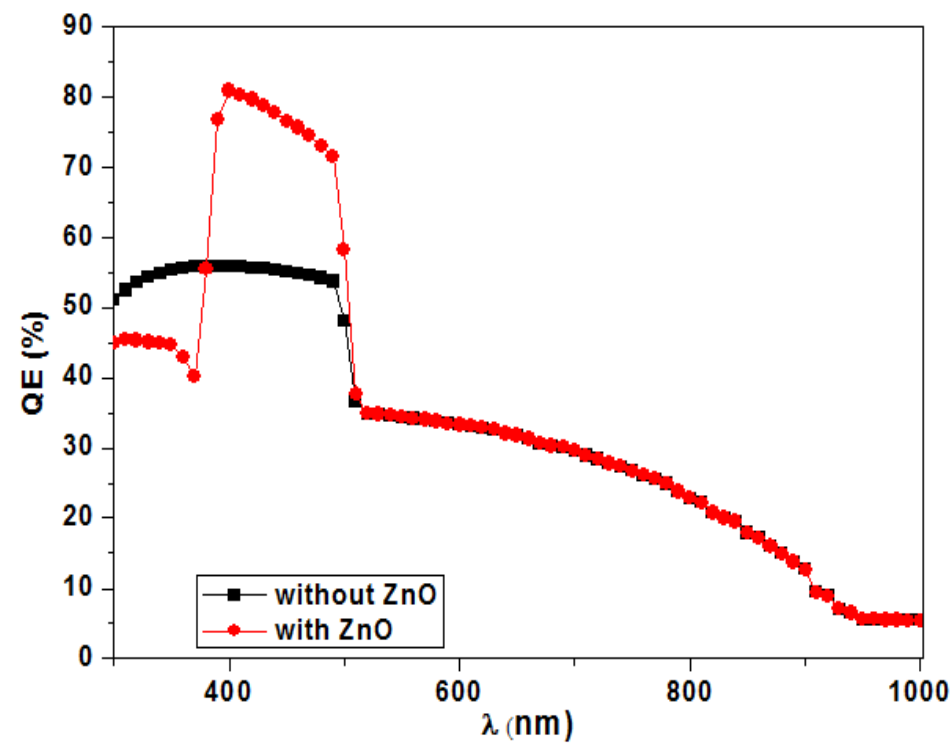

Figure 5.15: QE (\%) enhancement due to window layer

\section{iii. Effect of band gap on solar cell performance}

After the addition of the window layer, the PCE of solar cell simulated in SCAPS jumps to $2.29 \%$. The efficiency of a solar cell can further be improved by considering the optoelectronic characteristic of the device. As bandgap of material also plays a vital role in defining solar cell efficiency limits. Figure 5.16 shows the effect of band gap variation of SnS absorber material on solar cell PCE. And from Figure 5.16 this result can be 
comprehended that optimal band gap to achieve high PCE from SnS absorber material is $1.4 \mathrm{eV}$.

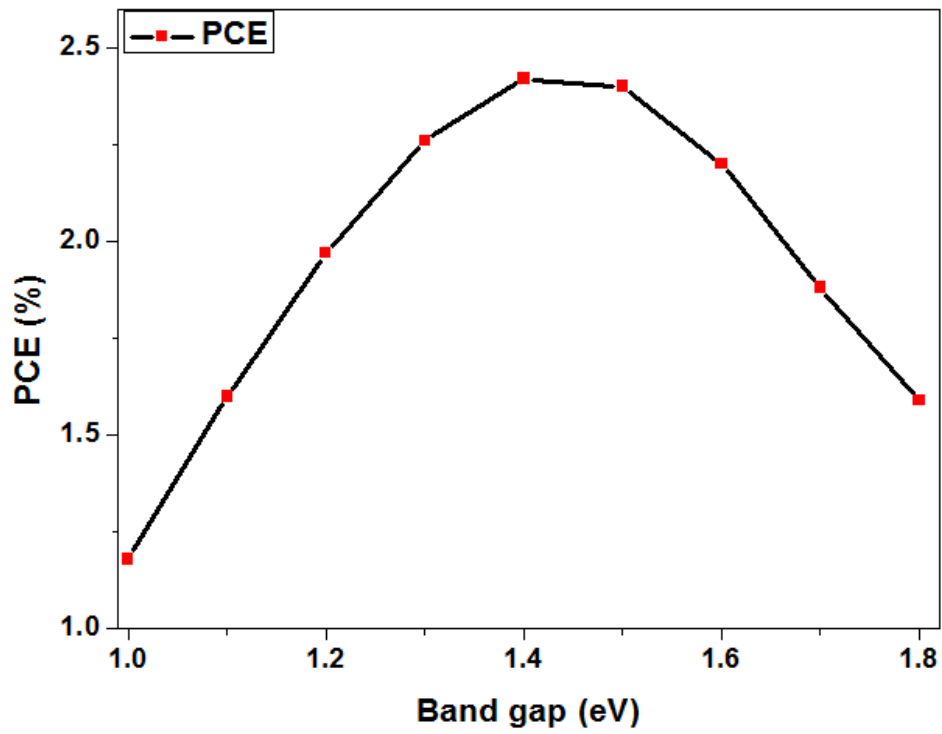

Figure 5.16: Bandgap variation effect on PCE

\section{iv. Effect of mobility and diffusion length on solar cell performance}

Impact of crystalline structure on solar cell performance can further be extended by analyzing the effect of minority carrier lifetime of $S n S$ absorber material. By improving bulk properties of SnS absorber layer minority carrier lifetime also improves, as minority carrier lifetime plays a key role in defining the efficiency of a solar cell [106,107]. Minority carrier lifetime is the average time required to the photogenerated carrier to recombine before reaching to contact and effect of minority carrier lifetime on solar cell performance is shown in Figure 5.17 and Figure 5.18. In Figure 5.17 with an increase in minority carrier lifetime the $\mathrm{J}-\mathrm{V}$ characteristics and solar cell performance shows remarkable improvements. This happens because with an increase in minority carrier lifetime defect density of SnS absorber material reduced. The relation between the minority carrier lifetime and defect density of the absorber layer is given in equation 5.8.

$$
\tau_{(n, p)}=\frac{1}{\delta_{(n, p)} v_{t h} N_{t}}
$$

$\delta_{(n, p)}$ is the capture cross-section area for electron and hole, $v_{t h}$ is the thermal velocity of carriers and $N_{t}$ is defect density in the absorber layer. So, if capture-cross section area and thermal velocity is constant than minority carrier lifetime has an inverse relation with defect density in absorber layer that why there is an improvement in solar cell performance. 


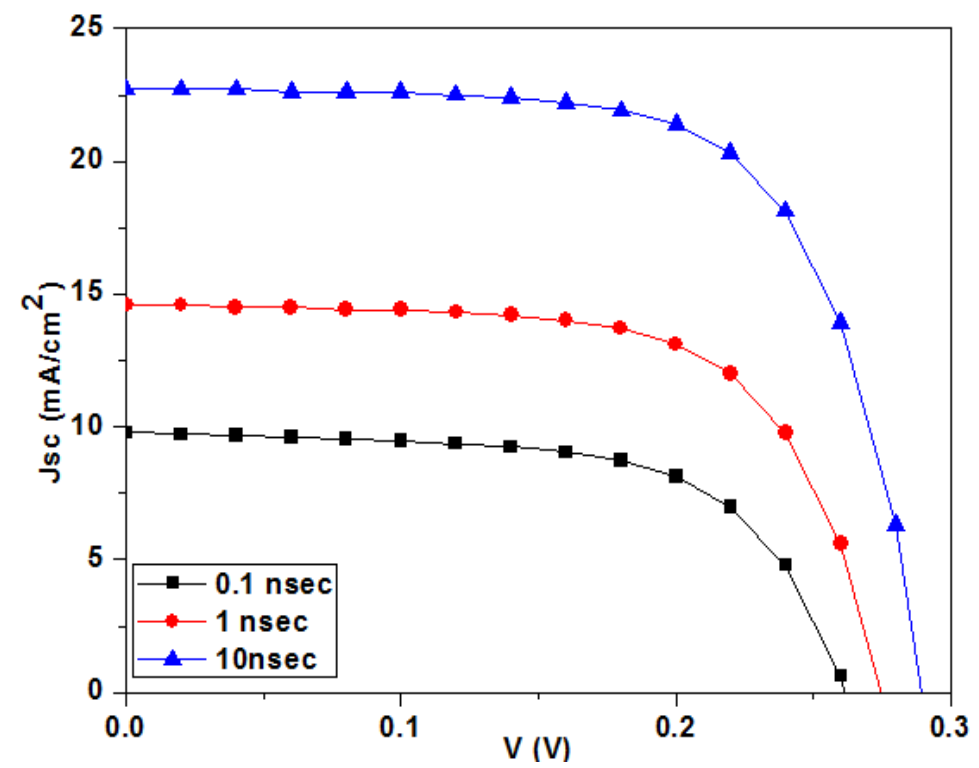

Figure 5.17: Minority carrier lifetime effect on J - V characteristics.
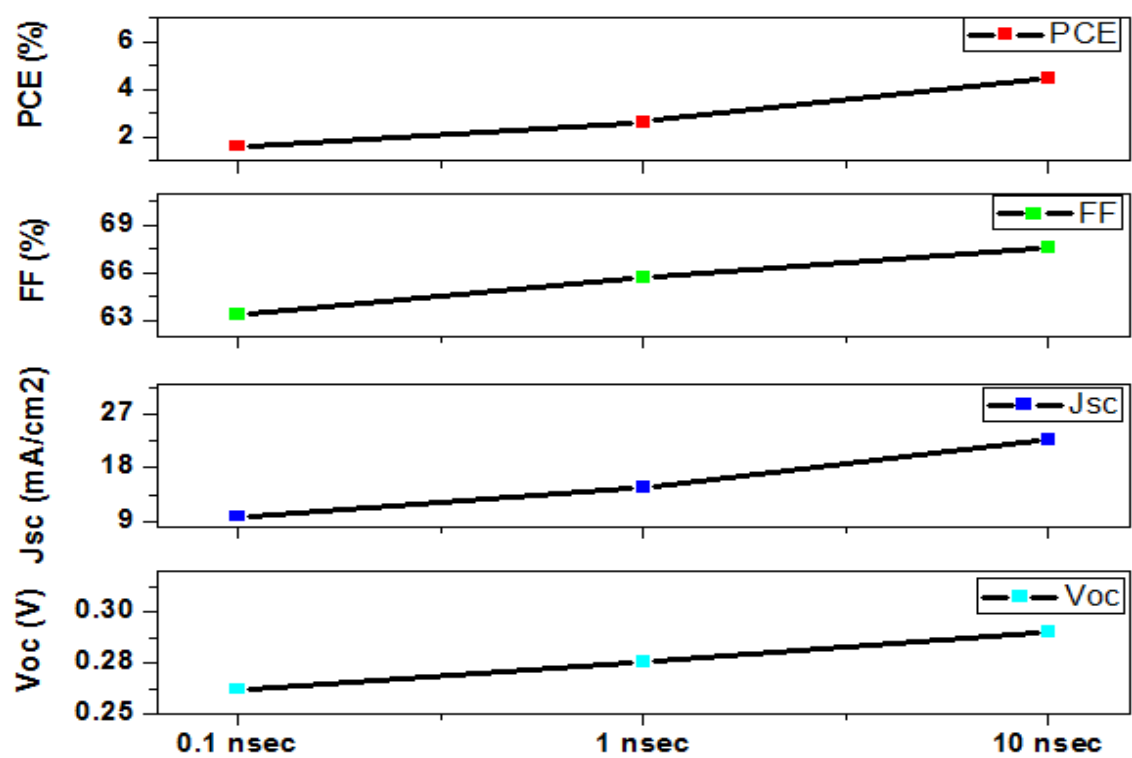

Figure 5.18: Minority carrier lifetime of SnS absorber layer effect of solar cell performance

The second parameter that affects the performance of a solar cell is the mobility of charge carrier in SnS absorber layer. And mobility is also depended upon crystal structure of SnS absorber material [108]. The relation of mobility with solar cell performance can be explained with the aid of equation 5.9.

$$
L_{D(n, p)}=\sqrt{\mu_{n, p} \frac{k T}{q} \tau_{(n, p)}}
$$

$\mathrm{L}_{(\mathrm{n}, \mathrm{p})}$ is the diffusion length of photogenerated carriers of SnS absorber layer and it is depended upon the product of carrier mobility and minority carrier lifetime. So, with an increase in mobility of carriers $\mathrm{L}_{\mathrm{D}(\mathrm{n}, \mathrm{p})}$ increases, and this also aids the photogenerated 
carriers to reach to contact without getting recombined. So, from equation 5.9 with an increase in mobility of carriers, PCE of the solar cell will also increase and for analysis to find the effect of mobility on solar cell performance a plot of $\mu_{n, p} v s$. PCE of $\mathrm{SnS} / \mathrm{CdS} / \mathrm{ZnO}$ solar cell is plotted in Figure 5.19. And with an increase in mobility PCE of solar cell also increases and this result can be comprehended that with an increase in carrier mobility solar cell performance will increase.

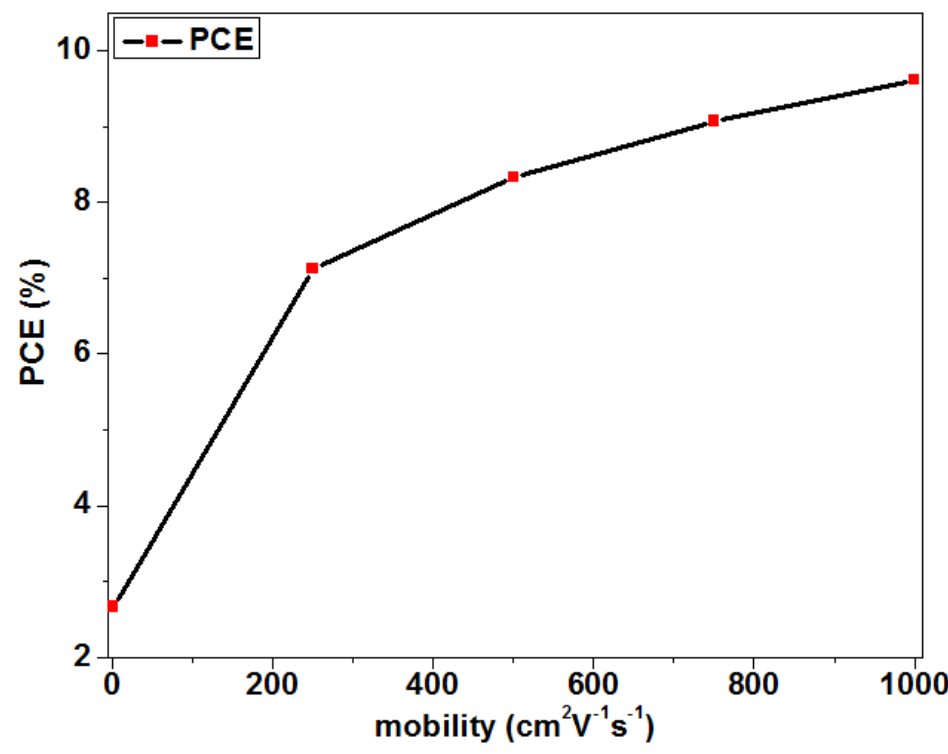

Figure 5.19: Mobility vs. PCE for SnS/CdS/ZnO solar cell

After the selection of optimal bandgap for SnS absorber material with carrier mobility given in Table 5.8 and improvements in minority carrier lifetime of the absorber layer, the PCE of solar cell improves to $4.47 \%$ with structure SnS/CdS/ZnO. To further increase the efficiency, we change the bulk properties of absorber and buffer layer by changing their doping density.

\section{v. Effect of absorber acceptor and buffer donor doping concentration}

Figure 5.20 shows the result for optimization of acceptor doping density of SnS absorber layer to further improve the efficiency of solar cell. The acceptor doping concentration was varied from $1 \times 10^{10} \mathrm{~cm}^{-3}$ to $1 \times 10^{17} \mathrm{~cm}^{-3}$, but in Figure 5.20 results are only plotted for $1 \times 10^{10} \mathrm{~cm}^{-3}$ to $1 \times 10^{15} \mathrm{~cm}^{-3}$ to get the optimum doping concentration value. With an increase in acceptor doping concentration the performance of solar cell decreased this happens due to high recombination in the absorber layer and at the interface with the presence of defects. The optimum value here chosen is $1 \times 10^{12} \mathrm{~cm}^{-3}$ on which the PCE of a solar cell is $12.16 \%$. 

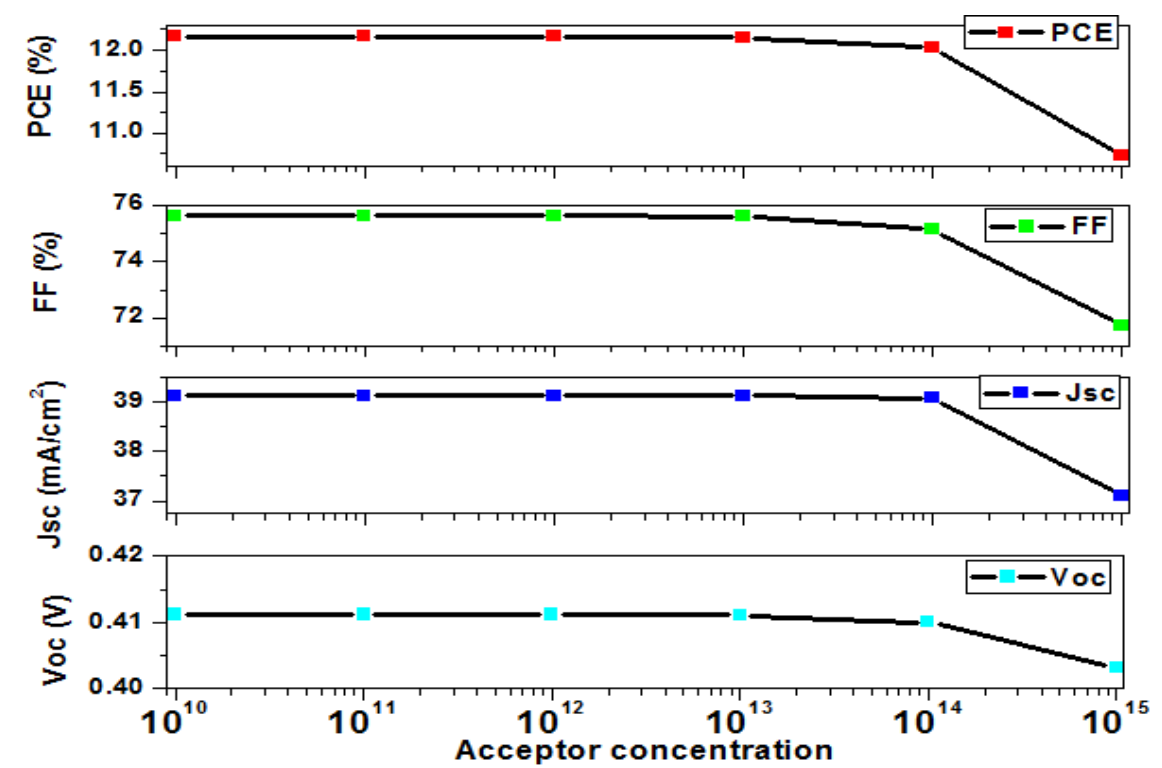

Figure 5.20: Acceptor doping concentration effect on solar cell performance

The effect of SnS acceptor doping concentration on solar cell band structure and build in potential is given in Figure 5.21 below. And form Figure 5.21 with an increase in acceptor doping concentration there is a decrease in built-in potential. So, a weaker potential will cause high interface recombination, and this leads to degradation in device performance.
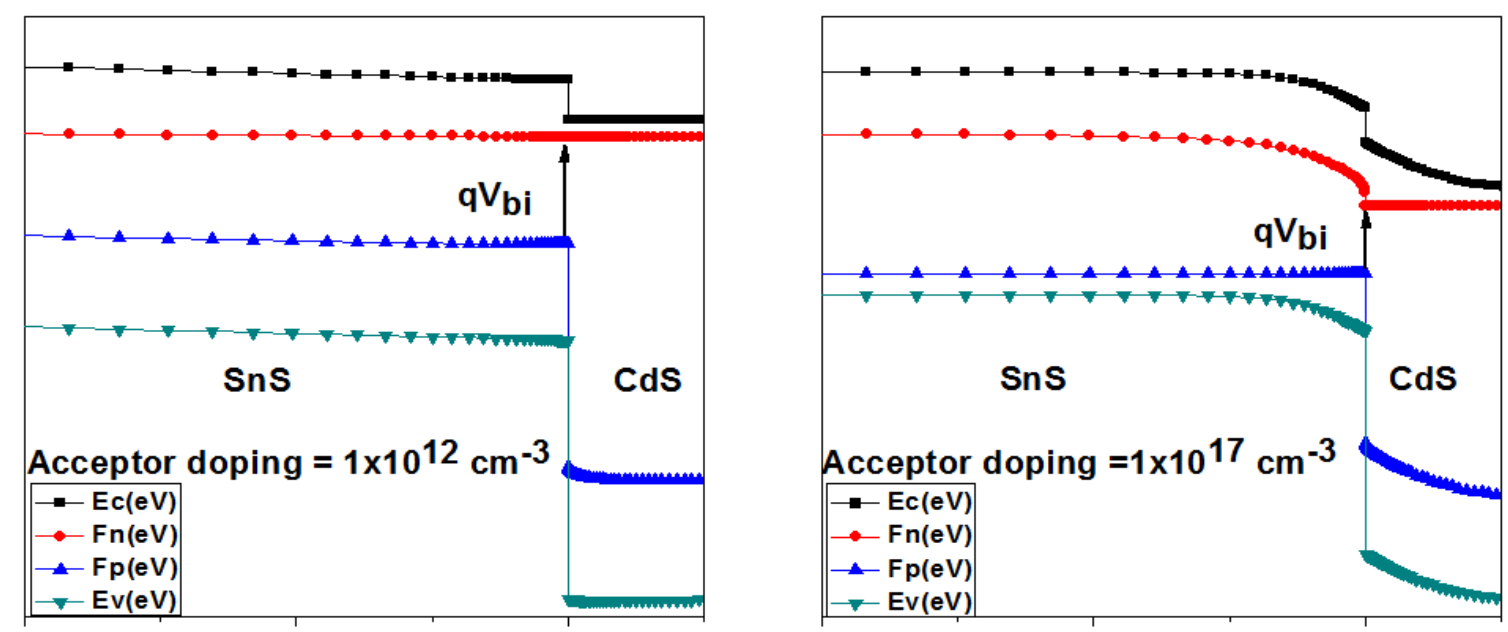

Figure 5.21: Band structure with different acceptor doping concentration

Figure 5.22 shows the result for donor doping concertation of buffer layer and the concentration of doping is varied from $1 \times 10^{16} \mathrm{~cm}^{-3}$ to $1 \times 10^{19} \mathrm{~cm}^{-3}$. With an increase in buffer layer donor doping concentration PCE of solar cell increases with FF. But at value of $1 \times 10^{18} \mathrm{~cm}^{-3} \mathrm{FF}$ starts to decrease with $\mathrm{J}_{\mathrm{sc}}$. So, the optimum value chosen for buffer donor doping density is $1 \times 10^{18} \mathrm{~cm}^{-3}$ on which the PCE of solar cell reached a value of $14.01 \%$. 

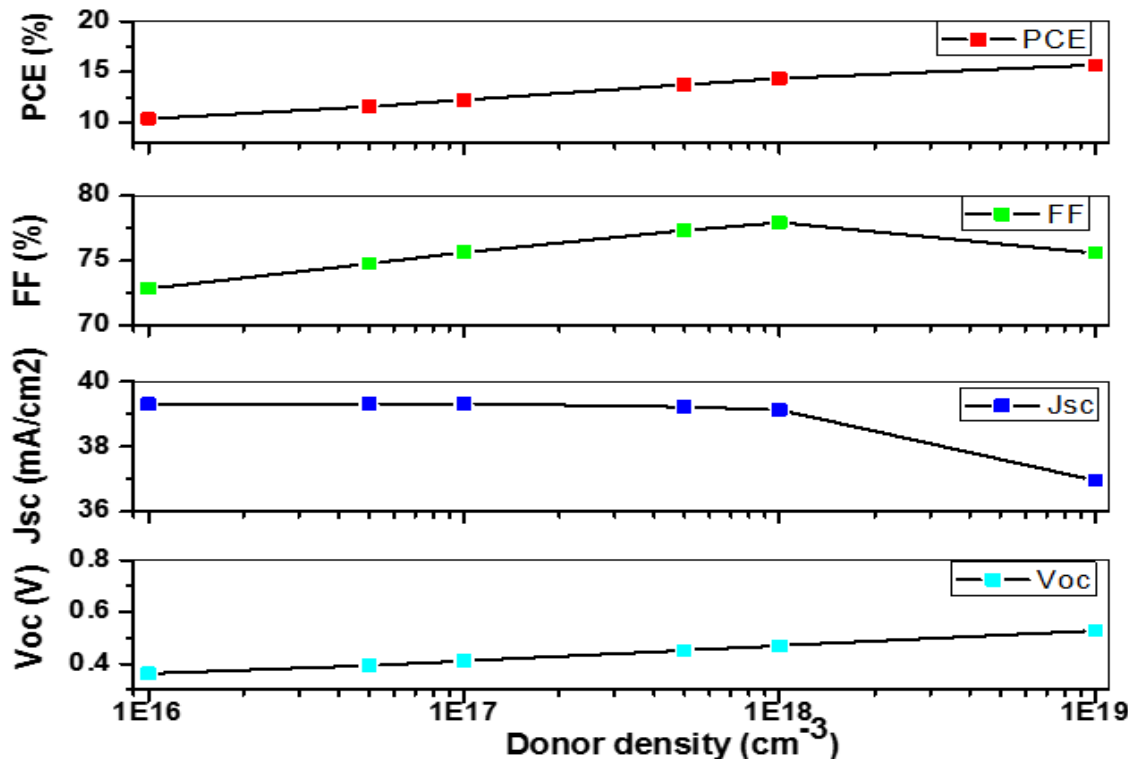

Figure 5.22: Effect of donor doping concentration of CdS layer on solar cell performance

\section{vi. Proposed design of solar cell}

Based on the above results if the structure of solar cell proposed in [84] with a careful design is updated to SnS/CdS/ZnO then the solar cell can reach to an efficiency of $14 \%$. Figure 5.23, Table 5.9 and Table 5.10 shows the comparison of experimentally simulated solar cell with and without optimization parameters.

(a) Experimental solar cell structure

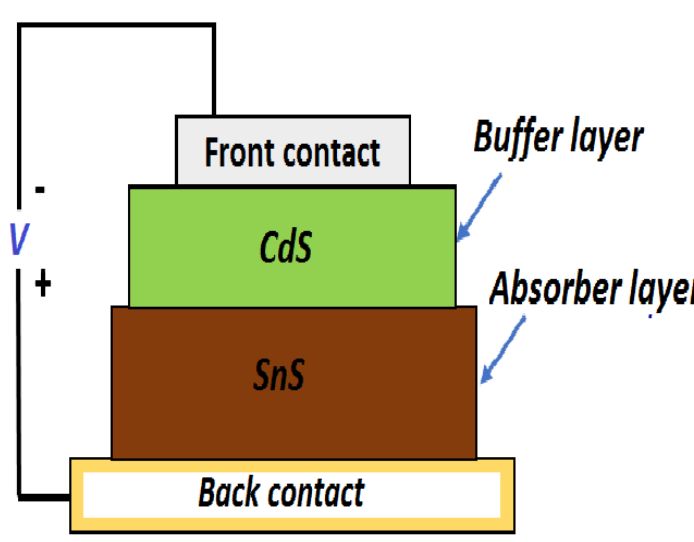

(b) Optimized new solar cell structure

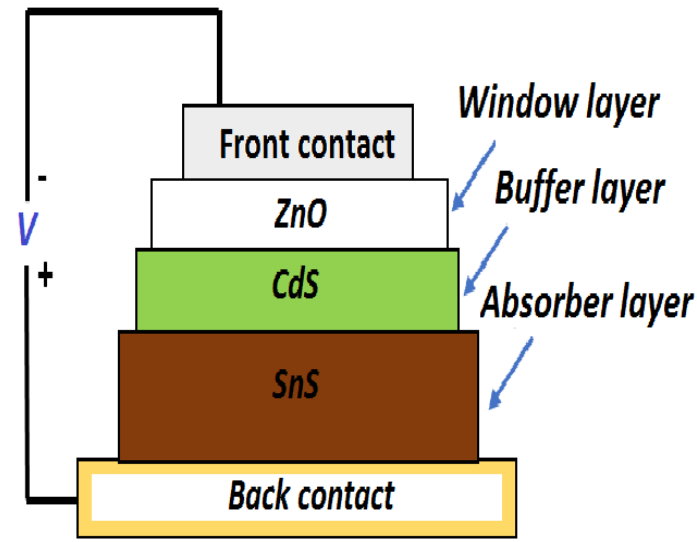

Figure 5.23: Comparison of structure between experimental and numerical optimized structure.

(a) shows the structure of experimental work with thickness of buffer layer $0.6 \mu \mathrm{m}$ and absorber thickness of $0.6 \mu \mathrm{m}$ (b) shows the structure of numerical optimized in SCAPS with buffer layer thickness of $0.1 \mu \mathrm{m}$ with $\mathrm{ZnO}$ thickness of $0.1 \mu \mathrm{m}$ and absorber layer thickness of $2 \mu \mathrm{m}$. 
CHAPTER 5 Efficiency Enhancement of Experimentally Designed Solar Cell

Table 5.9: Comparison of physical optimized parameters

\begin{tabular}{ccc}
\hline SnS & Without optimization & After optimization \\
\hline Thickness $(\mu \mathrm{m})$ & 0.6 & 2 \\
Acceptor Concentration $\left(\mathrm{cm}^{-3}\right)$ & $1 \times 10^{15}$ & $1 \times 10^{12}$ \\
\hline $\mathbf{C d S}$ & & \\
\hline Thickness $(\mu \mathrm{m})$ & Without optimization & After optimization \\
\hline Donor Concentration $\left(\mathbf{c m}^{-3}\right)$ & 0.6 & 0.1 \\
\hline
\end{tabular}

Table 5.10: Result comparison

\begin{tabular}{lccccc}
\hline & Cell Structure & $\begin{array}{c}\mathbf{V}_{\boldsymbol{o c}} \\
(\mathbf{V})\end{array}$ & $\begin{array}{c}\mathbf{J}_{\boldsymbol{s c}} \\
\left(\mathbf{m A} / \mathbf{c m}^{\mathbf{2}}\right)\end{array}$ & $\begin{array}{c}\text { PCE } \\
(\%)\end{array}$ & $\begin{array}{c}\mathbf{F F} \\
(\%)\end{array}$ \\
\hline Without optimization of parameters & SnS/CdS & 0.26 & 9.6 & 1.33 & 54.5 \\
With optimization of parameters & SnS/CdS/ZnO & 0.47 & 37.99 & 14.01 & 78.42 \\
\hline
\end{tabular}

\subsubsection{Conclusion}

We proposed a model guide about how numerical analysis can aid in the improvement of the power conversion efficiency of a solar cell. To perform analysis in first step experimental result was reproduced for SnS absorber layer based solar cell. In next step numerical analysis was performed in SCAPS to optimize the parameters of a solar cell like absorber layer thickness, buffer layer thickness, window layer effect, doping density and minority carrier lifetime. From observation, it was found that experimentally designed solar cell efficiency can be enhanced with the aid of numerical analysis. After optimization of physical parameters for solar cell PCE of $14.01 \%$ was achieved. The result presented in this work can provide a valuable guideline to a researcher for the efficient design of solar cell with optimized parameters. 


\section{CHAPTER 6}

EFFICIENCY ENHANCEMENT OF $\mathrm{CH}_{3} \mathrm{NH}_{3} \mathrm{SnI}_{3}$ SOLAR

CELL 
This page intentionally left blank 
Perovskite materials named after Russian mineralogist Lev Pervoski, the mineral was first discovered in 1839, in the Ural mountain of Russia [109]. The mineral with a chemical formula of $\mathrm{CaTiO}_{3}$, composed of calcium titanate. The name of this mineral was borrowed for a material having a crystal structure same as $\mathrm{CaTiO}_{3}$, known as perovskite structure. The perovskite mineral exits in nature in abundance and among them magnesium silicate perovskite is the most abundant one [110,111]. The chemical formula for perovskite material is AMX, where $\mathrm{A}$ and $\mathrm{M}$ are two different cations of varying sizes and $\mathrm{X}$ is an anion. These classes of devices have been under discussion for several decades but in the spring of 2009 methylammonium lead halide perovskite $\left(\mathrm{MAPbI}_{3}\right)$ was introduced with the name of visible light sensitizers for photovoltaic cells [112]. The first mesoporous $\mathrm{TiO}_{2}$ based $\mathrm{MAPbI}_{3}$ was sensitized with the conversion efficiency of $3.81 \%$ but the stability of the cell was very poor. After some year of extensive research in 2011 conversion efficiency of $\mathrm{MAPbI}_{3}$ is improved to $6.11 \%$ but stability was still poor until 2012, the efficiency of $\mathrm{MAPbI}_{3}$ jumped up to $9.7 \%$ with the solid hole transport layer Spiro-MeOTAD [113]. In 2013 the research in perovskite material has gained much attention because the reported conversion efficiency of perovskite material has reached to a value of $15 \%$ [114-118] and in 2014 the reported efficiency is of 17.9\% [119]. The fastgrowing in efficiency has triggered a tremendous amount of research in the fabrication and development of perovskite as an absorber layer for thin film solar cell. The major reason for the high efficiency of $\mathrm{MAPbI}_{3}$, is due to the high absorption coefficient and long carrier diffusion length [20-25,120-122]. Despite the rapid development in the design of $\mathrm{MAPbI}_{3}$ based solar cell the operation mechanism for further improvement in these devices is still not enough and some question still needs to be answered. Like stability of perovskite material, transportation of electron among $\mathrm{TiO}_{2}$ electron transport layer (ETL) and $\mathrm{TiO}_{2}$ deposition upon perovskite require high temperature and cost of hole transport material (HTM) like Spiro - OMETAD with gold or silver electrode [123-125].

Although improving in efficiency and simplification in process of perovskite fabrication still some drawback like stability and toxic nature of lead $(\mathrm{Pb})$ that hinders the way in the commercialization of $\mathrm{MAPbI}_{3}$ materials. Theoretical and experimental studies show that $\mathrm{CH}_{3} \mathrm{NH}_{3} \mathrm{SnI}_{3}\left(\mathrm{MASnI}_{3}\right)$ has an optimal band gap of $1.3 \mathrm{eV}$ and considered as a possible replacement for LHPSC. Due to its smaller bandgap, it can cover a wide range of the visible light spectrum, than the LHPSC. Tin $(S n)$ perovskite-based planner structure solar cell has been developed with heterostructure architecture [26-28]. The major limitation of 
$S n$ based perovskite is oxidation of $S n$ from $S n^{2+}$ to $S n^{4+}$ in the air which limits the performance of the device. With extensive research, development of encapsulation process increases the stability of the $S n$ based perovskite materials. By the addition of tin fluoride $\left(S n F_{2}\right)$ in the fabrication process reduces the chance of oxidation of $S n^{2+}$ to $S n^{4+}$ [29]. Moreover, like LHPSC its band gap can also be tuned by changing iodine $(I)$ with bromide $(\mathrm{Br})$ and with an addition of $\mathrm{Br}$ its bandgap increases. The tunability of bandgap provides an opportunity to use $S n$ based perovskite for solar cell application as a possible replacement for LHPSC [30].

Despite the rapid improvement in $S n$-based perovskite material still, PCE achieved from $S n$ based perovskite solar cell is very low. This is mainly due to the lack of understanding of device interface properties and effect of band structure at interfaces on device performance. Because with improvement in bulk material properties interface recombination remains very critical for device performance. To the best of our knowledge, there has been no report on a simulation model for $S n$-based perovskite solar cell for selection of an appropriate electron transport layer (ETL) for $\mathrm{MASnI}_{3}$ absorber material. In this chapter, we report on theoretical proven and experimentally expected effects of conduction band offset, the thickness of ETL and donor doping density of ETL layer on the performance of perovskite solar cell. Device simulation was carried out in solar cell capacitance simulator (SCAPS) developed by the University of Gent Belgium. SCAPS is a one-dimensional software used to calculate, band diagram, IV characteristic, quantum efficiency/spectral response (QE) and AC quantities. This program was mainly developed for the analysis of CIGS and CdTe solar cell and was widely used for the optimal design of (CIGS, CdTe) solar cells [76]. But recently, SCAPS has emerged as an alternate numerical tool for the analysis of kesterite and perovskite solar cell [126-131].

Our approach for the improvement of $\mathrm{MASnI}_{3}$ solar cell performance is by means of addressing the following facts:

i. Analyzing the effect of different ETL on solar cell performance.

ii. Effect of ETL conduction band offset on interface recombination and solar cell functional parameters.

iii. Effect of ETL thickness on interface recombination and solar cell performance parameters.

iv. Effect of ETL doping on interface recombination and solar cell performance parameters. 
v. Selection of ETL for $\mathrm{MASnI}_{3}$.

vi. Effect of absorber thickness on interface recombination and solar cell performance parameters.

vii. Effect of acceptor doping concentration on interface recombination and solar cell performance parameters.

viii. Effect of HTM layer on solar cell performance

The proposed results in this study will give a beneficial guideline for the designing of high performance $\mathrm{MASnI}_{3}$ based solar cells.

\subsection{Mitigation of interface recombination by careful selection of ETL for efficiency enhancement of MASnI3 solar cell [43]}

Lead halide perovskite solar cells (LHPSC) are of great potential for commercial application with conversion efficiency exceeding $20 \%$. But the toxic nature of lead, fabrication of perovskite solar cell is still not considered for commercial applications. Methylammonium tin halide perovskite $\left(\mathrm{MASnI}_{3}\right)$ is being used as an alternate absorber layer for replacement of LHPSC but the power conversion efficiency (PCE) achieved from $\mathrm{MASnI}_{3}$ solar cell is still far less from LHPSC. To investigate the limitation of $\mathrm{MASnI}_{3}$ solar cell performance numerical analysis was performed. For device modeling, different electron transport layer (ETL) and methylammonium tin halide $\left(\mathrm{MASnBr}_{3}\right)$ as the hole transport layer (HTL) was used. From the analysis it was revealed that open circuit voltage $\left(\mathrm{V}_{0 c}\right)$, short circuit current $\left(\mathrm{J}_{\mathrm{sc}}\right)$, fill factor $(\mathrm{FF})$ and PCE are highly depended on ETL conduction band offset (CBO) between ETL/Absorber $\left(\mathrm{MASnI}_{3}\right)$ interface, the thickness of ETL and donor doping concentration of ETL. With +CBO at the junction a "cliff" is formed at the interface, this leads to high interface recombination because of built-in potential to separate charge carriers. In contrast to - CBO a "spike" suppresses interface recombination, but a larger value of spike will lead to degradation of device performance. For selection of ETL, a moderate value of - CBO is required and this is achieved by changing elemental composition of ETL alloy materials $\left(\mathrm{Cd}_{1-\mathrm{x}} \mathrm{Zn}_{\mathrm{x}} \mathrm{S}, \mathrm{ZnS}_{1-\mathrm{x}} \mathrm{O}_{\mathrm{x}}\right)$. These materials are expected to provide higher conversion efficiency for $\mathrm{MASnI}_{3}$ solar cell. A novel concept in numerical modeling is presented which will categorically offer a new direction for the fabrication of high efficiency photovoltaic devices.

\subsubsection{Device physics}

Defects in perovskite solar cell are present at the interfaces between different layers and in absorber layer. The defect at interface arises because of lattice mismatch between two 
layers, size difference in grain boundaries and injection of impurities during junction formation [132]. Defects present at the interface create a trap state to capture electron and hole from either side of the junction (ETL side, Absorber side). The solar cell performance is highly degraded by interface recombination because recombination at interface reduced photocurrent of a solar cell and cause high diode current with a significant loss in $\mathrm{V}_{\mathrm{oc}}$. There are two types of band structure interfaces for ETL/Absorber that are plotted in Figure 6.1.
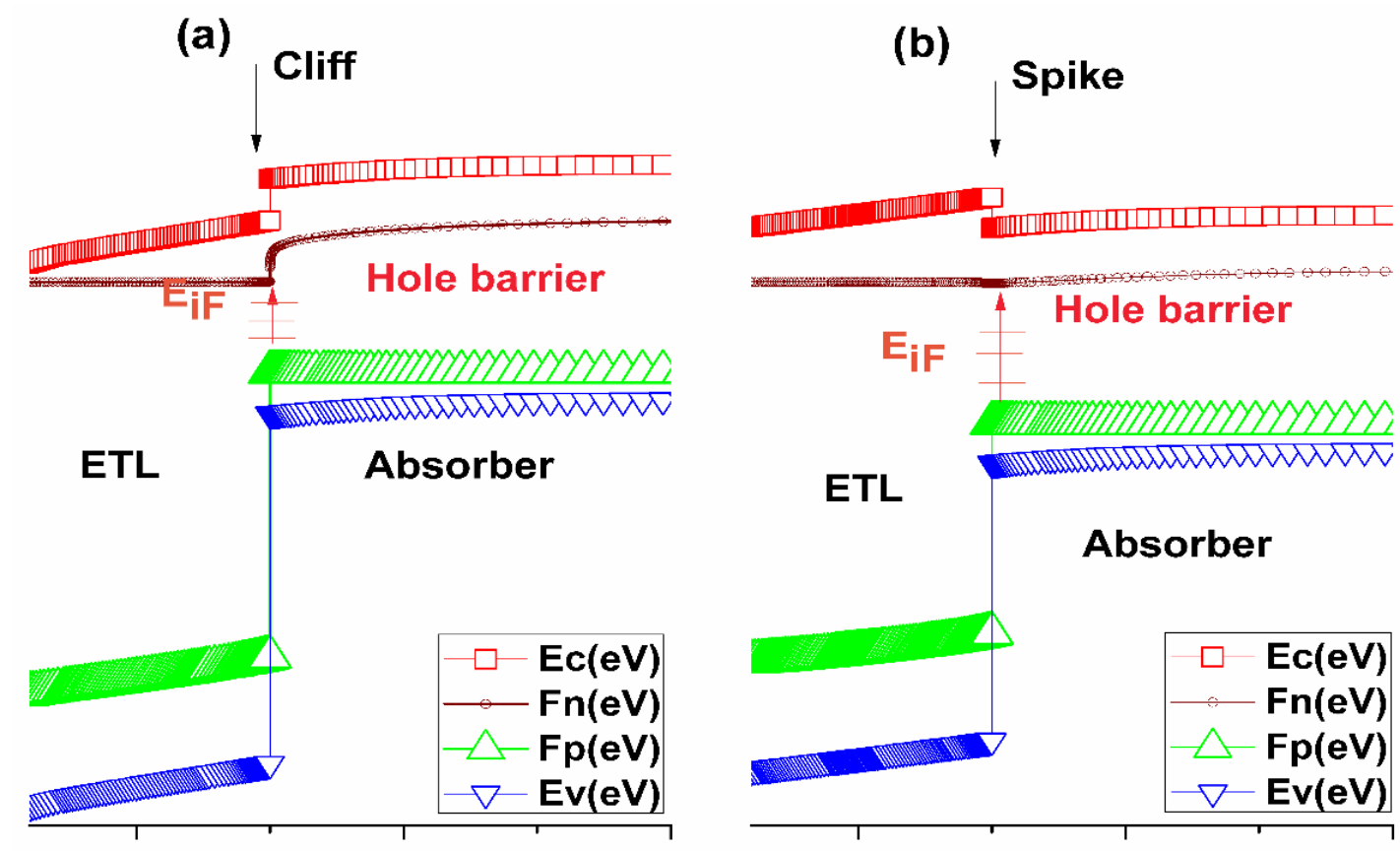

Figure 6.1: ETL/Absorber band structure diagram

Figure 6.1(a) has a cliff like band structure with a positive conduction band offset $\left(+\mathrm{CBO} /+\Delta \mathrm{E}_{\mathrm{c}}\right)$ between ETL/Absorber interface and for Figure 6.1(b) has a spike like band structure with a negative conduction band offset $\left(-\mathrm{CBO} /-\Delta \mathrm{E}_{\mathrm{c}}\right)$ between ETL/Absorber interface. The major difference between interface band structure under the forward biased condition is the build in potential at the interfaces which helps in charge separation of photogenerated charge carriers. The build in potential is represented as hole barrier for photogenerated holes and electron in Figure 6.1(a,b). From observation of Figure 6.1 that with cliff like structure $\left(+\Delta \mathrm{E}_{\mathrm{c}}\right)$ the value of built-in potential is smaller than that of a spike $\left(-\Delta \mathrm{E}_{\mathrm{c}}\right)$ which in terms affect the interface recombination. So, with $+\Delta \mathrm{E}_{\mathrm{c}}$ interface recombination will dominate with a comparison to spike.

Interface recombination for solar cell is depended upon an effective density of recombination center. This relation for interface recombination is expressed in equation $6.1[133]$. 


$$
\mathrm{R}_{\mathrm{iF}}=\frac{\mathrm{p}_{\mathrm{iF}} \mathrm{n}_{\mathrm{iF}}-\mathrm{n}_{\mathrm{i}}^{2}}{\mathrm{~S}_{\mathrm{p}}^{-1}\left(\mathrm{n}_{\mathrm{iF}}+\mathrm{n}\right)+\mathrm{S}_{\mathrm{n}}^{-1}\left(\mathrm{p}_{\mathrm{iF}}+\mathrm{p}\right)}
$$

$\mathrm{R}_{\mathrm{iF}}$ is total interface recombination where $\left(\mathrm{S}_{\mathrm{p}}, \mathrm{S}_{\mathrm{n}}\right)$ are the hole and electron interface recombination velocities. Recombination velocities for electron and hole are depended upon interface defect density $\left(\mathrm{N}_{\mathrm{t}(\mathrm{iF})}\right)$, thermal velocity of carrier $\left(\mathrm{v}_{\mathrm{th}}\right)$ (hole, electron) and capture cross area for electron and hole $\left(\delta_{n}, \delta_{p}\right)$. The relation for interface recombination is given in equation 6.2 .

$$
\mathrm{S}_{\mathrm{p}}=\mathrm{N}_{\mathrm{t}(\mathrm{iF})} \mathrm{V}_{\mathrm{th}} \delta_{\mathrm{p}}
$$

$\left(\mathrm{p}_{\mathrm{iF}}, \mathrm{n}_{\mathrm{iF}}\right)$ are the electron and hole concentration at the interface, and they determine the availability of carrier for interface recombination. Quantities ( $p=$ $\left.\mathrm{N}_{\mathrm{V}} \mathrm{e}^{-\left(\mathrm{E}_{\mathrm{iF}}-\mathrm{E}_{(\mathrm{V}, \mathrm{iF})}\right)} / \mathrm{kT}, \mathrm{n}=\mathrm{N}_{\mathrm{c}} \mathrm{e}^{-\left(\mathrm{E}_{(\mathrm{c}, \mathrm{iF})}-\mathrm{E}_{\mathrm{iF}}\right)} / \mathrm{kT}\right)$ are related to emission rate from defect energy state to the corresponding band edges $\left(\mathrm{E}_{\mathrm{c}}, \mathrm{E}_{\mathrm{V}}\right.$, ) at interface.

The effect of ETL CBO on solar cell performance parameters was analyzed in SCAPS software developed by the University of Gent Belgium. The basic solar cell structure that was simulated in SCAPS to analyze the effect of different ETL's CBO on solar cell performance given in Figure 6.2 and basic simulation parameters for given structure in SCAPS are given in Table 6.1, Table 6.2, Table 6.3 and Table 6.4. In table 6.3 neutral defect is an idealization of defects that only contribute to Shockley-Read-Hall recombination but does not contribute to the space charge.

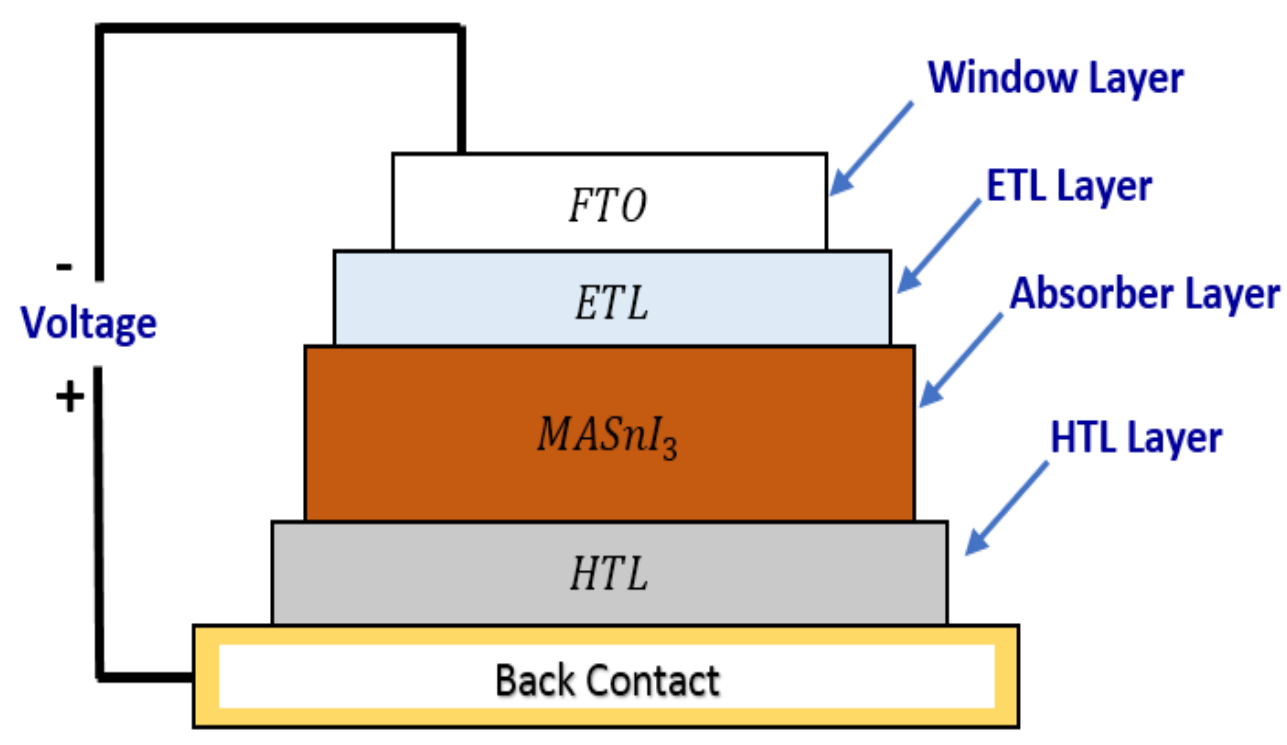

Figure 6.2: Solar cell structure 
Table 6.1: Parameters for SCAPS [134].

\begin{tabular}{lcccc}
\hline \multicolumn{1}{c}{ SCAPS Parameters } & $\begin{array}{c}\text { FTO } \\
\left(\mathbf{S n O}_{\mathbf{2}}\right)\end{array}$ & $\mathbf{E T L}$ & $\begin{array}{c}\text { Absorber } \\
\left(\mathbf{M A S n I}_{\mathbf{3}}\right)\end{array}$ & $\begin{array}{c}\text { HTL } \\
\left(\mathbf{M A S n B r}_{\mathbf{3}}\right)\end{array}$ \\
\hline Thickness $(\mathrm{nm})$ & 500 & $0.1 \sim 1000$ & $0.1 \sim 1000$ & 200 \\
CB effective DOS $\left(\mathrm{cm}^{-3}\right)$ & $10^{19}$ & $2.8 \times 10^{18}$ & $1 \times 10^{18}$ & $1 \times 10^{18}$ \\
VB effective DOS $\left(\mathrm{cm}^{-3}\right)$ & $10^{19}$ & $3.9 \times 10^{18}$ & $1 \times 10^{18}$ & $1 \times 10^{18}$ \\
Doping density $\left(\mathrm{cm}^{-3}\right)$ & $\mathrm{n}-2 \times 10^{19}$ & $\mathrm{n}-1 \times 10^{17}$ & $\mathrm{p}-1 \times 10^{14} \sim 1 \times 10^{17}$ & $\mathrm{p}-1 \times 10^{18}$ \\
Permittivity & 9 & 10 & 8.2 & 8.2 \\
Electron affinity $(\mathrm{eV})$ & 4 & Table 4 & 4.17 & 3.39 \\
Band Gap $(\mathrm{eV})$ & 3.50 & Table 4 & 1.3 & 2.15 \\
Electron/Hole mobility $\left(\mathrm{cm}^{2} / \mathrm{Vs}\right)$ & $100 / 25$ & $100 / 25$ & $1.6 / 1.6$ & $1.6 / 1.6$ \\
\hline
\end{tabular}

Front Contact Back contact

Surface recombination velocity for electron $(\mathrm{cm} / \mathrm{s})$

$\begin{array}{ll}1 \times 10^{7} & 1 \times 10^{7} \\ 1 \times 10^{7} & 1 \times 10^{7}\end{array}$

Surface recombination velocity for hole $(\mathrm{cm} / \mathrm{s})$

Table 6.2: Interface Defects

\begin{tabular}{ccc}
\hline \multicolumn{1}{c}{ Defect layer properties } & ETL/MASnI & MASnI $_{3} /$ \\
\hline Capture cross section area of electron/hole & $1.0 \times 10^{-15} \mathrm{~cm}^{2}$ & $1.0 \times 10^{-}$ \\
\hline Density of defect & $1.0 \times 10^{13} \mathrm{~cm}^{-2}$ & $1.0 \times 10^{13}$ \\
\hline Table 6.3: Defect layer properties (Neutral) & \\
\cline { 2 - 2 } Defect layer properties & MASnI $_{3}$ \\
\hline Capture cross section area of electron/hole & $1.0 \times 10^{-15} \mathrm{~cm}^{2}$ \\
Density of defect & $1.0 \times 10^{15} \mathrm{~cm}^{-3}$ \\
\hline
\end{tabular}

Table 6.4: Different ETL layers

\begin{tabular}{ccccc}
\hline Semiconductor & Band gap $\left(\mathbf{E}_{\mathbf{g}}(\mathbf{e V})\right)$ & Electron affinity $(\boldsymbol{\chi}(\mathbf{e V}))$ & Reference & $\mathbf{C B O}$ \\
\hline $\mathbf{C d S}$ & 2.4 & 4.4 & {$[135]$} & +0.23 \\
$\mathbf{T i O}_{\mathbf{2}}$ & 3.4 & 4.0 & {$[136]$} & -0.17 \\
$\mathbf{Z n S}$ & 3.76 & 3.44 & {$[137]$} & -0.57 \\
$\mathbf{I n}_{\mathbf{2}} \mathbf{S}_{\mathbf{3}}$ & 2.1 & 4.65 & {$[138]$} & +0.48 \\
$\mathbf{S n S}_{\mathbf{2}}$ & 2.38 & 4.16 & {$[139]$} & -0.01 \\
$\mathbf{Z n O}$ & 3.3 & 4.4 & {$[140]$} & +0.23 \\
$\mathbf{Z n S e}$ & 2.92 & 3.99 & {$[141]$} & -0.18 \\
$\mathbf{C a M n O}_{\mathbf{3}}$ & 1.7 & 4.2 & {$[142]$} & +0.03 \\
\hline
\end{tabular}




\subsubsection{Results and discussion}

Conversion of light energy into electrical energy is the main function of the photovoltaic cell. In the dark when there is no light, the photovoltaic solar cell acts as a large flat diode and produces the exponential $\mathrm{J}-\mathrm{V}$ curve. Under illumination condition solar cell starts working and current flows due to charge carriers generated by the incidence photons. Figure 6.3 shows J - V characteristic for different ETL applied to the solar cell structure. Results presented in Figure 6.3 shows that ETL having a -CBO with absorber layer gives maximum performance under illumination condition. CBO for different ETL are given in Table 6.4 and it was found that $\mathrm{TiO}_{2}$ and $\mathrm{ZnSe}$ gives good results.

From results plotted in Figure 6.3, it was comprehended that CBO between ETL/Absorber greatly affect the solar cell performance because CBO has a major impact on band bending. $\mathrm{A}-\mathrm{CBO}$ at the interface will induce a strong band bending and a good built-in potential to separate charge carriers at an interface. Whereas less band bending produces a smaller value of built-in potential barrier and this term increase interface recombination in a solar cell as shown in Figure 6.1(a) for +CBO [143].

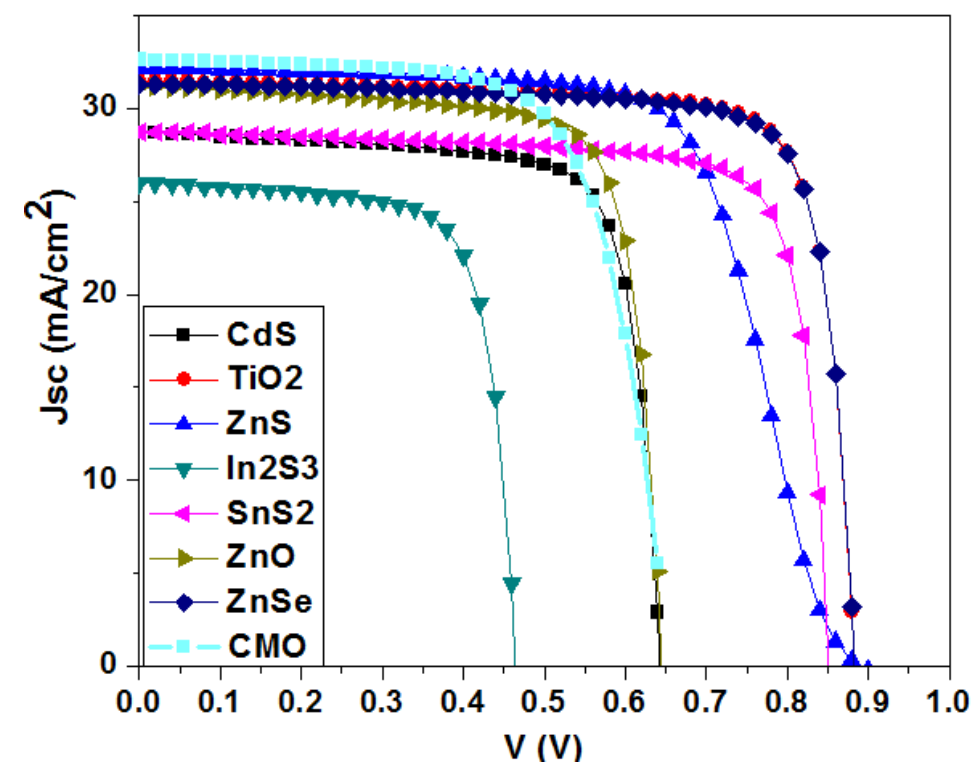

Figure 6.3: ETL effect on solar cell performance

\section{i. Effect of ETL CBO on J - V characteristics and interface recombination}

The key element in Interface recombination that results in loss of $V_{0 c}$ of solar cell is $\left(S_{p}\right.$, $\left.\mathrm{S}_{\mathrm{n}}\right)$ and $\left(\mathrm{p}_{\mathrm{iF}}, \mathrm{n}_{\mathrm{iF}}\right)$. Factors like $\left(\mathrm{S}_{\mathrm{p}}, \mathrm{S}_{\mathrm{n}}\right)$ cannot be controlled as interface recombination velocities are depended upon material interface properties but other parameters $\left(\mathrm{p}_{\mathrm{iF}}, \mathrm{n}_{\mathrm{iF}}\right)$ can be controlled by band alignment of ETL/Absorber, ETL thickness, and doping optimization. Effect of $\mathrm{CBO}$ on $\mathrm{V}_{\mathrm{oc}}$ was evaluated by assuming a mid-gap acceptor type 
trap state at the interface with (donor concentration of ETL $\mathrm{N}_{\mathrm{d}}>\mathrm{N}_{\mathrm{a}}$ acceptor concentration of absorber). Based on assumption that $\mathrm{n}_{\mathrm{iF}}>\mathrm{p}_{\mathrm{iF}}$ and neglecting $\mathrm{n}, \mathrm{p}, \mathrm{n}_{\mathrm{i}}^{2}$ equation 6.1 can be rewritten and is given in equation 6.3 .

$$
\mathrm{R}_{\mathrm{iF}}=\mathrm{S}_{\mathrm{p}} \mathrm{p}_{\mathrm{iF}}
$$

From equation 6.3 interface recombination is dominated by recombination velocity of holes and holes concentration of absorber side. CBO was adjusted by moving conduction band minimum towards vacuum energy level and keeping valance band position constant. For analysis, $\mathrm{CBO}$ was varied from $\mathrm{CBO}=+0.2 \mathrm{eV}$ to $\mathrm{CBO}=-0.2 \mathrm{eV}$. Figure 6.4 shows the results for band diagrams with the different values of CBO. From Figure 6.4(a) with cliff like conduction band alignment, the built-in potential is very small and that allows a significant number of holes to recombine with the electrons without getting separated at the interface. This results in a significant increase in carrier recombination and a loss to $\mathrm{V}_{\mathrm{oc}}$. While in Figure 6.4(b) with a spike the built-in potential is quite high thus resulting a strong force to separate charge carriers before recombining at an interface and results in reduced interface recombination with improvement in $\mathrm{V}_{\mathrm{oc}}$ of a solar cell. But a very high spike that is shown in 6.4(c), impedes the flow of electron and effect device performance causes a loss in FF (\%) of a solar cell. The detail of the CBO effect on $\mathrm{V}_{\mathrm{oc}}$ is well explained with the aid of equation 6.4 [133,144].

$$
\mathrm{V}_{\mathrm{oc}}=\frac{\mathrm{E}_{\mathrm{A}}}{\mathrm{q}}-\frac{\mathrm{nKT}}{\mathrm{q}} \ln \left(\frac{\mathrm{J}_{00}}{\mathrm{~J}_{\mathrm{sc}}}\right)
$$

$\mathrm{V}_{\mathrm{oc}}$ is open circuit voltage, $\mathrm{E}_{\mathrm{A}}$ is activation energy, $\mathrm{n}$ is diode ideality factor, $\mathrm{K}$ is Boltzmann's constant, $\mathrm{T}$ is a temperature in Kelvin, $\mathrm{J}_{00}$ is current prefactor and $\mathrm{J}_{\mathrm{sc}}$ is short circuit current. From equation 6.4 with an increase in temperature $V_{o c}$ will decrease. For analysis operating temperature of the solar cell was varied from $280 \mathrm{~K}$ to $400 \mathrm{~K}$. Result for effect of temperature on $\mathrm{V}_{\mathrm{oc}}$ is plotted in Figure 6.5 with different $\mathrm{CBO}$ and from Figure 6.5 with an increase in temperature for $\mathrm{CBO}(+)$ loss in $\mathrm{V}_{\mathrm{oc}}$ is higher than for $\mathrm{CBO}(-)$. If the assumption was made that $\mathrm{J}_{00}, \mathrm{n}$, and $\mathrm{J}_{\mathrm{sc}}$ are temperature independent than the plot of $\mathrm{V}_{\mathrm{oc}} \mathrm{vs} \mathrm{T}$ will give a straight line and its linear interpolation at $\mathrm{T}=0 \mathrm{~K}$ will give $\mathrm{V}_{\mathrm{oc}}=\mathrm{E}_{\mathrm{A}} / \mathrm{q}$ where $E_{A}=E_{g}-\Delta E_{c}$ as given in the literature [145].' So, with linear interpolation of data given in Figure 6.5, $\mathrm{V}_{\mathrm{oc}}$ is equal to band gap for $\mathrm{MASnI}_{3}$ given in Table 6.1 for spike interface and whereas for cliff interface $\mathrm{V}_{\mathrm{oc}}$ is less than the band gap of $\mathrm{MASnI}_{3}$. So, from Figure 6.5 this result was comprehended and as discussed in previous reports that although 
there is no barrier for transfer of electron charge for $+\mathrm{CBO}, \mathrm{V}_{\mathrm{oc}}$ will monotonically decrease with increase in $+\mathrm{CBO}$ value due to the decrease in $\mathrm{E}_{\mathrm{A}}$ [143]

(a) Cliff

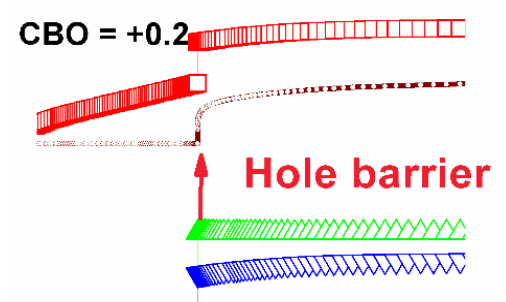

ETL

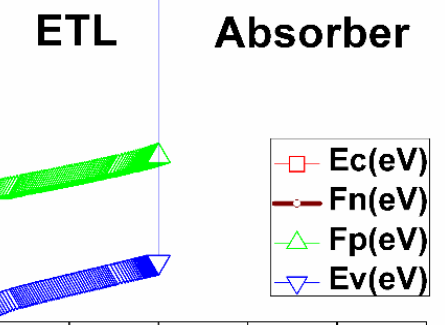

(b)
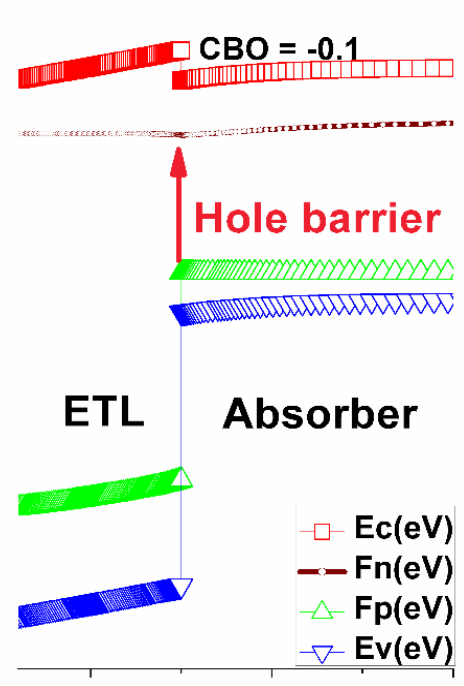

Spike

(c)

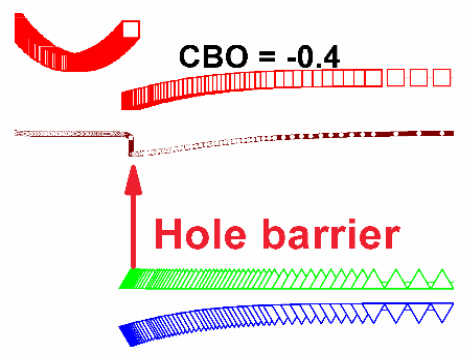

ETL Absorber

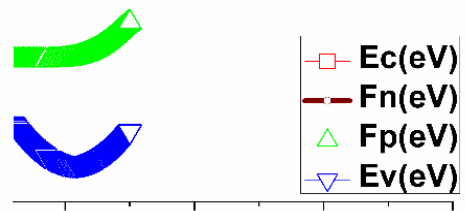

Figure 6.4: Different band diagram with different values of $\mathrm{CBO}$

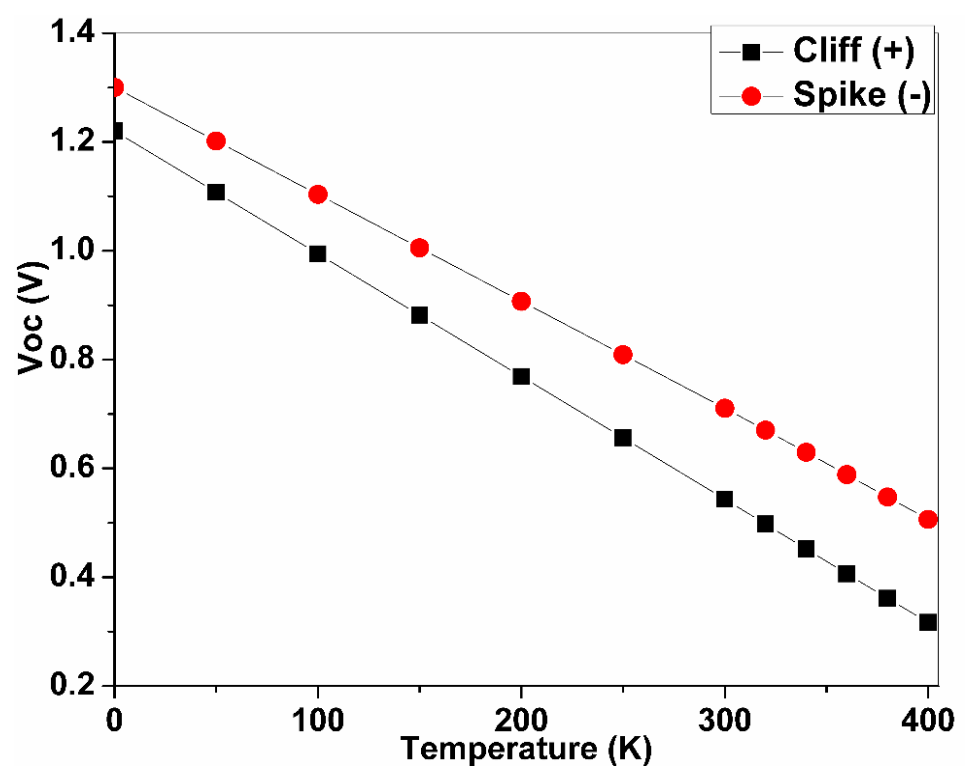

Figure 6.5: Temperature vs $\mathrm{V}_{\text {oc }}$ with data extrapolated to $0 \mathrm{~K}$

The effect of CBO on $\mathrm{J}-\mathrm{V}$ characteristics of the solar cell are plotted in Figure 6.6 below. From Figure 6.6 with a large conduction band offset there is no loss in $V_{\text {oc }}$ but there a reduction in $\mathrm{J}_{\mathrm{sc}}$. Based on results optimized band offset for $\mathrm{MASnI}_{3}$ is $\mathrm{CBO}(-0.1 \mathrm{eV})$. 


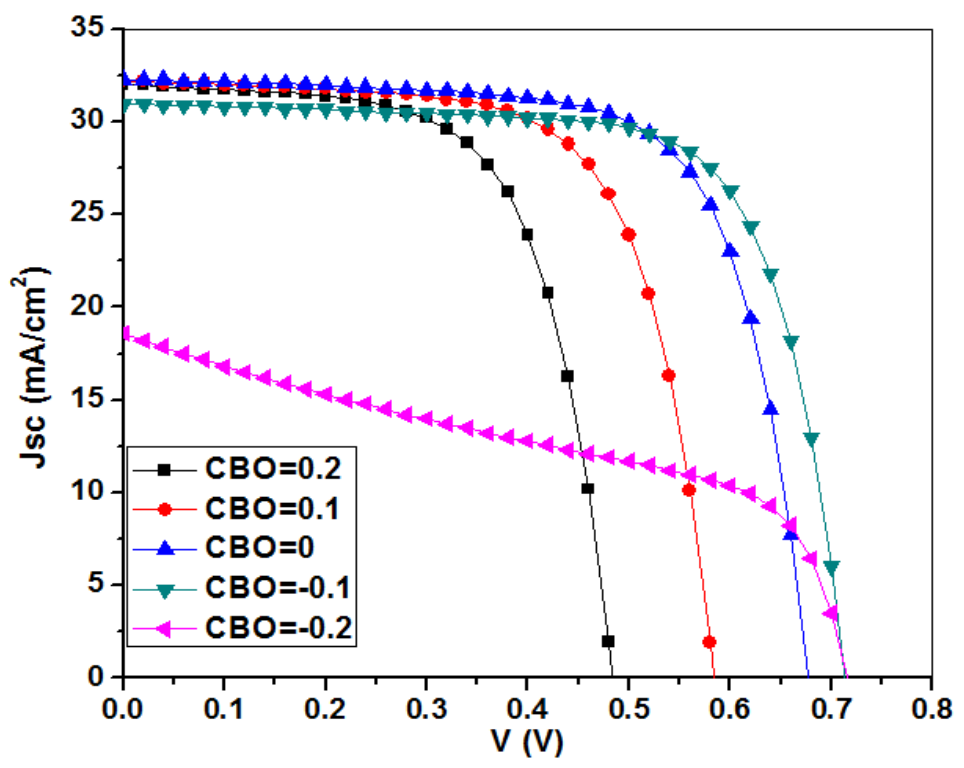

Figure 6.6: Effect of $\mathrm{CBO}$ of $\mathrm{J}-\mathrm{V}$ characteristics of solar cell

Effect of CBO on solar cell performance is given in Figure 6.7 with different interface recombination velocities. From Figure 6.7 it can be observed that for +CBO (cliff) solar cell performance is quickly degraded with increasing interface recombination velocity whereas for -CBO (spike) even at high recombination rate performance of the solar cell is still better then + CBO.
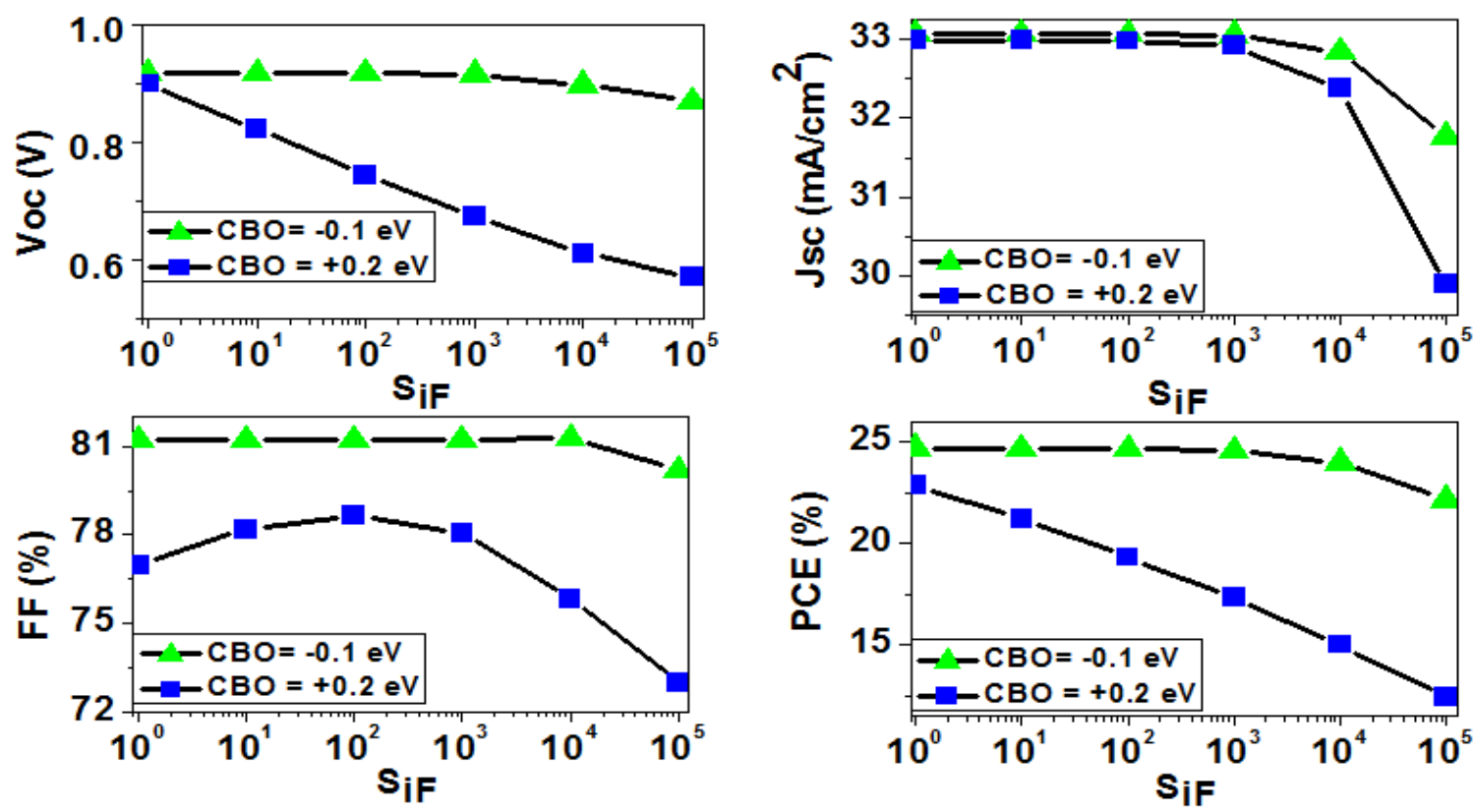

Figure 6.7: Effect of CBO on solar cell performance vs different interface recombination velocities

\section{ii. Effect of thickness of ETL on solar cell performance}

Thickness of ETL can also affect the performance of solar cell by suppressing interface recombination and for analysis thickness of ETL was varied from $10 \mathrm{~nm}$ to $100 \mathrm{~nm}$ for 
CBO values of $(+0.1 \mathrm{eV},-0.1 \mathrm{eV})$ and with assumption that ETL donor doping concentration is larger than absorber acceptor doping concentration $\left(\mathrm{N}_{\mathrm{d}}>\mathrm{N}_{\mathrm{a}}\right)$. And with these assumptions, from equation 6.3 interface recombination is largely governed by hole density at the interface. The result of the effect of ETL thickness on $V_{o c}$ is given in Figure 6.9. With cliff $(+\mathrm{CBO}=0.1 \mathrm{eV})$ an increase in ETL thickness will reduce the band bending of the absorber layer and allowing a larger number of holes at the interface for recombination and for the spike $(-\mathrm{CBO}=0.1 \mathrm{eV})$ it has a marginal effect otherwise it remains constant. Effect of thickness on hole density and $V_{\text {oc }}$ is shown in Figure 6.8 and 6.9 below.

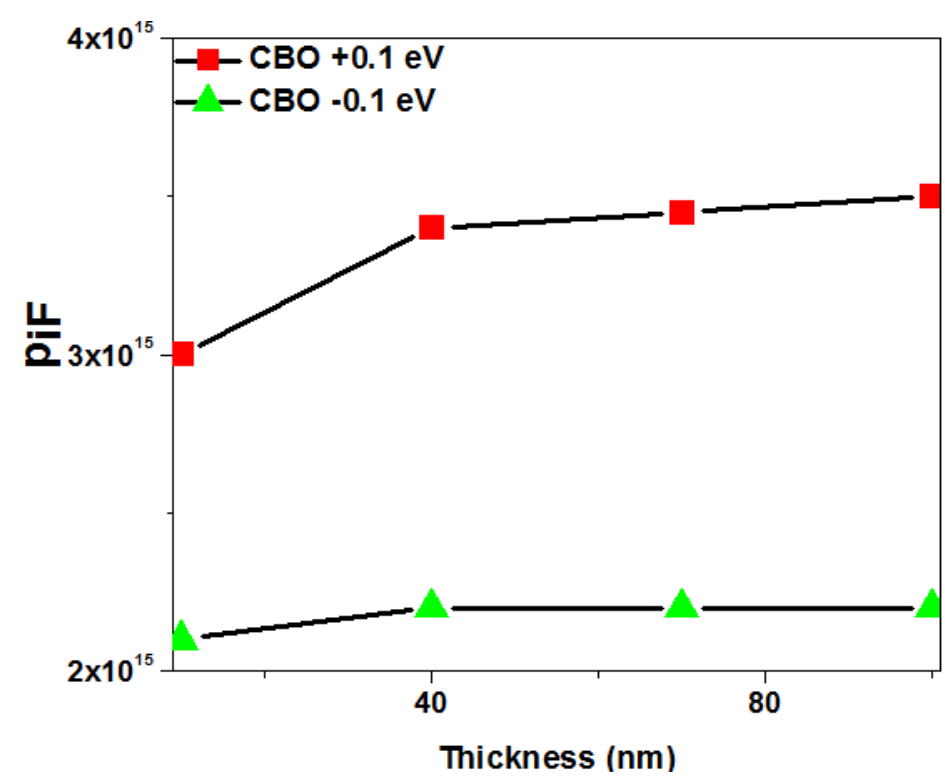

Figure 6.8: Effect of ETL thickness on hole concentration for recombination with different CBO

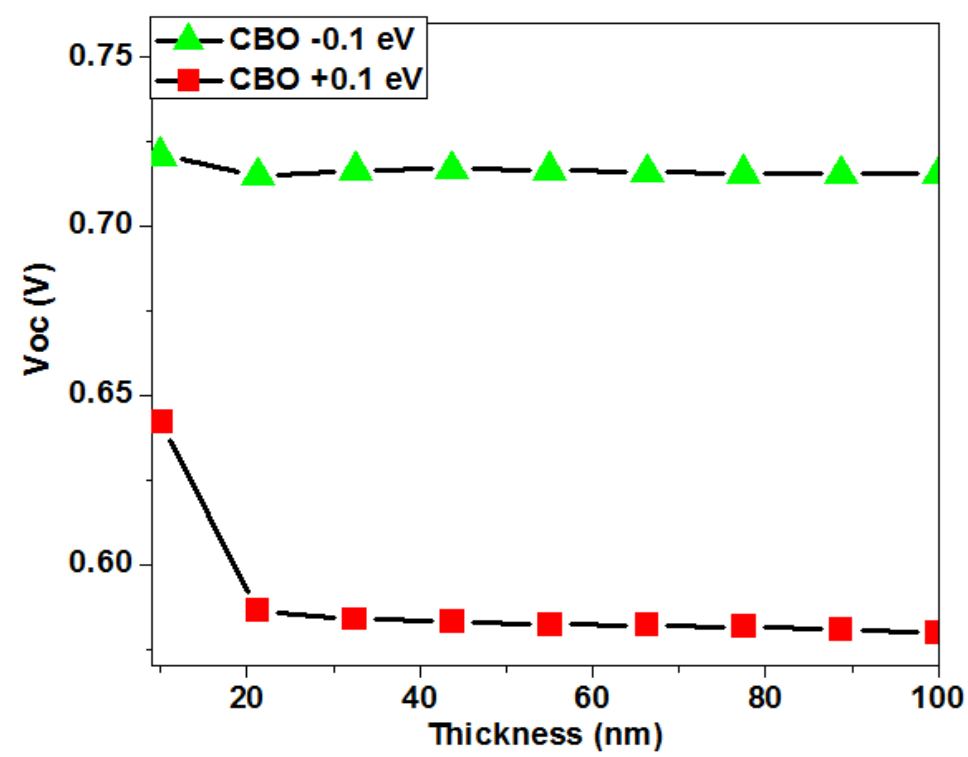

Figure 6.9: Effect of ETL thickness on $\mathrm{V}_{\mathrm{oc}}$ of solar cell with different $\mathrm{CBO}$ 
From Figure 6.8 it can be observed that with an increase in thickness of ETL the concentration of hole at interface also changes and for $(+\mathrm{CBO})$ this change is larger than (-CBO). By looking at equation 6.3 the surface that has larger hole concentration will have larger recombination at interface whereas for low concentration of hole at the interface the interface recombination will be reduced. Results plotted in Figure 6.9 shows that change in $\mathrm{V}_{\mathrm{oc}}$ for $-\mathrm{CBO}$ is smaller than that of +CBO.

\section{iii. Effect of donor doping of ETL on solar cell performance}

Like CBO and ETL thickness, donor doping of ETL also affects the performance of a solar cell. Increase in donor doping concentration changes the distribution of build in potential across the junction which causes a different degree of band bending. The result for band bending at different donor doping concentration are plotted in Figure 6.10.

(a)
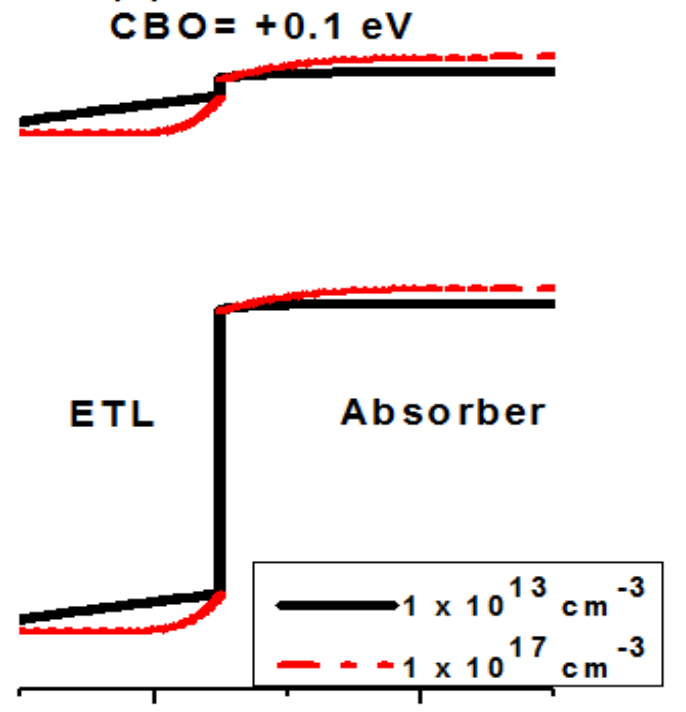

(b)
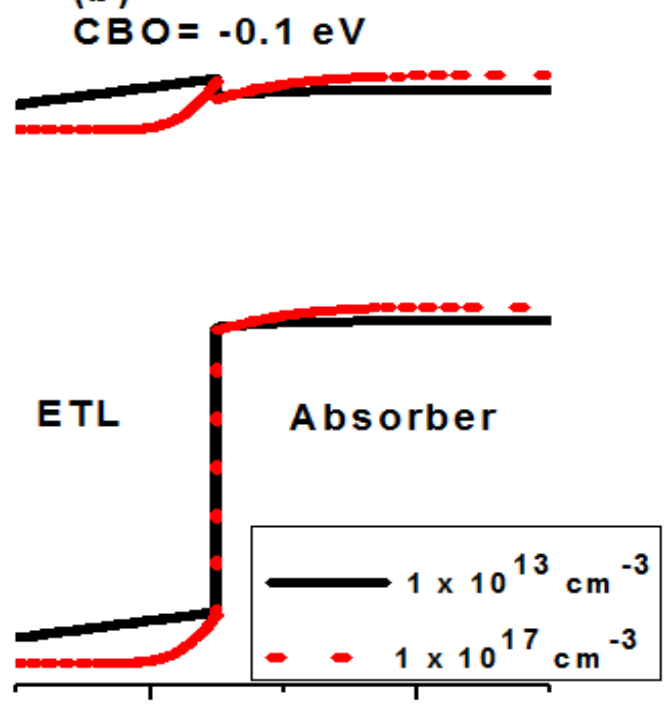

Figure 6.10: ETL donor doping vs band bending for different CBO values

With varying ETL donor doping equation 1 can be rewritten by considering that product of $\mathrm{p}_{\mathrm{iF}} \mathrm{n}_{\mathrm{iF}}>\mathrm{n}_{\mathrm{i}}^{2}, \mathrm{n}_{\mathrm{iF}}>\mathrm{n}, \mathrm{p}_{\mathrm{iF}}>\mathrm{p}$ then equation 6.1 will be rewritten as equation 6.5.

$$
\mathrm{R}_{\mathrm{iF}} \cong \frac{\mathrm{p}_{\mathrm{iF}} \mathrm{n}_{\mathrm{iF}}}{\mathrm{n}_{\mathrm{iF}}+\mathrm{p}_{\mathrm{iF}}} \mathrm{S}_{\mathrm{iF}}
$$

Based on equation 6.5, interface recombination is governed by recombination velocity, the density of electron and hole carrier at the interface and by varying ETL donor doping concentration equation 6.5 will switched between two conditions.

i. For (ETL donor doping $\mathrm{N}_{\mathrm{d}}<\mathrm{N}_{\mathrm{a}}$ Absorber acceptor doping), then $\mathrm{R}_{\mathrm{iF}}$ will be governed by the availability of electron at the interface and because of this $\mathrm{V}_{\mathrm{oc}}$ loss will happen. 
ii. For (ETL donor doping $\mathrm{N}_{\mathrm{d}}>\mathrm{N}_{\mathrm{a}}$ Absorber acceptor doping) then $\mathrm{R}_{\mathrm{iF}}$ will be governed by the holes at the interface and this will restore the loss in Voc.

The impact of doping concentration on solar cell functional parameters is given in Figure 6.11. From Figure 6.11, it can be observed that $\mathrm{V}_{\mathrm{oc}}$ of solar cell for both cases (+CBO, -CBO), with an increase in donor doping of buffer layer there is a decrease in $\mathrm{V}_{\mathrm{oc}}$. But the change in $\mathrm{V}_{\mathrm{oc}}$ for $(-\mathrm{CBO})$ is smaller than $(+\mathrm{CBO})$ due to spike at the interface by suppressing interface recombination and governing the density of hole at an interface. After reaching to a doping concentration of $1 \times 10^{17} \mathrm{~cm}^{-3}$ further increase in doping concentration loss in $\mathrm{V}_{\mathrm{oc}}$ will restored as discussed above.
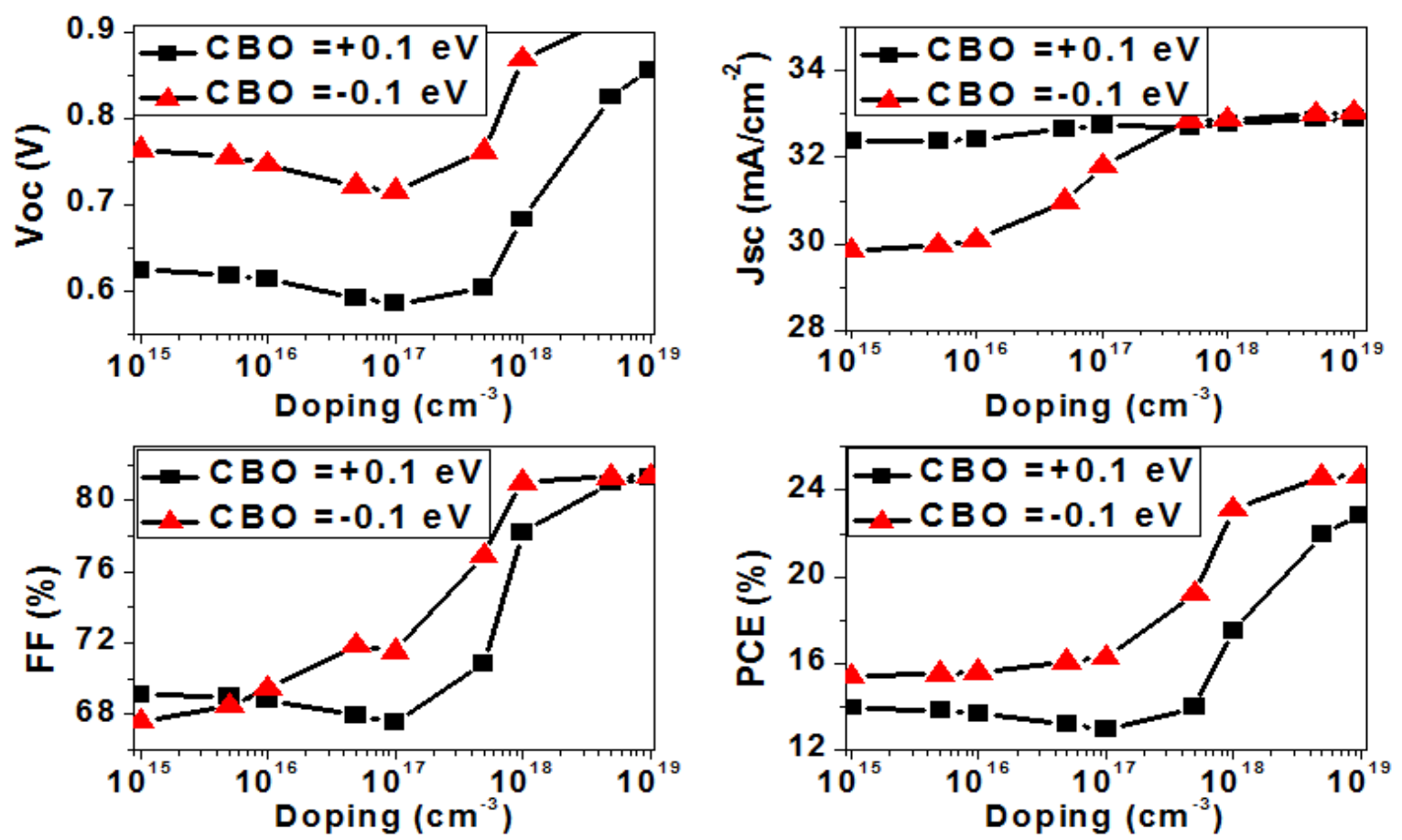

Figure 6.11: Effect of ETL doping on solar cell performance with different CBO values

\section{iv. Selection of ETL}

Based on the discussion above different ETL semiconductor materials and their alloys can be considered suitable for $\mathrm{MASnI}_{3}$ absorber layer solar cell. ETL with wide band gap and small -CBO should be considered suitable for fabrication of solar cell, because small -CBO suppresses the interface recombination. Here alloy semiconductor $\mathrm{Cd}_{1-\mathrm{x}} \mathrm{Zn}_{\mathrm{x}} \mathrm{S}$ [146], $\mathrm{Zn}(\mathrm{O}, \mathrm{S})$ are considered suitable as an alternate ETL for $\mathrm{MASnI}_{3}$ solar cell because of their wide bandgap and good band alignment with absorber layer of CBO $=-0.1 \mathrm{eV}$. Results of solar cell parameters vs interface recombination velocities for $\mathrm{Cd}_{1-\mathrm{x}} \mathrm{Zn}_{\mathrm{x}} \mathrm{S}$, $\mathrm{Zn}(\mathrm{O}, \mathrm{S})$ and $\mathrm{CdS}$ are given in Figure 6.12. With an increase in interface recombination 
from Figure 6.12 it can be observed that with $\mathrm{CdS}$ the device performance is highly affected. This happens as band alignment of CdS layer with $\mathrm{MASnI}_{3}$ creates a cliff interface with band offset of $+0.23 \mathrm{eV}$ and creates a small built-in potential that leads to high interface recombination velocity. In contrast to $\mathrm{CdS}$, the alloy semiconductor materials with band offset of $-0.1 \mathrm{eV}$ are less prone to interface recombination because of spike type band alignment with $\mathrm{MASnI}_{3}$ as shown in Figure 6.12.
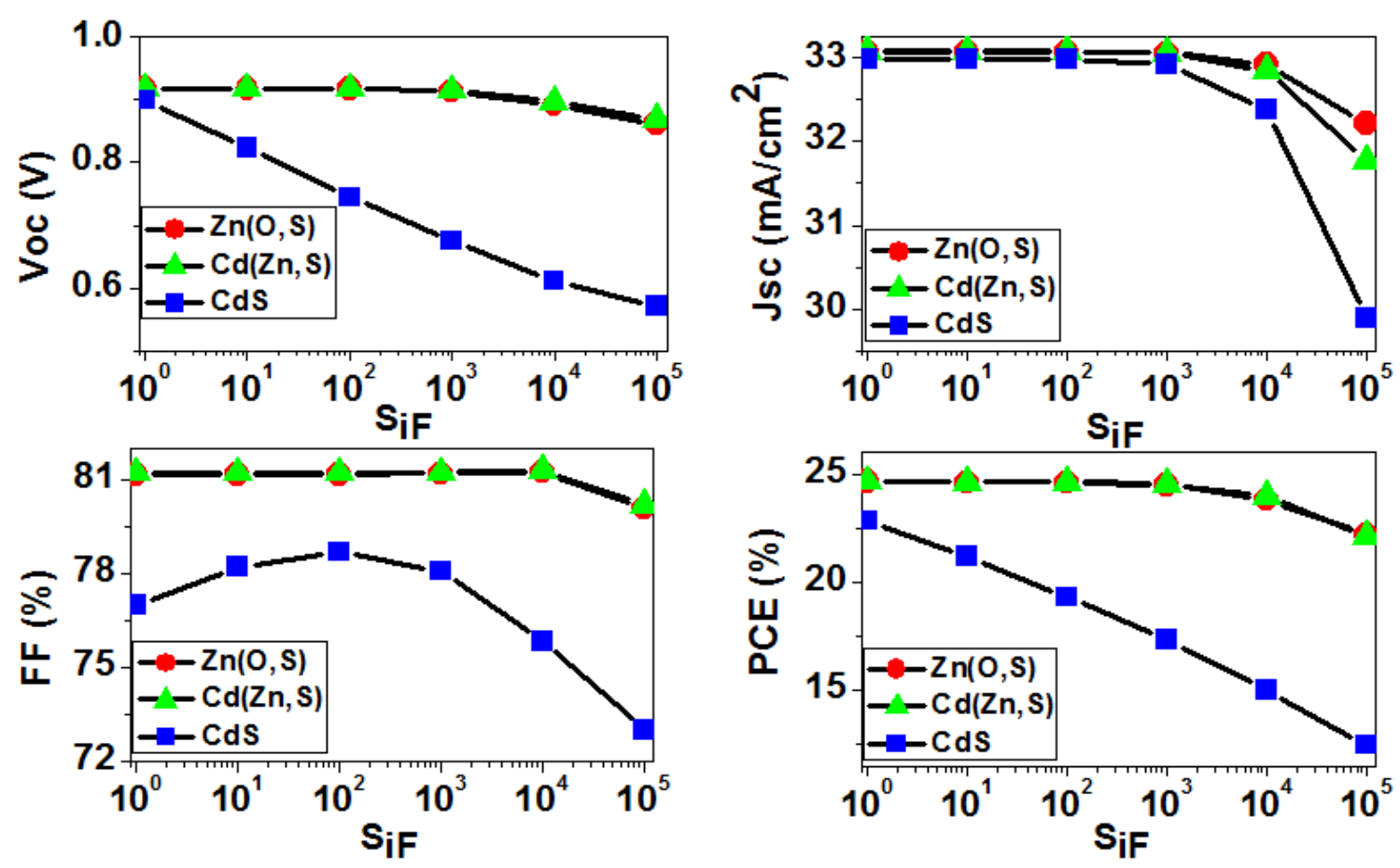

Figure 6.12: Solar cell performance parameters of different ETL as function of $S_{i F}$

After the detail explanation of effect of different ETL CBO on solar cell performance in next step we analyze the effect of absorber thickness and doping concentration on interface recombination of solar cell.

\section{v. Effect of absorber thickness on solar cell performance}

The thickness of a absorber layer can affect the performance of a solar cell because with increase in thickness more photon will be absorbed in the absorber layer. But here absorber layer thickness was varied to analyze its effect on interface recombination with CBO values of $+0.1 \mathrm{eV}$ and $-0.1 \mathrm{eV}$ with an assumption that $\mathrm{N}_{\mathrm{d}}>\mathrm{N}_{\mathrm{a}}$ and interface recombination is totally governed by the hole at the interface.

The results of hole concentration at the interface are plotted in Figure 6.13 and as with an increase in absorber thickness there is no change in hole density for CBO $(+0.1 \mathrm{eV})$ but for CBO $(-0.1 \mathrm{eV})$ with increase in thickness there is a slight decrease in hole concentration. 
So, with an increase in thickness, the change in $\mathrm{V}_{0 c}$ for $\mathrm{CBO}(-0.1 \mathrm{eV})$ is marginally higher than $\mathrm{CBO}(+0.1 \mathrm{eV})$. Figure 6.14 shows the result for effect of thickness on $\mathrm{V}_{0 \mathrm{c}}$ of a solar cell.

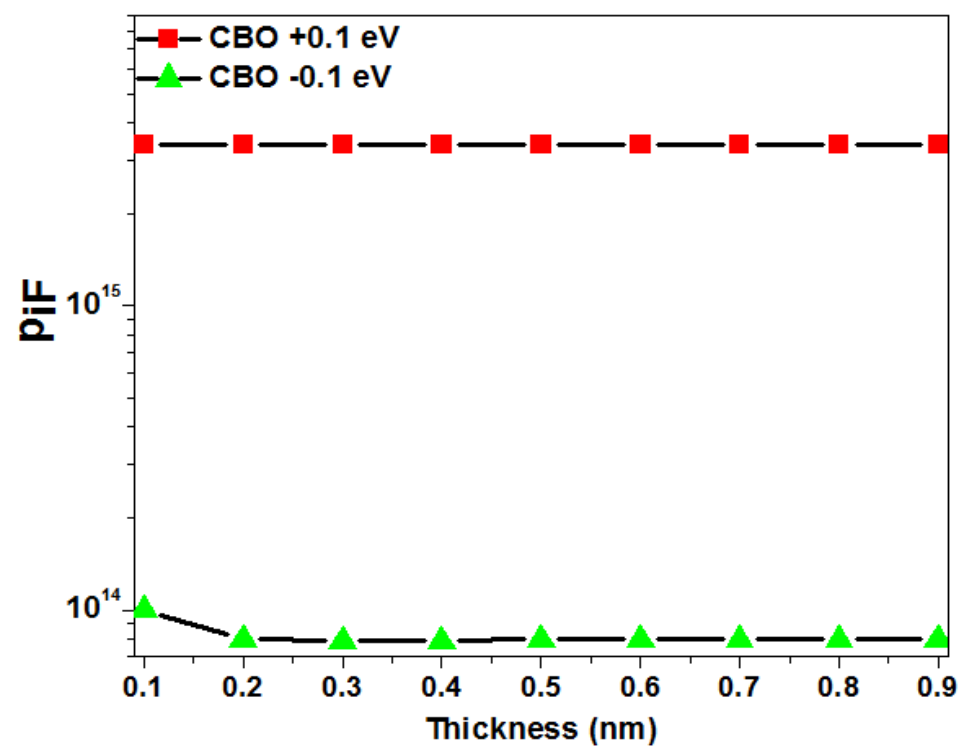

Figure 6.13: Effect of absorber thickness on hole concentration at interface

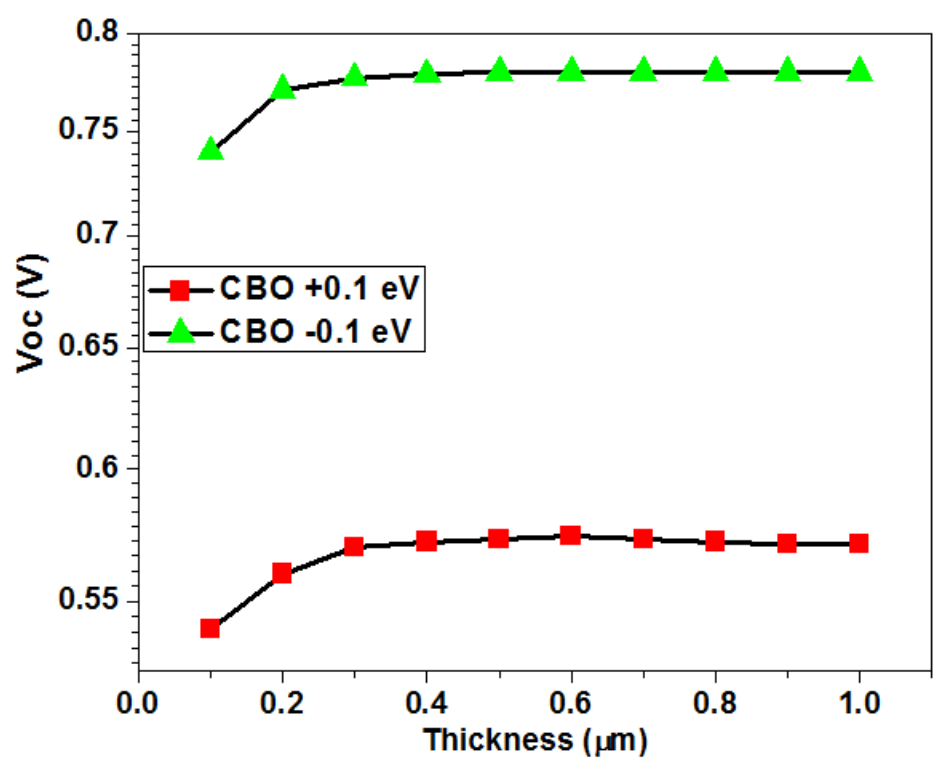

Figure 6.14: Effect of absorber thickness on $\mathrm{V}_{\mathrm{oc}}$ of solar cell with different $\mathrm{CBO}$

\section{vi. Effect of absorber layer doping on interface recombination}

Like ETL doping concertation, acceptor doping concertation of absorber layer also affect the performance and interface recombination of a solar cell. Equation 6.5 presented above will be switched between two states as discussed above depending upon acceptor doping concentration.

i. For (absorber acceptor doping $\mathrm{N}_{\mathrm{a}}<\mathrm{N}_{\mathrm{d}}$ ETL donor doping), then $\mathrm{R}_{\mathrm{iF}}$ will be governed by the availability of holes at the interface and because of this $V_{\text {oc }}$ loss will happen. 
ii. For (absorber acceptor doping $\mathrm{N}_{\mathrm{a}}>\mathrm{N}_{\mathrm{d}}$ ETL donor doping) then $\mathrm{R}_{\mathrm{iF}}$ will be governed by the electrons at the interface and will restore the loss in Voc.

The impact of the acceptor doping concentration of the absorber layer on solar cell functional parameters is given in Figure 6.15. So, in Figure 6.15 it can be seen with an increase in acceptor doping of absorber layer there is a decrease in $\mathrm{V}_{\mathrm{oc}}$ for both cases $(+\mathrm{CBO},-\mathrm{CBO})$. But the change in $\mathrm{V}_{\mathrm{oc}}$ for $(-\mathrm{CBO})$ is smaller than $(+\mathrm{CBO})$ due to spike at the interface by suppressing interface recombination and governing the density of hole at an interface. After reaching to a doping concentration of $1 \times 10^{17} \mathrm{~cm}^{-3}$ further increase in doping concentration loss in $\mathrm{V}_{\mathrm{oc}}$ was restored as discussed above.
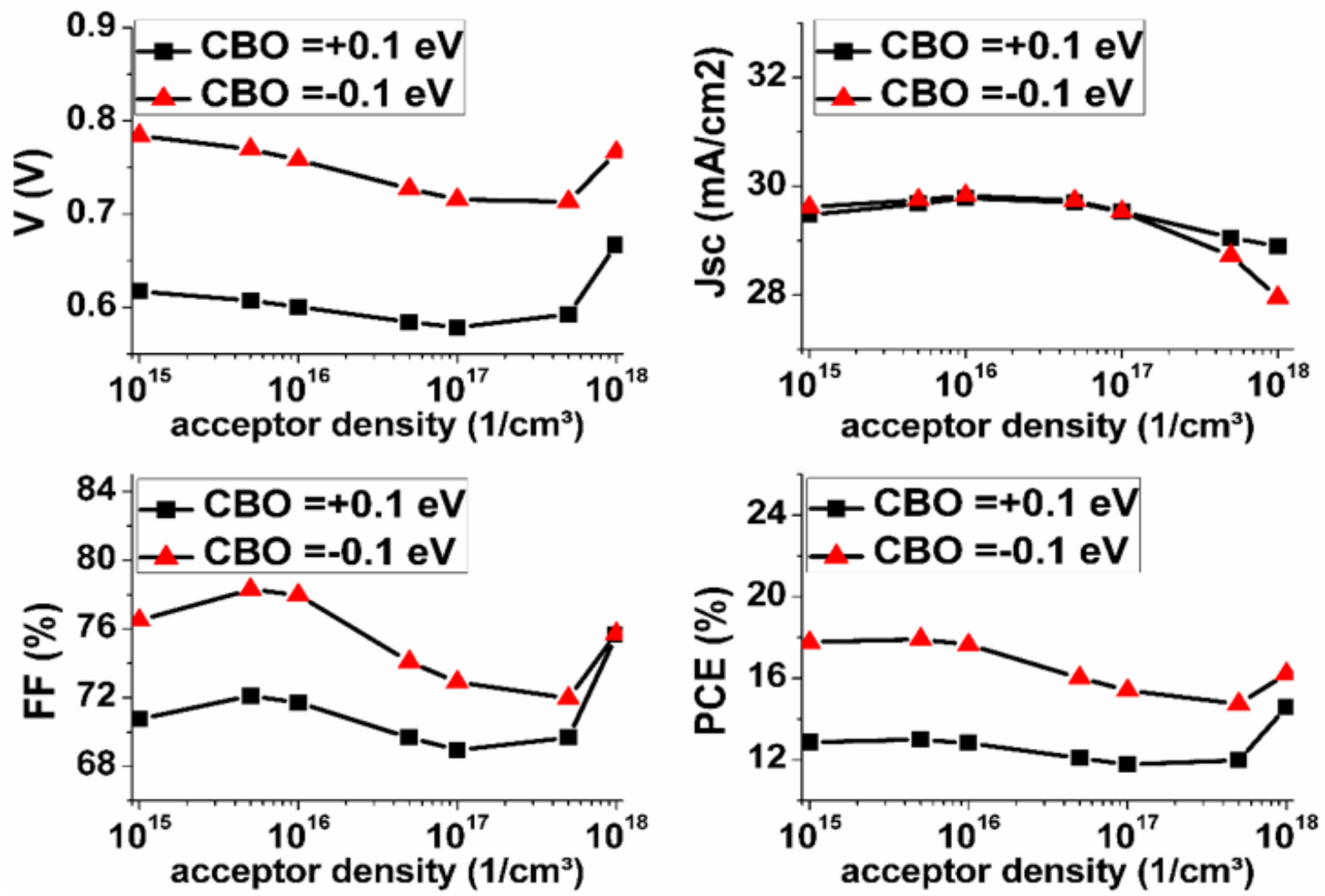

Figure 6.15: Effect of Absorber doping concentration on solar cell performance

\subsubsection{Conclusion}

Interface recombination is a major limitation for the design of high efficiency lead free perovskite solar cell and this can be suppressed by interface engineering. In this work impact of different ETL and effect of their band alignment on a solar cell, performance was analyzed. From the numerical analysis it was found that conduction band offset can play a significant role in solar cell performance by creating a hole barrier at the interface and suppressing the interface recombination. Based on the results it was found that interface recombination of $\mathrm{MASnI}_{3}$ solar cell can be controlled with ETL CBO, ETL thickness, ETL donor doping concentration and absorber doping concertation. With a 
small - CBO "Spike" at an interface is beneficial for efficiency enhancement of a solar cell, but too high spike will degrade solar cell performance by impeding the flow of charge carriers. Similarly, ETL with moderate - CBO is less prone to interface recombination with the comparison to ETL having a +CBO with absorber material. In terms of selection of ETL materials for $\mathrm{MASnI}_{3}$ absorber based solar cell, the solar cell with moderate - CBO should be advantageous for ETL choice.

\subsection{Efficiency enhancement of $\mathrm{CH}_{3} \mathrm{NH}_{3} \mathrm{SnI}_{3}$ solar cell by device modeling [31]}

Numerical analysis was performed to propose a novel structure for lead-free perovskite solar cell with $\mathrm{MASnI}_{3}$ as an absorber layer. Device modeling for $\mathrm{Cd}_{1-\mathrm{x}} \mathrm{Zn}_{\mathrm{x}} \mathrm{S}$ as ETL and methylamine tin halide $\left(\mathrm{MASnBr}_{3}\right)$ as HTL was proposed for the first time using solar cell capacitance simulator (SCAPS). Simulation revealed dependence of open circuit voltage $\left(\mathrm{V}_{0 \mathrm{c}}\right)$, short circuit current $\left(\mathrm{J}_{\mathrm{sc}}\right)$, fill factor $(\mathrm{FF})$ and power conversion efficiency (PCE) on HTL valance band offset, absorber layer thickness, doping concentration of absorber layer, band offset of ETL, diffusion length of minority carriers, defects at the interface between HTL/absorber and absorber/ETL. Optimum thickness for absorber layer was confirmed of and is well consistent with the thickness range for practical absorber layer design. Moreover, the conversion efficiency of $18.71 \%$ was revealed with absorber thickness of $500 \mathrm{~nm}$ and doping concentration of $1 \times 10^{16} \mathrm{~cm}^{-3}$. The result proposed in this work will provide an important guideline for a design of a low-cost perovskite solar cell.

Despite the rapid improvement in Sn-based perovskite material still PCE achieved from Sn-based perovskite solar cell is very low. This is mainly due to the lack of understanding of device properties and effect of band structure on device performance. To the best of our knowledge, there has been no report on a simulation model for Sn-based perovskite solar cell with $\mathrm{Cd}(\mathrm{Zn}, \mathrm{S})$ as electron transport layer (ETL) and $\mathrm{MASnBr}_{3}$ as the hole transport layer (HTL). In this article we report on theoretical proven and experimentally expected effects of conduction band offset (CBO) of $\mathrm{ETL} \mathrm{MASnI}_{3}$ layer of a performance of perovskite solar cell. To analyze the effect, it is necessary to control the band gap of CdS ETL layer and this is done by adding a control amount of zinc (Zn) to the ETL chemical bath solution containing (Cd) and Sulphur (S) ions as discussed in the literature [146-149]. $\mathrm{Cd}_{1-\mathrm{x}} \mathrm{Zn}_{\mathrm{x}} \mathrm{S}$ thin film was deposited by chemical bath deposition (CBD) technique. The parameters of the bath used for fabrication of $\mathrm{Cd}_{1-\mathrm{x}} \mathrm{Zn}_{\mathrm{x}} \mathrm{S}$ film on transparent conducting oxide (TCO) were similar to those used elsewhere [146]. Various ratios $(x=0 \%, 3 \%, 5 \%$ and $10 \%$ ) for zinc/cadmium were used in this experiment. After fabrication film on TCO 
substrate optical analysis was performed and it was found that there is a shift in the bandgap of $\mathrm{Cd}_{1-\mathrm{x}} \mathrm{Zn}_{\mathrm{x}} \mathrm{S}$ layer with various concentration of $\mathrm{Zn}$. The optical analysis of $\mathrm{Cd}_{1-\mathrm{x}} \mathrm{Zn}_{\mathrm{x}} \mathrm{S}$ layer with different concertation of $\mathrm{Zn}$ is given in Figure 6.16 and Figure 6.17.

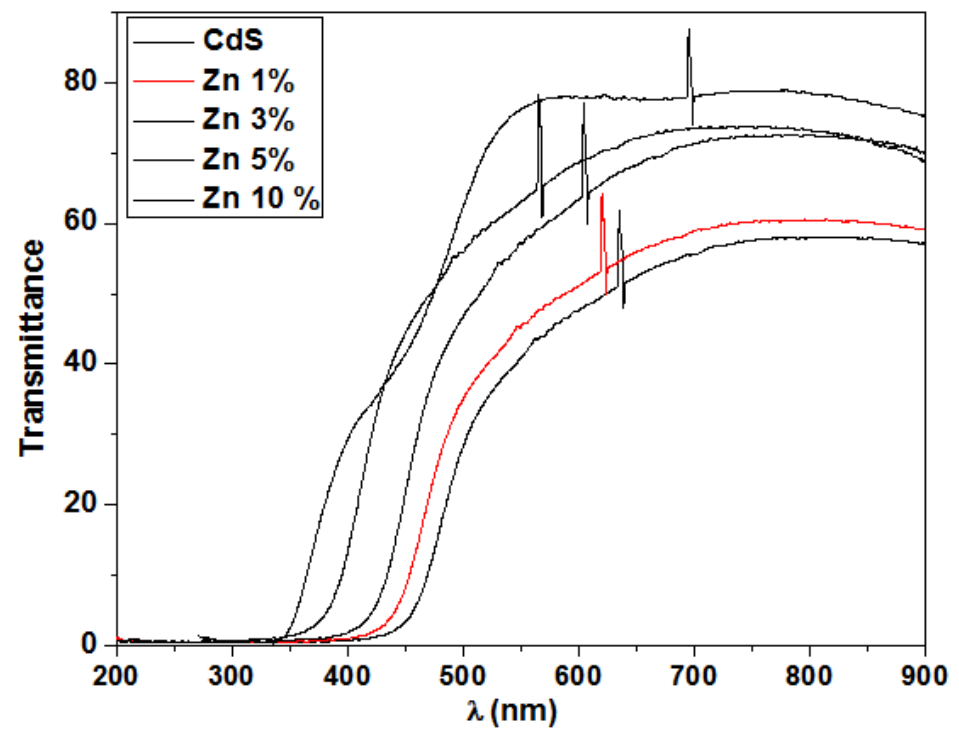

Figure 6.16: Transmittance of $\mathrm{Cd}_{1-\mathrm{x}} \mathrm{Zn}_{\mathrm{x}} \mathrm{S}$

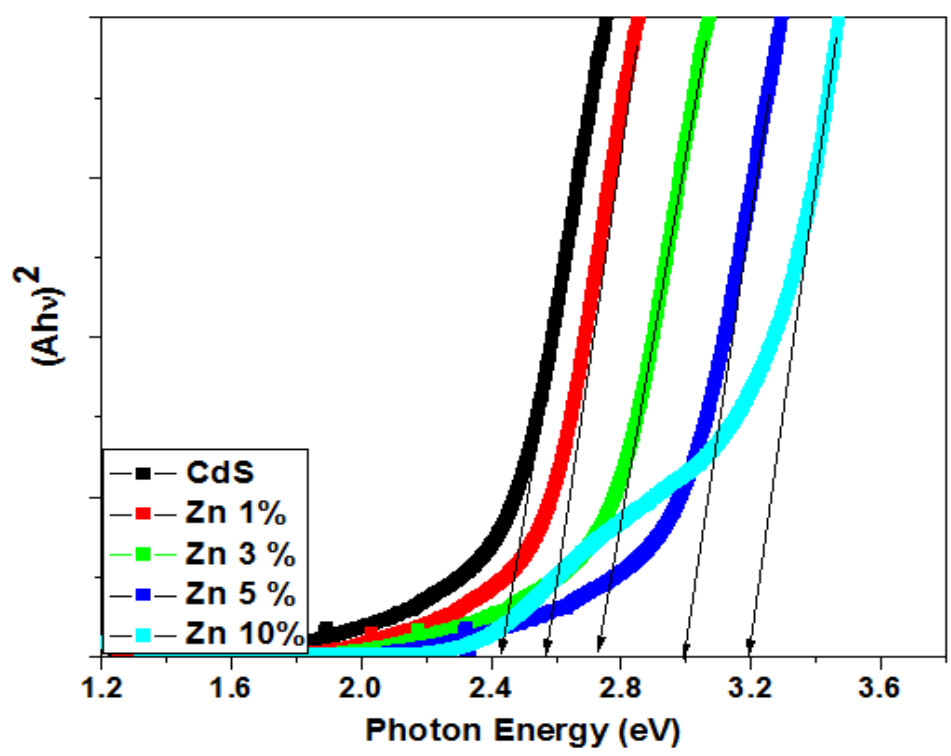

Figure 6.17: Plot of $(\mathrm{Ahv})^{2}$ vs photon energy $(\mathrm{eV})$

In this work device simulation was carried out in solar cell capacitance simulator (SCAPS) developed by the University of Gent belgium. SCAPS is a one-dimensional software used to calculate, band diagram, IV characteristic, quantum efficiency/spectral response (QE) and AC quantities. This program was mainly developed for the analysis of CIGS and CdTe solar cell and was widely used for the optimal design of (CIGS, CdTe) solar cells [76]. But recently, SCAPS has emerged as an alternate numerical tool for the analysis of perovskite solar cell $[79,126]$. 
Our approach for the improvement of $\mathrm{MASnI}_{3}$ solar cell performance is by means of addressing the following facts:

i. Validation of simulated results for Spiro - MeOTAD as HTL.

ii. Replacing Spiro - MeOTAD HTL with $\mathrm{MASnBr}_{3}$ of the validated simulation.

iii. Analyzing the effect of valance band offset of HTL on solar cell performance

iv. Optimization of absorber layer thickness and doping concentration.

v. Replacing $\mathrm{TiO}_{2}$ with CdS ETL layer.

vi. Analyzing the conduction band offset to improve the efficiency of the device.

vii. Effect of Absorber layer minority carrier diffusion length on a thickness of the absorber layer.

viii. Comparison of Results.

The proposed results in this study will give a beneficial guideline for the designing of high performance of $\mathrm{MASnI}_{3}$ based solar cells.

\subsubsection{Simulation setup}

A planner heterostructure of $\mathrm{MASnI}_{3}$ absorber material based solar cell is adopted in this work with layer configuration; glass substrate/transparent conducting oxide/ $\mathrm{Cd}_{\mathrm{x}} \mathrm{Zn}_{1-\mathrm{x}} \mathrm{S}(\mathrm{ETL}) / \mathrm{MASnI}_{3}$ (absorber) $/ \mathrm{MASnBr}_{3}$ (HTL)/Back contact is shown in Figure 6.18 .

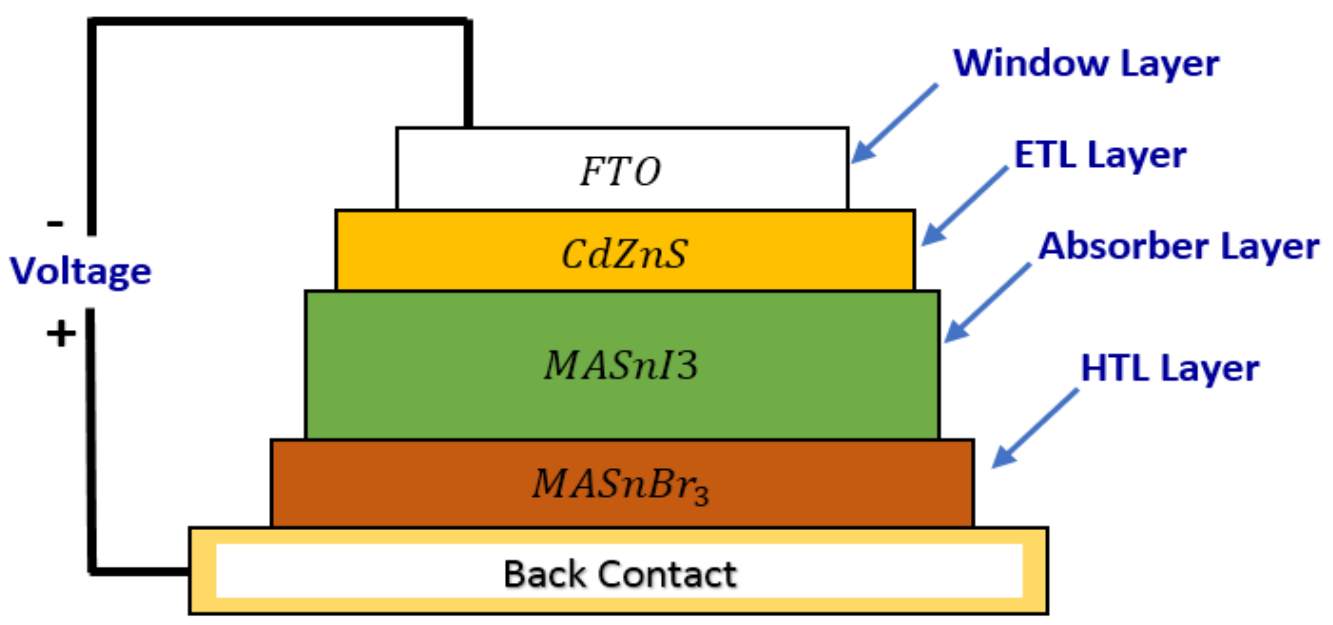

Figure 6.18: Solar cell structure.

Simulation parameters for different layers were carefully taken from experimental and from theoretical work [26-28,30,134]. The primary parameters of the proposed structure that were used in SCAPS simulation are summarized in Table 6.5. The defect in the absorber layer are considered as neutral gaussian distribution, with a characteristic energy of $0.1 \mathrm{eV}$ and energy of defect is above valance band with an energy of $0.6 \mathrm{eV}$. Interface 
CHAPTER 6 Efficiency Enhancement of $\mathrm{CH}_{3} \mathrm{NH}_{3} \mathrm{SnI}_{3}$ Solar Cell

defects for ETL/Absorber layer and Absorber/HTL are set to be neutral and single defect having an energy of defects $0.6 \mathrm{eV}$ on the top of valance band with the total concentration of interface defect to be $1 \times 10^{17} \mathrm{~cm}^{-2}$. The defects in the absorber layer and at the interface region are given in Table 6.6 and Table 6.7.

Table 6.5: parameters for SCAPS [29-30,31-35].

\begin{tabular}{lcccc}
\hline \multicolumn{1}{c}{ SCAPS Parameters } & $\begin{array}{c}\text { FTO } \\
\left(\mathbf{S n O}_{\mathbf{2}}\right)\end{array}$ & $\begin{array}{c}\text { ETL } \\
(\mathbf{C d Z n S})\end{array}$ & $\begin{array}{c}\text { Absorber } \\
\left(\mathbf{M A S n I}_{\mathbf{3}}\right)\end{array}$ & $\begin{array}{c}\text { HTL } \\
\left(\mathbf{M A S n B r}_{\mathbf{3}}\right)\end{array}$ \\
\hline Thickness $(\mathrm{nm})$ & 500 & $0.1 \sim 1000$ & $0.1 \sim 1000$ & 200 \\
CB effective DOS $\left(\mathrm{cm}^{-3}\right)$ & $10^{19}$ & $2.8 \times 10^{18}$ & $1 \times 10^{18}$ & $1 \times 10^{18}$ \\
VB effective DOS $\left(\mathrm{cm}^{-3}\right)$ & $10^{19}$ & $3.9 \times 10^{18}$ & $1 \times 10^{18}$ & $1 \times 10^{18}$ \\
Doping density $\left(\mathrm{cm}^{-3}\right)$ & $\mathrm{n}-2 \times 10^{19}$ & $\mathrm{n}-1 \times 10^{17}$ & $\mathrm{p}-1 \times 10^{14} \sim 1 \times 10^{17}$ & $\mathrm{p}-1 \times 10^{18}$ \\
Permittivity & 9 & 10 & 8.2 & 8.2 \\
Electron affinity $(\mathrm{eV})$ & 4 & $4.4 \sim 3.6$ & 4.17 & 3.39 \\
Band Gap (eV) & 3.50 & $2.42 \sim 3.2$ & 1.3 & 2.15 \\
Electron/Hole mobility $\left(\mathrm{cm}^{2} / \mathrm{Vs}\right)$ & $100 / 25$ & $100 / 25$ & $1.6 / 1.6$ & $1.6 / 1.6$ \\
\hline
\end{tabular}

Table 6.6: Interface Defects (Neutral)

\begin{tabular}{llc}
\hline \multicolumn{1}{c}{ Defect layer properties } & CdZnS/MASnI & MASnI $_{3} / \mathbf{M A S n B r}_{3}$ \\
\hline Capture cross section area of electron/hole & $1.0 \times 10^{-15} \mathrm{~cm}^{2}$ & $1.0 \times 10^{-15} \mathrm{~cm}^{2}$ \\
Density of defect & $1.0 \times 10^{17} \mathrm{~cm}^{-2}$ & $1.0 \times 10^{17} \mathrm{~cm}^{-2}$ \\
\hline
\end{tabular}

Table 6.7: Defect layer properties (Neutral)

\begin{tabular}{lcc}
\hline \multicolumn{1}{c}{ Defect layer properties } & MASnI $_{\mathbf{3}}$ & $\mathbf{M A S n B r}_{\mathbf{3}}$ \\
\hline Capture cross section area of electron/hole & $1.0 \times 10^{-15} \mathrm{~cm}^{2}$ & $1.0 \times 10^{-15} \mathrm{~cm}^{2}$ \\
Density of defect & $1.0 \times 10^{15} \mathrm{~cm}^{-3}$ & $1.0 \times 10^{15} \mathrm{~cm}^{-3}$ \\
\hline
\end{tabular}

\subsubsection{Result and Discussion}

\section{i. Effect of $\mathrm{MASnBr}_{3}$ HTL on solar cell performance}

Result for J-V characteristics for a solar cell with two different HTL's is given in Figure 6.19 below. By changing the HTL layer from Spiro-MeOTAD to $\mathrm{MASnBr}_{3}$ there is an increase in short circuit current $\left(\mathrm{J}_{\mathrm{sc}}\right)$ and open circuit voltage $\left(\mathrm{V}_{\mathrm{oc}}\right)$. 


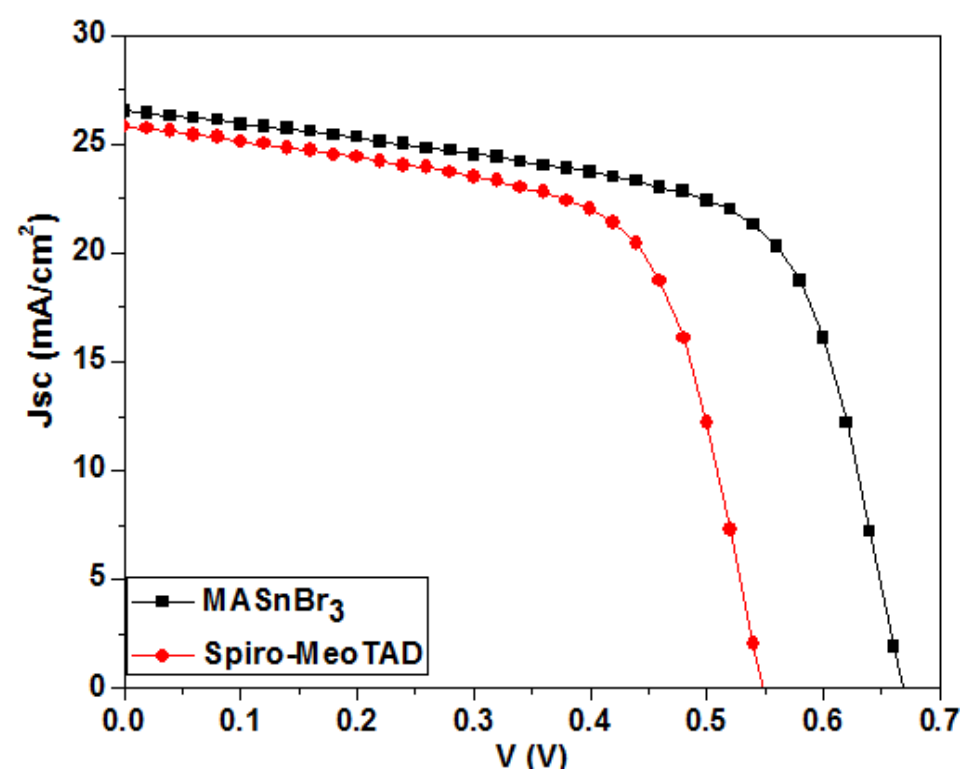

Figure 6.19: HTL effect on solar cell performance

This mainly happens because of valance band offset of HTL layer with absorber layer. With Spiro-MeOTAD as HTL layer the band structure forms a cliff like structure that reduces the activation energy of solar cell while for $\mathrm{MASnBr}_{3}$ band structure forms a small spike and because of this spike activation energy is equal to band gap energy thus increasing open circuit voltage for the solar cell [143]. Band structure for HTL interface with absorber layer is given in Figure 6.20. Figure 6.20a shows the band structure for Spiro-MeOTAD and Figure 6.20b shows band structure for $\mathrm{MASnBr}_{3}$.

(a)

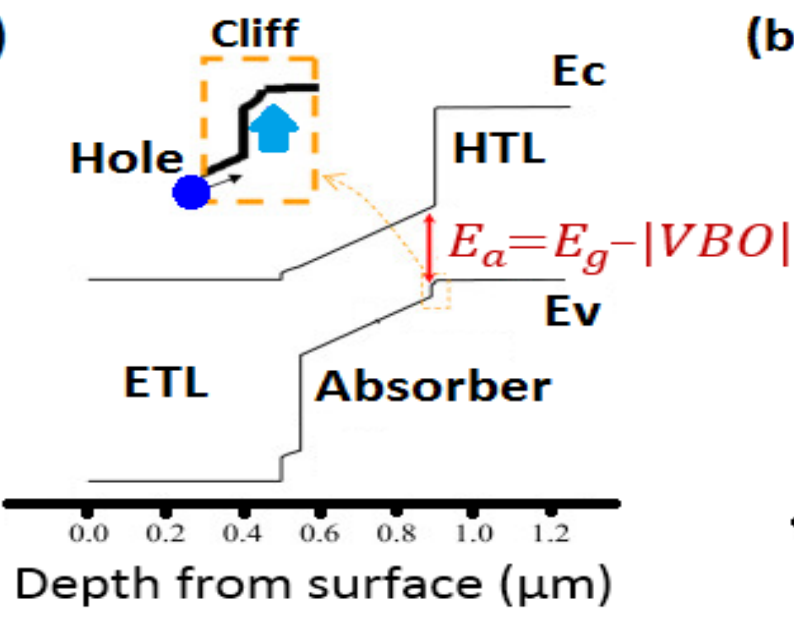

(b) Spike

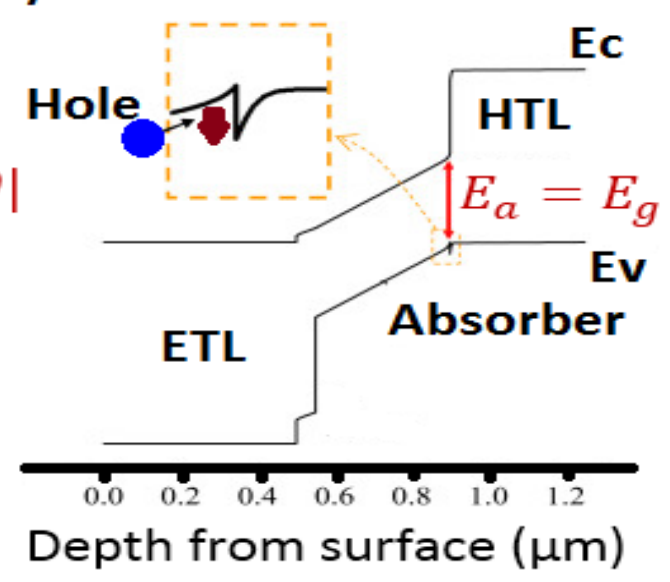

Figure 6.20: Band interface for HTL with absorber layer

Figure 6.21 shows that with an increase in electron affinity with a bandgap of $2.2 \mathrm{eV}$ the PCE tends to increase to a value of $3.3 \mathrm{eV}$ after which it starts to decrease. This happens because with an increase in EA value the valance band position changes for HTL and this result in an increase in VBO $\left(\chi_{\mathrm{HTL}}-\chi_{\mathrm{Absorber}}\right)$. So, with increase in VBO the band structure of valance band at interface changes from cliff to spike which that is already 
shown in Figure 6.20 above. But with further increase in VBO, increases the spike height which increases the resistance for the flow of hole towards back contact and causing a loss in PCE of a solar cell.

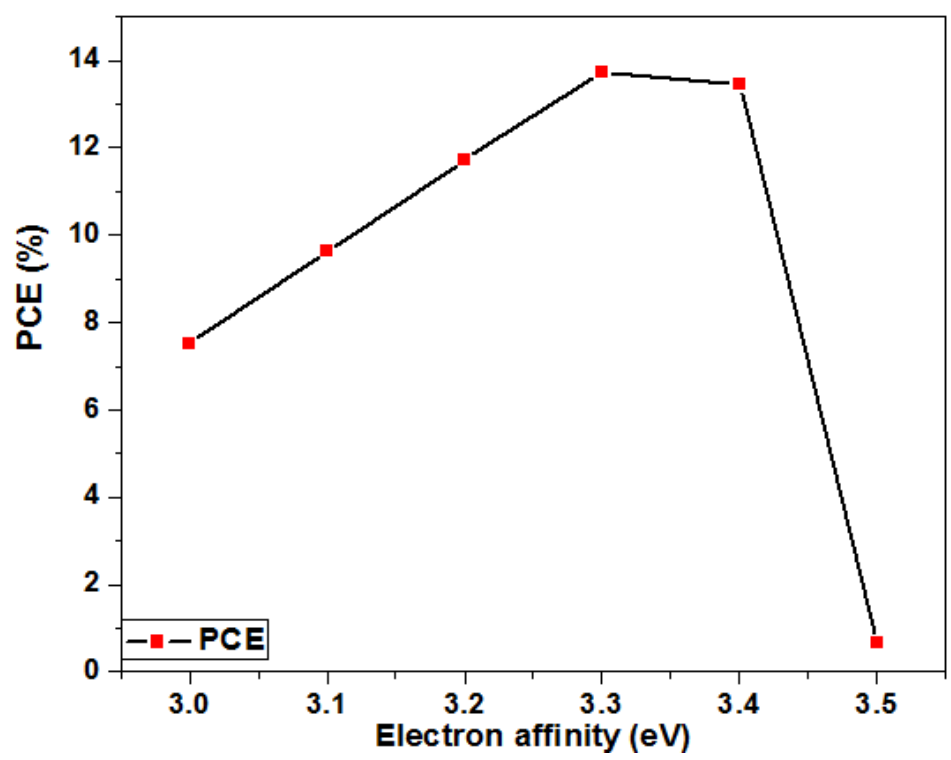

Figure 6.21: Effect of Electron affinity on solar cell performance

\section{ii. Effect of Absorber thickness and doping concentration of solar cell performance}

Absorber thickness has a direct effect on the performance of solar cell and for analysis absorber layer thickness was varied from $0.1 \mu \mathrm{m}$ to $1 \mu \mathrm{m}$. Figure 6.22 shows the plotted results for effect on absorber layer thickness on solar cell performance.
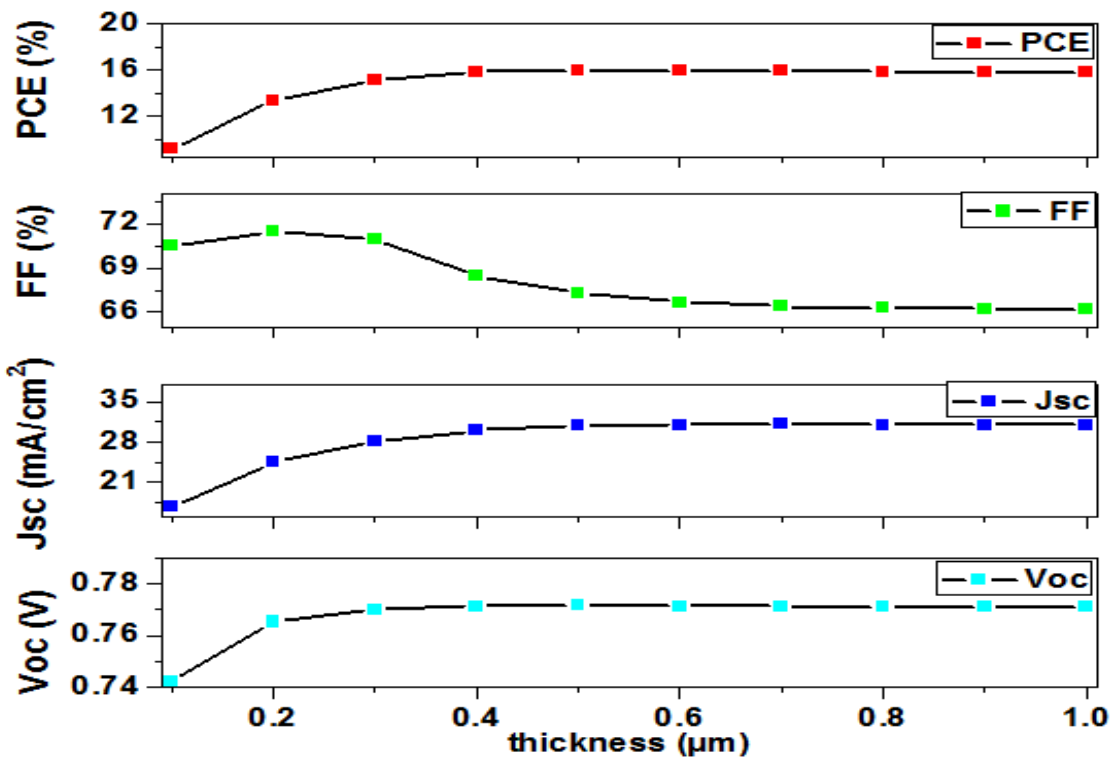

Figure 6.22: Absorber layer thickness effect on solar cell performance

With the change in thickness PCE, $\mathrm{J}_{\mathrm{SC}}, \mathrm{V}_{\mathrm{OC}}$ tends to increase with thickness but after reaching to a thickness of $0.5 \mu \mathrm{m}$ PCE, $\mathrm{J}_{\mathrm{SC}}, \mathrm{V}_{\mathrm{oc}}$ become constant. Whereas FF tends to increase with thickness at the start but with further increase in thickness FF starts to 
decrease and this mainly happens due to an increase in series resistance with an increase in thickness.

$\mathrm{MASnI}_{3}$ is unstable in air because of oxidization process of $\mathrm{Sn}^{2+}$ to $\mathrm{Sn}^{4+}$ which act as $\mathrm{p}$ type dopant for perovskite absorber layer. This self-doping process can greatly affect the performance of solar cell based on $\mathrm{MASnI}_{3}$ absorber layer solar cell. So, to investigate the effect of acceptor concentration on solar cell performance doping level was varied from $1 \times 10^{13} \mathrm{c} \mathrm{m}^{-3}$ to $1 \times 10^{17} \mathrm{c} \mathrm{m}^{-3}$. Result for acceptor concentration is plotted in Figure $6.23, \mathrm{~J}_{\mathrm{SC}}$ and $\mathrm{V}_{\mathrm{OC}}$ change is related to change in acceptor concentration. $\mathrm{J}_{\mathrm{SC}}$ reach to maximum value with acceptor concentration value of $1 \times 10^{16} \mathrm{c} \mathrm{m}^{-3}$ whereas $V_{\text {oc }}$ start to decrease at value of $1 \times 10^{16} \mathrm{c} \mathrm{m}^{-3}$ for acceptor concertation. The behavior is well explained with the aid of quantum efficiency (QE) (see Figure 6.24) of solar cell and with increase in acceptor concentration QE increases up to a value of $1 \times 10^{16} \mathrm{c} \mathrm{m}^{-3}$, which indicates that the generation rate of the photo-generated carriers increases under the same incident photon number. Hence, an optimal acceptor carrier concentration is necessary for improvement in $\mathrm{J}_{\mathrm{SC}}$ and photo-absorption efficiency. Acceptor concentration also affects the PCE and FF of a solar cell and with an increase in carrier concentration PCE and FF increase after reaching to a value of optimal acceptor concentration PCE starts to decrease whereas FF tends to increase. The increase in FF is depended upon $\mathrm{J}_{\mathrm{SC}}$ and $\mathrm{V}_{\mathrm{OC}}$ as depicted in equation 6.6 below.

$$
\mathrm{FF}=\frac{\mathrm{V}_{\mathrm{Max}} \mathrm{I}_{\mathrm{MAX}}}{\mathrm{V}_{\mathrm{OC}} \mathrm{I}_{\mathrm{SC}}}
$$

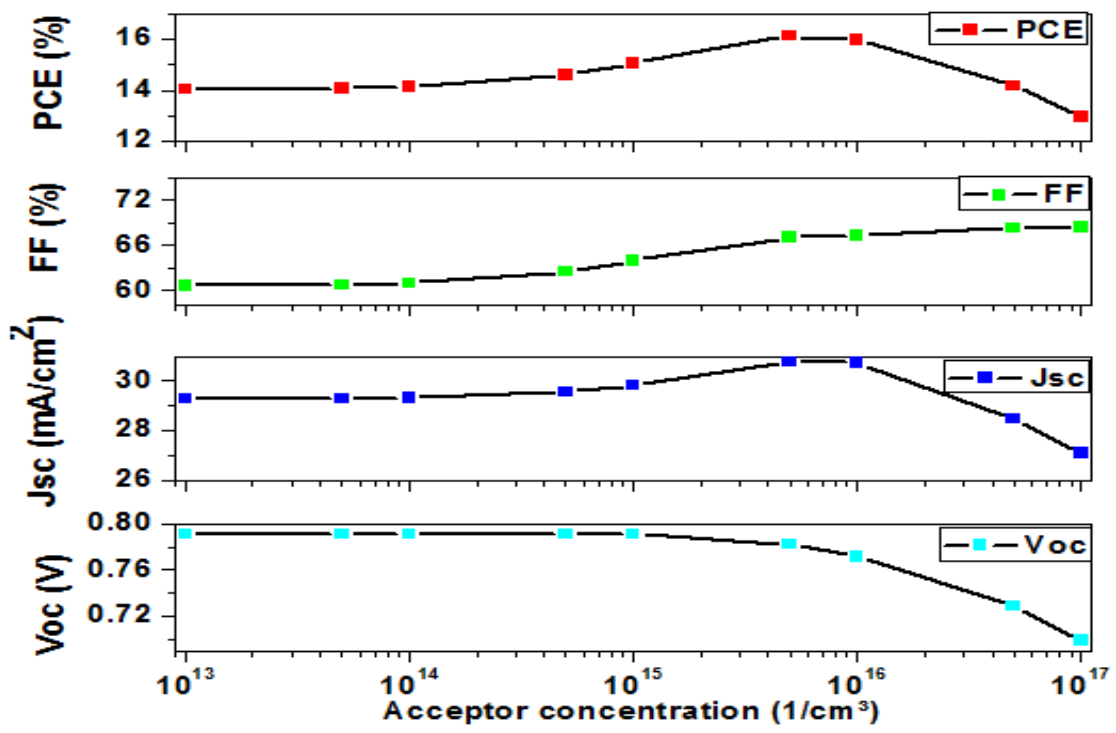

Figure 6.23: Acceptor carrier concentration effect on solar cell performance 


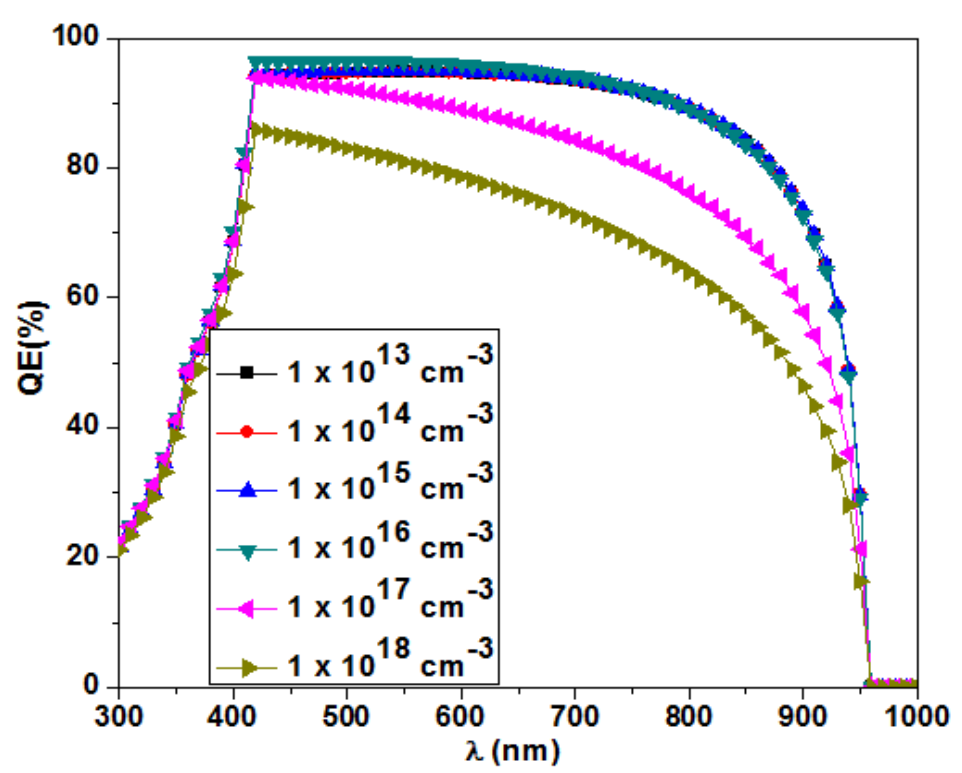

Figure 6.24: $\mathrm{QE}$ as a function of acceptor concentration vs wavelength

\section{iii. ETL band gap and electron affinity effect on solar cell performance}

By replacing $\mathrm{TiO}_{2}$ layer with $\mathrm{CdS}$ the conversion efficiency of solar cell is reduced, and this happens because of large conduction band offset (CBO) between ETL and absorber layer which give rise to interface recombination. Thus, CBO can greatly affect solar cell performance by observing the graph given in Figure 6.25a of $\mathrm{J}-\mathrm{V}$ characteristics for two different ETL layers with electron affinity of $4.4 \mathrm{eV}$ for $\mathrm{CdS}$ and $4.27 \mathrm{eV}$ for $\mathrm{TiO}_{2}$. So, by adjusting CBO of ETL/Absorber we can improve the efficiency of solar cell and the reason for the selection of CdS is because of its band gap tuneability. CdS band gap can be tuned by adding $\mathrm{Zn}$ in to the $\mathrm{CdS}$ bath solution as discussed above. As discussed above that band gap of $\mathrm{Cd}_{1-\mathrm{x}} \mathrm{Zn}_{\mathrm{x}} \mathrm{S}$ is varied from $2.42 \mathrm{eV}$ to $3.2 \mathrm{eV}$ by changing $\mathrm{Zn}$ concentration in the bath solution. So, by applying the change of band gap for $\mathrm{Cd}_{1-\mathrm{x}} \mathrm{Zn}_{\mathrm{x}} \mathrm{S}$ layer in SCAPS with assumption that only conduction band minimum changes with band gap of $\mathrm{Cd}_{1-\mathrm{x}} \mathrm{Zn}_{\mathrm{x}} \mathrm{S}$ whereas valance band mximum remain constant throughout. Thus, with change in band gap the electron affinity of $\mathrm{Cd}_{1-\mathrm{x}} \mathrm{Zn}_{\mathrm{x}} \mathrm{S}$ will change which will greatly affect the band structure between ETL/Absorber layer. The effect of CBO on solar cell performance and on band structure is shown in Figure 6.25b, 6.25c and 6.25d. The cliff like band structure (see Figure 6.25c) does not impede the flow of electron towards the front contact but the activation energy for carrier recombination $\left(\mathrm{E}_{\mathrm{a}}\right)$ becomes lower than absorber band gap $E_{g}$ and whereas $E_{a}$ is represented by $E_{g}-|C B O|$. Main recombination is interface recombination when $E_{a}$ is less than band gap of absorber layer [150-152]. Thus, CBO directly correlates with PCE of solar cell as $\mathrm{E}_{\mathrm{a}}$ directly correlates with Voc, 
and the negative $\mathrm{CBO}$ reduces $\mathrm{V}_{\mathrm{oc}}$. When the $\mathrm{CBO}$ is positive, $\mathrm{PCE}$ is excellent, however further increase in $\mathrm{CBO}$ values reduces PCE of solar cell. When the CBO is positive, a spike is formed at the buffer/absorber interface (see Figure 6.25d), an increase in spike impedes the flow of photo-generated electron towards the front electrode, thus affecting the PCE of solar cell as shown in Figure 6.25b.

(a)

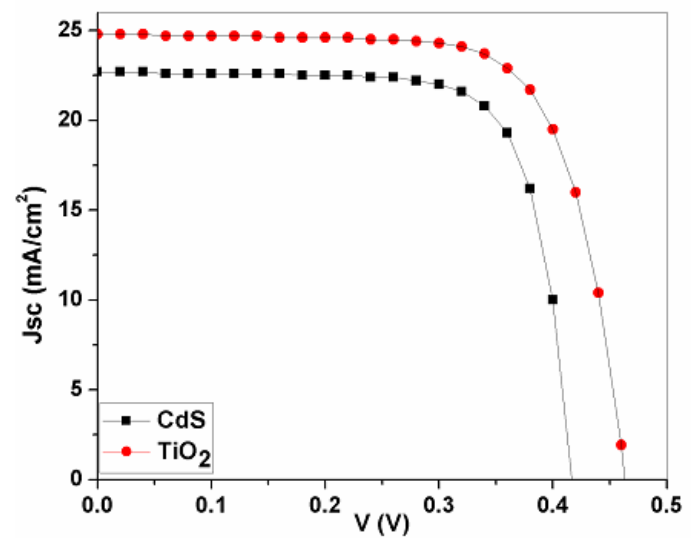

(c)

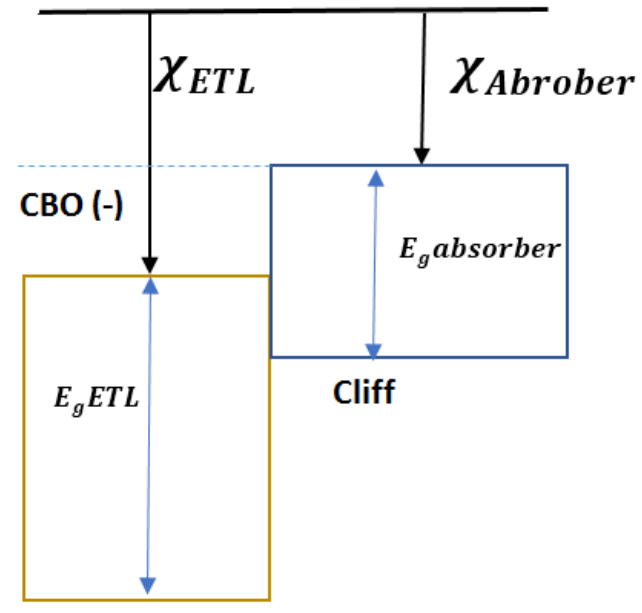

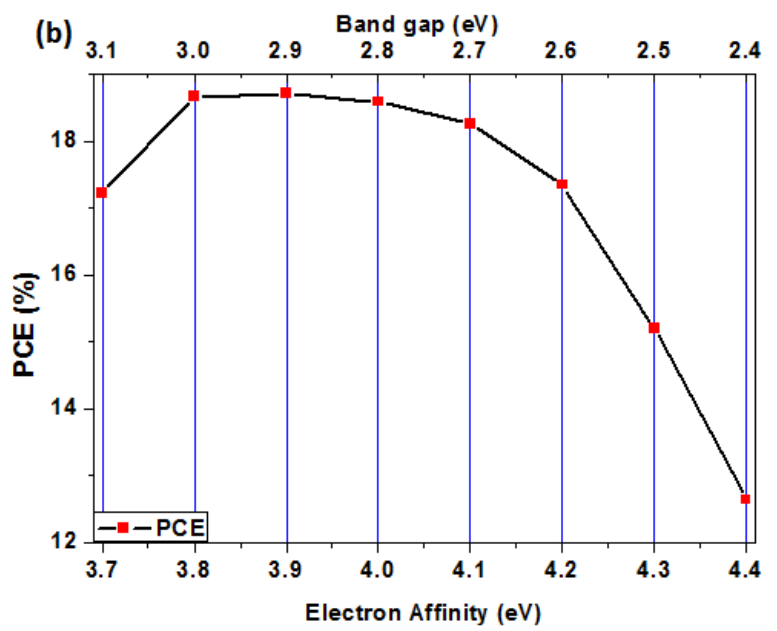

(d)

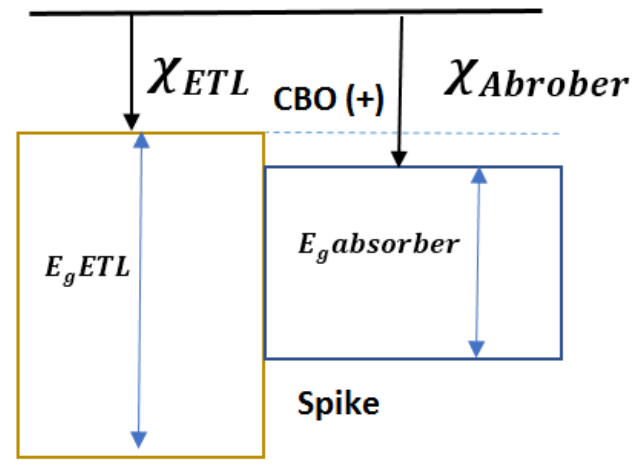

Figure 6.25: (a) Effect of ETL's on solar cell J-V characteristics curve (b) Effect of CBO of $\mathrm{Cd}_{1-\mathrm{x}} \mathrm{Zn}_{\mathrm{X}} \mathrm{S}$ on solar cell performance (c) Band structure for $\chi_{\mathrm{ETL}}>\chi_{\text {Absorber }}(\mathrm{d})$ Band structure for $\chi_{\mathrm{ETL}}<\chi_{\text {Absorber }}$

\section{iv. Effect of absorber layer defect on solar cell performance}

By setting the band offset of HTL and ETL we can improve the PCE of a solar cell by suppressing carrier recombination at the interface but still, PCE of a solar cell cannot get to it maximum theoretical conversion efficiency. The main reason is the defect density in the absorber layer of a solar cell, as the density of these defects in the absorber layer directly affect the photogenerated carrier lifetime and diffusion length. This is well 
expressed from equation 6.7 and equation 6.7 written below. The relation of diffusion length with the mobility of the carrier lifetime is expressed in equation 6.7.

$$
\mathrm{L}_{\mathrm{D}}=\sqrt{\frac{\mu_{(\mathrm{e}, \mathrm{h})}^{\mathrm{kT}}}{\mathrm{q}} \tau_{\text {lifetime }}}
$$

In equation $6.7, \mathrm{~L}_{\mathrm{D}}$ is diffusion length, $\mu_{(\mathrm{e}, \mathrm{h})}$ is mobility for electron and hole, $\tau_{\text {lifetime }}$ is the minority carrier lifetime. Whereas $\tau_{\text {lifetime depended upon defect trap density and }}$ capture cross section area for electron and hole. The relation of $\tau_{\text {lifetime }}$ with bulk defect density is expressed in equation 6.8 .

$$
\tau_{\text {lifetime }}=\frac{1}{\mathrm{~N}_{\mathrm{t}} \delta \mathrm{v}_{\mathrm{th}}}
$$

$\delta$ represents capture cross-section area of electron and hole, $v_{\text {th }}$ represents the thermal velocity of carriers $\left(10^{7} \mathrm{~cm} / \mathrm{s}\right)$ and $\mathrm{N}_{\mathrm{t}}$ density of traps. So, based on equation 6.7 and 6.8 with an increase in traps density the diffusion length of carrier will reduce thus reducing the chance of carrier to reach to the contact. Diffusion length constant can affect the performance of a solar cell and limiting the thickness of the absorber layer. This effect of diffusion length with a change in thickness of absorber material vs PCE is shown in Figure 6.26 below.

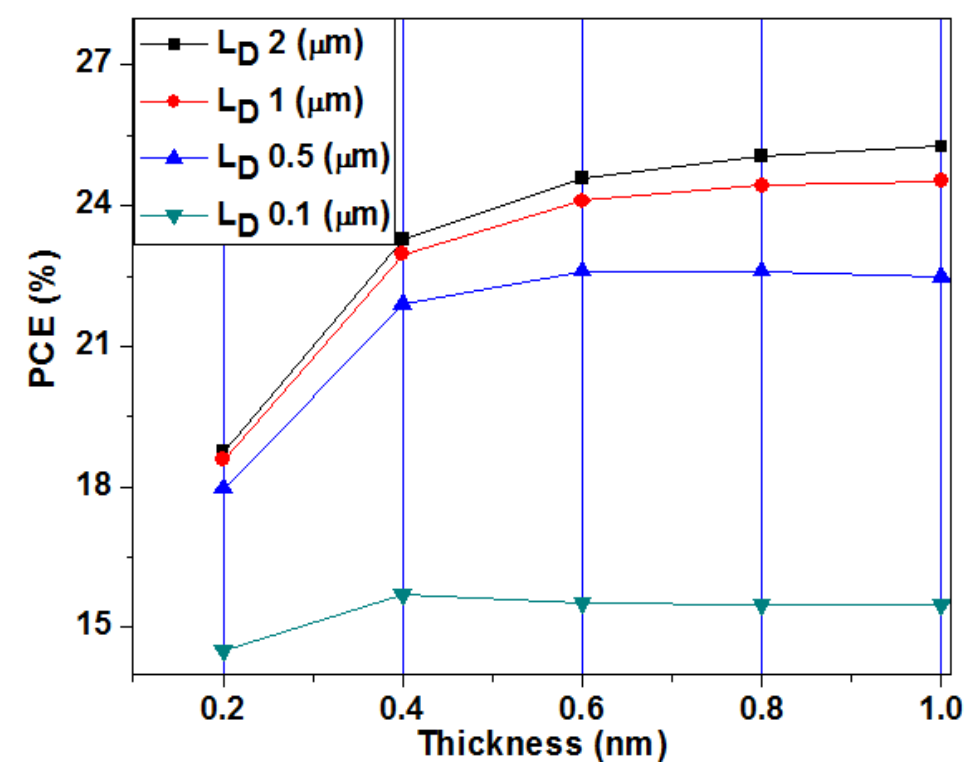

Figure 6.26: PCE vs Absorber thickness for different diffusion lengths

From Figure 6.26 the value of diffusion length limits the optimal thickness of the absorber layer on which we get maximum conversion efficiency. The effect of diffusion length on optimal thickness is well clear for diffusion length of $0.5 \mu \mathrm{m}$ and $0.1 \mu \mathrm{m}$. for $0.5 \mu \mathrm{m}$ the optimal thickness of absorber layer on which maximum PCE was achieved was $0.6 \mu \mathrm{m}$ whereas for $0.1 \mu \mathrm{m}$ the optimal thickness of absorber layer was $0.4 \mu \mathrm{m}$. Based on the results 
it was concluded that the diffusion length of the minority carrier or density of the defect in the absorber layer will limit the optimal thickness of the absorber layer.

\section{v. Comparison of results}

The result evaluated for every single step are plotted in Figure 6.27. And from Figure 6.27, the result for a final optimized solar cell with $\mathrm{Cd}_{1-\mathrm{x}} \mathrm{Zn}_{\mathrm{x}} \mathrm{S}$ as ETL and $\mathrm{MASnBr}_{3}$ as HTL are proven to be a good alternative for the design of high efficiency $\mathrm{MASnI}_{3}$ absorber layer solar cell with PCE of $18.71 \%$.

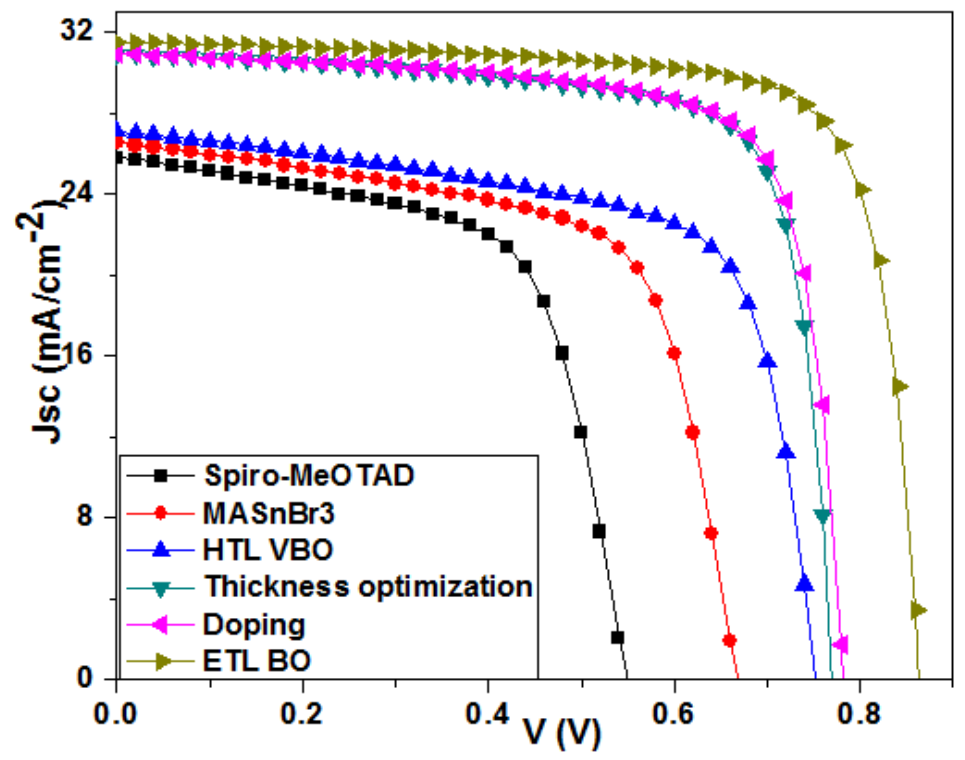

Figure 6.27: Result comparison

The detail of solar cell performance parameters for every action performed in this work is given in Table 6.8.

Table 6.8: Results comparison

\begin{tabular}{|c|c|c|c|c|}
\hline Steps Performed & $\mathbf{V}_{\mathbf{o c}}(\mathbf{V})$ & $\mathrm{J}_{\mathrm{sc}}\left(\mathrm{mA} / \mathbf{c m}^{-2}\right)$ & FF (\%) & $\begin{array}{c}\text { PCE } \\
(\%)\end{array}$ \\
\hline With Spiro-MeOTAD as HTL & 0.55 & 25.82 & 63.31 & 8.97 \\
\hline MASnBr3 as HTL & 0.67 & 26.54 & 65.02 & 11.53 \\
\hline Optimization of Absorber thickness & 0.77 & 30.74 & 67.31 & 15.96 \\
\hline Optimization of Acceptor doping concentration & 0.78 & 30.75 & 67.06 & 16.13 \\
\hline ETL CBO adjustment & 0.87 & 31.42 & 68.88 & 18.71 \\
\hline
\end{tabular}

\subsubsection{Conclusion}

Lead free perovskite solar cell was simulated in this works in SCAPS software. For the first time, a numerical model was presented for lead free HTL layer $\mathrm{MASnBr}_{3}$ with $\mathrm{Cd}_{1-\mathrm{x}} \mathrm{Zn}_{\mathrm{x}} \mathrm{S}$ as ETL for $\mathrm{MASnI}_{3}$ absorber layer. Effect of HTL layer band offset was 
analyzed and based on results it was concluded that HTL band offset can greatly affect solar cell performance. Optimal thickness $(0.5 \mu \mathrm{m})$ and optimal doping concentration of absorber layer $\left(1 \times 10^{16} \mathrm{~cm}^{-3}\right)$ was found in this work and exceeding the optimal limits lead to degradation in solar cell performance. Effect of two different ETL's on solar cell performance was analyzed and it was found that by adjusting the band offset of $\mathrm{Cd}_{1-\mathrm{x}} \mathrm{Zn}_{\mathrm{x}} \mathrm{S}$ layer can lead to a PCE of $18.71 \%$. Effect of the defect density of the absorber layer was analyzed, and it was found that with an increase in defect density will limit the thickness of the absorber layer. The results proposed in this paper should provide a baseline for alternate ETL and HTL layer selection and for the design of an efficient solar cell. 


\section{CHAPTER 7}

\section{CONCLUSION AND FUTURE WORK}


This page intentionally left blank 


\subsection{Conclusion}

Numerical simulation using the solar cell software SCAPS has been used for analyzing the main factors that limit the efficiency of SnS based solar cells. Owing to the optical and electrical characteristics of $\mathrm{SnS}$ semiconductor a photon conversion efficiency of $28 \%$ is expected for solar cells based on SnS absorber. However, up to date, practical solar cell devices do not surpass $4.36 \%$. The proposed method evaluates the efficiency limits of SnS thin film device under the influence of absorber thickness, temperature, band tailing energy and defects in a solar cell. From the analysis, the major limitation in efficiency enhancement of SnS solar cell was absorber thickness, band tailing, interface density defect, and absorber defects. We found that interface defects behave like a serial resistance and reduce the open circuit voltage $\left(\mathrm{V}_{\mathrm{oc}}\right)$, while absorber defects act as recombination centers and limits the short circuit current $\left(\mathrm{J}_{\mathrm{sc}}\right)$. The $\mathrm{J}-\mathrm{V}$ curve and PV parameters of experimental SnS-based solar curve were well fitted by introducing both types of defects in the SnS layer absorber and at the interface of buffer-absorber. The simulation carried out in this work will be very helpful in further investigating the efficiency limits of SnS solar cell.

So, after the investigation of efficiency limits of SnS solar cell, we proposed a numerical model guide about how numerical analysis can aid in the improvement of the power conversion efficiency of experimentally designed solar cell. To perform analysis in first step experimental result was reproduced for SnS absorber layer based solar cell in SCAPS environment. In next step numerical analysis was performed in SCAPS to optimize the parameters of a solar cell like absorber layer thickness, buffer layer thickness, window layer effect, doping density and minority carrier lifetime. From observation, it was found that experimentally designed solar cell efficiency can be enhanced with the aid of numerical analysis. After optimization of physical parameters for a solar cell, PCE jumps from $4.36 \%$ to $14.01 \%$. The result presented in this work can provide a valuable guideline to a researcher for the efficient design of solar cell with optimized parameters.

From numerical analysis guide about how to improve the efficiency of solar cell, we proposed a method for the selection criteria of ETL layer for lead free perovskite solar cell. In the design of high efficiency lead free perovskite solar cell Interface recombination is a major limitation. In this work impact of different ETL and effect of their band alignment on a solar cell, performance was analyzed. From the numerical analysis it was found that conduction band offset can play a significant role in solar cell performance by creating a 
hole barrier at the interface and suppressing the interface recombination. Based on the results it was found that interface recombination of $\mathrm{MASnI}_{3}$ solar cell can be controlled with ETL CBO, ETL thickness, ETL donor doping concentration and absorber doping concertation. With a small - CBO "Spike" at interface is beneficial for efficiency enhancement of solar cell, but too high spike will degrade solar cell performance by impeding the flow of charge carriers. Similarly, ETL with moderate - CBO are less prone to interface recombination with the comparison to ETL having a $+\mathrm{CBO}$ with absorber material. In terms of selection of ETL materials for $\mathrm{MASnI}_{3}$ absorber based solar cell, solar cell with moderate - CBO should be advantageous for ETL choice.

After detail studies of the effect of the defects and effect of an interface layer, band offset on solar cell performance an optimized structure was proposed for lead free perovskite solar cell in SCAPS software. For the first time, a numerical model was presented for lead free HTL layer $M A S n B r_{3}$ with $C d_{1-x} Z n_{x} S$ as ETL for $M A S n I_{3}$ absorber layer. Effect of HTL layer band offset was analyzed and based on results it was concluded that HTL band offset can greatly affect solar cell performance. Optimal thickness $(0.5 \mu \mathrm{m})$ and optimal doping concentration of absorber layer $\left(1 \times 10^{16} \mathrm{~cm}^{-3}\right)$ was found in this work. Effect of two different ETL's on solar cell performance was analyzed and it was found that by adjusting the band offset of $C d_{1-x} Z n_{x} S$ layer can lead to a PCE of $18.71 \%$. Effect of defect density of the absorber layer was analyzed, and it was found that with an increase in defect density will limit the thickness of the absorber layer. The results proposed in this paper should provide a baseline for alternate ETL and HTM layer selection and for the design of an efficient solar cell.

\subsection{Future Work}

The simulations presented here have been done for $\mathrm{SnS}$ and $\mathrm{Sn}$ based organic non-organic metal halide perovskite solar cell on SCAPS-1D. From results, it was evaluated that contact recombination can be reduced by using back surface field and interface recombination can be suppressed by adjusting the band offset of these materials. The simulation model used in this thesis is restricted to one dimension. Therefore, using two or three dimensional computer simulation programs will aid in to effectively analyze the effect of the scattering mechanism of a light photon, photon recycling, grain boundaries, and space charge region. These two dimensions and three dimensions effects will possibly not overturn our current understanding, but they will, however, be of interest for future research. 


\section{References:}

[1] J. Britt, C. Ferekides, Thinfilm CdS / CdTe solar cell with 15 . 8 \% efficiency Thin-film, 2851 (2012) 14-16. doi:10.1063/1.109629.

[2] C.J.J. Tool, A.R. Burgers, P. Manshanden, A.W. Weeber, B.H.M. Van Straaten, Influence of Wafer Thickness on the Performance of Multicrystalline Si Solar Cells : an Experimental Study, 291 (2002) 279-291. doi:10.1002/pip.421.

[3] S. Issue, Thin-Film Solar Cells: An Overview, 92 (2004) 69-92. doi:10.1002/pip.541.

[4] M.A. Green, Thin-film solar cells : review of materials, technologies and commercial status, (2007). doi:10.1007/s10854-007-9177-9.

[5] M. Gloeckler, I. Sankin, Z. Zhao, CdTe Solar Cells at the Threshold to $20 \%$ Efficiency, 3 (2013) 1389-1393.

[6] P. Jackson, D. Hariskos, E. Lotter, S. Paetel, R. Wuerz, R. Menner, W. Wischmann, M. Powalla, New world record efficiency for $\mathrm{Cu}$ ( In , Ga ) Se 2 thin-film solar cells beyond $20 \%$, (2011) 894-897. doi:10.1002/pip.

[7] J. Godt, F. Scheidig, C. Grosse-siestrup, V. Esche, P. Brandenburg, A. Reich, D.A. Groneberg, Journal of Occupational Medicine The toxicity of cadmium and resulting hazards for human health, 6 (2006) 1-6. doi:10.1186/1745-6673-1-22.

[8] D.A.R. Barkhouse, O. Gunawan, T. Gokmen, T.K. Todorov, D.B. Mitzi, Device characteristics of a 10.1\% hydrazine-processed Cu $2 \mathrm{ZnSn}$ ( Se , S ) 4 solar cell, (2012) 6-11. doi:10.1002/pip.

[9] N.K. Reddy, M. Devika, E.S.R. Gopal, Critical Reviews in Solid State and Materials Sciences Review on Tin ( II ) Sulfide ( SnS ) Material: Synthesis, Properties, and Applications Review on Tin ( II ) Sulfide ( SnS ) Material: Synthesis, Properties, and Applications, 8436 (2015). doi:10.1080/10408436.2015.1053601.

[10] G.G. Ninan, C.S. Kartha, K.P. Vijayakumar, Spray pyrolysed SnS thin films in $\mathrm{n}$ and $\mathrm{p}$ type: Optimization of deposition process and characterization of samples, J. Anal. Appl. Pyrolysis. (2016). doi:10.1016/j.jaap.2016.04.016.

[11] F. Niknia, F.J. Ramin, Examining the effect of Zn dopant on physical properties of nanostructured SnS thin film by using electrodeposition, J. Appl. Electrochem. 46 (2016) 323-330. doi:10.1007/s10800-015-0913-1.

[12] R. Chakraborty, P.H. Rekemeyer, R.E. Brandt, A. Polizzotti, C. Yang, A Two-Step Absorber Deposition Approach To Overcome Shunt Losses in Thin- Film Solar Cells : Using Tin Sulfide as a Proof-of-Concept Material System, (2016). doi:10.1021/acsami.6b07198.10.1021/acsami.6b07198.

[13] V. Steinmann, R. Jaramillo, K. Hartman, R. Chakraborty, R.E. Brandt, J.R. Poindexter, Y.S. Lee, L. Sun, A. Polizzotti, H.H. Park, R.G. Gordon, T. Buonassisi, 3 . 88 \% Effi cient 
Tin Sulfi de Solar Cells using Congruent Thermal Evaporation COMMUNICATION, (2014) 1-5. doi:10.1002/adma.201402219.

[14] P.A. Nwofe, R.W. Miles, K.T.R. Reddy, Effects of sulphur and air annealing on the properties of thermally evaporated $\mathrm{SnS}$ layers for application in thin film solar cell devices Effects of sulphur and air annealing on the properties of thermally evaporated $\mathrm{SnS}$ layers for application in thin fil, 011204 (2013) 1-8. doi:10.1063/1.4791784.

[15] H. Ullah, B. Marí, Numerical analysis of $\mathrm{SnS}$ based polycrystalline solar cells, Superlattices Microstruct. 72 (2014) 148-155. doi:10.1016/j.spmi.2014.03.042.

[16] S. De Wolf, J. Holovsky, S.J. Moon, P. Löper, B. Niesen, M. Ledinsky, F.J. Haug, J.H. Yum, C. Ballif, Organometallic halide perovskites: Sharp optical absorption edge and its relation to photovoltaic performance, J. Phys. Chem. Lett. 5 (2014) 1035-1039. doi:10.1021/jz500279b.

[17] C. Quarti, E. Mosconi, J.M. Ball, V. D’Innocenzo, C. Tao, S. Pathak, H.J. Snaith, A. Petrozza, F. De Angelis, Structural and optical properties of methylammonium lead iodide across the tetragonal to cubic phase transition: implications for perovskite solar cells, Energy Environ. Sci. 9 (2016) 155-163. doi:10.1039/C5EE02925B.

[18] Q. Dong, Y. Fang, Y. Shao, P. Mulligan, J. Qiu, L. Cao, J. Huang, Electron-hole diffusion lengths \&gt; 175 m in solution-grown CH3NH3PbI3 single crystals, Science (80-. ). 347 (2015) 967-970. doi:10.1126/science.aaa5760.

[19] W. Liao, D. Zhao, Y. Yu, N. Shrestha, K. Ghimire, C.R. Grice, C. Wang, Y. Xiao, A.J. Cimaroli, R.J. Ellingson, N.J. Podraza, K. Zhu, R.G. Xiong, Y. Yan, Fabrication of Efficient Low-Bandgap Perovskite Solar Cells by Combining Formamidinium Tin Iodide with Methylammonium Lead Iodide, J. Am. Chem. Soc. 138 (2016) 12360-12363. doi:10.1021/jacs.6b08337.

[20] A. Kojima, K. Teshima, Y. Shirai, T. Miyasaka, Organometal Halide Perovskites as Visible-Light Sensitizers for Photovoltaic Cells, J. Am. Chem. Soc. 131 (2009) 6050-6051. doi:10.1021/ja809598r.

[21] J.-H. Im, C.-R. Lee, J.-W. Lee, S.-W. Park, N.-G. Park, 6.5\% Efficient Perovskite Quantum-Dot-Sensitized Solar Cell, Nanoscale. 3 (2011) 4088. doi:10.1039/c1nr10867k.

[22] H.S. Kim, C.R. Lee, J.H. Im, K.B. Lee, T. Moehl, A. Marchioro, S.J. Moon, R. HumphryBaker, J.H. Yum, J.E. Moser, M. Grätzel, N.G. Park, Lead iodide perovskite sensitized allsolid-state submicron thin film mesoscopic solar cell with efficiency exceeding 9\%, Sci. Rep. 2 (2012) 1-7. doi:10.1038/srep00591.

[23] J. Burschka, N. Pellet, S.J. Moon, R. Humphry-Baker, P. Gao, M.K. Nazeeruddin, M. Grätzel, Sequential deposition as a route to high-performance perovskite-sensitized solar cells, Nature. 499 (2013) 316-319. doi:10.1038/nature12340.

[24] M. Liu, M.B. Johnston, H.J. Snaith, Efficient planar heterojunction perovskite solar cells 
by vapour deposition, Nature. 501 (2013) 395-398. doi:10.1038/nature12509.

[25] D.H.L. and A.W.Y.H.-B. Martin A. Green1*, Keith Emery2, Yoshihiro Hishikawa3, Wilhelm Warta4, Ewan D. Dunlop5, Solar cell efficiency tables (version 49) Martin, Prog. PHOTOVOLTAICS Res. Appl. (2016). doi:10.1002/pip.

[26] Y. Yu, D. Zhao, C.R. Grice, W. Meng, C. Wang, W. Liao, A.J. Cimaroli, H. Zhang, K. Zhu, Y. Yan, Thermally evaporated methylammonium tin triiodide thin films for lead-free perovskite solar cell fabrication, RSC Adv. 6 (2016) 90248-90254. doi:10.1039/C6RA19476A.

[27] T. Fujihara, S. Terakawa, T. Matsushima, C. Qin, M. Yahiro, C. Adachi, Fabrication of high coverage MASnI 3 perovskite films for stable, planar heterojunction solar cells, J. Mater. Chem. C. 5 (2017) 1121-1127. doi:10.1039/C6TC05069G.

[28] T.M. Koh, T. Krishnamoorthy, N. Yantara, C. Shi, W.L. Leong, P.P. Boix, A.C. Grimsdale, S.G. Mhaisalkar, N. Mathews, Formamidinium tin-based perovskite with low E $\mathrm{g}$ for photovoltaic applications, J. Mater. Chem. A. 3 (2015) 14996-15000. doi:10.1039/C5TA00190K.

[29] Z. Zhao, F. Gu, Y. Li, W. Sun, S. Ye, H. Rao, Z. Liu, Z. Bian, C. Huang, Mixed-OrganicCation Tin Iodide for Lead-Free Perovskite Solar Cells with an Efficiency of 8.12\%, Adv. Sci. 4 (2017). doi:10.1002/advs.201700204.

[30] F. Hao, C.C. Stoumpos, D.H. Cao, R.P.H. Chang, M.G. Kanatzidis, Lead-free solid-state organic-inorganic halide perovskite solar cells, Nat. Photonics. 8 (2014) 489-494. doi:10.1038/nphoton.2014.82.

[31] F. Baig, Y.H. Khattak, B. Marí, S. Beg, A. Ahmed, K. Khan, Efficiency Enhancement of CH3NH3SnI3 Solar Cells by Device Modeling, J. Electron. Mater. 47 (2018) 5275-5282. doi:10.1007/s11664-018-6406-3.

[32] F. Baig, Y.H. Khattak, S. Ullah, B.M. Soucase, S. Beg, H. Ullah, Numerical analysis a guide to improve the efficiency of experimentally designed solar cell, Appl. Phys. A. 124 (2018) 471. doi:10.1007/s00339-018-1877-x.

[33] pveducation, (n.d.). https://www.pveducation.org/pvcdrom/semiconductor-materials.

[34] A.P.G. U.A.Bakshi, Electronic Circuits - II, Technical Publications, 2009.

[35] T.L. Floyd, Electronic devices : electron flow version / Thomas L. Floyd.- 9th ed., Prentice Hall, n.d.

[36] M. Naidu, Engineering Physics, Pearson Education India, 2009.

[37] L.M. Fraas, History of Solar Cell Development, in: Low-Cost Sol. Electr. Power, Springer International Publishing, Cham, 2014: pp. 1-12. doi:10.1007/978-3-319-07530-3_1.

[38] M.A. Green, Y. Hishikawa, E.D. Dunlop, D.H. Levi, J. Hohl-Ebinger, A.W.Y. Ho-Baillie, Solar cell efficiency tables (version 52), Prog. Photovoltaics Res. Appl. 26 (2018) 427-436. doi:10.1002/pip.3040. 
[39] M.Z. Klaus Jager, Olindo Isabella, Arno H. M. Smets, Rene A. C. M. M. van Swaaij, Solar $\begin{array}{lllll}\text { Energy Fundamentals, Technology and } & \text { Systems, }\end{array}$ doi:10.1007/SpringerReference_29746.

[40] P. Wurfel, Physics of Solar Cells from Principles to nNew Concepts, 2009 doi:10.1002/9783527618545.

[41] F.A. Lindholm, J.G. Fossum, E.L. Burgess, Application of the superposition principle to solar-cell analysis, IEEE Trans. Electron Devices. 26 (1979) 165-171. doi:10.1109/TED.1979.19400.

[42] W. Shockley, W.T. Read, Statistics of the Recombinations of Holes and Electrons, Phys. Rev. 87 (1952) 835-842. doi:10.1103/PhysRev.87.835.

[43] F. Baig, Y.H. Khattak, B. Marí, S. Beg, S.R. Gillani, A. Ahmed, Mitigation of interface recombination by careful selection of ETL for efficiency enhancement of MASnI 3 solar cell, Optik (Stuttg). 170 (2018) 463-474. doi:10.1016/j.ijleo.2018.05.135.

[44] N.J. Woods, S. Hall, On the contribution of recombination currents in Schottky barrier diodes, Semicond. Sci. Technol. 9 (1994) 2295-2297. doi:10.1088/0268-1242/9/12/023.

[45] B. Chen, J. Chen, Y. Shen, K. Ge, J. Guo, F. Li, H. Liu, Y. Xu, Y. Mai, Magnesium thin film as a doping-free back surface field layer for hybrid solar cells, Appl. Phys. Lett. 110 (2017) 133504. doi:10.1063/1.4979345.

[46] H. Wen, H. Cai, Y. Du, X. Dai, Y. Sun, J. Ni, J. Li, D. Zhang, J. Zhang, Improving the organic/Si heterojunction hybrid solar cell property by optimizing PEDOT:PSS film and with amorphous silicon as back surface field, Appl. Phys. A. 123 (2017) 14. doi:10.1007/s00339-016-0612-8.

[47] A. Spies, J. Reinhardt, M. List, B. Zimmermann, U. Würfel, Impact of Charge Carrier Mobility and Electrode Selectivity on the Performance of Organic Solar Cells, in: 2017: pp. 401-418. doi:10.1007/978-3-319-28338-8_17.

[48] F. Baig, Y.H. Khattak, S. Ullah, B. Marí, S. Beg, H. Ullah, Numerical Analysis of a Novel FTO/n-MAPbI 3 /p-MAPbI 3 /p-MAPbBr 3 Organic-Inorganic Lead Halide Perovskite Solar Cell, J. Nanoelectron. Optoelectron. 13 (2018) 1320-1327. doi:10.1166/jno.2018.2363.

[49] C.A. Craig, S. Feng, Exploring utility organization electricity generation, residential electricity consumption, and energy efficiency: A climatic approach, Appl. Energy. 185 (2017) 779-790. doi:10.1016/j.apenergy.2016.10.101.

[50] P. Mir-Artigues, E. Cerdá, P. del Río, Analysing the economic impact of the new renewable electricity support scheme on solar PV plants in Spain, Energy Policy. 114 (2018) 323331. doi:10.1016/j.enpol.2017.11.048.

[51] E. Nuño, P. Maule, A. Hahmann, N. Cutululis, P. Sørensen, I. Karagali, Simulation of transcontinental wind and solar PV generation time series, Renew. Energy. 118 (2018) 425- 
436. doi:10.1016/j.renene.2017.11.039.

[52] A. Honrubia-Escribano, F.J. Ramirez, E. Gómez-Lázaro, P.M. Garcia-Villaverde, M.J. Ruiz-Ortega, G. Parra-Requena, Influence of solar technology in the economic performance of PV power plants in Europe. A comprehensive analysis, Renew. Sustain. Energy Rev. 82 (2018) 488-501. doi:10.1016/j.rser.2017.09.061.

[53] oecd-factbook-2015-2016, (n.d.). https://read.oecd-ilibrary.org/economics/oecd-factbook2015-2016/world-electricity-generation-by-source-of-energy_factbook-2015-graph86en\#page1.

[54] T. Novakov, M.O. Andreae, R. Gabriel, T.W. Kirchstetter, O.L. Mayol-Bracero, V. Ramanathan, Origin of carbonaceous aerosols over the tropical Indian Ocean: Biomass burning or fossil fuels?, Geophys. Res. Lett. 27 (2000) 4061-4064. doi:10.1029/2000GL011759.

[55] K. Caldeira, M.E. Wickett, Anthropogenic carbon and ocean pH, Nature. 425 (2003) 365365. doi:10.1038/425365a.

[56] W.B. Lyons, E. Saelens, K.A. Welch, The impact of fossil fuel burning related to scientific activities in the McMurdo Dry Valleys, Antarctica: Revisited, Elem Sci Anth. 6 (2018) 33. doi:10.1525/elementa.288.

[57] L. Järup, A. Åkesson, Current status of cadmium as an environmental health problem, Toxicol. Appl. Pharmacol. 238 (2009) 201-208. doi:10.1016/j.taap.2009.04.020.

[58] N. Espinosa, M. Hösel, D. Angmo, F.C. Krebs, Solar cells with one-day energy payback for the factories of the future, Energy Environ. Sci. 5 (2012) 5117-5132. doi:10.1039/C1EE02728J.

[59] D. Wang, M. Wright, N.K. Elumalai, A. Uddin, Stability of perovskite solar cells, Sol. Energy Mater. Sol. Cells. 147 (2016) 255-275. doi:10.1016/j.solmat.2015.12.025.

[60] Y.H. Khattak, F. Baig, S. Ullah, B. Marí, S. Beg, H. Ullah, Numerical modeling baseline for high efficiency (Cu 2 FeSnS 4 ) CFTS based thin film kesterite solar cell, Optik (Stuttg). 164 (2018) 547-555. doi:10.1016/j.ijleo.2018.03.055.

[61] R.A. Jabr, M. Hamad, Y.M. Mohanna, Newton-Raphson Solution of Poisson's Equation in a Pn Diode, Int. J. Electr. Eng. Educ. 44 (2007) 23-33. doi:10.7227/IJEEE.44.1.3.

[62] Chenming C. Hu, Modern Semiconductor Devices for Integrated Circuits, in: 2010.

[63] F. Baig, H. Ullah, Y.H. Khattak, B. Mari Soucase, Numerical analysis of SnS Photovoltaic cells, in: 2016 Int. Renew. Sustain. Energy Conf., IEEE, 2016: pp. 596-600. doi:10.1109/IRSEC.2016.7983899.

[64] M.A. Green, Y. Hishikawa, W. Warta, E.D. Dunlop, D.H. Levi, J. Hohl-Ebinger, A.W.H. Ho-Baillie, Solar cell efficiency tables (version 50), Prog. Photovoltaics Res. Appl. 25 (2017) 668-676. doi:10.1002/pip.2909.

[65] C. Yan, K. Sun, J. Huang, S. Johnston, F. Liu, B.P. Veettil, K. Sun, A. Pu, F. Zhou, J.A. 
Stride, M.A. Green, X. Hao, Beyond 11\% Efficient Sulfide Kesterite Cu2ZnxCd1xSnS4Solar Cell: Effects of Cadmium Alloying, ACS Energy Lett. 2 (2017) 930-936. doi:10.1021/acsenergylett.7b00129.

[66] T. Minemoto, S. Harada, H. Takakura, SnS thin film solar cells with Zn 1- x Mg x O buffer layers, Curr. Appl. Phys. 12 (2012) 171-173. doi:10.1063/1.4804603.

[67] H. Fu, Environment-Friendly and Earth-Abundant Colloidal Chalcogenide Nanocrystals for Photovoltaic Applications, J. Mater. Chem. C. (2017). doi:10.1039/C7TC04952H.

[68] A. Zakutayev, V. Stevanovic, S. Lany, Non-equilibrium alloying controls optoelectronic properties in $\mathrm{Cu} 2 \mathrm{O}$ thin films for photovoltaic absorber applications, Appl. Phys. Lett. 106 (2015) 123903. doi:10.1063/1.4914974.

[69] M. Mousavi-Kamazani, Z. Zarghami, M. Salavati-Niasari, Facile and Novel Chemical Synthesis, Characterization, and Formation Mechanism of Copper Sulfide (Cu2S, $\mathrm{Cu} 2 \mathrm{~S} / \mathrm{CuS}, \mathrm{CuS}$ ) Nanostructures for Increasing the Efficiency of Solar Cells, J. Phys. Chem. C. 120 (2016) 2096-2108. doi:10.1021/acs.jpcc.5b11566.

[70] V.R. Minnam Reddy, S. Gedi, C. Park, M. R.w, R.R. Ramakrishna, Development of sulphurized SnS thin film solar cells, Curr. Appl. Phys. 15 (2015) 588-598. doi:10.1016/j.cap.2015.01.022.

[71] J.A. Andrade-Arvizu, M. Courel-Piedrahita, O. Vigil-Galán, SnS-based thin film solar cells: perspectives over the last 25 years, J. Mater. Sci. Mater. Electron. 26 (2015) $4541-$ 4556. doi:10.1007/s10854-015-3050-z.

[72] P. Sinsermsuksakul, L. Sun, S.W. Lee, H.H. Park, S.B. Kim, C. Yang, R.G. Gordon, Overcoming Efficiency Limitations of SnS-Based Solar Cells, Adv. Energy Mater. 4 (2014) 1-7. doi:10.1002/aenm.201400496.

[73] W. Albers, C. Haas, H. Ober, G.R. Schodder, J.D. Wasscher, Preparation and properties of mixed crystals SnS(1-x)Sex, J. Phys. Chem. Solids. 23 (1962) 215-220. doi:10.1016/00223697(62)90004-5.

[74] M.M. Nassary, Temperature dependence of the electrical conductivity, Hall effect and thermoelectric power of SnS single crystals, J. Alloys Compd. 398 (2005) 21-25. doi:10.1016/j.jallcom.2005.02.025.

[75] A. Niemegeers, M. Burgelman, MODELLING OF ac-CHARACTERISTICS SOLAR CELLS, 1996 22nd IEEE Photovoltaics Spec. Conf. (1996) 901-904.

[76] M. Burgelman, P. Nollet, S. Degrave, Modelling polycrystalline semiconductor solar cells, Thin Solid Films. 361 (2000) 527-532. doi:10.1016/S0040-6090(99)00825-1.

[77] F. Baig, Y.H. Khattak, B. Mari, S. Ullah, H. Ullah, S. Ahmed, Efficiency enhancement of SnS solar cell using back surface field, in: 2018 1st Int. Conf. Power, Energy Smart Grid, IEEE, 2018: pp. 1-5. doi:10.1109/ICPESG.2018.8384496.

[78] T. Gotoh, Sub-gap absorption study of $\mathrm{SnS}$ films deposited by thermal evaporation of 
sulfurized Sn powder, Phys. Status Solidi. 9 (2012) 2407-2410. doi:10.1002/pssc.201200274.

[79] T. Minemoto, M. Murata, Device modeling of perovskite solar cells based on structural similarity with thin film inorganic semiconductor solar cells, J. Appl. Phys. 116 (2014) 054505. doi:10.1063/1.4891982.

[80] O.D. Miller, E. Yablonovitch, S.R. Kurtz, Strong Internal and External Luminescence as Solar Cells Approach the Shockley-Queisser Limit, IEEE J. Photovoltaics. 2 (2012) 303311. doi:10.1109/JPHOTOV.2012.2198434.

[81] J. Xu, Y. Yang, Study on the performances of SnS heterojunctions by numerical analysis, Energy Convers. Manag. 78 (2014) 260-265. doi:10.1016/j.enconman.2013.10.062.

[82] S. Lin, X. Li, H. Pan, H. Chen, X. Li, Y. Li, J. Zhou, Numerical analysis of SnS homojunction solar cell, Superlattices Microstruct. 91 (2016) 375-382. doi:10.1016/j.spmi.2016.01.037.

[83] A. Verma, P. Asthana, Modeling of Thin Film Solar Photovoltaic Based on Zno/SnS OxideAbsorber, (n.d.).

[84] K.T. Ramakrishna Reddy, N. Koteswara Reddy, R.W. Miles, Photovoltaic properties of SnS based solar cells, Sol. Energy Mater. Sol. Cells. 90 (2006) 3041-3046. doi:10.1016/j.solmat.2006.06.012.

[85] H. Noguchi, A. Setiyadi, H. Tanamura, T. Nagatomo, O. Omoto, Characterization of vacuum-evaporated tin sulfide film for solar cell materials, Sol. Energy Mater. Sol. Cells. 35 (1994) 325-331. doi:10.1016/0927-0248(94)90158-9.

[86] N. Koteswara Reddy, K.T. Ramakrishna Reddy, Tin sulphide films for solar cell application, in: Conf. Rec. Twenty Sixth IEEE Photovolt. Spec. Conf. - 1997, IEEE, n.d.: pp. 515-518. doi:10.1109/PVSC.1997.654141.

[87] B. Ghosh, M. Das, P. Banerjee, S. Das, Fabrication of vacuum-evaporated SnS/CdS heterojunction for PV applications, Sol. Energy Mater. Sol. Cells. 92 (2008) 1099-1104. doi:10.1016/j.solmat.2008.03.016.

[88] A. Schneikart, H.-J. Schimper, A. Klein, W. Jaegermann, Efficiency limitations of thermally evaporated thin-film SnS solar cells, J. Phys. D. Appl. Phys. 46 (2013) 305109. doi:10.1088/0022-3727/46/30/305109.

[89] Y. Kawano, J. Chantana, T. Minemoto, Impact of growth temperature on the properties of SnS film prepared by thermal evaporation and its photovoltaic performance, Curr. Appl. Phys. 15 (2015) 897-901. doi:10.1016/j.cap.2015.03.026.

[90] M. Gunasekaran, M. Ichimura, Photovoltaic cells based on pulsed electrochemically deposited SnS and photochemically deposited CdS and Cd1-xZnxS, Sol. Energy Mater. Sol. Cells. 91 (2007) 774-778. doi:10.1016/j.solmat.2006.10.026.

[91] T. Ikuno, R. Suzuki, K. Kitazumi, N. Takahashi, N. Kato, K. Higuchi, SnS thin film solar 
cells with Zn1-xMgxO buffer layers, Appl. Phys. Lett. 102 (2013) 193901. doi:10.1063/1.4804603.

[92] V.R. Minnam Reddy, S. Gedi, C. Park, M. R.W., R.R. K.T., Development of sulphurized SnS thin film solar cells, Curr. Appl. Phys. 15 (2015) 588-598. doi:10.1016/j.cap.2015.01.022.

[93] P. Sinsermsuksakul, K. Hartman, S. Bok Kim, J. Heo, L. Sun, H. Hejin Park, R. Chakraborty, T. Buonassisi, R.G. Gordon, Enhancing the efficiency of SnS solar cells via band-offset engineering with a zinc oxysulfide buffer layer, Appl. Phys. Lett. 102 (2013) 053901. doi:10.1063/1.4789855.

[94] H.H. Park, R. Heasley, L. Sun, V. Steinmann, R. Jaramillo, K. Hartman, R. Chakraborty, P. Sinsermsuksakul, D. Chua, T. Buonassisi, R.G. Gordon, Co-optimization of SnS absorber and $\mathrm{Zn}(\mathrm{O}, \mathrm{S})$ buffer materials for improved solar cells, Prog. Photovoltaics Res. Appl. 23 (2015) 901-908. doi:10.1002/pip.2504.

[95] V. Steinmann, R. Jaramillo, K. Hartman, R. Chakraborty, R.E. Brandt, J.R. Poindexter, Y.S. Lee, L. Sun, A. Polizzotti, H.H. Park, R.G. Gordon, T. Buonassisi, 3.88\% Efficient Tin Sulfide Solar Cells using Congruent Thermal Evaporation, Adv. Mater. 26 (2014) 7488-7492. doi:10.1002/adma.201402219.

[96] P. Sinsermsuksakul, L. Sun, S.W. Lee, H.H. Park, S.B. Kim, C. Yang, R.G. Gordon, Overcoming Efficiency Limitations of SnS-Based Solar Cells, Adv. Energy Mater. 4 (2014) 1400496. doi:10.1002/aenm.201400496.

[97] Y. Wang, H. Gong, B. Fan, G. Hu, Photovoltaic Behavior of Nanocrystalline SnS/TiO 2, J. Phys. Chem. C. 114 (2010) 3256-3259. doi:10.1021/jp9075756.

[98] S. Gedi, V.R. Minna Reddy, B. Pejjai, C.-W. Jeon, C. Park, R.R. K.T., A facile inexpensive route for SnS thin film solar cells with SnS 2 buffer, Appl. Surf. Sci. 372 (2016) 116-124. doi:10.1016/j.apsusc.2016.03.032.

[99] G. Yue, Y. Lin, X. Wen, L. Wang, D. Peng, SnS homojunction nanowire-based solar cells, J. Mater. Chem. 22 (2012) 16437. doi:10.1039/c2jm32116e.

[100] T.H. Sajeesh, N. Poornima, C.S. Kartha, K.P. Vijayakumar, Unveiling the defect levels in $\mathrm{SnS}$ thin films for photovoltaic applications using photoluminescence technique, Phys. Status Solidi. 207 (2010) 1934-1939. doi:10.1002/pssa.200925593.

[101] K.T. Ramakrishna Reddy, P.A. Nwofe, R.W. Miles, Determination of the minority carrier diffusion length of SnS using electro-optical measurements, Electron. Mater. Lett. 9 (2013) 363-366. doi:10.1007/s13391-013-2194-3.

[102] M. Burgelman, P. Nollet, S. Degrave, Modelling polycrystalline semiconductor solar cells, Thin Solid Films. 361-362 (2000) 527-532. doi:10.1016/S0040-6090(99)00825-1.

[103] N. Amin, K. Sopian, M. Konagai, Numerical modeling of CdS/CdTe and CdS/CdTe/ZnTe solar cells as a function of CdTe thickness, Sol. Energy Mater. Sol. Cells. 91 (2007) 1202- 
1208. doi:10.1016/j.solmat.2007.04.006.

[104] R. Chakraborty, V. Steinmann, N.M. Mangan, R.E. Brandt, J.R. Poindexter, R. Jaramillo, J.P. Mailoa, K. Hartman, A. Polizzotti, C. Yang, R.G. Gordon, T. Buonassisi, Nonmonotonic effect of growth temperature on carrier collection in SnS solar cells, Appl. Phys. Lett. 106 (2015) 203901. doi:10.1063/1.4921326.

[105] P.A. Nwofe, R.W. Miles, K.T. Ramakrishna Reddy, Effects of sulphur and air annealing on the properties of thermally evaporated $\mathrm{SnS}$ layers for application in thin film solar cell devices, J. Renew. Sustain. Energy. 5 (2013) 011204. doi:10.1063/1.4791784.

[106] A. Polizzotti, A. Faghaninia, J.R. Poindexter, L. Nienhaus, V. Steinmann, R.L.Z. Hoye, A. Felten, A. Deyine, N.M. Mangan, J.P. Correa-Baena, S.S. Shin, S. Jaffer, M.G. Bawendi, C. Lo, T. Buonassisi, Improving the Carrier Lifetime of Tin Sulfide via Prediction and Mitigation of Harmful Point Defects, J. Phys. Chem. Lett. 8 (2017) 3661-3667. doi:10.1021/acs.jpclett.7b01406.

[107] Y.H. Khattak, F. Baig, H. Toura, S. Ullah, B. Marí, S. Beg, H. Ullah, Effect of CZTSe BSF and minority carrier life time on the efficiency enhancement of CZTS kesterite solar cell, Curr. Appl. Phys. 18 (2018) 633-641. doi:10.1016/j.cap.2018.03.013.

[108] A.R. Garcia-Angelmo, R. Romano-Trujillo, J. Campos-Álvarez, O. Gomez-Daza, M.T.S. Nair, P.K. Nair, Thin film solar cell of SnS absorber with cubic crystalline structure, Phys. Status Solidi. 212 (2015) 2332-2340. doi:10.1002/pssa.201532405.

[109] M. DE GRAEF, M.E. McHENRY, Structure of Materials AN INTRODUCTION TO CRYSTALLOGRAPHY, DIFFRACTION AND SYMMETRY, Cambridge University Press, n.d.

[110] D.B. Mitzi, Templating and structural engineering in organic-inorganic perovskites, J. Chem. Soc. Dalt. Trans. (2001) 1-12. doi:10.1039/b007070j.

[111] A.G. Chynoweth, Surface Space-Charge Layers in Barium Titanate, Phys. Rev. 102 (1956) 705-714. doi:10.1103/PhysRev.102.705.

[112] A. Kojima, K. Teshima, Y. Shirai, T. Miyasaka, Organometal Halide Perovskites as Visible-Light Sensitizers for Photovoltaic Cells, J. Am. Chem. Soc. 131 (2009) 6050-6051. doi:10.1021/ja809598r.

[113] J.-H. Im, C.-R. Lee, J.-W. Lee, S.-W. Park, N.-G. Park, 6.5\% efficient perovskite quantumdot-sensitized solar cell, Nanoscale. 3 (2011) 4088. doi:10.1039/c1nr10867k.

[114] N. Pellet, P. Gao, G. Gregori, T.-Y. Yang, M.K. Nazeeruddin, J. Maier, M. Grätzel, MixedOrganic-Cation Perovskite Photovoltaics for Enhanced Solar-Light Harvesting, Angew. Chemie. 126 (2014) 3215-3221. doi:10.1002/ange.201309361.

[115] J. Burschka, N. Pellet, S.-J. Moon, R. Humphry-Baker, P. Gao, M.K. Nazeeruddin, M. Grätzel, Sequential deposition as a route to high-performance perovskite-sensitized solar cells, Nature. 499 (2013) 316-319. doi:10.1038/nature12340. 
[116] M. Liu, M.B. Johnston, H.J. Snaith, Efficient planar heterojunction perovskite solar cells by vapour deposition, Nature. 501 (2013) 395-398. doi:10.1038/nature12509.

[117] J.T.-W. Wang, J.M. Ball, E.M. Barea, A. Abate, J.A. Alexander-Webber, J. Huang, M. Saliba, I. Mora-Sero, J. Bisquert, H.J. Snaith, R.J. Nicholas, Low-Temperature Processed Electron Collection Layers of Graphene/TiO 2 Nanocomposites in Thin Film Perovskite Solar Cells, Nano Lett. 14 (2014) 724-730. doi:10.1021/n1403997a.

[118] D. Liu, T.L. Kelly, Perovskite solar cells with a planar heterojunction structure prepared using room-temperature solution processing techniques, Nat. Photonics. 8 (2014) 133-138. doi:10.1038/nphoton.2013.342.

[119] K. Wojciechowski, M. Saliba, T. Leijtens, A. Abate, H.J. Snaith, Sub-150 ${ }^{\circ}$ C processed meso-superstructured perovskite solar cells with enhanced efficiency, Energy Environ. Sci. 7 (2014) 1142-1147. doi:10.1039/C3EE43707H.

[120] P. Bhatt, K. Pandey, P. Yadav, B. Tripathi, P. Chandra Kanth, M.K. Pandey, M. Kumar, Investigating the charge carrier transport within the hole-transport material free perovskite solar cell processed in ambient air, Sol. Energy Mater. Sol. Cells. 140 (2015) 320-327. doi:10.1016/j.solmat.2015.04.028.

[121] A. Albadri, P. Yadav, M. Alotaibi, N. Arora, A. Alyamani, H. Albrithen, M.I. Dar, S.M. Zakeeruddin, M. Grätzel, Unraveling the Impact of Rubidium Incorporation on the Transport-Recombination Mechanisms in Highly Efficient Perovskite Solar Cells by Small-Perturbation Techniques, J. Phys. Chem. C. 121 (2017) 24903-24908. doi:10.1021/acs.jpcc.7b04766.

[122] S.D. Stranks, G.E. Eperon, G. Grancini, C. Menelaou, M.J.P. Alcocer, T. Leijtens, L.M. Herz, A. Petrozza, H.J. Snaith, Electron-Hole Diffusion Lengths Exceeding 1 Micrometer in an Organometal Trihalide Perovskite Absorber, Science (80-. ). 342 (2013) 341-344. doi:10.1126/science.1243982.

[123] L. Huang, X. Sun, C. Li, R. Xu, J. Xu, Y. Du, Y. Wu, J. Ni, H. Cai, J. Li, Z. Hu, J. Zhang, Electron transport layer-free planar perovskite solar cells: Further performance enhancement perspective from device simulation, Sol. Energy Mater. Sol. Cells. 157 (2016) 1038-1047. doi:10.1016/j.solmat.2016.08.025.

[124] Z. Wang, Q. Dong, Y. Xia, H. Yu, K. Zhang, X. Liu, X. Guo, Y. Zhou, M. Zhang, B. Song, Copolymers based on thiazolothiazole-dithienosilole as hole-transporting materials for high efficient perovskite solar cells, Org. Electron. $33 \quad$ (2016) 142-149. doi:10.1016/j.orgel.2016.03.020.

[125] L. Huang, Z. Hu, J. Xu, X. Sun, Y. Du, J. Ni, H. Cai, J. Li, J. Zhang, Efficient planar perovskite solar cells without a high temperature processed titanium dioxide electron transport layer, Sol. Energy Mater. Sol. Cells. 149 (2016) 1-8. doi:10.1016/j.solmat.2015.12.033. 
[126] K.R. Adhikari, S. Gurung, B.K. Bhattarai, B.M. Soucase, Comparative study on MAPbI3 based solar cells using different electron transporting materials, Phys. Status Solidi Curr. Top. Solid State Phys. 13 (2016) 13-17. doi:10.1002/pssc.201510078.

[127] T. Minemoto, M. Murata, (SCAPS) Device modeling of perovskite solar cells based on structural similarity with thin film inorganic semiconductor solar cells Device modeling of perovskite solar cells based on structural similarity with thin film inorganic semiconductor solar cells, 054505 (2016). doi:10.1063/1.4891982.

[128] P. Yadav, K. Pandey, P. Bhatt, D. Raval, B. Tripathi, C. Kanth P., M.K. Pandey, M. Kumar, Exploring the performance limiting parameters of perovskite solar cell through experimental analysis and device simulation, Sol. Energy. 122 (2015) 773-782. doi:10.1016/j.solener.2015.09.046.

[129] Y.H. Khattak, F. Baig, S. Ullah, B. Marí, S. Beg, H. Ullah, Enhancement of the conversion efficiency of thin film kesterite solar cell, J. Renew. Sustain. Energy. 10 (2018) 033501. doi:10.1063/1.5023478.

[130] Y.H. Khattak, F. Baig, H. Toura, S. Ullah, B. Marí, S. Beg, H. Ullah, Effect of CZTSe BSF and minority carrier life time on the efficiency enhancement of CZTS kesterite solar cell, Curr. Appl. Phys. 18 (2018) 633-641. doi:10.1016/j.cap.2018.03.013.

[131] Y.H. Khattak, F. Baig, S. Ullah, B. Marí, S. Beg, H. Ullah, Numerical Modeling Baseline for high efficiency ( $\mathrm{Cu} 2 \mathrm{FeSnS} 4$ ) CFTS based Thin Film Kesterite Solar Cell, Optik (Stuttg). 164 (2018) 547-555. doi:10.1016/j.ijleo.2018.03.055.

[132] H. Zhou, Q. Chen, G. Li, S. Luo, T.B. Song, H.S. Duan, Z. Hong, J. You, Y. Liu, Y. Yang, Interface engineering of highly efficient perovskite solar cells, Science (80-. ). 345 (2014) 542-546. doi:10.1126/science.1254050.

[133] H. Wilhelm, H.W. Schock, R. Scheer, Interface recombination in heterojunction solar cells: Influence of buffer layer thickness, J. Appl. Phys. 109 (2011). doi:10.1063/1.3554409.

[134] H.-J. Du, W.-C. Wang, J.-Z. Zhu, Device simulation of lead-free $\mathrm{CH}_{3} \mathrm{NH}_{3} \mathrm{SnI}_{3}$ perovskite solar cells with high efficiency, Chinese Phys. B. 25 (2016) 108802. doi:10.1088/16741056/25/10/108802.

[135] S. Benabbas, Z. Rouabah, N. Bouarissa, N. Chelali, The role of back surface field SnS layer in improvement of efficiency of CdTe thin film solar cells, Optik (Stuttg). 127 (2016) 62106217. doi:10.1016/j.ijleo.2016.04.050.

[136] F. Zhang, Y. Zheng, Y. Cao, C. Chen, Y. Zhan, X. Lin, Q. Zheng, K. Wei, J. Zhu, Ordered mesoporous Ag-TiO2-KIT-6 heterostructure: synthesis, characterization and photocatalysis, J. Mater. Chem. 19 (2009) 2771. doi:10.1039/b818495j.

[137] L.-Y. Lin, Y. Qiu, Y. Zhang, H. Zhang, Analysis of Effect of $\mathrm{Zn}(\mathrm{O}, \mathrm{S})$ Buffer Layer Properties on CZTS Solar Cell Performance Using AMPS, Chinese Phys. Lett. 33 (2016) 107801. doi:10.1088/0256-307X/33/10/107801. 
[138] N. Barreau, S. Marsillac, J.C. Bernède, L. Assmann, Evolution of the band structure of $\beta$ In2S3 - 3xO3x buffer layer with its oxygen content, J. Appl. Phys. 93 (2003) 5456-5459. doi:10.1063/1.1565823.

[139] L.A. Burton, T.J. Whittles, D. Hesp, W.M. Linhart, J.M. Skelton, B. Hou, R.F. Webster, G. O’Dowd, C. Reece, D. Cherns, D.J. Fermin, T.D. Veal, V.R. Dhanak, A. Walsh, Electronic and optical properties of single crystal $\mathrm{SnS}_{2}$ : an earth-abundant disulfide photocatalyst, J. Mater. Chem. A. 4 (2016) 1312-1318. doi:10.1039/C5TA08214E.

[140] S. Yaşar, S. Kahraman, S. Çetinkaya, Apaydın, Bilican, Uluer, Numerical thickness optimization study of CIGS based solar cells with wxAMPS, Optik (Stuttg). 127 (2016) 8827-8835. doi:10.1016/j.ijleo.2016.06.094.

[141] Y. Hinuma, A. Grüneis, G. Kresse, F. Oba, Band alignment of semiconductors from density-functional theory and many-body perturbation theory, Phys. Rev. B. 90 (2014) 155405. doi:10.1103/PhysRevB.90.155405.

[142] K. Pandey, D. Singh, S.K. Gupta, P. Yadav, Y. Sonvane, I. Lukačević, M. Kumar, M. Kumar, R. Ahuja, Improving electron transport in the hybrid perovskite solar cells using CaMnO3-based buffer layer, Nano Energy. $45 \quad$ (2018) 287-297. doi:10.1016/j.nanoen.2018.01.009.

[143] T. Minemoto, M. Murata, Theoretical analysis on effect of band offsets in perovskite solar cells, Sol. Energy Mater. Sol. Cells. 133 (2015) 8-14. doi:10.1016/j.solmat.2014.10.036.

[144] P. Yadav, M.H. Alotaibi, N. Arora, M.I. Dar, S.M. Zakeeruddin, M. Grätzel, Influence of the Nature of A Cation on Dynamics of Charge Transfer Processes in Perovskite Solar Cells, Adv. Funct. Mater. 1706073 (2017) 1706073. doi:10.1002/adfm.201706073.

[145] X. Zheng, B. Chen, M. Yang, C. Wu, B. Orler, R.B. Moore, K. Zhu, S. Priya, The Controlling Mechanism for Potential Loss in CH3NH3PbBr3Hybrid Solar Cells, ACS Energy Lett. 1 (2016) 424-430. doi:10.1021/acsenergylett.6b00215.

[146] S. Ullah, H. Ullah, M. Mollar, B. Mari, Fabrication of Cd1-xZnxS buffer layer deposited by Chemical Bath Deposition for photovoltaic applications, in: 2016 Int. Renew. Sustain. Energy Conf., IEEE, 2016: pp. 94-97. doi:10.1109/IRSEC.2016.7983932.

[147] J.S.J. Song, S.S. Li, S. Yoon, W.K. Kim, J.K.J. Kim, J. Chen, V. Craciun, T.J. Anderson, O.D. Crisalle, F.R.F. Ren, Growth and characterization of $\mathrm{CdZnS}$ thin film buffer layers by chemical bath deposition, Conf. Rec. Thirty-First IEEE Photovolt. Spec. Conf. 2005. (2005) 5-8. doi:10.1109/PVSC.2005.1488166.

[148] L.L. Baranowski, S. Christensen, A.W. Welch, S. Lany, M. Young, E.S. Toberer, A. Zakutayev, Conduction band position tuning and Ga-doping in $(\mathrm{Cd}, \mathrm{Zn}) \mathrm{S}$ alloy thin films, Mater. Chem. Front. 1 (2017) 1342-1348. doi:10.1039/C6QM00291A.

[149] K.T.R. Reddy, P.J. Reddy, Studies of Zn x Cd 1-x S films and Zn x Cd 1-x S/CuGaSe 2 heterojunction solar cells, J. Phys. D. Appl. Phys. 25 (1992) 1345-1348. doi:10.1088/0022- 
$3727 / 25 / 9 / 011$

[150] U. Rau, H.W. Schock, Electronic properties of $\mathrm{Cu}(\mathrm{In}, \mathrm{Ga}) \mathrm{Se} 2$ heterojunction solar cellsrecent achievements, current understanding, and future challenges, Appl. Phys. A Mater. Sci. Process. 69 (1999) 131-147. doi:10.1007/s003390050984.

[151] M. Turcu, U. Rau, Fermi level pinning at $\mathrm{CdS} / \mathrm{Cu}(\mathrm{In}, \mathrm{Ga})(\mathrm{Se}, \mathrm{S}) 2$ interfaces: Effect of chalcopyrite alloy composition, J. Phys. Chem. Solids. 64 (2003) 1591-1595. doi:10.1016/S0022-3697(03)00137-9.

[152] K. Tanaka, T. Minemoto, H. Takakura, Analysis of heterointerface recombination by Zn1xMgxO for window layer of $\mathrm{Cu}(\mathrm{In}, \mathrm{Ga}) \mathrm{Se} 2$ solar cells, Sol. Energy. 83 (2009) 477-479. doi:10.1016/j.solener.2008.09.003. 
This page intentionally left blank 


\section{LIST OF PUBLICATIONS}

[1] F. Baig, Y.H. Khattak, S. Ullah, B.M. Soucase, S. Beg, H. Ullah, Numerical analysis a guide to improve the efficiency of experimentally designed solar cell, Appl. Phys. A. 124 (2018) 471. doi:10.1007/s00339-018-1877-x.

[2] F. Baig, Y.H. Khattak, B. Marí, S. Beg, S.R. Gillani, A. Ahmed, Mitigation of interface recombination by careful selection of ETL for efficiency enhancement of MASnI3 solar cell, Optik. 170 (2018) 463-474. doi:10.1016/j.ijleo.2018.05.135.

[3] F. Baig, Y.H. Khattak, B. Marí, S. Beg, A. Ahmed, K. Khan, Efficiency Enhancement of CH3NH3SnI3 Solar Cells by Device Modeling, J. Electron. Mater. 47 (2018) 5275-5282. doi:10.1007/s11664-018-6406-3.

[4] F. Baig, H. Ullah, Y.H. Khattak, B. Mari Soucase, Numerical analysis of SnS Photovoltaic cells, in: 2016 Int. Renew. Sustain. Energy Conf., IEEE, 2016: pp. 596-600. doi:10.1109/IRSEC.2016.7983899.

[5] F. Baig, Y.H. Khattak, B. Mari, S. Ullah, H. Ullah, S. Ahmed, Efficiency enhancement of SnS solar cell using back surface field, in: 2018 1st Int. Conf. Power, Energy Smart Grid, IEEE, 2018: pp. 1-5. doi:10.1109/ICPESG.2018.8384496.

[6] Y.H. Khattak, F. Baig, S. Ullah, B.M. Soucase, S. Beg, H. Ullah, Enhancement of the conversion efficiency of thin film kesterite solar cell, J. Renew. Sustain. Energy. 10 (2018) 033501. doi:10.1063/1.5023478.

[7] Y.H. Khattak, F. Baig, H. Toura, S. Ullah, B.M. Soucase, S. Beg, H. Ullah, Effect of CZTSe BSF and minority carrier life time on the efficiency enhancement of CZTS kesterite solar cell, Curr. Appl. Phys. 18 (2018) 633-641. doi:10.1016/j.cap.2018.03.013.

[8] Y.H. Khattak, F. Baig, S. Ullah, B.M. Soucase, S. Beg, H. Ullah, Numerical modeling baseline for high efficiency $(\mathrm{Cu} 2 \mathrm{FeSnS} 4)$ CFTS based thin film kesterite solar cell, Optik (Stuttg). 164 (2018) 547-555. doi:10.1016/j.ijleo.2018.03.055.

[9] Y.H. Khattak, F. Baig, S. Ullah, B.M. Soucase, S. Beg, H. Ullah, Efficiency Enhancement of Cu2FeSnS4 Based Thin Film Solar Cell: A Numerical Analysis, J. Nanoelectron. Optoelectron. 13 (2018) 1096-1101. doi:10.1166/jno.2018.2337.

[10] Y.H. Khattak, F. Baig, B.M. Soucase, S. Beg, S.R. Gillani,T. Ahmed, Effect of CdTe Back Surface Field on the Efficiency Enhancement of a CGS Based Thin 
Film Solar Cell, J. Electron. Mater. 47 (2018) 5183-5190. doi:10.1007/s11664018-6405-4.

[11] F. Baig, Y.H. Khattak, B.M. Soucase, S. Beg, S.Ullah, Effect of anionic bath temperature on morphology and photo electrochemical properties of $\mathrm{Cu} 2 \mathrm{O}$ deposited by SILAR, Mater. Sci. Semicond. Process. 88 (2018) 35-39. doi:10.1016/j.mssp.2018.07.031.

[12] Y.H. Khattak, F. Baig, B.M. Soucase, S. Beg, S.R. Gillani, S. Ahmed, Efficiency enhancement of novel CNTS/ZnS/Zn(O,S) thin film solar cell, Optik (Stuttg). 171 (2018) 453-462. doi:10.1016/j.ijleo.2018.06.001.

[13] Y.H. Khattak, F. Baig, S. Ullah, B.M. Soucase, S. Beg, K. Khan, Effect of Cu2O hole transport layer and improved minority carrier life time on the efficiency enhancement of $\mathrm{Cu} 2 \mathrm{NiSnS} 4$ based experimental solar cell, J. Renew. Sustain. Energy. 10 (2018) 043502. doi:10.1063/1.5037471.

[14] F. Baig, Y.H. Khattak, B.M. Soucase, S. Beg, S.R. Gillani, S. Ahmed, A Baseline for the Numerical Study of Sb2Se3 Absorber Material Based Solar Cell, J. Nanoelectron. Optoelectron. 14 (2019) 72-79. doi:10.1166/jno.2019.2451.

[15] Y.H. Khattak, F. Baig, B.M. Soucase, S. Beg, S.R. Gillani, S. Ahmed, Effect of $\mathrm{Cu} 2 \mathrm{O}$ Back Surface Field on the Efficiency Enhancement of CZTSe Kesterite Photovoltaic Cell, Mater. Focus. 7 (2018) 604-609. doi:10.1166/mat.2018.1563.

[16] Y.H. Khattak, F. Baig, B.M. Soucase, S. Beg, S. Ahmed, Baseline for the Numerical Analysis of High Efficiency Copper Manganese Tin Sulfide Cu2MnSnS4 Based Thin Film Solar Cell, J. Nanoelectron. Optoelectron. 13 (2018) 1678-1684. doi:10.1166/jno.2018.2421.

[17] F. Baig, Y.H. Khattak, S. Ullah, B.M. Soucase, S. Beg, H. Ullah, Numerical Analysis of a Novel FTO/n-MAPbI3/p-MAPbI3/p-MAPbBr3 Organic-Inorganic Lead Halide Perovskite Solar Cell, J. Nanoelectron. Optoelectron. 13 (2018) 1320 1327. doi:10.1166/jno.2018.2363.

[18] H. Bayad, A. El Manouni, B.M. Soucase, Y.H. Khattak, S. Ullah, F. Baig, Influence of $\mathrm{P}+\mathrm{ZnTe}$ back surface contact on photovoltaic performance of $\mathrm{ZnTe}$ based solar cells, Opt. Quantum Electron. 50 (2018) 259. doi:10.1007/s11082-0181530-0.

[19] F. Baig, Y.H. Khattak, S. Ullah, B.M. Soucase, S. Beg, K. Khan, Effect of MAPbBr3 HTL and CBD Deposited Cd1-xZnxS ETL Band Offset on Lead Halide 
Perovskite Solar Cell, Mater. Focus. 7 (2018) 610-616. doi:10.1166/mat.2018.1555.

[20] Y.H. Khattak, F. Baig, B.M. Soucase, H. Ullah, T. Ahmed, Numerical Modeling of Cd1-xZnxS/Cd1-xZnxTe Photovoltaic Solar Cells, in: 2017 Int. Renew. Sustain. Energy Conf., IEEE, 2017: pp. 1-4. doi:10.1109/IRSEC.2017.8477588.

[21] A. Rehman, F. Baig, Y.H. Khattak, B.M. Soucase, A. Mahmood, Centralized Intelligent Home Energy Management System, in: 2017 Int. Renew. Sustain. Energy Conf., IEEE, 2017: pp. 1-4. doi:10.1109/IRSEC.2017.8477352. 
This page intentionally left blank 



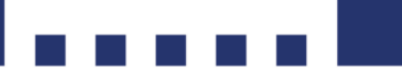

Escuela Técnica Superior de Inneniería del Diseño School of Design Engineering
INSTITUTO
DE DISENEO Y
FABRICACIÓN

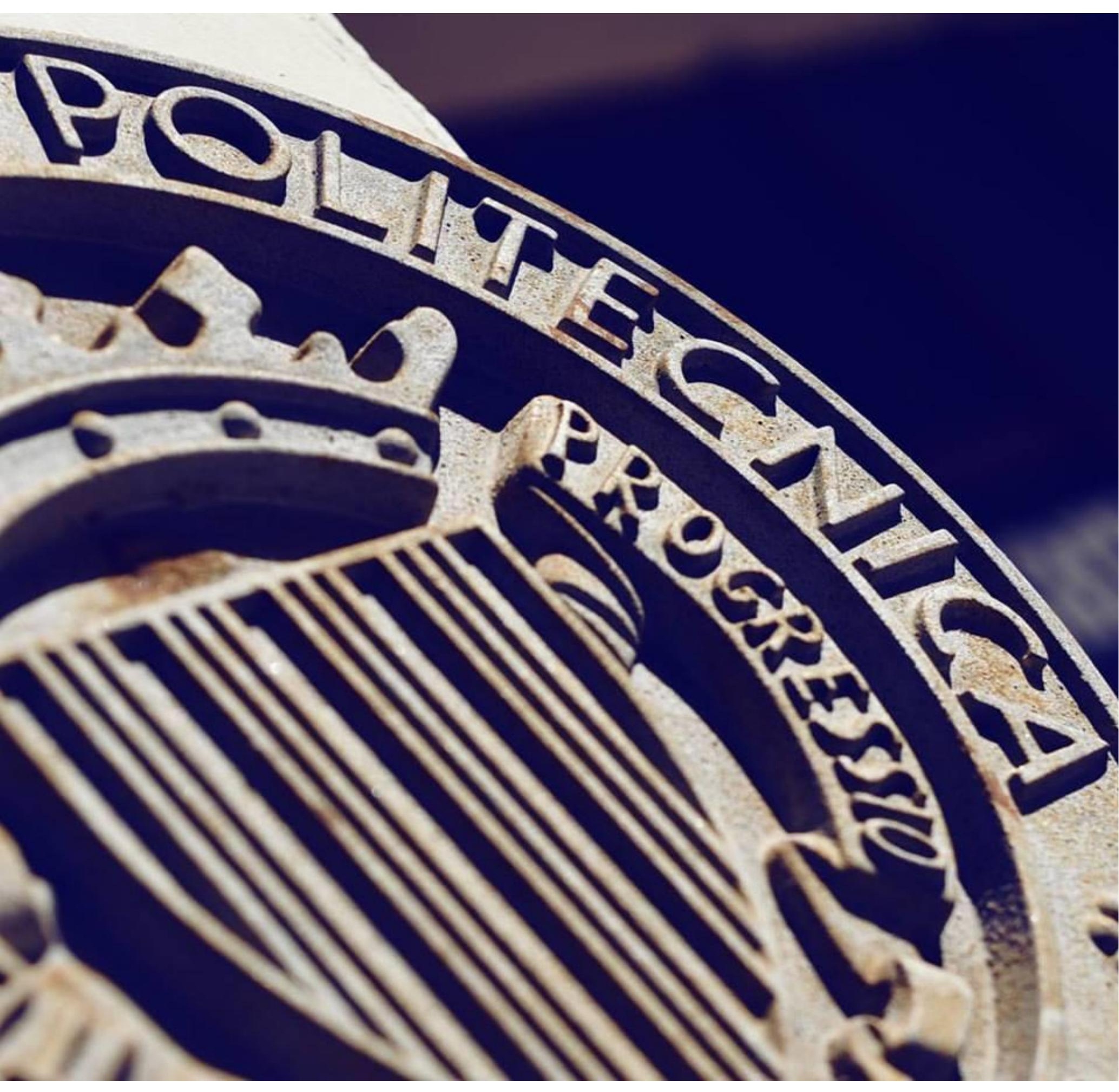

VLC

CAMPUS

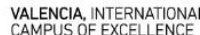

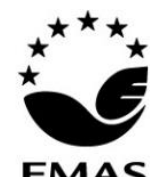

EMAS 